\title{
Where I come from and how I got here
}

\author{
Citation for published version (APA):
}

van Veldhuizen, T. S. (2017). Where I come from and how I got here: assessing credibility in asylum cases. [Doctoral Thesis, Maastricht University]. Gildeprint Drukkerijen. https://doi.org/10.26481/dis.20170922tsv

Document status and date:

Published: 01/01/2017

DOI:

10.26481/dis.20170922tsv

Document Version:

Publisher's PDF, also known as Version of record

\section{Please check the document version of this publication:}

- A submitted manuscript is the version of the article upon submission and before peer-review. There can be important differences between the submitted version and the official published version of record.

People interested in the research are advised to contact the author for the final version of the publication, or visit the DOI to the publisher's website.

- The final author version and the galley proof are versions of the publication after peer review.

- The final published version features the final layout of the paper including the volume, issue and page numbers.

Link to publication

\footnotetext{
General rights rights.

- You may freely distribute the URL identifying the publication in the public portal. please follow below link for the End User Agreement:

www.umlib.nl/taverne-license

Take down policy

If you believe that this document breaches copyright please contact us at:

repository@maastrichtuniversity.nl

providing details and we will investigate your claim.
}

Copyright and moral rights for the publications made accessible in the public portal are retained by the authors and/or other copyright owners and it is a condition of accessing publications that users recognise and abide by the legal requirements associated with these

- Users may download and print one copy of any publication from the public portal for the purpose of private study or research.

- You may not further distribute the material or use it for any profit-making activity or commercial gain

If the publication is distributed under the terms of Article $25 \mathrm{fa}$ of the Dutch Copyright Act, indicated by the "Taverne" license above, 


\section{WHERE I COME FROM AND HOW I GOT HERE:}

Assessing credibility in asylum cases 
Lay-out and printing: Gildeprint - Enschede

ISBN: 978-94-6233-701-5 


\title{
WHERE I COME FROM AND HOW I GOT HERE:
}

\author{
Assessing credibility in asylum cases
}

DISSERTATION

To obtain the degree of Doctor of Philosophy by the University of Gothenburg, on the authority of the Deputy Vice-Chancellor dr. Mette Sandoff, in accordance with the decision of the Faculty Board of Social Sciences and the degree of Doctor at the Maastricht University, on the authority of the Rector Magnificus, Prof. dr. Rianne M. Letschert, in accordance with the decision of the Board of Deans, to be defended in public on

Friday $22^{\text {nd }}$ of September 2017 at 10.00 hours

By

Tanja Susan van Veldhuizen 


\section{SUPERVISORS:}

prof. dr. P.J. van Koppen

prof. dr. P.A. Granhag

\section{CO-SUPERVISORS:}

dr. R. Horselenberg

dr. S. Landström
VU University Amsterdam, the Netherlands

University of Gothenburg, Sweden

\section{ASSESSMENT COMMITTEE:}

Prof. mr. A.H. Klip (Chairman)

Prof. dr. M. Jelicic

Prof. dr. J.W. de Keijser

Prof. dr. S.D. Penrod

Prof. dr. L.A. Strömwall
Maastricht University, the Netherlands

University of Gothenburg, Sweden

\begin{abstract}
Maastricht University, the Netherlands
Maastricht University, the Netherlands

Leiden University, the Netherlands

John Jay College, New York, USA

University of Gothenburg, Sweden
\end{abstract}

The research presented in this dissertation was supported by a grant in the Erasmus Mundus Joint Doctorate Programme in Legal Psychology (EMJD-LP) awarded to Tanja S. van Veldhuizen (FPA 2013-0036 with SGA 2013-1438). 


\section{CONTENTS}

Chapter 1 Asylum Assessments: A Question of Credibility 7

Chapter 2 Proving Identity, Origin, and Persecution: Challenges and 43

Future Directions in EU Asylum Assessments

Chapter 3 Interviewing Asylum Seekers: a Vignette Study on the

Questions Asked to Assess Credibility of Claims about Origin and Persecution

Chapter 4 Establishing Origin: Analysing Questions in Asylum

Interviews

Chapter 5 The Provenance of Émigrés: The Validity of Measuring

Knowledge of Places

Chapter 6 What We Have Learned about Effective Assessments in Asylum Cases

Chapter 7 About the Relevance of All This: Why, Who, What and How?

Summaries

English Summary

Dutch Summary (Samenvatting)

Swedish Summary (Sammanfattning)

Acknowledgements

Curriculum Vitae 


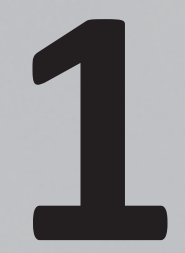

Asylum Assessments:

A Question of Credibility 



\section{ASYLUM SEEKERS: WHERE THEY COME FROM AND HOW THEY GOT HERE}

In the last five years, the number of people seeking asylum in the European Union (EU) has accelerated (see Figure 1, Eurostat, 2016a). In 2015 more than 1.3 million people applied to an EU Member State for asylum (Eurostat, 2016a). Despite efforts to curb irregular immigration (European Council, 2016), there remains an influx of asylum seekers to the EU (Eurostat, 2016c). As of 2016, the majority of asylum seekers to the EU come from Syria, Iraq and Afghanistan (Eurostat, 2016b); they are fleeing civil war and religious conflict. Other asylum seekers mainly come from hotspots on the African continent (United Nations High Commissioner for Refugees [UNHCR], 2016b); Eritreans flee the repressive regime in their country, people in Sudan flee violence and the humanitarian crisis incited by major armed conflict in Darfur, and Nigerians seek protection from Boko Haram terrorist attacks (UNHCR, 2016a).

\section{EU (28 countries)}

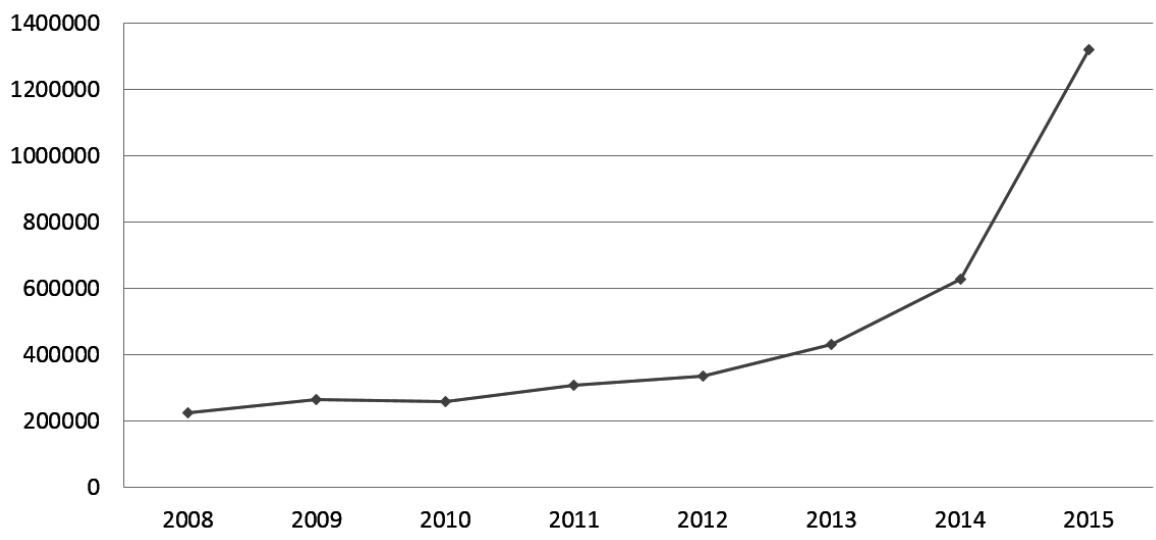

Figure 1. Number of first instance asylum applications (in millions) in the 28 Member States of the EU from 2008 - 2015. Data acquired from Eurostat (2016a).

To arrive in Europe often asylum seekers have undertaken a strenuous journey. As most asylum seekers are unable to obtain a visa, they must travel over land and sea (Fargues, 2016). They face life-threatening situations while crossing desert, sea, and nation-state borders (Fargues, 2016; Van Reisen \& Rijken, 2015). During their journey they frequently rely on smugglers and criminal networks, who are 
not always trustworthy. Smugglers sometimes exploit asylum seekers, they might use blackmail, provide false information about the travelling conditions or their services, or use violence against them. Including in the best of cases, in which a smuggler remains true to the agreement, often the transport is unsafe and uncomfortable (Freedman, 2016; Hassan \& Biörklund, 2016; Kaytaz, 2016). Deep in the Sinai desert, organised groups take advantage of people fleeing their homes; asylum seekers - mostly Eritrean - are abducted, sexually harassed, tortured and sometimes even killed while their families pay a ransom, hoping for their release (Van Reisen \& Rijken, 2015). Many asylum seekers heading for the EU never reach the border, and a large number because they do not survive the journey (EASO, 2016; Murray, 2016). Asylum seekers who do manage to reach Europe then face new challenges; they are in a new country and culture, and must navigate the European asylum procedure for international protection

\section{DECIDING ON ELIGIBILITY}

The stakes in the asylum procedure are high. Not only does the outcome determine the applicant's future, the receiving society will also be affected by the outcome (J. Bond, 2012; Inter-Parliamentary Union [IPU], 2001). The recent influx of asylum seekers puts immense pressure on state authorities. Tension is between the desire to offer an inclusive asylum system that provides protection to those who need it, and the need to prevent a mass inflow of immigrants from safe countries who take advantage of a generous asylum system (Sales, 2005; Stern, 2014; Vollmer, 2011). In public discourse, the media and in the political arena, a distinction is made between deserving refugees and fortune-seekers. The question is raised whom of the asylum seekers are genuinely in need of protection and whom are merely trying to improve their standard of living or enter with other illegitimate intentions (e.g., Dearden, 2016; Deira, 2015; Verkuyten, 2004).

Theoretically, the distinction is clear. Someone is a genuine refugee if he or she has a well-founded fear of being persecuted for reasons of race, religion, nationality, membership of a particular social group or political opinion, or being subjected to indiscriminate violence, degrading treatment or torture in their country of origin 
(Qualification Directive, 2011; United Nations, 1951). In practice however, determining eligibility is complex.

In the refugee status determination process, as in other law enforcement settings, the objective is to reach the right decision for each individual within the boundaries set by international and national law. Assessment of asylum claims is shaped by the legal context (for example through the eligibility criteria and standards for any evidence submitted) and the evidential context (i.e., the availability of different kinds of evidence; Gyulai, 2013). Immigration boards have little power to influence these factors; they are restricted by the legal framework, and by the limited evidence applicants can provide. Other factors that may influence the assessment include applicants' memory and literacy. Such individual differences cannot be affected by the migration board, and can only be accounted for while evaluating the applicant's story (and are therefore referred to as estimator variables, Wells, 1978). Immigration boards do have control, however, over the context in which evidence is elicited and the way in which it is evaluated. For example, by combining a friendly interview setting with appropriate interviewing techniques, they can help asylum applicants to present their claim to the best of their ability (e.g., Vrij, Hope, \& Fisher, 2014). Additionally, by employing diagnostic methods to evaluate claims, they can increase their chance of making a valid judgment. The interview setting, the method of questioning and assessment tools are referred to as system variables, as they affect the accuracy of a statement or judgment and the criminal justice system can control them (Wells, 1978; Wells, Memon, \& Penrod, 2006).

Owing to the interplay of system variables, the question of how to discriminate between legitimate and illegitimate asylum applications becomes an interesting question also from a legal psychological perspective. Previous legal psychological research has focused on similar issues in a criminal context. As such, much knowledge is available on effective interviewing techniques for witnesses, victims and suspects (e.g., Bull, 2010; Fisher, 1995; Milne \& Bull, 1999; Snook, Luther, Quinlan, \& Milne, 2012; Vrij, Hope, et al., 2014) and on methods for evaluating witness', victims', and suspects' statements (e.g., C. F. Bond \& DePaulo, 2006; Meissner \& Kassin, 2002; Penrod \& Cutler, 1995; Porter \& ten Brinke, 2009; Vrij, Granhag, Mann, \& Leal, 2011; Vrij, Mann, Jundi, Hillman, \& Hope, 2014). However, legal psychological research has largely neglected asylum seekers and few studies consider 
the specific factors involved in interviewing and decision-making in asylum cases (for exceptions cf. Cohen, 2001; Granhag, Strömwall, \& Hartwig, 2005; Herlihy, Gleeson, \& Turner, 2010).

To address this gap in the literature, in the current thesis the refugee status determination process is studied from a legal psychological perspective. The issue of interest is how - given the legal and evidential context of the asylum procedure - can European immigration authorities make highly valid assessments of asylum claims i.e., make the most correct determinations possible within their legal and contextual limitations. The central research question is, to what extent are the methods of questioning used to assess credibility in the EU asylum procedure valid, in the sense that they discriminate between legitimate and illegitimate asylum claims. In the following four chapters, I present four studies examining this question. First, in this chapter I provide a brief introduction to the context of credibility assessment in the asylum procedure, and outline the theoretical foundations of the studies used.

\section{THE LEGAL CONTEXT OF REFUGEE STATUS DETERMINATION PROCEDURES}

The legal context of refugee status determination (RSD) procedures is rooted in the principle of non-refoulement as laid down in Article 33 of the Geneva Convention of 1951 (United Nations, 1951, Chapter V, Article 33.1):

"No Contracting State shall expel or return ("refouler") a refugee in any manner whatsoever to the frontiers of territories where his life or freedom would be threatened on account of his race, religion, nationality, membership of a particular social group or political opinion."

The duty not to refoule has been argued to be a logical complement to the universal human right to seek asylum, and is considered a rule of customary international law, binding on all states (UNHCR, 2001, §16; see also the case of M.S.S. v. Belgium and Greece, §54-56). Accordingly, in asylum procedures preventing the risk of returning an applicant who could be persecuted in their country of origin is to be prioritized above the risk of granting access to an individual who does not meet the 
eligibility criteria, or even the risk of political destabilization or national security threats that an individual may impose (Labita v. Italy §119; Saadi v. Italy §137-138; UNHCR, 2001,§18). This prioritization is reflected in the relatively low standard of proof generally required in asylum cases. In contrast to criminal law, in which a suspect's guilt must be established beyond a reasonable doubt, asylum applicants support their case with their identity or with accounts of past experiences that are verified by a reasonable degree of likelihood (Gorlick, 2002; Sweeney, 2009; Thomas, 2006; UNHCR, 1998). The European Court of Human Rights (ECtHR) has additionally ruled in the case of Saadi v. Italy (\$137-139) that the standard of proof may not be heightened, as the protection of the right to life, liberty and security of person afforded by Article 3 of the Universal Declaration of Human Rights (UN General Assembly, 1948) is absolute.

Non-refoulement also is the foundation of the Common European Asylum System (CEAS; effectuated by the European Council since 1999; European Parliament, 1999). The CEAS provides a set of common standards for asylum procedures and the assessment of asylum claims; this harmonises legal frameworks and procedures across Member States. For instance, directives such as the Qualification Directive (2004; 2011) and the Asylum Procedure Directive (2013) impose minimum standards for the way in which asylum assessments should be conducted. All Member States ${ }^{1}$ have to adopt these or more favourable standards in their domestic legislation. Thus, CEAS regulations form the framework for asylum assessments across the EU.

Burden of proof is a key principle of the CEAS. In asylum cases, burden of proof lies with the applicant (Qualification Directive, 2004; 2011, Article 4.1); asylum seekers must provide proof of their identity, country of origin, and qualifying circumstance. They must submit all available documentation that can corroborate claims about identity, origins, persecution, travel route and previous asylum applications. In addition, seekers must present their core arguments for their asylum

1. In accordance with the protocols on the position of the United Kingdom and Ireland and the position of Denmark annexed to the Treaty on European Union, these countries form an exception. For the UK, Ireland, and Denmark EU directives are not automatically binding; they decide for each directive whether or not they wish to take part in its adoption. None of the three countries takes part in the adoption of the Qualification Directive (2011) and are therefore not bound by it or subject to its application. The UK and Ireland do take part in the Asylum Procedure Directive (2013), whereas Denmark does not. 
at the earliest possible moment in the procedure. Thus, asylum seekers are responsible for presenting and corroborating their claim.

The determining authority has the duty to ascertain and evaluate the information relevant to the claim (Qualification Directive, 2011, Article 4.1), and decides whether the core arguments are substantial (UNHCR, 2013). That is, whether they give rise to a well-founded fear of persecution, indiscriminate violence, torture or degrading treatment. In its assessment, the authority considers all relevant facts pertaining to the country of origin at the time of making a decision, all the relevant documents and statements adduced by the applicant, and the personal circumstances of the applicant (Qualification Directive, 2011, Article 4.3). This obligation, and the duty to dispel any doubts raised by the evidence, has also been acknowledged by the ECtHR (see e.g., F.G. v. Sweden, §119-127 on jurisprudence in this matter). Before the substantiality of the claim can be assessed a decision must be made about which of the core arguments meet the standard of proof. Based on the available evidence, the believability of each element is determined. Only accepted elements are considered in the substantiality assessment (UNHCR, 2013). Or as the Court of Justice of the European Union (CJEU) put it in M. M. v. Minister for Justice, Equality and Law Reform, Ireland, Attorney General (§64):

'In actual fact, that 'assessment' takes place in two separate stages. The first stage concerns the establishment of factual circumstances which may constitute evidence that supports the application, while the second stage relates to the legal appraisal of that evidence, which entails deciding whether, in the light of the specific facts of a given case, the substantive conditions laid down by Articles 9 and 10 or Article 15 of Directive 2004/83 for the grant of international protection are met."

Assessing which elements in the story are accepted hence is an essential element of the asylum adjudication process.

In the assessment, potential difficulties that the applicant may have encountered in substantiating statements with documentary or other evidence are recognised. The ECtHR has accordingly ruled "that the lack of direct documentary evidence cannot be decisive per se", and that frequently the benefit of the doubt must be given when assessing the evidence in asylum cases (J.K and others v. Sweden, §92). There are four conditions under which an unsubstantiated aspect of an asylum claim should be accepted as believable without further confirmation (Qualifica- 
tion Directive, 2004, Article 4.5). First, the applicant must have made a genuine effort to substantiate the application and should be able to provide a satisfactory explanation for any lacking elements. Second, the applicant should have applied for international protection at the earliest time possible. Third, the applicant's statements should be coherent and plausible, and fourth, the applicant should be judged as generally credible. Thus, despite the fact that burden of proof is on the applicant, Member States must consider the circumstances under which applicants cannot provide evidence to corroborate their statements. Uncorroborated aspects of a story may be accepted if the asylum seeker's statements are found credible and the general credibility of the applicant is established (UNHCR, 2013).

Credibility of the asylum story and the applicant is assessed in asylum interviews. CEAS regulations stipulate that every asylum seeker has the right to a personal interview (Asylum Procedure Directive, 2013), and that all asylum applications be assessed on an individual basis (Qualification Directive, 2004; 2011, Article 4.1). Only under exceptional circumstances may the interview may be skipped. For example, a positive decision can be made based solely on available evidence, or when an applicant is unfit to be interviewed. CEAS further maintains that the absence of an interview due to circumstances beyond the asylum seeker's control must not adversely affect the decision on the request.

\section{THE EVIDENTIAL CONTEXT IN ASYLUM CASES}

In reality, corroborating evidence for asylum seekers' statements is more often lacking than present (Doornbos, Koers, \& Wijngaard, 2012; Goodman, 2013; Gyulai, 2013; Herlihy \& Turner, 2009; Kagan, 2002; Noll, 2005a, 2005b; Szypszak, 2000). Asylum seekers often do not possess identity documents, or their authenticity is ambiguous (Doornbos et al., 2012; Gyulai, 2013; Kagan, 2002; UNHCR, 2013). Smugglers may confiscate their original documents and they may be left with false documents or no documents at all (Koser, 2011). Authentic evidence to support claims of fear of persecution, such as arrest warrants or proof of detention, is even more scarce (Doornbos et al., 2012; Goodman, 2013; Gyulai, 2013; Szypszak, 2000; UNHCR, 2013). 
Another complication is that it is impossible to effectuate an adversarial process (Noll, 2005a). Contacting the authorities in the home country to validate the asylum story may put the applicant or their relatives in danger. Consequently, in the assessment of asylum claims officials typically rely on the applicant's story and general knowledge of the country of origin (Byrne, 2007; Cohen, 2001; Herlihy et al., 2012; Herlihy \& Turner, 2009; Kagan, 2002; Sweeney, 2009).

\subsection{The inevitability of credibility assessments}

Because supporting evidence is rare, the credibility assessment is often the key aspect of examination for asylum (e.g., Gyulai, 2013b; Noll, 2005b). Judge Fura summarized this concisely in his dissenting opinion in the case of R.C. v. Sweden $(\S 5$, p. 19) "In examining the case before them the domestic authorities must assess facts that are presented by the parties. In this exercise the authorities might come across difficulties when facts are in dispute. Evidence presented must be evaluated and credibility will be of the essence". Indeed, across EU Member States, negative decisions on asylum applications are predominantly based on credibility grounds (UNHCR, 2013). The rather direct relationship between the credibility assessment and the decision in asylum cases is illustrated by arrow 3 in Figure 2 (See paragraph 5.2: overview of chapters).

The outcome of a credibility assessment will have far reaching consequences. Returning a genuine refugee may result in persecution, serious harm, or even fatal violence, and thereby, a violation of human rights (e.g., Inter-Parliamentary Union [IPU], 2001), conversely, granting asylum to an illegitimate seeker may inflict danger on the receiving society (J. Bond, 2012; Larsaeus, 2004). For the safety of all parties, credibility assessments should be conducted for optimal efficacy, that is, in the discrimination of legitimate from illegitimate asylum claims, the credibility assessment should be a tool of exceedingly high precision.

\section{THE CURRENT THESIS}

Despite striving for precision, recent reports suggest that decisions based on credibility grounds are of insufficient quality and that, in a considerable proportion (approximately a quarter) of cases, the first instance decision would not withstand 
judicial review (Home Affairs Committee, 2013; Shaw \& Kaye, 2013). These statistics "suggest certain methodological weaknesses" in the credibility assessment (Sweeney, 2016, pp. 87-89). In addition, although the ECtHR has argued that as a general principle national authorities are best placed to assess "the credibility of witnesses since it is they who have had an opportunity to see, hear and assess the demeanour of the individual concerned" (see e.g., J.K. and others v. Sweden, $\S 118 ;$ R.C. v. Sweden §52), asylum officials seem to hold stereotypical beliefs about what characterises credible and non-credible accounts, how people behave under persecution (i.e., their demeanour), and how those who persecute, including local authorities, behave (Granhag et al., 2005; Herlihy et al., 2010). Beliefs and assumptions that do not correspond to empirical evidence of valid and reliable cues of deception (Granhag et al., 2005). These findings call into question the extent to which the current methods are valid.

To date, little empirical research has considered what actually occurs in credibility assessments (cf. Herlihy et al., 2010; Millbank, 2009), and there is no empirical evidence to support this method as a reliable and valid tool to distinguishing between legitimate and illegitimate claims. In the current thesis, I aim to fill this gap with a policy review and three empirical studies. The main question addressed is: To what extent are the methods used to assess credibility in the European asylum procedure valid, in the sense that they discriminate between honest and fabricated asylum claims?

To answer the research question, knowledge about best practice in investigative interviewing and credibility assessments in the criminal context is applied to the context of credibility assessments in the asylum procedure. With this approach, I hope to identify the key factors for effective interviewing and decision making practices in asylum cases. My predominant focus will be variables that are within the control of the migration board such as interview setting, questions asked, and the criteria used to evaluate asylum claims (i.e., system factors). The influence of individual differences on the ability to provide a credible account, such as an applicant's age, gender, or level of literacy (i.e., estimator variables), are beyond the scope of this study. Before presenting the sub-questions, the themes and theoretical foundations of the current thesis are outlined. 


\subsection{Theoretical foundations and conceptual framework}

Much of the empirical literature underlying the studies in the current thesis concerns interviewing and decision making in a criminal context. The criminal context differs from the asylum context in several respects (Noll, 2005a). For example, alien law falls under administrative law rather than criminal law and it is Asylum seekers who initiate application and burden of proof lies with them, whereas in criminal law the state prosecutes an individual and the burden of proof lies with the state. These contexts further differ with respect to the availability of verifiable evidence (Gyulai, 2013a). However, there are similarities. The consequences of an erroneous decision (i.e., a wrongful conviction or wrongful expulsion) are grave (Inter-Parliamentary Union [IPU], 2001; Van Koppen, 2011). In addition, asylum seekers share characteristics with both suspects, witnesses, and victims in criminal cases. For this reason, literature on investigative interviewing and credibility assessments in criminal law can be applied to the asylum context. In the following sections, I will provide evidence of the similarities between asylum seekers and actors in criminal cases, I will then define and discuss concepts from the legal psychological literature that are relevant to credibility assessments in asylum cases.

\subsubsection{Asylum seekers: Similarities with witnesses, suspects, and victims of crime}

An asylum seeker is someone whose request for international protection has yet to be processed (Qualification Directive, 2011). The applicant becomes a refugee when a genuine fear of persecution or fear of serious harm or degrading treatment in the country of origin is established, and refugee status is granted.

As suspects in the judicial process who may either be convicted or acquitted, asylum seekers applying for a residence permit too have strong interest in the outcome of the procedure. Suspects - regardless of being guilty or innocent of the crime they are accused of - will try to avoid incriminating themselves in the police investigation (DePaulo \& Morris, 2004). While an innocent suspect may try to provide as much information as possible to prove his innocence, a guilty suspect may withhold information or provide false information about his activities or location to appear innocent and to reduce suspicion (Granhag, Hartwig, Giolla, \& Clemens, 2014; Hartwig, Granhag, Stromwall, \& Doering, 2010). Similarly, asylum seekers are motivated to appear credible in order to obtain refugee status (Herlihy, Jobson, \& Turner, 2012; Herlihy \& Turner, 2009). In this process, honest asylum 
seekers may simply tell their story as they remember it, however, they may also embellish partly true events or lie about their identity, origin or past experiences, assuming that with a fabricated story their chances of acquiring refugee status will increase (Beneduce, 2015). Others may withhold information or change their story for a variety of reasons. Owing to a lack of trust in authorities, in this case the interviewer and those who process their case, asylum seekers may not tell the truth about what happened to them in their country of origin, or may fear repercussions against their family in their country of origin (Ní Raghallaigh, 2013). Irrespective of what the applicant's motive for lying might be, finding out the truth about the applicant's identity, origin, and past experiences is important to determine whether an applicant is eligible for a refugee status. Empirical literature on the truthfulness of suspects' statements and methods for the assessment of honesty, are therefore relevant to the asylum context.

At the same time, asylum seekers are also witnesses to their own life (Herlihy et al., 2012; Herlihy \& Turner, 2009). To establish a genuine fear of persecution in their country of origin, they must provide an elaborate and accurate narrative about who they are, where they come from, what happened to them in their country of origin, and how they came to Europe (Cameron, 2010; Cohen, 2001; Herlihy et al., 2012; UNHCR, 2013). To do so successfully, they must search their autobiographical memory, recall the relevant information, and present that information convincingly to the state authorities (Cameron, 2010; Herlihy et al., 2012). Witnesses in the police context go through a similar process. They are required to search their memory for information that will help the police to establish what happened, identify the perpetrator, or to find additional evidence (Pansky, Koriat, \& Goldsmith, 2005; Wells \& Loftus, 2003). In the police context, much effort is put into eliciting as much accurate information as possible from a witness. As a result, much research has been conducted with the primary focus of identifying the most effective interviewing strategies (i.e., those that will elicit accurate information from witnesses. E.g., Eisen, Gomes, Lorber, Perez, \& Uchishiba, 2013; Fahsing \& Rachlew, 2009; Fisher, 1995; Fisher, Milne, \& Bull, 2011; Gilbert \& Fisher, 2006; Perfect et al., 2008; Shawyer, Milne, \& Bull, 2009). Considering that in both witness and asylum interviews there is immense reliance on the subject's memory, literature that examines methods to effectively cue autobiographical memory in a police interview is also relevant to interviewing in the asylum context. 
Lastly, asylum seekers often have experienced or witnessed horrendous events, either in the country of origin or during their journey (UNHCR, 2013). As a result, they may be considered victims with corresponding vulnerabilities (Commission of the European Communities, 2003, p. 37 see point 6.1 sub g). The ECtHR also recognized this in the case of M.S.S. v. Belgium and Greece (\$232) by stating: "the Court must take into account that the applicant, being an asylum seeker, was particularly vulnerable because of everything he had been through during his migration and the traumatic experiences he was likely to have endured previously". Even if an applicant does not suffer from post-traumatic stress disorder (PTSD; see Memon, 2012 for discussion of the effects of trauma on asylum narratives), both stress experienced during encoding and stress experienced during recall, may influence an applicant's ability to provide coherent and detailed statements (Deffenbacher, Bornstein, Penrod, \& McGorty, 2004; Houston, Clifford, Phillips, \& Memon, 2013; Smeets, 2011). Trauma and the stress experienced during the encoding of events relevant to the asylum application is beyond the control of the asylum official (i.e., an estimator variable), and can only be taken into account in hindsight when evaluating the asylum narrative (Wells, 1978). In contrast, the setting of the asylum interview and the demeanour of the asylum official, which often induce stress in asylum applicants (Bögner, Brewin, \& Herlihy, 2009; Sourander, 2003), are factors that the authorities have substantial control over. Literature on interviewing style and maintaining a positive work relationship in investigative interviews (e.g., Bull, 2010; Walsh \& Bull, 2010) is therefore relevant to the evaluation of interviewing practice in the asylum context.

\subsubsection{Statements}

Before discussing theory about the elicitation and evaluation of statements, it is helpful to briefly consider different concepts related to asylum seekers' statements. When speaking of the asylum story or the asylum narrative, I refer to the complete set of oral and written statements, on the basis of which the eligibility of the applicant for a refugee status is assessed. Therefore, everything that the asylum seeker or his legal representative says or writes down in the asylum procedure is part of the asylum story (Johnson, 2011). Throughout the current thesis I will distinguish three elements of the asylum story: the identity claim, the origin claim, and the persecution claim. The identity claim can contain information about the applicant's 
gender, ethnicity, religious affiliation, and sexual preference. An origin claim is a claim about the applicant's nationality and last place of residence in the home country (i.e., region and hometown), it may also contain information about the applicant's birthplace or other places where the applicant has lived. The persecution claim pertains to what instigated the applicant to flee their country of origin (i.e., his flight motives). All three elements (i.e., identity, origin and persecution) act as a material fact in asylum cases, in the sense that they can constitute a ground for asylum (UNHCR, 2013). For instance, homosexuality may give rise to a genuine fear of persecution due to membership of a social group (Millbank, 2009), and having a specific nationality may itself imply a real risk of serious harm if there exists indiscriminate violence in that country (EASO, 2015). For this reason, information on all three aspects are gathered in asylum interviews and written statements.

\subsubsection{Evidence}

To establish the facts in any legal procedure, evidence is required to demonstrate what happened, when it happened, where it happened and which actors were involved (De Poot \& Van Koppen, 2010). In the current thesis two types of evidence are distinguished: documentary evidence and oral evidence. Documentary evidence is defined as "Such evidence as is furnished by written instruments, inscriptions, documents of all kinds, and also any inanimate objects admissible for the purpose" (Black's Law Dictionary, 1910). In the context of asylum documentary evidence, documentation may consist of identity documents, birth or marriage certificates, travel documents (e.g., tickets), membership cards, and arrest warrants (Mackey \& Barnes, 2013; UNHCR, 2011). If documentary evidence is available, the documents must be authenticated (Immigration and Naturalisation Service [INS], 2016). Oral or testimonial evidence, is defined as, "all written or oral assertions offered as proof of truth in court" (Black's Law Dictionary, 1910). During the asylum procedure, all statements provided by the applicant or their legal representative are considered testimonial evidence (Mackey \& Barnes, 2013; Qualification Directive, 2011). In some cases, testimonial evidence is corroborated with documentary evidence. If not, the credibility of the testimonial evidence must be assessed to determine the weight of the evidence (Mackey \& Barnes, 2013; UNHCR, 2013). Weight of the evidence is defined as the "preponderance of the truth" or "what will convince a judge one way or another" (Black's Law Dictionary, 1910). 


\subsubsection{Credibility assessment}

The credibility assessment is a determination of which of an applicant's statements can be accepted; only accepted statements are considered in the analysis of well-founded fear of persecution and real risk of serious harm (UNHCR, 2013). The objective of the credibility assessment is assessing the accuracy of the asylum narrative. (Lamb, Sternberg, \& Esplin, 1994; Mackey \& Barnes, 2013). Or in other words, to what extent specific statements correspond to who the applicant truly is, where the applicant truly comes from, or what truly happened to the applicant in the country of origin.

In practice, the term credibility is sometimes used interchangeably with reliability (see e.g., Granhag et al., 2005). This use of reliability likely stems from its use in interpersonal communication. If someone is a reliable person, that person can be trusted. From a methodological perspective, however, reliability is not the same as credibility. Reliability refers to the consistency of a measure (Giesbrecht \& Peters, 2010). A reliable measure provides the same result on several measurements. For example, if I weigh the same five potatoes three times in a row, the scale should indicate the same weight each time. A reliable measure does not, however, necessarily also give a correct or true representation. For example, if I weigh the five potatoes and the scale consistently tells me that they weigh 5 kilograms, the scale is reliable but probably inaccurate. It seems unlikely that the potatoes weigh 1 kilogram each. The accuracy of a measure - or the extent to which a measure reflects the truth - is referred to as validity (Giesbrecht \& Peters, 2010). Even though reliability is often a precondition for validity (if the scale first says 1 kilo, then 3 kilos, and then 5 kilos, then the scale cannot be accurate), consistency is not sufficient to establish validity (Giesbrecht \& Peters, 2010).

The extent to which consistency is an indicator for the validity of an asylum story will be discussed in Chapter 2. The purpose of the discussion here is to clarify that when referring to the extent to which a statement reflects the truth, I will either use the term credibility or validity. With the term reliability, I refer to the consistency of the statements.

5.1.4.1 Credibility assessments and lie detection. Credibility assessments are not unique to the asylum context. In the criminal context police and judges must regularly assess the credibility of allegations by victims, witnesses and suspects (Lamb et al., 1994; Novo \& Seijo, 2010). Much research has been conducted in the 
area of credibility assessments, especially when lie detection research is considered. The terms credibility assessments and lie detection are used interchangeably when referring to the process of finding out whether statements of suspects correspond to the true unfolding of events (see eg., Porter \& ten Brinke, 2009; Vrij, Hope, et al., 2014).

Using the term 'lie detection' in the context of the asylum procedure might be controversial because asylum seekers' motives for lying are generally different than those of suspects (Beneduce, 2015; DePaulo \& Morris, 2004). The reality is, however, that asylum seekers are sometimes motivated to lie (Beneduce, 2015; Herlihy et al., 2012) and that it is essential to the refugee status determination process to find the truth of the applicant's identity, origin, and past experiences. In discussing credibility assessment and lie detection literature, I will refer to truth and lies. I recognize that there is a grey area between complete truth and an outright lie; people may make mistakes while being honest (Cohen, 2001), embellish otherwise true events, or lie about some aspects but not about other aspects of their testimony (Beneduce, 2015). For the sake of clarity, I will refer to truth-tellers, whom I define as people who intend to provide an honest narrative, and liars, people with the intention to fully or partly deceive the migration board.

5.1.4.2 A professional's ability to detect lies. It is a common conception that others are honest unless they have a motive to lie (Levine, Kim, \& Blair, 2010). Indeed, there is evidence to suggest that most people will only lie when they think that their goals are unobtainable through honest means (Levine et al., 2010). Owing to this truth-default, higher accuracy rates for detecting the truth than deceit are expected in situations in which the observer is not explicitly reminded of the possibility that the interviewee is lying (Levine, 2014). In the asylum adjudication process, however, a culture of disbelief has been identified (Home Affairs Committee, 2013; Jubany, 2011; Sweeney, 2016). A culture of disbelief refers to the tendency of asylum officials to "start from the assumption that the applicant is not telling the truth" (Home Affairs Committee, 2013, p. 11). Such a culture risks biased processing of applications (Home Affairs Committee, 2013; Jubany, 2011; Sweeney, 2016). Valid and reliable methods for credibility assessment could minimise the effects of this and other biases.

Unfortunately, there are very few valid cues to deceit, and cues that do set truthful and fabricated accounts apart are difficult to accurately perceive and interpret 
(DePaulo et al., 2003). Accordingly, evidence suggests that most people are poor lie-detectors. In a meta-analysis by Bond and DePaulo (2006), the mean accuracy rate to detect deception in others was only slightly above chance with 54\%. Professionals - that is, people who conduct credibility assessments as a part of their job, such as police officers, judges, and immigration officials - do not outperform lay people, even though they are more confident (Meissner \& Kassin, 2002; Vrij, 2004). Instead, professionals often rely on stereotypical beliefs about deception cues (Granhag et al., 2005; Strömwall \& Granhag, 2003; Vrij, 2004; Vrij \& Semin, 1996), and experience and training increase the tendency to judge a statement to be deceptive (i.e., deception bias; Meissner \& Kassin, 2002). That is why in recent years, scholars have moved from settings in which deception is passively observed to approaches in which cues to deception are actively elicited in the interview setting (Levine, 2014; Vrij, Fisher, Mann, \& Leal, 2008; Vrij et al., 2011).

Interviewing techniques have been developed that magnify the differences between truth-tellers and liars. Most techniques start from the assumption that lying is more cognitively demanding than is telling the truth, and accordingly, that liars and truth-tellers employ different strategies during the interview (e.g., Vrij, Fisher, Mann, \& Leal, 2006; Vrij et al., 2011; Vrij, Mann, et al., 2008). For example, liars must fulfil several simultaneous tasks in order to appear credible. Their story should be convincing, coherent and plausible, they must tell the story consistently multiple times, monitor the interviewer's demeanour and maintain constant control over their own (e.g. Vrij, Granhag, \& Mann, 2010). Meanwhile, it is also necessary to suppress the truth, an additionally mentally taxing task. As a result, liars typically employ a withholding strategy, keeping their story straight and simple (Hartwig et al., 2010; Strömwall, Hartwig, \& Granhag, 2006). In contrast, truth-tellers can rely on their memory to reconstruct what happened and tell their story accordingly. They tend to be forthcoming with information (Hartwig et al., 2010), and less concerned with appearing credible as they believe that the truth will prevail. A commonly held but incorrect belief reported in truth-tellers, is that their honesty will be apparent in their statements and easily recognized by interviewers, this is referred to as the illusion of transparency (Gilovich, Savitsky, \& Medvec, 1998; Granhag \& Hartwig, 2008; Kassin, 2005).

An extensive amount of studies in the lie-detection literature detailing difference-based interviewing techniques such as those discussed above, provide 
evidence of effectively elicited cues to detection. For example, the lack of cognitive resources has been exploited by asking interviewees to recall events in reverse order, and asking unanticipated questions (Ewens, Vrij, Mann, \& Leal, 2015; Granhag \& Mac Giolla, 2014; Lancaster, Vrij, Hope, \& Waller, 2013; Liu et al., 2010; Mac Giolla, Granhag, \& Liu-Jönsson, 2013; Roos af Hjelmsäter, Öhman, Granhag, \& Vrij, 2014; Vrij et al., 2009; Vrij, Mann, et al., 2008). Other techniques, such as the verifiability approach and the strategic use of evidence technique, have proven to effectively circumvent liars' counter-interrogation strategies (Nahari, Vrij, \& Fisher, 2014a, 2014b; Tekin et al., 2015). These relatively recent approaches to lie detection have mostly been tested in the criminal context, and have seldom been applied to other contexts, such as insurance claims (Leal, Vrij, Warmelink, Vernham, \& Fisher, 2015; Nahari, Leal, Vrij, Warmelink, \& Vernham, 2014). In the current thesis I explore the extent to which cognitive lie detection techniques are applicable to credibility assessments in the asylum context.

\subsubsection{Investigative interviewing}

In addition to the validity of the credibility assessment methods, the way in which statements are elicited should also be taken into account. Different questions elicit different answers and affect the detail and accuracy of an account (Griffiths, Milne, \& Cherryman, 2011; Oxburgh, Myklebust, \& Grant, 2010; Snook et al., 2012). Poor interviewing techniques can impede a credibility assessment by yielding insufficient, biased or contaminated information. In contrast, effective interviewing techniques can aid the credibility assessment by eliciting rich and accurate narratives (Hershkowitz, Fisher, Lamb, \& Horowitz, 2007; Yuille, 1988). Furthermore, some approaches to interviewing are more effective at eliciting cues to deception than others (K. Colwell, Hiscock, \& Memon, 2002; Vrij, Hope, et al., 2014).

5.1.5.1 The effects of different questions. In the current thesis I focus on three concepts in relation to eliciting rich, detailed and accurate accounts: question style, question type, and question content. Style refers to how the interviewer approaches the interviewee (Vrij, Hope, et al., 2014). The way in which questions are delivered is more important in analysing question style than is the content or technical classification of the question. Two styles are distinguished: the information gathering style, and the accusatory style (Moston \& Engelberg, 1993). The 
former style emphasizes truth-gathering and the interviewer communicates a genuine interest in the interviewee's story. The latter style is confrontational and the interviewer communicates disbelief (Meissner, Redlich, Bhatt, \& Brandon, 2012; Moston \& Engelberg, 1993; Vrij, Mann, \& Fisher, 2006). Interviewing style is linked the working relationship between the interviewer and interviewee, with an information gathering style resulting in a better working alliance (Vanderhallen, Vervaeke, \& Holmberg, 2011; Vrij, Hope, et al., 2014; Vrij, Mann, et al., 2006). In interviews in which a good rapport is established through an information gathering style, interviewees are more likely to provide additional diagnostic information, even if they were initially reluctant (Meissner et al., 2012; Vrij, Mann, et al., 2006; Vrij, Mann, Kristen, \& Fisher, 2007; Walsh \& Bull, 2010, 2012). Questioning style may be an interesting factor to evaluate in asylum interviews. This is owing to evidence that asylum seekers often report feeling doubted from the outset of the interview (Bögner et al., 2009; Home Affairs Committee, 2013), and that as a result, they may be less forthcoming with information (Bögner et al., 2009). However, it should also be noted that asylum officials have reported being sceptical from the outset to certain stories (e.g., rape stories; Jubany, 2011).

Question type refers to a technical classification of the question, and more specifically, the kind of answer a question could be expected to elicit. Although various typologies are used (Oxburgh et al., 2010), three types of questions are commonly distinguished: open questions, closed questions, and suggestive questions. Open questions, which invite interviewees to provide extensive answers in their own words, typically yield longer, more detailed and more accurate answers than other question types (Oxburgh et al., 2010; Snook et al., 2012). Closed questions only require a short yes or no response and incite guessing (Waterman, Blades, \& Spencer, 2001). When the goal of the interview is to obtain as much valid information as possible, they are therefore less effective than open questions (Oxburgh et al., 2010; Thoresen, Lønnum, Melinder, Stridbeck, \& Magnussen, 2006). Suggestive questions steer the interviewee's answer (e.g., 'You assumed that he would help you, did you not?') or include information not previously disclosed by the interviewee. Such questions should be avoided as much as possible, as they hamper the interviewee to provide an accurate account (Vrij, Hope, et al., 2014), they can mislead the interviewee and even contaminate the interviewee's memory (Bull, 2010; Loftus, 2005; Patihis \& Loftus, 2016). An analysis of question type is valuable 
to assess whether the questions are likely to elicit relevant and accurate information for the judicial process (Oxburgh et al., 2010). In the credibility assessment in the asylum procedure, questions are the primary tool to obtain information, and as such, eliciting relevant and accurate information is a high priority (UNHCR, 2013). To date, however, the questions asked in asylum interviews have not been systematically evaluated.

The final concept considered in the current thesis is question content. That is, the topics that are addressed in asylum interviews. The main purpose of examining question content is to explore whether asylum officials use specific strategies to assess the credibility of origin and persecution claims. By identifying the types of information they typically search for, it becomes possible to assess the extent to which an honest applicant might be able to provide a convincing claim. In other words, the diagnostic utility of the information obtained with those strategies can be assessed (Levine, 2014). Some information is more useful to a credibility assessment than other information. The most effective interview strategies prompt useful information that can logically be explained by either honesty or dishonesty.

\subsubsection{Decision making}

Increasing the amount of diagnostic information obtained in interviews, reduces the chances of errors in the decision-making process (Levine, 2014). In the asylum procedure, two types of errors can be made. The first is the decision to reject the asylum claim of a genuine applicant, referred to as a Type I error or false alarm (MacMillan, 2002). The second is the decision to grant asylum to a non-genuine applicant, a Type II error or miss (MacMillan, 2002). The probability that each test or method will make each type of error can be expressed in terms of sensitivity and specificity, terms that find their origin in signal detection theory (MacMillan, 2002). Sensitivity, when applied to lie detection, is the proportion of correctly identified truth-tellers (Altman \& Bland, 1994). Specificity, in contrast, is the proportion of correctly identified liars (Altman \& Bland, 1994).

The costs of both types of errors are substantial. False alarms may result in a violation of the principle of non-refoulement and thereby in a violation of human rights, whereas misses undermine the public interest (Thomas, 2006). Hence, both errors should be avoided and migration boards should strive for credibility assessment methods that are both highly sensitive and highly specific. However, finding a 
test that correctly identifies $100 \%$ of applicants is unrealistic. As non-refoulement is forbidden in states that endorse the Geneva Convention (United Nations, 1951), and it is the primary principle underlying the CEAS (European Parliament, 1999), it appears that truth-detection should be prioritized over lie-detection in EU asylum procedures. The current thesis is written from that perspective, although I do evaluate the efficacy of currently-employed interview methods both in terms of truth-detection (i.e., do the methods enable truth-tellers to provide a convincing account?) and lie-detection (i.e., do the methods make it difficult for liars to appear credible?).

5.1.6.1 Decision making under uncertainty. Throughout this thesis I also recognize that asylum officials face a very difficult task, and must make decisions in an uncertain context (see also Granhag et al., 2005; Thomas, 2006). Establishing the relevant facts in asylum cases is complex (this is also recognized by the ECtHR, for example in R.C. v. Sweden §52). Asylum officials work in an multicultural setting, under time-pressure, and seldom receive feedback on the accuracy of their past decisions (Granhag et al., 2005). Combining that with the scarcity of verifiable evidence (Gyulai, 2013b), they have little to base their decisions on.

The uncertainty that asylum officials face may affect their decision-making strategies. In uncertain contexts, people often rely on heuristics (general decisionrules based on prior knowledge or experiences (Rassin, in press)) to minimize complexity (Tversky \& Kahneman, 1974). This often involves focusing on one aspect of a situation to base a decision on while ignoring other aspects (Tversky \& Kahneman, 1974). You may, for example, assume that a child is very intelligent based on the sole fact that their father is a professor. In most situations, heuristics assist us to understand the world in an effective and efficient manner. For the majority of life situations, it is more appropriate to estimate a person's intelligence using heuristics than to request an IQ test. In everyday situations, mistakes owing to heuristics often have minor consequences that the benefits easily outweigh (Rassin, in press).

In the legal process the use of heuristics may be more problematic because the consequences of a wrong decision can be extensive and irreversible (L. H. Colwell, 2005; Rassin, in press). In the legal context, heuristics can prevent deeper and controlled processing of information and may as a result feed erroneous decisions (L. H. Colwell, 2005; Porter \& ten Brinke, 2009; Porter, ten Brinke, \& Gustaw, 2010). If the desire to reduce complexity is accompanied by a high motivation to make a 
good decision, the chances of erroneous decisions may further increase. Although highly motivated decision-makers tend to make better decisions when the problem is easy, motivation hampers decision-making in complex cases (Pelham, 1995). Thus, in the uncertain and high-stake decision context in which asylum officials operate the use of heuristics may be tempting yet precarious.

Asylum officials themselves indicate a need for more education and guidance about effective credibility assessments (Granhag et al., 2005). Considering that asylum cases are often complex and uncertain, empirical research that provides guidance on effective methods for credibility assessments may be especially valuable.

\subsection{Overview of chapters}

Having outlined the most relevant concepts and theory, next I provide an overview of the way in which these concepts are examined in the remainder of this thesis. Each chapter focuses on one of three sub-questions that have been formulated to resolve the primary research question. The three sub-questions are discussed in relation to Figure 2.

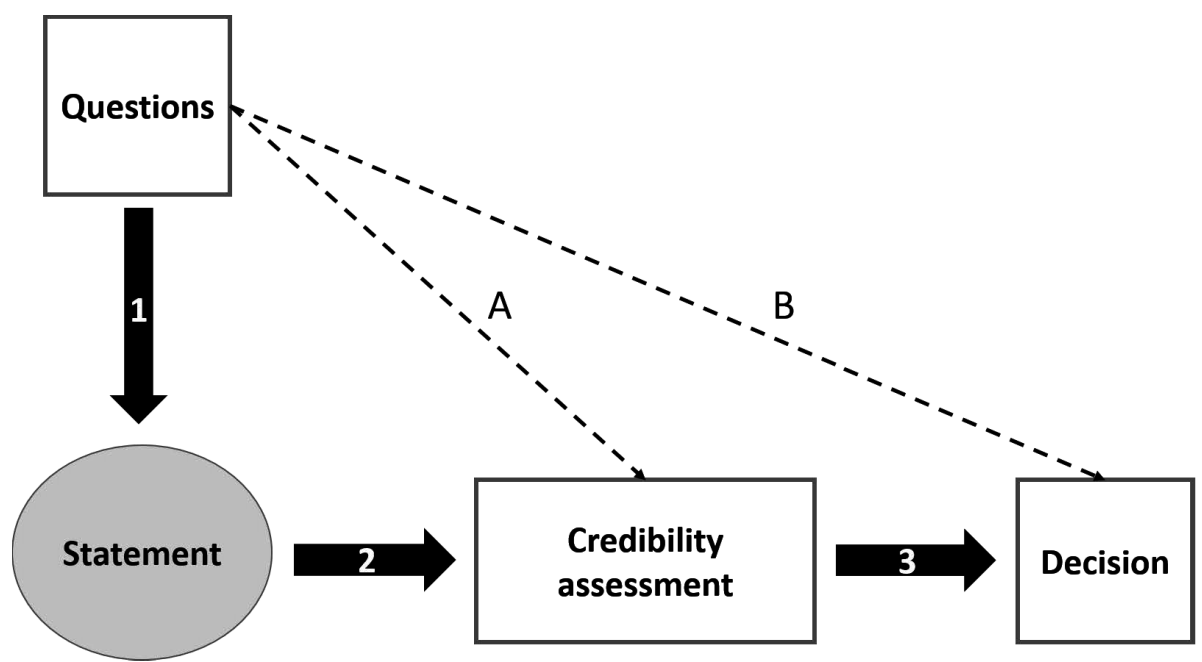

Figure 2. An overview of the relation between interviewing, credibility assessment, and decision-making in asylum cases, and how they are considered in relation to the main research question and the sub-questions. 


\subsubsection{Chapter 2}

In order to evaluate current practice, what constitutes current practice must first be established. The first sub-question therefore concerns the evaluation of the statements asserted by the asylum seeker, which is illustrated with the second arrow in Figure 2: how is the credibility of asylum seekers' statements generally assessed? In Chapter 2, I aim to answer this question by evaluating policy guidelines for credibility assessments in the European asylum procedure. I focus on credibility indicators that are commonly used to evaluate asylum seekers' statements. The validity of those indicators is evaluated according to psychological research on the functioning of human memory and the detection of deception. In addition, gaps in the current literature are identified.

\subsubsection{Chapters 3 and 4}

Focusing solely on the different indicators used to evaluate asylum seekers' statements is not sufficient. As was outlined above, statements do not emerge in a vacuum; they are a direct result of the questions asked in an interview, as is illustrated with the arrow number 1 in Figure 2. As questions affect the amount and accuracy of information obtained in an interview (Vrij, Hope, et al., 2014), they also affect the likelihood that the statement will be perceived as credible (as is illustrated by arrow $A$ in Figure 2). Thereby, interview questions can indirectly influence the outcome of the asylum procedure (as is illustrated with arrow B in Figure 2). In this thesis I evaluate the extent to which the questions asked in asylum interviews stimulate a genuine applicant to provide statements that meet the requirements for being perceived as credible. The second sub-question therefore is: which style, type, and kind of questions are typically asked to assess the credibility of a claim about origin or persecution? To answer this question, I will present two studies.

5.2.2.1 Chapter 3. In Chapter 3 a vignette study among Swedish asylum officials is presented. This study is an analysis of the questions formulated by asylum officials in response to four different case-vignettes in which either the origin or persecution claim of the applicant is doubted. The aims of the study are twofold. The first is to evaluate whether the style and type of the formulated questions promote elaborate, detailed and accurate responses. The second aim is to organize the questions thematically, to assess whether there is a typical interviewing strategy to assess credibility in origin cases and in persecution cases. With the vignette 
methodology, a first insight into interviewing practice in the asylum procedure is obtained.

5.2.2.1 Chapter 4. As a follow-up of the vignette study, in Chapter 4 an analysis of real-life cases is presented. Specifically, interview transcripts of 40 cases from the Dutch Immigration Service are assessed. In none of these cases could the applicants corroborate their origin with authentic documentary evidence, hence, in all cases the credibility of origin claim was assessed by means of an interview. There are multiple advantages to analysing real-life cases. For example, actual practice can be studied, and more questions analysed, the questions can be analysed in relation to previous questions, and there is a reduced possibility of socially-desirable answering. The aims of the study are the same as in the vignette study. Although, compared to the vignette study more closed questions are expected. This is for the reason that, rather than only five questions formulated in response to a vignette, this study utilises complete interview transcripts, and interviews tend to start with a few open questions and become more closed as the interview proceeds (Fisher, Geiselman, \& Raymond, 1987; Wright \& Alison, 2004). Regarding question content, similar thematic structures are expected as in the vignette study, and thereby similar strategies to assess the honesty of an origin claim are expected.

\subsubsection{Chapter 5}

The experimental study presented in Chapter 5 elaborates on findings concerning question content in Chapters 3 and 4. This chapter concentrates on the validity of questions typically asked in order to assess the credibility of origin-claims. The corresponding sub-question is whether or not the typically asked questions are also valid as a method to discriminate between honest and fabricated claims (i.e., assessing the relationship between arrow $1 \& 2$ ).

In this study participants are either asked to lie or tell the truth about their origin. Each must convince an interviewer that they come from Tilburg. In the interview they are asked 10 knowledge questions typically asked to asylum seekers to assess their origin claim. Half of the participants are able to prepare for the interview. The aim is to test the assumption that somebody who truly originates from a specific town has sufficient knowledge to pass the knowledge-questions. It is hypothesised that - despite truth-tellers being comparatively more knowledgeable about the claimed hometown - that this method is not sufficiently sensitive 
or specific to adequately distinguish genuine participants from lying participants, especially when liars prepare for the interview.

An additional purpose of the experimental study in chapter 5 is to explore the applicability of lie detection techniques that have proven effective in the criminal context. Two techniques are tested: asking impossible questions and changing the output modality from verbal answering to sketching. It is expected that these techniques will be valid tools for the credibility assessment of origin claims owing to differences between truth-tellers and liars in cognitive flexibility and strategies employed in the interview (Liu et al., 2010; Roos af Hjelmsäter et al., 2014).

\subsubsection{Chapter 6}

Based on the answers obtained for these sub-questions, an initial answer to the main research question will be formulated. In Chapter 6, I will summarize information obtained in the four studies and use it to evaluate the extent to which the methods used to assess credibility in the European asylum procedure are valid. By discussing the findings from the policy review (in chapter 2 ) and the empirical studies (in chapter 3-5) in relation to the legal psychological literature on best practice in investigative interviewing and credibility assessments, I provide an overview of what constitutes effective interviewing and decision-making practice in the asylum procedure. In this discussion, remaining gaps in the literature are identified and future research needs are articulated. 


\section{REFERENCES}

Altman, D. G., \& Bland, J. M. (1994). Diagnostic tests 1: sensitivity and specificity. BMJ: British Medical Journal, 308, 1552-1552.

Asylum Procedure Directive 013/32/EU, L3180/60 C.F.R. (2013).

Beneduce, R. (2015). The moral economy of lying: Subjectcraft, narrative capital, and uncertainty in the politics of asylum. Medical Anthropology, 34, 551-571. doi:10.1080/014 59740.2015.1074576

Black's Law Dictionary. (1910). The law dictionary. Free Black's Law Dictionary online legal dictionary 2nd Ed. . Retrieved from http://thelawdictionary.org/

Bögner, D., Brewin, C., \& Herlihy, J. (2009). Refugees' experiences of home office interviews: A qualitative study on the disclosure of sensitive personal information. Journal of Ethnic and Migration Studies, 36, 519-535. doi:10.1080/13691830903368329

Bond, C. F., \& DePaulo, B. M. (2006). Accuracy of deception judgments. Personality and Social Psychology Review, 10, 214-234. doi:10.1207/s15327957pspr1003_2

Bond, J. (2012). Excluding justice: The dangerous intersection between refugee claims, criminal Law, and 'guilty' asylum seekers. International Journal of Refugee Law, 24, 37-59. doi:10.1093/ijrl/eer039

Bull, R. (2010). The investigative interviewing of children and other vulnerable witnesses: Psychological research and working/professional practice. Legal and Criminological Psychology, 15, 5-23. doi:10.1348/014466509X440160

Cameron, H. E. (2010). Refugee status determinations and the limits of memory. International Journal of Refugee Law, 22, 469-511. doi:10.1093/ijrl/eeq041

Cohen, J. (2001). Questions of credibility: omissions, discrepancies and errors of recall in the testimony of asylum seekers. International Journal of Refugee Law, 13, 293-309.

Colwell, K., Hiscock, C. K., \& Memon, A. (2002). Interviewing techniques and the assessment of statement credibility. Applied Cognitive Psychology, 16(3), 287-300. doi:10.1002/ acp.788

Colwell, L. H. (2005). Cognitive heuristics in the context of legal decision making. American Journal of Forensic Psychology, 23(2), 17-41.

Commission of the European Communities. (2003). Green paper from the commission. Procedural safeguards for suspects and defendants in criminal proceedings throughout the European Union. . Retrieved from Brussels: http://eur-lex.europa.eu/legal-content/ EN/TXT/PDF/?uri=CELEX:52003DC0075\&from $=N L$

De Poot, C. J., \& Van Koppen, P. J. (2010). Het opsporingsonderzoek [The criminal investigation] In P.J. van Koppen, H.L.G.J. Merkelbach, M. Jelicic, \& J. W. d. Keijser (Eds.), Reizen met mijn rechter: Psychologie van het recht [Travelling with my judge: Psychology of law] (pp. 175-202). Deventer: Kluwer.

Dearden, L. (2016, January 27, 2016). Isis fighters 'virtually impossible'to detect as group continues to use fake passports to exploit refugee crisis. Independent. Retrieved from http://www.independent.co.uk/news/world/europe/isis-fighters-virtually-impossible-to-detect-as-group-continues-to-use-fake-passports-to-exploit-a6836376.html

Deffenbacher, K. A., Bornstein, B. H., Penrod, S. D., \& McGorty, E. K. (2004). A meta-analytic review of the effects of high stress on eyewitness memory. Law and Human Behavior, 28, 687-706.

Deira, S. (2015, October 13, 2015). Gaat Nederland ook economische migrant scheiden? [Will the Netherlands be separating economic migrants as well?]. Elsevier.nl. 
DePaulo, B. M., Lindsay, J. J., Malone, B. E., Muhlenbruck, L., Charlton, K., \& Cooper, H. (2003). Cues to deception. Psychological Bulletin, 129, 74-118. doi:10.1037/00332909.129.1.74

DePaulo, B. M., \& Morris, W. L. (2004). Discerning lies from truths: Behavioural cues to deception and the indirect pathway of intuition. In P. A. Granhag \& L. Strömwall (Eds.), The detection of deception in forensic contexts (pp. 15-40). New York: Cambridge University Press.

EASO. (2015). EASO The implementation of Article 15(c) QD in EU Member States. Retrieved from Malta: http://www.asylumlawdatabase.eu/sites/www.asylumlawdatabase.eu/ files/aldfiles/EASO_The-Implementation-of-Art-15c-QD-in-EU-Member-States.pdf

EASO. (2016). Annual report on the situation of asylum in the European Union 2015. Retrieved from Malta:

Eisen, M. L., Gomes, D. M., Lorber, W. G., Perez, C. I., \& Uchishiba, H. (2013). Using an individual differences approach to examine two distinct types of suggestibility effects. Applied Cognitive Psychology, 27, 2-11. doi:10.1002/acp.2864

European Council. (2016). EU-Turkey statement, 18 march 2016 (144/16) [Press release]. Retrieved from http://www.consilium.europa.eu/en/press/press-releases/2016/03/18eu-turkey-statement/

European Parliament. (1999). Tampere European council 15 and 16 october 1999: Presidency conclusions. Retrieved from http://www.europarl.europa.eu/summits/tam_en.htm

Eurostat. (2016a). Asylum and first time asylum applicants - annual aggregated data (rounded). Luxembourg: European Commission.

Eurostat. (2016b). Asylum in the EU Member States: Record number of over 1.2 million first time asylum seekers registered in 2015 (44/2016) [Press release]. Retrieved from http://ec.europa.eu/eurostat/documents/2995521/7203832/3-04032016-AP-EN. pdf/790eba01-381c-4163-bcd2-a54959b99ed6

Eurostat. (2016c). Asylum quarterly report: First time asylum applicants and first instance decisions on asylum applications: second quarter 2016. Statistics explained. Retrieved from http://ec.europa.eu/eurostat/statistics-explained/index.php/Asylum_quarterly_report\#Increase_in_asylum_applicants

Ewens, S., Vrij, A., Mann, S., \& Leal, S. (2015). Using the reverse order technique with nonnative speakers or through an interpreter. Applied Cognitive Psychology, n/a-n/a. doi:10.1002/acp.3196

Fahsing, I. A., \& Rachlew, A. (2009). Investigative interviewing in the Nordic region. In T. Williamson, R. Milne, \& S. P. Savage (Eds.), International developments in Investigative Interviewing (pp. 39-65). Devon: Willan Publishing.

Fargues, P. (2016). Who are the million migrants who entered Europe without a visa in 2015? Population \& Sociétés, 532, 1-4.

F.G. v. Sweden. (23 March 2016). Application no. 43611/1. Strasbourg: European Court of Human Rights

Fisher, R. P. (1995). Interviewing victims and witnesses of crime. Psychology, Public Policy, and Law, 1, 732-764. doi:10.1037/1076-8971.1.4.732

Fisher, R. P., Milne, R., \& Bull, R. (2011). Interviewing cooperative witnesses. Current Directions in Psychological Science, 20, 16-19. doi:10.1177/0963721410396826

Freedman, J. (2016). Engendering security at the borders of Europe: Women migrants and the Mediterranean 'crisis'. Journal of Refugee Studies, 1-15. doi:https://doi. org/10.1093/jrs/few019 
Giesbrecht, T., \& Peters, M. (2010). Tests en schalen in de forensische context [Tests and scales in the forensic context]. In P.J. van Koppen, H.L.G.J. Merkelbach, M. Jelicic, \& J. W. d. Keijser (Eds.), Reizen met mijn rechter: Psychologie van het recht [Travelling with my judge: Psychology of law] (pp. 91-104). Deventer: Kluwer.

Gilbert, J. A. E., \& Fisher, R. P. (2006). The effects of varied retrieval cues on reminiscence in eyewitness memory. Applied Cognitive Psychology, 20, 723-739. doi:10.1002/ acp.1232

Gilovich, T., Savitsky, K., \& Medvec, V. H. (1998). The illusion of transparency: Biased assessments of others' ability to read one's emotional states. Journal of Personality and Social Psychology, 75, 332-346. doi:10.1037/0022-3514.75.2.332

Gorlick, B. (2002). Common burdens and standards: Legal elements in assessing claims to refugee status. Retrieved from Geneva: http://www.uio.no/studier/emner/jus/ jus/JUR5530/v07/undervisningsmateriale/Gorlick\%20Burden\%20of\%20Proof\%20 Article.pdf

Granhag, P. A., \& Hartwig, M. (2008). A new theoretical perspective on deception detection: On the psychology of instrumental mind-reading. Psychology, Crime \& Law, 14, 189200. doi:10.1080/10683160701645181

Granhag, P. A., Hartwig, M., Giolla, E. M., \& Clemens, F. (2014). Suspects' Verbal CounterInterrogation Strategies. In P. A. Granhag, A. Vrij, \& B. Verschuere (Eds.), Detecting Deception (pp. 293-313). Chichester: John Wiley \& Sons, Ltd.

Granhag, P. A., \& Mac Giolla, E. (2014). Preventing future crimes: Identifying markers of true and false intent. European Psychologist, 19, 195-206. doi:10.1027/1016-9040/ a000202

Granhag, P. A., Strömwall, L. A., \& Hartwig, M. (2005). Granting asylum or not? Migration board personnel's beliefs about deception. Journal of Ethnic and Migration Studies, 31, 29-50. doi:10.1080/1369183042000305672

Griffiths, A., Milne, B., \& Cherryman, J. (2011). A question of control? The formulation of suspect and witness interview question strategies by advanced interviewers. International Journal of Police Science \& Management, 13, 255-267. doi:10.1350/ ijps.2011.13.3.219

Gyulai, G. (2013a). Credibility assessment in asylum procedures: a multidisciplinary training manual. Budapest, Hungary: Hungarian Helsinki Comittee.

Gyulai, G. (2013b). The evidentiary framework of credibility assessment. In G. Gyulai (Ed.), Credibility assessment in asylum procedures: a multidisciplinary training manual ( $p$. 9-20). Budapest, Hungary: Hungarian Helsinki Comittee.

Hartwig, M., Granhag, P. A., Stromwall, L., \& Doering, N. (2010). Impression and information management: On the strategic self- regulation of innocent and guilty suspects. The Open Criminology Journal, 3, 10-16.

Hassan, A., \& Biörklund, L. (2016). The journey to dreamland never ends: A refugee's journey from somalia to sweden. Refugee Survey Quarterly, 35, 116-136. doi:10.1093/ $\mathrm{rsq} / \mathrm{hdw007}$

Herlihy, J., Gleeson, K., \& Turner, S. (2010). What assumptions about human behaviour underlie asylum judgments? International Journal of Refugee Law, 22, 351-366. doi:10.1093/ijrl/eeq027

Herlihy, J., Jobson, L., \& Turner, S. (2012). Just tell us what happened to you: Autobiographical memory and seeking asylum. Applied Cognitive Psychology, 26, 661-676. doi:10.1002/acp.2852

Herlihy, J., \& Turner, S. W. (2009). The psychology of seeking protection. International Journal of Refugee Law, 21, 171-192. doi:10.1093/ijrl/eep004 
Hershkowitz, I., Fisher, S., Lamb, M. E., \& Horowitz, D. (2007). Improving credibility assessment in child sexual abuse allegations: The role of the NICHD investigative interview protocol. Child Abuse \& Neglect, 31, 99-110. doi:http://dx.doi.org/10.1016/j. chiabu.2006.09.005

Home Affairs Committee. (2013). Asylum. Seventh Report of Session 2013-14. Retrieved from London: http://www.publications.parliament.uk/pa/cm201314/cmselect/ cmhaff/71/71.pdf

Houston, K. A., Clifford, B. R., Phillips, L. H., \& Memon, A. (2013). The emotional eyewitness: The effects of emotion on specific aspects of eyewitness recall and recognition performance. Emotion, 13, 118-128. doi:10.1037/a0029220

IND-Werkinstructie nr. 2016/7 (AUA): DNA onderzoek en identificerend gehoor [INS-work instruction nr. 2016/7: DNA testing and identifying interview], (2016).

Inter-Parliamentary Union [IPU]. (2001). Refugee Protection: A guide to international refugee law. Retrieved from Geneva: http://www.ipu.org/pdf/publications/refugee_en.pdf

J.K and others v. Sweden. (23 August 2016). Application no. 59166/12. Strasbourg: European Court of Human Rights

Johnson, T. A. M. (2011). On silence, sexuality and skeletons: Reconceptualizing narrative in asylum hearings. Social \& Legal Studies, 20, 57-78. doi:10.1177/0964663910391205

Jubany, O. (2011). Constructing truths in a culture of disbelief. International Sociology, 26, 74-94. doi:10.1177/0268580910380978

Kassin, S. M. (2005). On the psychology of confessions: Does innocence put innocents at risk? , 60, 215-228. doi:10.1037/0003-066X.60.3.215

Kaytaz, E. S. (2016). Afghan Journeys to Turkey: Narratives of Immobility, Travel and Transformation. Geopolitics, 21, 284-302. doi:10.1080/14650045.2016.1151874

Labita v. Italy. (6 April 2000). Application no. 26772/95. Strasbourg: European Court of Human Rights

Lamb, M. E., Sternberg, K. J., \& Esplin, P. W. (1994). Factors influencing the reliability and validity of statements made by young victims of sexual maltreatment. Journal of $A p$ plied Developmental Psychology, 15, 255-280. doi:http://dx.doi.org/10.1016/01933973(94)90016-7

Lancaster, G. L. J., Vrij, A., Hope, L., \& Waller, B. (2013). Sorting the liars from the truth tellers: The benefits of asking unanticipated questions on lie detection. Applied Cognitive Psychology, 27, 107-114. doi:10.1002/acp.2879

Larsaeus, N. (2004). The relationship between safeguarding internal security and complying with international obligations of protection. The unresolved issue of excluded asylum seekers. Nordic Journal of International Law, 73, 69-97. doi:doi:http://dx.doi. org/10.1163/157181004323056392

Leal, S., Vrij, A., Warmelink, L., Vernham, Z., \& Fisher, R. P. (2015). You cannot hide your telephone lies: Providing a model statement as an aid to detect deception in insurance telephone calls. Legal and Criminological Psychology, 20, 129-146. doi:10.1111/ Icrp. 12017

Levine, T. R. (2014). Truth-Default Theory (TDT). Journal of Language and Social Psychology, 33, 378-392. doi:10.1177/0261927X14535916

Levine, T. R., Kim, R. K., \& Blair, J. P. (2010). (in)accuracy at detecting true and false confessions and denials: An initial test of a projected motive model of veracity judgments. Human Communication Research, 36, 82-102. doi:10.1111/j.1468-2958.2009.01369.x

Liu, M., Granhag, P. A., Landström, S., Hjelmsaeter, E. R. a., Strömwall, L., \& Vrij, A. (2010). Can you remember what was in your pocket when you were stung by a bee?': Eliciting 
cues to deception by asking the unanticipated. Open Criminology Journal, 3, 31-36. doi:10.2174/1874917801003010031

Loftus, E. F. (2005). Planting misinformation in the human mind: A 30-year investigation of the malleability of memory. Learning \& Memory, 12, 361-366. doi:10.1101/Im.94705

Mac Giolla, E., Granhag, P. A., \& Liu-Jönsson, M. (2013). Markers of good planning behavior as a cue for separating true and false intent. PsyCh Journal, 2(3), 183-189. doi:10.1002/ pchj.36

Mackey, A., \& Barnes, J. (2013). Assessment of credibility in refugee and subsidiary protection claims under the EU Qualification Directive: Judicial criteria and standards. Retrieved from Haarlem, the Netherlands: http://www.refworld.org/docid/557028564.html

MacMillan, N. A. (2002). Signal Detection Theory. In H. Pashler \& S. Yantis (Eds.), Stevens' Handbook of Experimental Psychology. New York: John Wiley \& Sons, Inc.

Meissner, C. A., \& Kassin, S. M. (2002). "He's guilty!": Investigator bias in judgments of truth and deception. Law and Human Behavior, 26, 469-480. doi:10.2307/1394522

Meissner, C. A., Redlich, A., Bhatt, S., \& Brandon, S. (2012). Interview and interrogation methods and their effects on investigative outcomes. Campbell systematic reviews, Article 13. doi:doi:10.4073/csr.2012.13

Memon, A. (2012). Credibility of asylum claims: Consistency and accuracy of autobiographical memory reports following trauma. Applied Cognitive Psychology, 26, 677-679. doi:10.1002/acp.2868

Millbank, J. (2009). 'The ring of truth': A case study of credibility assessment in particular social group refugee determinations. International Journal of Refugee Law, 22, 1-33. doi:10.1093/ijrl/een040

Milne, R., \& Bull, R. (1999). Investigative Interviewing: psychology and practice. Chichester: Wiley.

Moston, S., \& Engelberg, T. (1993). Police questioning techniques in tape recorded interviews with criminal suspects. Policing and Society, 3, 223-237. doi:10.1080/1043946 3.1993.9964670

M. M. v. Minister for Justice, Equality and Law Reform, Ireland, Attorney General. (22 November 2012). C-277/11. European Union: Court of Justice of the European Union

M.S.S. v. Belgium and Greece. (21 January 2011). Application no. 30696/09. Strasbourg: European Court of Human Rights

Murray, D. (2016, 21 October 2016). Refugees in Egypt risk all on deadly sea crossing to Europe. UNHCR news and stories. Retrieved from http://www.unhcr.org/news/ latest/2016/10/580a203b4/refugees-egypt-risk-deadly-sea-crossing-europe.html

Nahari, G., Leal, S., Vrij, A., Warmelink, L., \& Vernham, Z. (2014). Did Somebody See It? Applying the Verifiability Approach to Insurance Claim Interviews. Journal of Investigative Psychology and Offender Profiling, 11, 237-243. doi:10.1002/jip.1417

Nahari, G., Vrij, A., \& Fisher, R. P. (2014a). Exploiting liars' verbal strategies by examining the verifiability of details. Legal and Criminological Psychology, 19, 227-239. doi:10.1111/j.2044-8333.2012.02069.x

Nahari, G., Vrij, A., \& Fisher, R. P. (2014b). The verifiability approach: Countermeasures facilitate its ability to discriminate between truths and lies. Applied Cognitive Psychology, 28, 122-128. doi:10.1002/acp.2974

Ní Raghallaigh, M. (2013). The causes of mistrust amongst asylum seekers and refugees: Insights from research with unaccompanied asylum-seeking minors living in the republic of ireland. Journal of Refugee Studies, 27, 82-100. doi:10.1093/jrs/fet006 
Noll, G. (2005a). Introduction: Re-mapping evidentiary assessment in asylum procedures. In N. Gregor (Ed.), Proof, evidentiary assessment and credibility in asylum procedures (pp. 1-12). Leiden, the Netherlands: Koninklijke Brill NV.

Noll, G. (2005b). Salvation by the grace of state? Explaining credibility assessment in the asylum procedure. In G. Noll (Ed.), Proof, evidentiary assessment and credibility in asylum procedures (pp. 197-214). Leiden, the Netherlands: Koninklijke Brill NV.

Novo, M., \& Seijo, D. (2010). Judicial judgment-making and legal criteria of testimonial credibility. European Journal of Psychology Applied to Legal Context, 2, 91-115.

Oxburgh, G. E., Myklebust, T., \& Grant, T. (2010). The question of question types in police interviews: A review of the literature from a psychological and linguistic perspective. International Journal of Speech Language and the Law, 17, 45-66. doi:10.1558/ijsII. v17i1.45

Pansky, A., Koriat, A., \& Goldsmith, M. (2005). Eyewitness recall and testimony. In N. Brewer \& K. Williams (Eds.), Psychology and law: An empirical perspective (pp. 93-150). New York: Guilford.

Patihis, L., \& Loftus, E. F. (2016). Crashing memory 2.0: False memories in adults for an upsetting childhood event. Applied Cognitive Psychology, 30, 41-50. doi:10.1002/acp.3165

Pelham, B. W. (1995). The effect of motivation of judgment depends on the difficulty of the judgment. Journal of Personality and Social Psychology, 68, 581.

Penrod, S., \& Cutler, B. (1995). Witness confidence and witness accuracy: Assessing their forensic relation. Psychology, Public Policy, and Law, 1, 817-845. doi:10.1037/10768971.1.4.817

Perfect, T. J., Wagstaff, G. F., Moore, D., Andrews, B., Cleveland, V., Newcombe, S., . . Brown, L. (2008). How can we help witnesses to remember more? It's an (eyes) open and shut case. Law and Human Behavior, 32, 314-324. doi:10.2307/25144631

Porter, S., \& ten Brinke, L. (2009). Dangerous decisions: A theoretical framework for understanding how judges assess credibility in the courtroom. Legal and Criminological Psychology, 14, 119-134. doi:10.1348/135532508X281520

Porter, S., ten Brinke, L., \& Gustaw, C. (2010). Dangerous decisions: the impact of first impressions of trustworthiness on the evaluation of legal evidence and defendant culpability. Psychology, Crime \& Law, 16, 477-491. doi:10.1080/10683160902926141

Qualification Directive 2004/83/EC, L304/12 C.F.R. (2004).

Qualification Directive 2011/95/EU [Recast QD 2004], L336/09 C.F.R. (2011).

Rassin, E. (in press). Heuristieken [Heuristics]. In P.J. van Koppen, M. Jelicic, J. W. d. Keijser, \& R. Horselenberg (Eds.), Gezichten van het recht [Faces of the law].

R.C. v. Sweden. (9 March 2010). Application no. 41827/07. Strasbourg: European Court of Human Rights

Roos af Hjelmsäter, E., Öhman, L., Granhag, P. A., \& Vrij, A. (2014). 'Mapping' deception in adolescents: Eliciting cues to deceit through an unanticipated spatial drawing task. Legal and Criminological Psychology, 19, 179-188. doi:10.1111/j.2044-8333.2012.02068.x

Saadi v. Italy. (28 February 2008). Application no. 37201/06. Strasbourg: European Court of Human Rights

Sales, R. (2005). Secure borders, safe haven: A contradiction in terms? Ethnic and Racial Studies, 28, 445-462. doi:10.1080/0141987042000337830

Shaw, J., \& Kaye, M. (2013). A question of credibility: Why so many initial asylum decisions are overturned on appeal in the UK. Retrieved from London: http://www.amnesty. org.uk/sites/default/files/a_question_of_credibility_final_0.pdf 
Shawyer, A., Milne, R., \& Bull, R. (2009). Investigative interviewing in the UK. In T. Williamson, R. Milne, \& S. P. Savage (Eds.), International developments in Investigative Interviewing (pp. 39-65). Devon: Willan Publishing.

Smeets, T. (2011). Acute stress impairs memory retrieval independent of time of day. Psychoneuroendocrinology, 36, 495-501. doi:http://dx.doi.org/10.1016/j. psyneuen.2010.08.001

Snook, B., Luther, K., Quinlan, H., \& Milne, R. (2012). Let 'em talk!: A field study of police questioning practices of suspects and accused persons. Criminal Justice and Behavior, 39, 1328-1339. doi:10.1177/0093854812449216

Sourander, A. (2003). Refugee families during asylum seeking. Nordic Journal of Psychiatry, 57, 203-207. doi:10.1080/08039480310001364

Stern, R. (2014). "Our Refugee Policy is Generous": Reflections on the Importance of a State's Self-Image. Refugee Survey Quarterly, advance access. doi:10.1093/rsq/hdt020

Strömwall, L. A., \& Granhag, P. A. (2003). How to detect deception? Arresting the beliefs of police officers, prosecutors and judges. Psychology, Crime \& Law, 9, 19-36. doi:10.1080/10683160308138

Strömwall, L. A., Hartwig, M., \& Granhag, P. A. (2006). To act truthfully: Nonverbal behaviour and strategies during a police interrogation. Psychology, Crime \& Law, 12, 207-219. doi:10.1080/10683160512331331328

Sweeney, J. A. (2009). Credibility, proof and refugee law. International Journal of Refugee Law, 21, 700-726. doi:10.1093/ijrl/eep027

Sweeney, J. A. (2016). A 'credible' response to persons fleeing armed conflict. In M. Happold \& M. Pichou (Eds.), The Protection of Persons Fleeing Armed Conflict and Other Situations of Violence. (pp. 81-103). Brussels: Larcier.

Tekin, S., Granhag, P. A., Strömwall, L., Giolla, E. M., Vrij, A., \& Hartwig, M. (2015). Interviewing strategically to elicit admissions from guilty suspects. Law and Human Behavior, 39, 244-252. doi:10.1037//hb0000131

Thomas, R. (2006). Assessing the credibility of asylum claims: EU and UK approaches examined. European Journal of Migration and Law, 8, 79-96. doi:doi:http://dx.doi. org/10.1163/157181606776911969

Thoresen, C., Lønnum, K., Melinder, A., Stridbeck, U., \& Magnussen, S. (2006). Theory and practice in interviewing young children: A study of Norwegian police interviews 19852002. Psychology, Crime \& Law, 12, 629-640. doi:10.1080/10683160500350546

Tversky, A., \& Kahneman, D. (1974). Judgment under Uncertainty: Heuristics and Biases. Science, 185, 1124-1131. doi:10.1126/science.185.4157.1124

UN General Assembly. (1948). Universal declaration of human rights (217 [III] A). Paris.

UNHCR. (1998). Note on burden and standard of proof in refugee claims. Retrieved from Geneva: United Nations High Commissioner for Refugees.

UNHCR. (2001). Note on international protection. A/AC.96/951. Retrieved from New York: http://www.refworld.org/docid/3bb1c6cc4.html

UNHCR. (2011). Handbook and guidelines on procedures and criteria for determining refugee status under the 1951 Convention and the 1967 Protocol relating to the status of refugees. Geneva: United Nations High Commissioner for Refugees.

UNHCR. (2013). Beyond proof, credibility asessment in EU asylum systems. Retrieved from Brussels: United Nations High Commissioner for Refugees.

UNHCR. (2016a). Assistance to refugees, returnees, and displaced persons in Africa. Retrieved from New York: http://www.unhcr.org/excom/unhcrannual/5808d8677/ assistance-refugees-returnees-displaced-persons-africa.html 
UNHCR. (2016b). Global trends: Forced Displacement in 2015. Retrieved from Geneva:

United Nations. (1951). The 1951 convention relating to the status of refugees. Geneva: United Nations.

Van Koppen, P. J. (2011). Overtuigend bewijs: Indammen van rechterlijke dwalingen [Convincing evidence: Reducing the number of miscarriages of justice]. Amsterdam: Nieuw Amsterdam.

Van Reisen, M., \& Rijken, C. (2015). Sinai trafficking: Origin and definition of a new form of human trafficking. Social Inclusion, 3, 113-124. doi:DOI: http://dx.doi.org/10.17645/ si.v3i1.180

Vanderhallen, M., Vervaeke, G., \& Holmberg, U. (2011). Witness and suspect perceptions of working alliance and interviewing style. Journal of Investigative Psychology and Offender Profiling, 8, 110-130.

Verkuyten, M. (2004). Emotional reactions to and support for immigrant policies: Attributed responsibilities to categories of asylum seekers. Social Justice Research, 17, 293-314. doi:10.1023/B:SORE.0000041295.83611.dc

Vollmer, B. A. (2011). Policy discourses on irregular migration in the EU - 'number games' and 'political games'. European Journal of Migration and Law, 13, 317-339. doi:doi:1 $0.1163 / 157181611 \times 587874$

Vrij, A. (2004). Why professionals fail to catch liars and how they can improve. Legal and Criminological Psychology, 9, 159-181. doi:10.1348/1355325041719356

Vrij, A., Fisher, R., Mann, S., \& Leal, S. (2006). Detecting deception by manipulating cognitive load. Trends in Cognitive Sciences, 10, 141-142. doi:http://dx.doi.org/10.1016/j. tics.2006.02.003

Vrij, A., Fisher, R., Mann, S., \& Leal, S. (2008). A cognitive load approach to lie detection. Journal of Investigative Psychology and Offender Profiling, 5, 39-43. doi:10.1002/ jip.82

Vrij, A., Granhag, P. A., Mann, S., \& Leal, S. (2011). Outsmarting the liars: Toward a cognitive lie detection approach. Current Directions in Psychological Science, 20, 28-32. doi:10.1177/0963721410391245

Vrij, A., Granhag, P. A., \& Mann, S. A. (2010). Good liars. Journal of Psychiatry \& Law, 38, 77-98.

Vrij, A., Hope, L., \& Fisher, R. P. (2014). Eliciting reliable information in investigative interviews. Policy Insights from the Behavioral and Brain Sciences, 1, 129-136. doi:10.1177/2372732214548592

Vrij, A., Leal, S., Granhag, P., Mann, S., Fisher, R., Hillman, J., \& Sperry, K. (2009). Outsmarting the liars: The benefit of asking unanticipated questions. Law and Human Behavior, 33, 159-166. doi:10.1007/s10979-008-9143-y

Vrij, A., Mann, S., \& Fisher, R. P. (2006). Information-gathering vs accusatory interview style: Individual differences in respondents' experiences. Personality and Individual Differences, 41, 589-599. doi:http://dx.doi.org/10.1016/j.paid.2006.02.014

Vrij, A., Mann, S., Jundi, S., Hillman, J., \& Hope, L. (2014). Detection of concealment in an information-gathering Interview. Applied Cognitive Psychology, 28, 860-866. doi:10.1002/acp.3051

Vrij, A., Mann, S., Kristen, S., \& Fisher, R. P. (2007). Cues to deception and ability to detect lies as a function of police interview styles. Law and Human Behavior, 31, 499-518. doi:10.1007/s10979-006-9066-4 
Vrij, A., Mann, S. A., Fisher, R. P., Sharon, L., Milne, R., \& Bull, R. (2008). Increasing cognitive load to facilitate lie detection: The benefit of recalling an event in reverse order. Law and Human Behavior, 32, 253-265. doi:10.2307/25144624

Vrij, A., \& Semin, G. R. (1996). Lie experts' beliefs about nonverbal indicators of deception. Journal of nonverbal behavior, 20, 65-80. doi:10.1007/BF02248715

Walsh, D., \& Bull, R. (2010). What really is effective in interviews with suspects? A study comparing interviewing skills against interviewing outcomes. Legal and Criminological Psychology, 15, 305-321. doi:10.1348/135532509X463356

Walsh, D., \& Bull, R. (2012). Examining rapport in investigative interviews with suspects: Does its building and maintenance work? Journal of Police and Criminal Psychology, 27, 73-84. doi:10.1007/s11896-011-9087-x

Waterman, A. H., Blades, M., \& Spencer, C. (2001). Interviewing children and adults: the effect of question format on the tendency to speculate. Applied Cognitive Psychology, 15, 521-531. doi:10.1002/acp.741

Wells, G. L. (1978). Applied eyewitness-testimony research: System variables and estimator variables. Journal of Personality and Social Psychology, 36, 1546-1557. doi:10.1037/0022-3514.36.12.1546

Wells, G. L., \& Loftus, E. F. (2003). Eyewitness memory for people and events. In I.B. Weiner \& D. K. Freedheim (Eds.), Handbook of Psychology (pp. 617-629). Hoboken (NJ): John Wiley \& Sons, Inc.

Wells, G. L., Memon, A., \& Penrod, S. D. (2006). Eyewitness evidence: Improving its probative value. Psychological Science in the Public Interest, 7, 45-75. doi:10.2307/40062354

Yuille, J. C. (1988). The systematic assessment of children's testimony. Canadian Psychology/ Psychologie canadienne, 29, 247-262. doi:10.1037/h0079769 


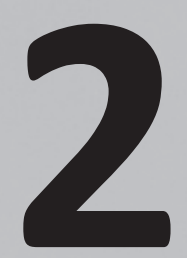

\section{Proving Identity, Origin, and Persecution: Challenges and Future Directions in EU Asylum Assessments}

This chapter is a translated and extended version of a Dutch chapter for a textbook about Legal Psychology:

van Veldhuizen, T. S., \& Horselenberg, R (in press).

Bewijsproblemen in de asielprocedure [Problems of proof in the asylum procedure]. In P.J. van Koppen, J. W. de Keijser, R. Horselenberg, \& M. Jelicic (Eds.), Routes van het Recht: Over de Rechtpsychologie [Routes of the Law: About Legal Psychology].

The manuscript in its present form has been submitted to the European Journal of Migration and Law:

van Veldhuizen, T. S., Horselenberg, R., \& Van Koppen, P. J. (2016). Proving identity, origin, and persecution: Challenges and future directions in EU asylum assessments. Manuscript submitted for publication. 


\begin{abstract}
EU asylum officials must frequently rely solely on asylum seekers' statements to determine eligibility, as documentary evidence for identity, origin and persecution is rare. In many cases, the decisive factor for granting status is the perceived credibility of the asylum narrative. The current paper discusses the challenges associated with credibility assessments from a legal psychological perspective and future research needs are emphasized. We review policy and practice, and evaluate commonly-used credibility indicators as level of detail, consistency, and plausibility based on research about autobiographical memory, lie detection, and decision-making. Circumstances under which these indicators may or may not be valid indicators of truthfulness are outlined. We conclude that the indicators should only be used if interviews assist honest applicants to present a credible account and if shortcomings in asylum narratives are assessed with consideration for alternative explanations. Future research should investigate the extent to which current practice meets these conditions.
\end{abstract}

Keywords: European asylum procedure, credibility assessment, uncertain decision context, autobiographical memory, interviewing techniques, open-minded assessments. 


\section{INTRODUCTION}

A 20-year-old man seeks asylum in Europe. He claims to originate from Eritrea, and to have fled the repressive regime and compulsory military service in that country. The story he tells is not improbable. Eritrea is a country without democracy where citizens are repressed systematically. Evaders risk imprisonment, torture, and sometimes lethal violence. Many citizens therefore flee Eritrea to seek protection in foreign countries. ${ }^{2}$ However, the man cannot prove his Eritrean origin. He claims that smugglers confiscated the only documents that could support his story. This raises a problem for the migration board. The man could falsely present himself as an Eritrean citizen to improve his chances of acquiring a residence permit in the EU. In order to decide on eligibility, an asylum official has to assess whether the man truly comes from Eritrea. The official finds himself in a challenging situation considering that the consequences of an incorrect decision about refugee status can be significant for all parties involved. ${ }^{3}$

The above example, although fictitious, is realistic and illustrates a current challenge for European migration boards. The numbers of people seeking asylum the EU are high. In 2015 more than 1.3 million people applied for asylum in one of the member states, ${ }^{4}$ and in the first two quarters of 2016 asylum applications have increased once more. ${ }^{5}$ Asylum officials must assess for each individual claim whether it meets the requirements for international protection. The numbers by themselves already pose a challenge, as they result in a high workload. Asylum assessments are further complicated by the uncertain decision context and the fact that applicants may lack the capability of providing a credible claim, or may even try to deceive the adjudicator. Hence, to properly understand the challenges that asylum officials face in asylum assessments, they must be examined and discussed in relation to the legal, evidential, and psychological context in which they arise.

2. UK Home Office. (2013). Eritrea: Country of Origin Information Report. Croydon, UK: Country of Origin Information Service.

3. Bond, J. 2012. Excluding justice: The dangerous intersection between refugee claims, criminal Law, and 'guilty' asylum seekers. International Journal of Refugee Law, 24, 37-59. doi: 10.1093/ijrl/eer039; Inter-Parliamentary Union [IPU]. (2001). Refugee Protection: A guide to international refugee law. Geneva: Inter-Parliamentary Union \& Office of the UNHCR.

4. Eurostat. (2016). Asylum and first time asylum applicants - annual aggregated data (rounded). Luxembourg: European Commission.

5. Eurostat. (2016). Asylum quarterly report: First time asylum applicants and first instance decisions on asylum applications: second quarter 2016. Statistics explained. Luxembourg: European Commission. 
We discuss these challenges below. Our objective is to inform decision-makers, legal representatives, and policy makers about how credibility assessments may be affected by the applicant's memory (in relation to the questions asked), interrogative strategies of truth-tellers and liars, and cultural factors. We further aim to stimulate future research by social scientists in this under-researched area.

\section{BURDEN OF PROOF IN ASYLUM CASES}

To be eligible for international protection in the EU, asylum seekers must establish a grounded fear of persecution in their country of origin due to race, religion, nationality, political orientation or membership of a particular social group. ${ }^{6}$ The burden of proof largely rests with the applicant. ${ }^{7}$ Applicants must provide the migration board with all the relevant information in their possession as soon as possible, including information about their identity, origin, reasons for fleeing (i.e., persecution claim), and flight to Europe and any documents supporting their oral statements.

The migration board, on the other hand, must assess each application independently and examine all the material facts in the case. ${ }^{8}$ Material facts - or relevant elements - are the elements of the asylum narrative that could constitute a reason to grant refugee status. To make a decision about status the migration board assesses which relevant elements are believed. For believed elements, the migration board then decides whether the elements substantiate a genuine fear of persecution in the country of origin. ${ }^{9}$ In doing so, the board takes into account all relevant facts relating to the country of origin and the individual position and personal circumstances of the applicant. ${ }^{10}$ For the case described in the introduction, the relevant elements are the proclaimed Eritrean nationality and the objections against fulfilling military service. If believed, these elements would likely be substantial in light of the available country information about Eritrea.

6. Qualification Directive 2011/95/EU; United Nations. (1951). The 1951 convention relating to the status of refugees. Geneva: United Nations.

7. Qualification Directive $2011 / 95 / E U$.

8. Ibid.

9. United Nations High Commissioner for Refugees [UNHCR]. (2013). Beyond proof, credibility asessment in EU asylum systems. Brussels: UNHCR.

10. Qualification Directive 2011/95/EU 


\section{DECIDING UNDER UNCERTAINTY}

Even though migration boards strive for a correct assessment of the claim in as many cases as possible, errors cannot always be avoided. Two types of errors can occur in asylum decisions: first, rejecting the claim of someone who has a genuine fear of persecution in the country of origin (also called false alarms or Type I errors); second, granting a refugee status to someone who does not meet the eligibility criteria (also called misses or Type II errors). ${ }^{11}$

As in other decision-making contexts, a choice must be made as to which error is more detrimental. In the asylum context, Type I errors may result an unjustified expulsion of the asylum seeker, and thereby possibly to the persecution, torture or degrading treatment of that individual in the country of origin. Such an expulsion is in contravention with the fundamental principle of non-refoulement that lies at the heart of international refugee law, regulations, and treaties. ${ }^{12}$ Nevertheless, type II errors may also have undesirable consequences for the receiving state, the public, and the refugee population in the receiving country. ${ }^{13}$ As such, both types of errors should be avoided as much as possible. Considering however that an absolute respect of the right to asylum and the principle of non-refoulement form the starting point for the Common European Asylum System, ${ }^{14}$ the prevention of type I errors is emphasized in the remainder of this paper.

Distinguishing genuine applicants is complicated by the scarcity of evidence in asylum cases. Asylum seekers often cannot support their claims with documents,

11. MacMillan, N. A. (2002). Signal Detection Theory. In H. Pashler \& S. Yantis (Eds.), Stevens' Handbook of Experimental Psychology, pp. 43-90, New York: John Wiley \& Sons, Inc.

12. Qualification Directive 2011/95/EU; United Nations op. cit.

13. See for example Bond op. cit.; Martin, S., Schoenholtz, A. I., \& Fisher, D. (2005). The impact of asylum on receiving countries. In G. J. Borjas \& J. Crisp (Eds.), Poverty, International Migration and Asylum (pp. 99-120). London: Palgrave Macmillan UK; and Verkuyten, M. 2004. Emotional reactions to and support for immigrant policies: Attributed responsibilities to categories of asylum seekers. Social Justice Research, 17, 293-314. doi:10.1023/B:SORE.0000041295.83611. dc.

14. European Parliament. (1999). Tampere European council 15 and 16 october 1999: Presidency conclusions. Retrieved from http://www.europarl.europa.eu/summits/tam en.htm 
such as identification documents or arrest warrants. ${ }^{15}$ The applicant may not have been in possession of such documents, or documents issued in the country of origin are not admissible in the country of reception. In other instances, documents are confiscated by a smuggler. Furthermore, asking authorities in the country of origin for information about the asylum seeker could endanger the applicant and their family ${ }^{16}$. Asylum seekers' oral statements hence are often the only available evidence in asylum cases.

The statements are not always accurate or true. Asylum seekers sometimes lie in their application to increase their chances of acquiring status. ${ }^{17}$ Applicants may fully fabricate a story or may embellish partly true events. To complicate matters further, an otherwise truthful story may contain inaccurate elements resulting of honest mistakes or false memories. ${ }^{18}$ Asylum officials are faced with the difficult task to sort truthful statements from fabrications, embellishments and false memories, and to make a decision only on the believable elements. The lack of evidence and the notion that people may be lying or forgetful, together with the cultural and linguistic barriers encountered in the asylum procedure, renders the decision-making context in the asylum procedure uncertain. ${ }^{19}$ The question is when uncorroborated elements of the asylum narrative should be believed.

\section{CREDIBILITY ASSESSMENTS IN ASYLUM CASES}

The scarcity of evidence is acknowledged in the legal rules and regulations guiding asylum assessments. The European Council accepts that applicants cannot

15. Doornbos, N. 2004. Gescheiden werelden: De beoordeling van geloofwaardigheid van vluchtverhalen [Separate worlds: the assessment of credibility of flight stories]. In P. Mascini \& N. Doornbos (Eds.), Amsterdams Sociologisch Tijdschrift [Sociological Journal Amsterdam] (Vol. 31, pp. 80-112). Amsterdam, the Netherlands; European Migration Network [EMN]. (2013). Establishing Identity for International Protection: Challenges and Practices. Brussels: European Commission.; Noll, G. (2005). Introduction: Re-mapping evidentiary assessment in asylum procedures. In N. Gregor (Ed.), Proof, evidentiary assessment and credibility in asylum procedures (pp. 1-12). Leiden, the Netherlands: Koninklijke Brill NV.

16. Noll op. cit.

17. Beneduce, R. 2015. The moral economy of lying: Subjectcraft, narrative capital, and uncertainty in the politics of asylum. Medical Anthropology, 34, 551-571. doi:10.1080/01459740.2015.1074576

18. Cohen, J. 2001. Questions of credibility: omissions, discrepancies and errors of recall in the testimony of asylum seekers. International Journal of Refugee Law, 13, 293-309.

19. Gyulai, G. (2013). Credibility assessment in asylum procedures: a multidisciplinary training manual. Budapest: Hungarian Helsinki Comittee. 
always substantiate their statements with documentary evidence. Uncorroborated aspects of an asylum claim should hence be accepted as true without further confirmation if the following conditions are met: first, the applicant has made a genuine effort to substantiate the application, and provided a satisfactory explanation for any lacking elements (e.g., for the lack of documentary evidence); second, the applicant applied for international protection at the earliest time possible; third, the applicant made coherent and plausible statements that correspond to information about the country of origin; and fourth, the applicant is judged as generally credible. ${ }^{20}$ Consequently, credibility assessments are inevitable when applicants are unable to corroborate their statements with documents.

Ensuing from the general scarcity of evidence in asylum cases, credibility assessments are at the core of most adjudications. ${ }^{21}$ The UNHCR has noted that, apart from the reference to credibility assessment in the Qualification Directive outlined above, the EU asylum acquis offers little guidance as to how a credibility assessment should be conducted in practice. In an effort to promote to a harmonized approach to credibility assessment in EU member states, and to contribute to better structured, objective, and protection oriented credibility assessment practices in asylum procedures conducted by EU Member States, the CREDO project was launched in 2011. The project resulted in three output documents: a summary of member state practices, ${ }^{22}$ a training manual for asylum officials, ${ }^{23}$ and judicial guidance for refugee law judges. ${ }^{24}$ In these documents the most commonly used credibility indicators are discussed along with underlying assumptions about human memory and deceptive behaviour.

Five criteria are typically used to determine credibility of the information elicited in asylum interviews: plausibility, sufficiency of detail and specificity, internal consistency, consistency with information from external sources, and consistency with other witnesses. ${ }^{25}$ The same indicators are also adopted in practical training

20. Qualification Directive 2011/95/EU, Article 4.5.

21. UNHCR (2013) op. cit.

22. Ibid.

23. Gyulai op. cit.

24. Mackey, A., \& Barnes, J. (2013). Assessment of credibility in refugee and subsidiary protection claims under the EU Qualification Directive: Judicial criteria and standards. Retrieved from Haarlem, the Netherlands: http://www. refworld.org/docid/557028564.html

25. Gyulai Op. cit.; UNHCR (2013) Op. cit. 
programs for decision makers. ${ }^{26}$ They are all based on assumptions about the quality of statements containing genuine memories, and how such statements deviate from statements about fabricated events. ${ }^{27}$ Asylum officials seem to believe that the indicators assist them to sort truthful from fabricated statements. ${ }^{28}$ However, that assumption is not always valid in light of empirical research about autobiographical memory ${ }^{29}$ or the strategies of truth-tellers and liars. ${ }^{30}$

Several factors that may impair the applicant's ability to provide highly detailed, consistent and plausible statements are outlined in the CREDO documents and discussed in the EASO training modules. Practitioners are urged to take memory limitations, personal background of the applicant and other factors that may influence a statement into account. In addition, the CREDO authors advocate for extra caution when using plausibility because it is a culturally and personally determined concept. ${ }^{31}$ Yet, we argue that in practice this will be difficult for the decision maker. First, because state policy documents guiding credibility assessments often contain little nuance. For example, the UK Home Office asylum policy instruction only briefly mentions memory limitations and personal factors that may impair the applicant's ability to provide detailed, coherent and plausible statements; ${ }^{32}$ and the Dutch work instruction instructs decision-makers to use the indicators without mentioning confounding factors at all. ${ }^{33}$ With such limited guidance for decision makers, nuance may easily be lost in the application of credibility indicators. Second, because in an uncertain decision-context like the asylum procedure people tend to rely on rules of thumb or heuristics to cope with the complexity of the situation. ${ }^{34}$ Heuristics are generally adaptive, because they help people to navigate efficiently through complex situations. However, when heuristics prevent

26. EASO. (2014). EASO e-learning platform. European Asylum Curriculum. Module 7: Evidence Assessment. Retrieved January 10, 2014, from https://ceac.easo.europa.eu/eac/

27. UNHCR (2013) op. cit.

28. Granhag, P. A., Strömwall, L. A., \& Hartwig, M. 2005. Granting asylum or not? Migration board personnel's beliefs about deception. Journal of Ethnic and Migration Studies, 31, 29-50. doi: 10.1080/1369183042000305672

29. See for example: Cohen op.cit.

30. See for example Granhag et al. (2005) op. cit.

31. Gyulai (2013) op. cit.

32. And neither do they explain how these memory limitations or personal factors should be accounted for: Home Office. (2015). Asylum policy instruction. Assessing credibility and refugee status. United Kingdom: Home Office, Section 5.5

33. Immigration and Naturalisation Service [INS]. (2014). IND-Werkinstructie $n r .2014 / 10$ (AUB): Inhoudelijke beoordeling (asiel) [INS-work instruction nr. 2014/10 (AUB): Substantive assessment (asylum)]. Rijswijk, the Netherlands: Immigration and Naturalisation Service [IND].

34. Tversky, A., \& Kahneman, D. (1974). Judgment under Uncertainty: Heuristics and Biases. Science, 185, 1124-1131. doi: $10.1126 /$ science.185.4157.1124 
deeper and controlled processing of information in a legal context, they may feed erroneous decisions. ${ }^{35}$ The credibility indicators can be easily applied as a heuristic, especially under the time pressure faced by asylum officials and in combination with stereotypical beliefs. ${ }^{36}$

For these reason we now briefly review the possible risks associated with a rigid application of each credibility indicator in relation to the psychological literature on human memory and the detection of deception. Besides informing practitioners about the circumstances under which the indicators may or may not be indicative of truthfulness, our objective is also to show that credibility assessments are influenced by the questions asked and the assessors' personal beliefs. To illustrate this, we provide examples from real cases.

\subsection{Detail and Specificity}

The first indicator of credibility in asylum cases is the extent to which the statements are detailed and specific. That is, whether the level and nature of detail provided by the applicant about the asserted material facts are indicative of a genuine personal experience. ${ }^{37}$ The underlying assumption is that authentic statements are more detailed because re-experiencing true events would evoke a variety of sensory details. In contrast, fabricating a highly detailed story would be difficult. ${ }^{38}$

Lie detection research is inconclusive as to the validity of this assumption. Some studies have shown that truthful statements in response to free recall questions are more detailed than fabricated statements, ${ }^{39}$ whereas in other studies fabricators' and truth-tellers' statements were equally detailed or fabricators gave more detailed free narratives. ${ }^{40}$ Perhaps the liars used diverging strategies in these studies. Truth-tellers are generally more forthcoming than liars and may

35. Colwell, L. H. (2005). Cognitive heuristics in the context of legal decision making. American Journal of Forensic Psychology, 23(2), 17-41; Daftary-Kapur, T., Dumas, R., \& Penrod, S. D. (2010). Jury decision-making biases and methods to counter them. Legal and Criminological Psychology, 15, 133-154. doi:10.1348/135532509X465624

36. Granhag et al. (2005) op. cit.

37. Gyulai op. cit.

38. UNHCR (2013) op. cit.

39. For example, Vrij, A., Mann, S., Jundi, S., Hillman, J., \& Hope, L. 2014. Detection of concealment in an informationgathering Interview. Applied Cognitive Psychology, 28, 860-866. doi: 10.1002/acp.3051

40. For example, Lancaster, G. L. J., Vrij, A., Hope, L., \& Waller, B. 2013. Sorting the liars from the truth tellers: The benefits of asking unanticipated questions on lie detection. Applied Cognitive Psychology, 27, 107-114. doi: 10.1002/acp.2879 
therefore spontaneously provide relatively detailed stories. ${ }^{41}$ Still, liars may know that richer statements are perceived as more credible and prepare extensively for the interview or embed their lies in true experiences to provide highly detailed fabrications. ${ }^{42}$ The strategy works as long as questions can be anticipated. Liars may however encounter difficulties when asked unexpected questions, because now they must improvise. ${ }^{43}$ Moreover, even liars who successfully generate a detailed story may provide different kinds of details than truth-tellers; the details provided by truth-tellers are more often verifiable. ${ }^{44}$

Despite being forthcoming, providing detailed statements sometimes is difficult for truth-tellers. ${ }^{45}$ In the training for asylum officials several factors that could negatively influence the level of detail in a truthful statement are acknowledged, such as educational level, cultural background, and trauma. ${ }^{46}$ But even when such individual differences are taken out of the equation, there are other reasons why asylum seekers may be unable to reproduce certain information in an interview.

As human beings we cannot attend to all the information contained in a situation. ${ }^{47}$ To prevent information overload, we selectively attend to those aspects of the situation that are relevant, extraordinary, or otherwise salient, and only these

41. Strömwall, L. A., Hartwig, M., \& Granhag, P. A. 2006. To act truthfully: Nonverbal behaviour and strategies during a police interrogation. Psychology, Crime \& Law, 12, 207-219. doi:10.1080/10683160512331331328

42. Leins, D. A., Fisher, R. P., \& Ross, S. J. 2013. Exploring liars' strategies for creating deceptive reports. Legal and Criminological Psychology, 18, 141-151. doi:10.1111/j.2044-8333.2011.02041.x

43. Vrij, A., Leal, S., Granhag, P., Mann, S., Fisher, R., Hillman, J., \& Sperry, K. 2009. Outsmarting the liars: The benefit of asking unanticipated questions. Law and Human Behavior, 33, 159-166. doi:10.1007/s10979-008-9143-y

44. Nahari, G., Vrij, A., \& Fisher, R. P. 2014. Exploiting liars' verbal strategies by examining the verifiability of details. Legal and Criminological Psychology, 19, 227-239. doi: 10.1111/j.2044-8333.2012.02069.x; Nahari, G., Vrij, A., \& Fisher, R. P. 2014. The verifiability approach: Countermeasures facilitate its ability to discriminate between truths and lies. Applied Cognitive Psychology, 28, 122-128. doi: 10.1002/acp.2974

45. See for example Graham, B., Herlihy, J., \& Brewin, C. R. 2014. Overgeneral memory in asylum seekers and refugees. Journal of Behavior Therapy and Experimental Psychiatry, 45, 375-380. doi: http://dx.doi.org/10.1016/j. jbtep.2014.03.001; and Moore, S. A., \& Zoellner, L. A. 2007. Overgeneral autobiographical memory and traumatic events: An evaluative review. Psychological Bulletin, 133, 419-437. doi: 10.1037/0033-2909.133.3.419

46. See EASO op. cit. A discussion of the effects of trauma on memory is beyond the scope of this paper, we focus instead on the normal limitations of memory in healthy individuals. See Memon, A. 2012. Credibility of asylum claims: Consistency and accuracy of autobiographical memory reports following trauma. Applied Cognitive Psychology, 26, 677-679. doi:10.1002/acp.2868 for an overview about how trauma affects memory in asylum seekers, and Rogers, H., Fox, S., \& Herlihy, J. 2015. The importance of looking credible: the impact of the behavioural sequelae of posttraumatic stress disorder on the credibility of asylum seekers. Psychology, Crime \& Law, 21, 139-155. doi:10.1080/ 1068316X.2014.951643 for a recent study on how trauma behaviors may negatively affect credibility judgments.

47. Nørby, S. 2015. Why forget? On the adaptive value of memory loss. Perspectives on Psychological Science, 10, 551578. doi: $10.1177 / 1745691615596787$ 
aspects are stored in memory and can be recalled. ${ }^{48}$ In addition, certain kinds of details are typically not attended to because they are not very relevant. For example, people find it more difficult to remember temporal details than details about what happened and with whom. ${ }^{49}$ Specific dates are generally remembered only if they hold importance, such as a wedding or a child's birth. ${ }^{50}$

Due to attention processes, memory may also be enhanced for central as opposed to peripheral aspects of an event or situation. For instance, when experiencing negative emotions during the encoding of an event, people narrow their attention to key aspects in the situation. ${ }^{51}$ Consequently, memory for one aspect may be elaborate, whereas memory for other elements in the situation may be poor. Applying this knowledge to the credibility assessment of oral statements raises the question of how to distinguish between central and peripheral information. Determining the centrality of information in a situation is complex. Central could refer to spatial or visual position but could also designate information or actions central to the meaning of the scene. ${ }^{52}$ Others have argued that centrality depends on the perceiver's goals. That is, a person will focus on the information that is most relevant to the successful realization of the currently active personal goal. ${ }^{53} \mathrm{Re}$ search also shows that it is sometimes difficult to predict which information will be remembered best. For example, Houston and colleagues found that emotionality in eyewitnesses enhanced memory for the perpetrator's physical appearance but impaired memory for the perpetrator's actions, ${ }^{54}$ although you would expect that what transpires in a crime is central to a witness. Regardless of what is considered central in a specific situation, the research suggest that - depending on how a situation is encoded - a person can have a very detailed memory for specific aspects of a situation, while remembering little about other aspects of the situation.

48. Chun, M. M., \& Turk-Browne, N. B. 2007. Interactions between attention and memory. Current Opinion in Neurobiology, 17, 177-184. doi: http://dx.doi.org/10.1016/j.conb.2007.03.005; Knudsen, E. I. 2007. Fundamental components of attention. Annual Review of Neuroscience, 30, 57-78. doi: doi:10.1146/annurev.neuro.30.051606.094256

49. Friedman, W. J. 2004. Time in autobiographical memory. Social Cognition, 22, 591-605. doi: 10.1521/ soco.22.5.591.50766; Wagenaar, W. A. 1986. My memory: A study of autobiographical memory over six years. Cognitive Psychology, 18, 225-252. doi: http://dx.doi.org/10.1016/0010-0285(86)90013-7

50. Friedman op. cit.

51. Levine, L., \& Edelstein, R. 2009. Emotion and memory narrowing: A review and goal-relevance approach. Cognition \& Emotion, 23, 833-875. doi:10.1080/02699930902738863

52. Houston, K. A., Clifford, B. R., Phillips, L. H., \& Memon, A. 2013. The emotional eyewitness: The effects of emotion on specific aspects of eyewitness recall and recognition performance. Emotion, 13, 118-128. doi:10.1037/a0029220

53. Levine \& Edelstein, op. cit.

54. Houston et al. op cit. 
Even when someone initially stored a detailed representation of an event, multiple factors influence memory retention and recall and may hamper the ability to give a detailed statement. One factor is the passage of time. As the time between an event and providing a statement increases, memory recollections become less vivid and less detailed. ${ }^{55}$ Another influential factor is the method of retrieval. The way in which memory is searched and the cues that are used affect what information is retrieved. The more a retrieval cue matches the condition under which the information was stored in memory, the more likely it is that the information will also be recalled. ${ }^{56}$ Interviewees in a cognitive interview are therefore asked to mentally go back to the situation before describing the situation. ${ }^{57}$ With this procedure, called context reinstatement, the context of encoding is simulated in order to stimulate reproduction. ${ }^{58}$

The presence of an interpreter is yet another factor that can affect the number of details in asylum seekers' statements. In the asylum procedure an interpreter is always present to translate the conversation between the asylum official and the asylum seeker. Recent research shows that interference from an interpreter has consequences. ${ }^{59}$ Interviewees spontaneously provide less detailed statements when communicating through an interpreter than in interviews conducted in their mother tongue.

Based on the above analysis several recommendations can be made concerning the use of detail and specificity as a credibility indicator. First, the indicator should not be used as a heuristic or rule of thumb. Statements about a true personal experience may be unspecific or vague, and a highly detailed statement is not necessarily true. Second, if detailed answers are desired, an asylum interview should be carefully planned. Questions should invite the applicant to give elaborate and

55. Janssen, S. M. J., Rubin, D. C., \& St. Jacques, P. L. 2011. The temporal distribution of autobiographical memory: changes in reliving and vividness over the life span do not explain the reminiscence bump. Memory \& Cognition, 39, 1-11. doi:10.3758/s13421-010-0003-x

56. Smith, S. M., \& Vela, E. 2001. Environmental context-dependent memory: a review and meta-analysis. Psychonomic bulletin \& review, 8, 203-220. doi: 10.3758/BF03196157; Tulving, E., \& Thomson, D. M. 1973. Encoding specificity and retrieval processes in episodic memory. Psychological review, 80, 352-373. doi: 10.1037/h0020071

57. Fisher, R. P., \& Geiselman, R. E. 2010. The Cognitive Interview method of conducting police interviews: Eliciting extensive information and promoting Therapeutic Jurisprudence. International Journal of Law and Psychiatry, 33, 321-328. doi: 10.1016/j.jilp.2010.09.004

58. Smith \& Vela, op. cit.

59. Ewens, S., Vrij, A., Leal, S., Mann, S., Jo, E., \& Fisher, R. P. 2016. The effect of interpreters on eliciting information, cues to deceit and rapport. Legal and Criminological Psychology, 21(2), 286-304. doi:10.1111/lcrp.12067 
detailed responses. The interviewer should also anticipate what information and which knowledge the applicant possesses, and formulate the questions accordingly. For example, in a Dutch case an Afghan applicant argued to have been locked in a room of an army general. ${ }^{60}$ He was asked to describe the rest of the house, but only gave vague and unspecific answers. According to his story he was only allowed to leave the room to use the bathroom. Expecting the applicant to have detailed knowledge about a place he claimed to have rarely seen is unreasonable. A more detailed description may be expected about the room in which he was kept. Finally, when evaluating a statement based on a level of detail indicator, asylum officials should take into account the effect an interpreter may have on the elicitation of details.

\subsection{Consistency}

\subsubsection{Internal consistency}

Out of the five credibility indicators, three are related to consistency. The first, internal consistency, is based on the assumption that a truthful story can be told in the same way on different occasions. ${ }^{61}$ More specifically, asylum officials assess whether there are serious contradictions or discrepancies within the information provided by the applicant during the asylum interview or two successive interviews, and between the applicant's statements and the submitted evidence. ${ }^{62}$ Discrepancies within the asylum seeker's account should be adequately explained. ${ }^{63}$

Asylum officials believe that consistency is an indicator of truthfulness. ${ }^{64}$ They assume that upholding a fabricated but consistent story over multiple interviews would be difficult because one has to keep track of what one has divulged the last

60. AWB 16/5648, No. ECLI:NL:RBDHA:2016:4271 (District Court The Hague, the Netherlands 2016).

61. UNHCR (2013) op. cit.

62. Gyulai op. cit.

63. Home Office op. cit.; INS op. cit.

64. Granhag et al. (2005) op. cit. 
time. ${ }^{65}$ Applicants who give statements about real personal experiences would, in contrast, search their memory at each instance of recall and report in a consistent way. This implies the belief that human memory works like a video recorder; that each time an event is prompted, our memory simply rewinds and replays the story. The same - and equally accurate - story could then be told at each recall.

This idea however is a myth. Retrieving a memory is a reconstructive process. ${ }^{66}$ A video recording of an event cannot be simply replayed within the mind. Instead, specific memory cues are used to access our memory. Depending on the cue, several components of the recollection are activated and a story about the event is formed. ${ }^{67}$ During each memory search, slightly different aspects of the event are activated. Although the core of a true story will likely remain stable, additional information may be reported that was not previously reported (i.e., commissions), and information that was previously reported may be left out (i.e., ommissions). ${ }^{68}$

Reasoning from the reconstructive nature of memory, Granhag and Strömwall proposed the repeat-versus-reconstruct hypothesis. ${ }^{69}$ They argue that inconsistencies in a truthful story are not surprising, because truth-tellers reconstruct what has happened each time they are interviewed about a certain event. Liars, in comparison, know that they have to tell a convincing and consistent story. They invent and rehearse a story that they can repeat in successive interviews. Because liars merely repeat a story, their story may only contain a few or no inconsistencies.

65. Herlihy, J., Gleeson, K., \& Turner, S. 2010. What assumptions about human behaviour underlie asylum judgments? International Journal of Refugee Law, 22, 351-366. doi: 10.1093/ijrl/eeq027; Herlihy, J., Jobson, L., \& Turner, S. 2012. Just tell us what happened to you: Autobiographical memory and seeking asylum. Applied Cognitive Psychology, 26, 661-676. doi: 10.1002/acp.2852; Herlihy, J., Scragg, P., \& Turner, S. 2002. Discrepancies in autobiographical memories - implications for the assessment of asylum seekers: repeated interviews study. British Medical Journal, 324 324-327. doi: 10.1136/bmj.324.7333.324; Herlihy, J., \& Turner, S. 2006. Should discrepant accounts given by asylum seekers be taken as proof of deceit? Torture, 16, 81-92.

66. See for example Conway, M. A., \& Pleydell-Pearce, C. W. 2000. The construction of autobiographical memories in the self-memory system. Psychological review, 107, 261-288. doi: 10.1037/0033-295X.107.2.26; and Schacter, D. L. 1999. The seven sins of memory: Insights from psychology and cognitive neuroscience. American Psychologist, 54, 182-203. doi: 10.1037/0003-066X.54.3.182.

67. Gilbert, J. A. E., \& Fisher, R. P. 2006. The effects of varied retrieval cues on reminiscence in eyewitness memory. Applied Cognitive Psychology, 20, 723-739. doi: 10.1002/acp.1232

68. Granhag, P. A., \& Strömwall, L. A. 2002. Repeated interrogations: verbal and non-verbal cues to deception. Applied Cognitive Psychology, 16, 243-257. doi:10.1002/acp.784

69. Granhag, P. A., \& Strömwall, L. A. 1999. Repeated interrogations -stretching the deception detection paradigm. Expert Evidence, 7, 163-174. doi: 10.1023/A:1008993326434

Granhag, P. A., \& Strömwall, L. A. (2001). Deception detection: Examining the consistency heuristic. In C. M. Breur, M. M. Kommer, J. F. Nijboer, \& J. M. Reijntjes (Eds.), New trends in criminal investigation and evidence (pp. 309-321). Antwerpen: Intresentia. 
The repeat-versus-reconstruct hypothesis is now widely supported by empirical research. ${ }^{70}$ Hence, even if an asylum story reflects true events, inconsistencies within statements in the form of omissions or commissions can occur and are generally not informative of the accuracy of the statement. ${ }^{71}$

Contradictions are more problematic, because they imply that at least one of the statements was incorrect or untrue. Liars' statements indeed contain more contradictions than those of truth-tellers. ${ }^{72}$ Contradictions can, however, also result of memory errors. The reconstruction of a genuine memory can be influenced by a variety of factors such as social demands of the retrieval context, schemata, question types, suggestion, and misinformation. ${ }^{73}$ These factors can all contribute to memory errors. Mistakes may be made in the reporting of details that are irrelevant or peripheral. For example, in a study assessing students' memory for the $9 / 11$ terrorist attacks as much as $40 \%$ of the participants reported contradictory weather conditions in two successive interviews. ${ }^{74}$ Moreover, a small proportion of participants also contradicted themselves on more central elements, such as who told them about the attacks or where they were when being told. Although contradictions in central elements only occurred sparsely, the results indicate that honest statements can contain contradictions even about central elements. In this study the contradictions resulted in response to two identical questions. If the questions posed in successive interviews differ or are suggestive of misleading, contradictions and memory errors be even more likely to occur. ${ }^{75}$ The assumption that truth-tellers' statements are consistent and accurate, thereby, seems insufficiently supported by memory research. ${ }^{76}$

70. Vredeveldt, A., van Koppen, J. P., \& Granhag, P. A. (2014). The inconsistent suspect: A systematic review of different types of consistency in truth tellers and liars. In R. Bull (Ed.), Investigative Interviewing (pp. 183-207). New York, NY: Springer New York.

71. Smeets, T., Candel, I., \& Merckelbach, H. 2004. Accuracy, completeness, and consistency of emotional memories. The American Journal of Psychology, 117, 595-609. doi: 10.2307/4148994

72. Vrij, A., \& Granhag, P. A. 2012. Eliciting cues to deception and truth: What matters are the questions asked. Journal of Applied Research in Memory and Cognition, 1, 110-117. doi:http://dx.doi.org/10.1016/j.jarmac.2012.02.004

73. Hyman, I. E., \& Loftus, E. F. 1998. Errors in autobiographical memory. Clinical Psychology Review, 18, 933-947. doi: http://dx.doi.org/10.1016/S0272-7358(98)00041-5

74. Schmidt, S. R. 2004. Autobiographical memories for the September 11th attacks: Reconstructive errors and emotional impairment of memory. Memory \& Cognition, 32, 443-454. doi:10.3758/bf03195837

75. Orbach, Y., \& Lamb, M. E. 2001. The relationship between within-interview contradictions and eliciting interviewer utterances. Child Abuse \& Neglect, 25, 323-333. doi:http://dx.doi.org/10.1016/S0145-2134(00)00254-4; Patihis, L., \& Loftus, E. F. 2016. Crashing memory 2.0: False memories in adults for an upsetting childhood event. Applied Cognitive Psychology, 30, 41-50. doi:10.1002/acp.3165

76. Vredeveldt et al. (2014) op. cit. 
However, acknowledging that inconsistencies in truthful stories occur does not imply that major changes in the storyline should be accepted. ${ }^{77}$ The key aspects of a story can be reasonably expected to remain consistent over multiple interviews. For example, an applicant who states in the first interview that he was violently arrested and detained for several months whereas in the second interview he denies ever being detained would certainly evoke suspicion. Refugee law judges accordingly make a distinction between minor inconsistencies and inconsistencies that are at the core of the claim. They argue that: "Whilst questions about events outside the core elements of evidence are a proper basis for testing the general consistency of an account, they will not render core testimony incredible unless they undermine central, as opposed to peripheral or incidental, elements of the account" ${ }^{78}$ As such, only inconsistencies that undermine material facts should be considered in the credibility assessment.

In practice, however, credibility determinations are generally made by asylum officials. Judges only review their decisions in appeal procedures. ${ }^{79}$ In work instructions for asylum officials, the distinction between minor and major inconsistencies is not always clear. Dutch work instructions postulate that adequate explanations should be provided for any addition to an initial statement. ${ }^{80}$ The instructions imply that commissions - although being relatively common in hones accounts - are a sign of non-credibility. In addition, even if different inconsistencies are distinguished in policy documents, asylum officials are given little guidance as to how they should assess the significance of inconsistencies. ${ }^{81}$ This may lead to a rigid use of the indicator in practice. Indeed, according to an Amnesty International UK report, minor discrepancies are used to discredit asylum claims as a whole. ${ }^{82}$ Without an explanation of what constitutes minor and more serious inconsistencies, the indicator may be used as a rule of thumb.

77. Granhag \& Strömwall (1999) op. cit.

78. Mackey \& Barnes op. cit. p. 36

79. Inter-governmental Consultations on Migration Asylum and Refugees. (2012). Asylum procedures. Report on policies and practices in IGC participating states 2012. Geneva: IGC.

80. INS op. cit.

81. See for example, Home Office op. cit.

82. Shaw, J., \& Witkin, R. (2004). Get it right. How Home Office decision making fails refugees. London: Amnesty International UK. 


\subsubsection{Consistency with others}

Consistency with other people's statements is another measure of truth-telling used in asylum interviews. For example, asylum officials assume that the stories of a husband and wife fleeing together are consistent with each other, meaning that there are no serious contradictions or discrepancies between the facts presented by both applicants. ${ }^{83}$ The underlying assumption is that individuals who have witnessed the same event also narrate about that situation similarly, whereas it would be difficult to fully align fabricated stories. ${ }^{84}$ Undermining that theory, research shows that lying pairs actively and successfully attempt to tell a consistent story. ${ }^{85}$ Statements by lying pairs are often equally or even more consistent than those of truth-telling pairs.

Research examining how pairs help each other remember demonstrates the differences in recollections. ${ }^{86}$ Vredeveldt and colleagues interviewed pairs about an emotional scene in a theater play. The pairs were either twice interviewed individually, or were first interviewed individually and then jointly. Pairs who were interviewed jointly in the second interview were able to correct more errors in their statements than the other pairs. Apparently, the two individuals made different mistakes in the first interview and corrected each other in the joint interview. The diverging statements in the initial interview indicate that two people who have experienced the same event may encode, store and recall an event differentially.

Differences between the statements of two truth-tellers can be explained through the functioning of autobiographical memory. Earlier we explained that attention plays a decisive role in the formation of memories, and that personal relevance steers attention. How an event is perceived and reacted upon is also determined by characteristics such as age, sex, education, and social role and status. ${ }^{87}$

83. Gyulai op. cit.

84. UNHCR (2013) op. cit.

85. Vrij, A., Mann, S., Leal, S., \& Granhag, P. A. 2010. Getting into the minds of pairs of liars and truth tellers: An examination of their strategies. Open Criminology Journal, 3, 17-22. doi: 10.2174/1874917801003010017; Granhag, P. A., Strömwall, L. A., \& Jonsson, A.-C. 2003. Partners in crime: How liars in collusion betray themselves. Journal of Applied Social Psychology, 33, 848-868. doi: 10.1111/j.1559-1816.2003.tb01928.x

86. Vredeveldt, A., Hildebrandt, A., \& van Koppen, P. J. 2015. Acknowledge, repeat, rephrase, elaborate: Witnesses can help each other remember more. Memory, 1-14. doi: 10.1080/09658211.2015.1042884

87. DiMaggio, P. 1997. Culture and Cognition. Annual Review of Sociology, 23, 263-287. doi: 10.1146/annurev. soc.23.1.263; Markus, H., \& Kitayama, S. 1991. Culture and the self: Implications for cognition, emotion, and motivation. Psychological review, 98, 224-253. doi: 10.1037/0033-295X.98.2.224;

Markus, H., \& Wurf, E. 1987. The dynamic self-concept: A social psychological perspective. Annual Review of Psychology, 38, 299-337. doi: doi:10.1146/annurev.ps.38.020187.001503 
Additionally, the reconstruction of the event depends on personal experiences and knowledge, ${ }^{88}$ the search-strategy used, and the questions asked. ${ }^{89}$ These factors can all contribute to two observers perceiving, interpreting, storing and reporting the same event much differently.

An example of diverging statements by two witnesses can be found in a Dutch family reunification case. ${ }^{90}$ A Somali couple was interviewed individually by the INS about their family life to confirm their marital status. Both the man and woman were asked to describe their wedding day. The husband described renting thirteen cars to drive from the ceremony to the reception. The wife only mentioned two cars in her interview. The statements contradict each other and were interpreted as a sign of non-credibility. Due to the numbers two and thirteen being so far apart the couple's story perhaps is unconvincing. Before concluding that the couple was lying about their wedding, however, alternative explanations for the inconsistencies should be considered. Arranging cars often is the groom's responsibility in Somali culture. The number of cars may therefore be more relevant to the man than to his wife, and as a result he may have a better memory for the number of cars. Alternatively, the man may have boasted about the cars, because the number of cars indicate status for Somali men.

\subsubsection{Consistency with general knowledge}

The third and last form of consistency used to assess the credibility of an asylum story is consistency with general knowledge or information from external sources. ${ }^{91}$ For instance, when a large mosque is mentioned in the interview about origin, the migration board seeks to verify the existence of that mosque in the hometown. If the named location and name of the mosque prove correct, this would support the statement's credibility. This form of consistency is often key in cases in which the applicant's origin is uncorroborated, such as the case of the Eritrean man that was described in the introduction of this article.

To assess consistency with general knowledge the migration board often poses questions about the claimed place of origin. ${ }^{92}$ The questions focus on describing

\footnotetext{
88. Conway \& Pleydell-Pearce, op. cit.

89. Tulving \& Thomson, op. cit.

90. AWB $11 / 37548$ (District Court The Hague, The Netherlands 2012)

91. UNHCR (2013) op. cit.

92. EMN, op. cit.
} 
identity documents, daily life in the country of origin, landmarks in the village or city of origin, the city-plan, other nearby villages and cities, and common objects in the country of origin. ${ }^{93}$ The applicant's answers are expected to align with facts outlined in Country of Origin Information (COI) reports. COI reports are often created by governmental organizations and contain information about the customs, traditions, religion, geography and history of a country, and about the political system and situation in that country.

There are two remarks to be made about assessing the alignment of statements with COI. First, the information in COI reports is not always accurate and is almost always incomplete. ${ }^{94}$ The reports describe the general situation in a country. Sometimes important events are mentioned but smaller events are not covered. The information is mostly collected from public sources and representatives in the country of origin. ${ }^{95}$ These sources are fallible, thus statements that deviate from $\mathrm{COI}$ are not necessarily incorrect or non-credible. ${ }^{96}$ Second, as when searching for rich and detailed statements, the knowledgeability of the asylum seeker must be considered. Many things visible in the living environment or features of commonlyused objects may not be relevant to a person. As a result they may not be (properly) stored in memory. To illustrate, think for a moment about a banknote in your national currency (for example a 20-Euro note). Now give a detailed description of it. We regularly use banknotes, but probably only their color or relative size is relevant to easily distinguish one banknote from another. Expecting anyone to provide many other details in the description of money is unreasonable, ${ }^{97}$ let alone to expect such details in the description of someone who has not used the local currency for several years.

93. Van Veldhuizen, T. S., Horselenberg, R., Landström, S., Granhag, P. A., \& van Koppen, P. J. (2017). Interviewing asylum seekers: A vignette study on the questions asked to assess credibility of claims about origin and persecution. Journal of Investigative Psychology and Offender Profiling, 14, 3-22. doi:10.1002/jip.1472

94. UNHCR (2013) op. cit.

95. See e.g., Dutch Ministry of Foreign Affairs. (2012). Werkinstructie totstandkoming Algemene Ambtsberichten [Work instruction on the creation of official country reports]. De Hague, The Netherlands: Ministry of Foreign Affairs

96. UNHCR (2013) op cit.

97. See also: Nickerson, R. S., \& Adams, M. J. 1979. Long-term memory for a common object. Cognitive Psychology, 11, 287-307. doi:http://dx.doi.org/10.1016/0010-0285(79)90013-6 


\subsection{Plausibility}

Plausibility is the third and last indicator used in EU asylum assessments. Although its definition is being debated, plausibility has been defined as the apparent likelihood or compliance with common sense of the asylum claim in the context of general country information and other evidence. ${ }^{98}$ Regardless of the CREDO authors urging caution with the indicator, ${ }^{99}$ migration boards seem to use plausibility to determine whether the asylum seeker's statements reflect true and personal experiences. ${ }^{100}$

Research demonstrates that truthful statements are often judged to be more plausible than fabricated statements. ${ }^{101}$ This does not mean, however, that plausible stories are always true or that implausible stories are always untrue. Furthermore, plausibility is not an objective criterion. Individual asylum officials judge whether something is likely or compliant with common sense, and such decisions - made under uncertainty - are often influenced by personal experiences, knowledge and the cultural background of the decision maker. ${ }^{102}$ Consequently, the official's perspective will presumably affect the plausibility judgment. Events that do not accord with the experiences of the official are easily, but not always duly, perceived as unrealistic or implausible. ${ }^{103}$ That risk is considerable in the asylum context, due to the cultural differences between the applicant and the asylum officials. ${ }^{104}$

An anecdote that illustrates how personal knowledge and experiences can negatively influence plausibility judgments comes from Sweden. ${ }^{105}$ An asylum seeker claimed to have escaped a prison. He explained that he was arrested and interrogated, and that during an unguarded moment he fled into the garden, jumped over the wall, and ran away. The official at first could not picture this, thinking of the walls that normally protect Swedish prisons. He nonetheless decided to

\footnotetext{
98. UNHCR (2013) op cit.

99. UNHCR (2013) op. cit.; Gyulai, op. cit.

100. e.g., Home Office, op. cit; INS, op. cit.; UNHCR (2013) op. cit.

101. DePaulo, B. M., Lindsay, J. J., Malone, B. E., Muhlenbruck, L., Charlton, K., \& Cooper, H. 2003. Cues to deception. Psychological Bulletin, 129, 74-118. doi: 10.1037/0033-2909.129.1.74

102. Markus \& Kitayama, op. cit.; Tversky \& Kahneman, op. cit.

103. Bohmer, C., \& Shuman, A. 2007. Producing epistemologies of ignorance in the political asylum application process. Identities: Global Studies in Culture and Power, 14, 603-629. doi: 10.1080/10702890701662607; Herlihy et al. (2010) op. cit.

104. Good, A. 2007. Anthropology and expertise in the asylum courts. Londen: Routledge-Cavendish.; Gutchess, A. H., \& Indeck, A. (2009). Cultural influences on memory. In J. Y. Chiao (Ed.), Progress in Brain Research (pp. 137-150). The Netherlands: Elsevier.
}

105. A. Molin, personal communication, December 5, 2013 
further examine the story. Eventually the official realised that what the asylum seeker denoted as a prison - because he was arrested by the police and detained resembled a shed, without any prison structure. A search on the internet revealed that the shed was only surrounded by a small stone wall of less than a meter high and approximately 40 centimetres wide. With the new image of the prison and wall, the asylum seeker's story became more plausible and hence more credible.

A second example illustrates how cultural differences can cause a misunderstanding. A Dutch refugee law judge told us about an African asylum seeker who fled his home country after his brother allegedly had been killed by the local authorities. ${ }^{106}$ The applicant claimed to have visited his brother the day before the murder. The INS could, however, deduce from local news reports that his brother was killed on the same day that the man contended to have visited him. Based on this discrepancy, the man's story was deemed implausible and he was denied asylum. ${ }^{107}$ The applicant appealed the decision, and the discrepancy was discussed in court. In the discussion, the interpreter asked the judge permission to make a personal remark. He explained that in the applicant's culture it is common to speak of the next day when the sun has set. The interruption led to a comparison between the time of death of the applicant's brother and the time that the sun had set that day. The killing turned out to have taken place after sunset, which would locally be regarded as the next day. With the additional information the narrative was judged to be plausible after all.

Besides recognizing that misunderstandings can cause biased plausibility judgments, the option that unlikely or unrealistic actions or events may actually be possible and true must be acknowledged. For example, crossing a controlled border with a clearly forged passport seems highly unlikely. However, the story of 9-year old Emily Harris of Wales, who crossed the Turkish border with a passport she made for her stuffed animal, confirms its possibility. ${ }^{108}$ In another equally implausible situation, a British journalist showed that she was able to pass two separate

106. J. Bouwman, personal communication, March 20, 2014

107. A single discrepancy could lead to a rejection due to the Positive Persuasiveness Criterion (in Dutch: POK-toets), imposing a higher standard of proof on undocumented asylum seekers. Without documentary evidence for their statements, applicants' had to present their claims without a single vagueness, congruity or inconsistency. The Positive Persuasiveness Criterion was abandoned in the Netherlands on January 1, 2015.

108. Matthews, B. (2013, 12 juni 2013). U.K. girl uses her toy unicorn's fake passport to get through Turkish customs. NY Daily News. Retrieved from http://www.nydailynews.com/news/world/girl-toy-unicorn-fake-passport-pass-turkishcustoms-report-article-1.1370480 
British border controls with two different forged European passports. ${ }^{109}$ Although instances like this may not happen regularly, the fact they do happen demonstrates that they are not impossible. That is especially true when forged passports look more authentic than the ones made by a little girl for her stuffed animal.

The following case also illustrates that distinguishing what is plausible from what is possible can be difficult. The same judge who told us about the cultural misunderstanding around time denotations, also told us about a man who, during his flight, had to cross a wide river. ${ }^{110}$ The INS asked how he managed to cross the river. The man claimed that he had stuffed a deflated truck tire under his jacket. Upon arrival at the riverbank he inflated the tire by blowing and crossed the river. The INS maintained in their rejection of the application that inflating a truck tire without a pump or other aid was implausible. In appeal the man appeared in court with an empty truck tire, and asked the judge whether he could support his story with a demonstration. He then inflated the truck tire on the spot. He proved that something that seems unlikely, does not necessarily has to be impossible.

Summarizing, implausible or unlikely events may still be true. Asylum officials should keep in mind that their perception of a story's plausibility is likely to be colored by their own culture and past experiences. In their assessment, they should actively try to counteract cultural and subjective distortions and take into account the cultural background and unique circumstances of the applicant. At the very least, policies and work instructions should actively inform asylum officials of these risks associated with the plausibility indicator.

\section{CHALLENGES IN EU ASYLUM ASSESSMENTS}

We have learned that migration boards operate in complex situations. They must decide on an increasing number of asylum applications, which all must be assessed individually and in a timely manner. The high workload and time pressure are accompanied by a general lack of documentary evidence corroborating asylum seekers' claims. Hence, asylum assessments frequently are contingent on the applicants' statements only. As we have outlined, assessing those statements'

109. BBC. (2006). My fake passports and me. Retrieved from http://news.bbc.co.uk/2/hi/uk_news/6169678.stm 110. J. Bouwman op. cit. 
credibility is difficult because the often-used credibility indicators are not always valid indicators of truthfulness. Although several factors that may hamper the ability of asylum applicants to provide detailed, consistent and plausible statements have been outlined in UNHCR documents and training manuals for asylum officials, these nuances may be easily lost in an uncertain decision context like the asylum procedure.

Another challenge in credibility assessments arises from Article 4 of the Qualification Directive. The article prescribes that - in order to be believed - uncorroborated elements must be coherent and plausible, and correspond to COI. Besides that, however, the applicant's general credibility also must be established. The question is to what extent the finding that an applicant has fabricated some aspects of his story (unrelated to the material facts of the asylum claim) undermines the general credibility of the applicant, and thereby weakens the believability of otherwise credible elements in the asylum claim. Imagine, for example, that the Eritrean man described in the introduction of this paper provides detailed, consistent, and plausible statements about his hometown in Eritrea and his objections against military service. Nevertheless, he evidently lies about his flight to Europe. The migration board could argue that by lying the man's general credibility is undermined and that henceforth uncorroborated aspects of the asylum story cannot be believed. If, however, the migration board has no reason to doubt the man's Eritrean nationality or his objections against fulfilling military service, rejecting his application could result in a violation of the principle of non-refoulement. Migration boards should recognize that although asylum seekers may lie about some aspects of their asylum claim, they may still have a genuine fear of persecution in the country of origin and may be in need of international protection. ${ }^{111}$ The same position is taken by the UK Tribunal. ${ }^{112}$

Both the finding that truthful narratives can sometimes be vague or unspecific, inconsistent, or unlikely, and the realisation that asylum seekers may sometimes lie about some elements of their application but be truthful about other aspects call for a credibility assessment in which emphasis is put on the core elements of the

111. See also United Nations High Commissioner for Refugees. (2015). Summary of deliberations on credibility assessment in asylum procedures, expert roundtable, 14-15 January 2015, Budapest, Hungary. Retrieved from http://www. refworld.org/docid/554c9aba4.html

112. Thomas, R. 2006. Assessing the credibility of asylum claims: EU and UK approaches examined. European Journal of Migration and Law, 8, 79-96. doi:doi:http://dx.doi.org/10.1163/157181606776911969 
asylum claim. How this can be accomplished in the uncertain decision context that was described above, and which role the credibility indicators should play in this process is a question that warrants further research.

\section{IMPLICATIONS FOR PRACTICE AND DIRECTIONS FOR FUTURE RESEARCH}

Throughout this paper we have been critical of the five credibility indicators. That does not mean, however, that we argue for the abandonment of the indicators altogether. At present there is no alternative method for credibility assessments that will undeniably lead to a significant increase in correct decisions. However, when using the indicators, we must acknowledge that statements are not made in a vacuum. They are formulated in response to questions, and the questions may influence the detail, consistency and plausibility of the statements. In addition, determining authorities should be aware that memory errors of genuine applicants, strategies of fabricators, and the assessors' personal beliefs may all affect the validity of the indicators. Hence, interviewing and decision making practice should be designed such that genuine asylum seekers are assisted in their effort to present a credible narrative, whereas appearing credible should be made as hard as possible for fabricators.

Currently, the knowledge base about effective interviewing and decision making practice in asylum assessments is limited. Most of the research discussed above was conducted in police contexts, such as eyewitness and suspect interviews. This knowledge is relevant to any investigative interviewing context, but more contextspecific research is needed before advising on specific improvements for credibility assessments in the asylum procedure. Current practice needs to be systematically studied, and pitfalls and opportunities in asylum assessments need to be identified. The following lines of research may be beneficial for asylum officials, policy makers, legal representatives and all other parties involved in asylum assessments.

\subsection{Evaluating current interviewing practice}

Over the past years, much knowledge about best practice in investigative interviewing has been gained. For instance, both question style (i.e., how the in- 
terviewer approaches the interviewee) and question type (e.g., open vs. closed vs. suggestive questions) affect the quantity and accuracy of the information obtained, and certain interviewing methods are more challenging for fabricators. ${ }^{113}$ Open and information gathering questions usually yield more information than closed questions, which is also more diagnostic for truthfulness. ${ }^{114}$ Thereby, the questions asked in asylum interviews may indirectly influence the credibility assessment. Questions that stimulate short answers or guesses hinder truth-tellers' by eliciting accounts containing little detail and possibly inaccuracies, whereas they assist liars who in response to closed and accusatory question can keep their stories relatively simple.

If credibility is determined by assessing detail and specificity, questions should invite applicants to provide elaborate and accurate narratives such that any lack of detail cannot be explained by the questions asked. The Dutch court recognized this in the case of a Somali woman. ${ }^{115}$ Her statements were judged to be vague and lacking detail. The court wrote in her verdict: 'The judge thereby points to the relatively "closed" questions that were asked to the claimant and marks that if the defendant had wanted to obtain more elaborate answers of the claimant, this - also considering the age and background of the claimant - should have been taken into account in the questions'.

Asking open questions - although preferable - is however difficult. Police interviews have shown to start with open questions, but tend to become more closed as they proceed. ${ }^{116}$ Similar studies evaluating interviewing practice in the asylum procedure are scarce. ${ }^{117}$ A systematic evaluation of the extent to which interviewing practice in the asylum procedure is in line with best practice in investigative interviewing would be valuable. By focusing on the style, type and kind of questions asked, opportunities for the elicitation of more accurate and diagnostic information in asylum assessments may be identified. In addition to evaluating current practice,

113. Vrij, A., Hope, L., \& Fisher, R. P. 2014. Eliciting reliable information in investigative interviews. Policy Insights from the Behavioral and Brain Sciences, 1, 129-136. doi: 10.1177/2372732214548592

114. See for example Meissner, C., Redlich, A., Bhatt, S., \& Brandon, S. 2012. Interview and interrogation methods and their effects on investigative outcomes. Campbell systematic reviews, Article 13. doi:10.4073/csr.2012.13

115. AWB-13_18748, No. ECLI:NL:RBLIM:2013:12106 (District Court Limburg, the Netherlands 2013).

116. See for example Fisher, R. P., Geiselman, R. E., \& Raymond, D. S. 1987. Critical analysis of police interview techniques. Journal of Police Science and Administration, 15, 177-185; Wright, A. M., \& Alison, L. 2004. Questioning sequences in canadian police interviews: Constructing and confirming the course of events? Psychology, Crime \& Law, 10, 137-154. doi:10.1080/1068316031000099120

117. To our knowledge, only one study has been conducted so far, see Van Veldhuizen et al., op. cit. 
scholars could also search for methods of questioning that help asylum seekers to provide more detailed or more consistent statements about their experiences by effectively cuing their memories.

\subsection{Investigating transparency and objectivity of decision-making}

In addition to evaluating interviewing techniques, more knowledge about the decision making process in asylum assessments could be informative. Many factors may influence the detail, consistency and plausibility of asylum statements, and all these factors - including the assessor's own biases - should be accounted for in the decision making process. Besides evaluating to what extent these influences are systematically considered in current asylum decisions, future research could focus on exploring different methods of evidence evaluation in which alternative explanations for negative credibility findings, such as a lack of detail or consistency, are methodically considered and assessed. ${ }^{118}$ This is especially relevant because research suggests that asylum judgments are not always sufficiently motivated. ${ }^{119}$ When asylum officials become more aware of the different explanations they considered for their findings, providing a transparent explanation of how they arrived at their final judgment becomes easier.

In addition, to ensure that assessments are not influenced by the assessors' personal knowledge or biases, the use of plausibility in the decision-making process should be studied. As was explained in the section about plausibility, plausibility assessments are at risk of becoming intuitive. Intuitive judgments are precarious in any investigation. For example, in a criminal context, police officers' intuitive beliefs of guilt have demonstrated to influence both the interviewing strategy and the evaluation of evidence, feeding erroneous decisions. ${ }^{120}$ Such consequences of intuitive assessments - if found in asylum adjudication processes - should be recognized and counteracted as much as possible. A study of the extent to which the adjudicator's intuition about a case's plausibility biases the further examination

118. Scholars could, for example, look into the method of scenario thinking, see van Koppen, P. J. (2013). Gerede twijfel: Over bewijs in strafzaken. [Reasonable doubt: About evidence in criminal cases]. Amsterdam: De Kring.

119. Millbank, J. 2009. 'The ring of truth': A case study of credibility assessment in particular social group refugee determinations. International Journal of Refugee Law, 22, 1-33. doi:10.1093/ijrl/een040

120. Hill, C., Memon, A., \& McGeorge, P. 2008. The role of confirmation bias in suspect interviews: A systematic evaluation. Legal and Criminological Psychology, 13, 357-371. doi:10.1348/135532507X238682 
could hence inform policy decisions about the use of plausibility as a credibility indicator.

\subsection{Exploring alternative methods for credibility assessments}

A final line of research could explore alternative methods of credibility assessments. Recent research suggests that instead of passively searching for cues to truthfulness and deception in statements, actively eliciting those cues in interviews by drawing on truth-tellers' and liar's differences in cognitive flexibility and interrogative strategies is more effective. ${ }^{121}$ Certain strategies, such as asking unanticipated questions or imposing cognitive load, have demonstrated their effectiveness in separating genuine from fabricated narratives in a criminal context. ${ }^{122}$ For example, truthful suspects who rely on their memory provide consistent answers to anticipated and unanticipated questions, whereas liars provide less consistent answers once they have to improvise. ${ }^{123}$ These so-called cognitive lie detection techniques seem promising tools for credibility assessments. Before applying the techniques, however, their effectiveness for asylum assessments needs to be tested. Especially because all asylum applicants - regardless of their truthfulness may experience a high cognitive load (and therefore little cognitive flexibility), for example due to having to communicate in an intercultural context with language barriers or negative past experiences with authorities.

\section{CONCLUSION}

In the uncertain context of the European asylum procedure, credibility judgment is often decisive for the granting or refusal of a refugee status. To objectify the judgment, the UNHCR and the EASO have proposed decision aids in the form of credibility indicators. The above analysis discussed circumstances under which these indicators may or may not be valid indicators of truthfulness, and demonstrated that credibility assessments may be distorted by memory errors, strategies

\footnotetext{
121. See for the complete rationale behind the cognitive lie detection approach, and a summary of different studies supporting the approach: Vrij, A., Granhag, P. A., Mann, S., \& Leal, S. 2011. Outsmarting the liars: Toward a cognitive lie detection approach. Current Directions in Psychological Science, 20, 28-32. doi:10.1177/0963721410391245 122. Idem.

123. Idem.
} 
of dishonest applicants, and the assessors' own knowledge and past experiences. We hence conclude that the indicators should only be used if interviews assist honest applicants to present a credible account and if shortcomings in asylum narratives are assessed with consideration for alternative explanations. Future research should investigate the extent to which current practice meets these conditions, and should test alternative methods for credibility assessments in the context of asylum. Based on such research, more evidence-based work-instructions for asylum officials can be designed. 



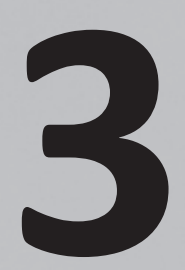

\section{Interviewing Asylum Seekers:}

a Vignette Study on the Questions

Asked to Assess Credibility of Claims about Origin and Persecution

This chapter has been published as:

van Veldhuizen, T. S., Horselenberg, R., Landström, S., Granhag, P. A., \& van Koppen, P. J. (2017). Interviewing asylum seekers: A vignette study on the questions asked to assess credibility of claims about origin and persecution. Journal of Investigative Psychology and Offender Profiling, 14, 3-22. doi:10.1002/ jip.1472 


\section{ABSTRACT}

The aim of the current vignette study is to map the style, type, and themes of questions that are asked when assessing the credibility of asylum seekers' claims. Sixty-five officials from the Swedish Migration Agency (Migrationsverket), were asked to respond to one out of four different vignettes that contained fictitious asylum narratives. Each vignette presented the types of problems often encountered by officials at the migration board. Two of the vignettes contained no evidence of the origin of the asylum seeker. The other two contained no evidence for the claim of persecution. The asylum officials were asked to formulate five questions that would help them to assess the veracity of the applicant's claim. Our analyses showed that they mainly formulated open questions in an information gathering style. A thematic analysis of the questions revealed that when a claim about origin was assessed, asylum officials mostly asked questions about life in the country of origin, identity documents, and the flight to Europe. When the claim about persecution was assessed, in contrast, asylum officials mostly formulated case-specific questions (e.g., how the applicant was arrested). Hence, when the credibility of claims about origin is assessed there seems to be a typical set of questions that asylum officials use. The asylum officials seem to assume that if the applicant is truly originating from a specific country or area, he or she should have ample knowledge about that area, its customs, and frequently encountered objects.

Keywords: credibility assessment, asylum procedure, question style and type, thematic analysis, vignette study 


\section{INTRODUCTION}

With the high influx of asylum seekers (Eurostat Press Office, 2015), the pressure on European immigration authorities is increasing as they need to determine who is genuinely in need of international protection and who is not. For each application, asylum officials have to assess and decide whether the applicant is eligible for international protection according to the criteria that are set out in the Geneva Convention (United Nations, 1951) and the EU qualification directive (Qualification Directive, 2011).

The decisions of asylum officials are significant. A wrongful decision can have tremendous consequences for all parties involved. An incorrect rejection may potentially result in refoulement, a forbidden return of an individual to a place where they are persecuted, tortured, or executed (Inter-Parliamentary Union [IPU], 2001; United Nations High Commissioner for Refugees [UNHCR], 2013). In contrast, an incorrect decision to grant asylum may result in providing international protection to so-called bogus refugees, to people who have committed crimes in their country of origin and were prosecuted rather than persecuted, or even the people who are guilty of war-crimes or crimes against humanity (Bond, 2012; UNHCR, 2003).

The assessment of an asylum application is complicated by the general scarcity of evidence to corroborate the asylum seekers' narratives (e.g., Byrne, 2007; Gyulai, 2013; Noll, 2005a; Rousseau, Crépeau, Foxen, \& Houle, 2002; United Nations High Commissioner for Refugees, 2013). In many cases asylum seekers cannot provide evidence of who they are, where they come from, or what has happened to them. In addition, the documents that they have may not be recognized as official documents by the authorities in the receiving country (Doornbos, 2004; European Migration Network [EMN], 2013; Goodman, 2013; Koser, 2011; Szypszak, 2000).

Consequently, asylum officials usually have to rely on the statements of the asylum seeker and decide whether or not they trust those statements. Thereby, the credibility of the asylum seeker's story becomes the main focus of attention during the asylum procedure (e.g., Byrne, 2007; Doornbos, 2004; Gyulai, 2013; IND-Werkinstructie nr. 2010/14; Kagan, 2002; Noll, 2005b; Sweeney, 2009). One of the few tools that asylum officials can use in the process is asking questions to the asylum seeker. The aim of the present vignette study is to form a first impression 
of the questions that asylum officials typically ask in order to assess whether an asylum narrative is credible or not.

\subsection{Credibility assessment in the asylum procedure}

As the asylum seekers' narratives often constitute the only piece of evidence in asylum cases, both researchers and practitioners (e.g., immigration authorities, NGO's, legal representatives) in the field of international protection have primarily focused on how the credibility of the statements should be assessed. For example, according to guidelines by the UNHCR statements should be plausible, sufficiently detailed, and consistent over multiple interviews, with statements of other applicants and witnesses, and with other available information about the country of origin in order to be credible (United Nations High Commissioner for Refugees, 2013).

Even though these indicators seem to be endorsed in practice (Granhag, Strömwall, \& Hartwig, 2005), they are disputed. Scholars argue that statements that are vague, inconsistent or lack detail may be a result of a failing memory as opposed to deception (e.g., Juliet Cohen, 2001; Graham, Herlihy, \& Brewin, 2014; Herlihy, Jobson, \& Turner, 2012; Herlihy, Scragg, \& Turner, 2002; Herlihy \& Turner, 2006; Herlihy \& Turner, 2009). The UNCHR also recognizes that, when using the credibility indicators, asylum officials should take into account the possibilities and limitations of human memory and the personal background and circumstances of the applicant (United Nations High Commissioner for Refugees, 2013).

\subsection{Asking questions to assess credibility}

Less attention has been paid to how statements are elicited. Asylum seekers' statements are produced in response to questions in an institutional setting. The statements are obtained in an interaction with an interviewer and translated by an interpreter. All these aspects can influence what information is provided by the asylum applicant (e.g., Bögner, Brewin, \& Herlihy, 2009; Doornbos, 2004; Ewens et al., 2014).

Asylum officials try to obtain as much information as possible from the asylum seeker by asking questions about who they are, where they came from, how they travelled to Europe, and what they have experienced in the country of origin (Doornbos, 2004; Wettergren \& Wikström, 2013). During this process, the asylum 
seeker essentially becomes an eyewitness of his or her own life and the statements obtained through the questions form the input for the credibility assessment. The credibility assessment, in turn, is often at the core of the decision to grant or reject international protection. Thus, in the asylum interview information is sought that can be used to discriminate truthful from fabricated claims, and the questions asked should match that objective. In order to evaluate whether current interviews are likely to be successful in this respect, we study the style, type and content of questions formulated by Swedish asylum officials in response to fictitious yet realistic vignettes.

\subsubsection{Question style}

Two types of interview techniques are generally distinguished: the information gathering style and the accusatory style (Vrij, Hope, \& Fisher, 2014; Vrij, Mann, \& Fisher, 2006). With the information gathering style interviewers actively seek information by asking open questions, whereas with the accusatory style interviewers seek to confirm guilt of the interviewee by primarily asking closed questions. The former style is beneficial for the interviewee as he or she is allowed search his or her memory and accurately reconstruct past experiences. This style also provides longer, more detailed, and more correct answers as opposed to the accusatory style. An information gathering interview will also be more demanding for people who are fabricating a story, because for them it is probably easier to just provide short answers than to provide a full narrative (Vrij et al., 2014).

The accusatory style may also make the interviewee feel uncomfortable (Vrij et al., 2006). Asylum seekers are often already anxious as they enter the interview, due to their past experiences with authorities in their home country or because they know that their future largely depends on the interview (Herlihy \& Turner, 2009). Subsuming asylum seekers in an accusatory interview under additional pressure and stress therefore seems ineffective and is sometimes considered unethical. The stress induced by the interview may further impair recall (Smeets, 2011). The information gathering style thus seems more suitable to obtain information from the asylum seeker that can be sensibly used in a credibility assessment. 


\subsubsection{Question type}

Different types of questions can also influence how much accurate information is obtained in the interview. Interviewers who ask open questions and do not interrupt the interviewee tend to be most successful in obtaining comprehensive and accurate answers (e.g., Bull, 2010; Jacob Cohen, 1968; Fisher, Milne, \& Bull, 2011; Memon \& Bull, 1991; Memon, Holley, Milne, Koehnken, \& Bull, 1994; Milne \& Bull, 2006; Snook, Luther, Quinlan, \& Milne, 2012). Closed questions, that only require a yes or no response, and forced choice questions, that require the interviewee to choose from a limited number of alternatives result in less information (Horselenberg, Merkelbach, Crombag, \& Van Bergen, 2010; Snook et al., 2012; Thoresen, Lønnum, Melinder, Stridbeck, \& Magnussen, 2006). The risk that interviewees start guessing also increases in response to closed and forced choice questions (Milne \& Bull, 2006). A last category of questions, suggestive questions, communicate what answer is expected, or ask for a clarification or confirmation of information that was not previously disclosed by the interviewee (Johnson et al., in press; Thoresen et al., 2006). With such questions the interviewer may steer answers into a particular direction, and reduce the extent to which answers accurately reflect the interviewee's memory (e.g., Henkel, 2013; Milne \& Bull, 2006; Rassin \& Candel, 2010; Smeets et al., 2006).

If the information obtained in asylum interviews is to be used for credibility assessment, it would be best to primarily ask open-ended questions. Open questions may aid the memory search of an honest applicant. With appropriate memory cues it is most likely that a rich, detailed, and valid narrative is obtained. Liars, in contrast, may experience difficulties when asked open questions. Providing long and detailed answers is more cognitively demanding than providing short answers (Vrij \& Granhag, 2012). Furthermore, sometimes a liar tries to say as little as possible (Vrij, Granhag, \& Mann, 2010). A strategy that is more difficult to maintain in response to open questions than in response to closed questions.

\subsubsection{Question content}

Besides question type and style, the amount of information obtained in the interview also depends on the memory of the applicant. A lack of knowledge or detail may infringe on the applicant's credibility (e.g., UNHCR, 2013). However, people do not encode, store, and remember all the information that is enclosed in a 
single situation. Instead, they select and encode the salient information of an event (Conway \& Pleydell-Pearce, 2000; Knudsen, 2007; Levine \& Edelstein, 2009). Any event or object that diverges from expectations, is novel, or is otherwise irregular is likely to be more salient than an ordinary, often encountered event or object, and therefore more easily remembered (Barclay \& Subramaniam, 1987; Bluck \& Habermas, 2000; Pillemer, 2001). Details that are less relevant, for example timemarkers and visual details in the periphery of an event, are typically more difficult to recall (Conway \& Pleydell-Pearce, 2000).

Hence, when assessing the detail of a statement, it should be considered whether or not the interviewer asked for information that the asylum seeker can be expected to remember. The questions in an asylum interview should be tailored to the semantic and autobiographical memory of the applicant. In order to assess whether this is currently the case, it is necessary to map the content of the questions that are typically asked.

\subsection{The present study}

As reviewed above, the style, type, and content of questions asked during the asylum procedure can significantly affect statements made by asylum seekers (e.g., Bull, 2010; Fisher et al., 2011; Snook et al., 2012; Vrij et al., 2014; Vrij et al., 2006). Thus far, however, the questions asked to assess the credibility of asylum claims have not been studied. As a first attempt to fill this gap, we conducted an online vignette study in which Swedish asylum officials formulated questions in response to fictitious cases. Our first aim was to evaluate the style and type of the formulated questions. Our second aim was organize the questions thematically to assess whether there is a thematic overlap in the questions formulated in response to alike cases.

\section{METHOD}

\subsection{Participant selection and sample}

In cooperation with the Swedish Migration Agency (Migrationsverket), 100 asylum officials equally divided over four different locations in Sweden were invited to participate in the present study. A total of 74 case officers entered the survey 
and agreed to participate. Of them, 65 officers completed the substantial part of the study, meaning that they formulated questions to ask the asylum seeker and made a judgment about the likelihood that they would grant an asylum status. Two case officers dropped out after making this judgment, therefore 63 officers fully completed the study. The drop-out rate was $15 \%$. The nine officials that dropped out before formulating questions were excluded from data analyses. There was an unequal distribution of drop-outs over the vignettes. Of the nine drop-outs, four were presented with vignette 4; one was presented with vignette 2; one was presented with vignette 3; and the other 3 dropped out before any vignette was displayed.

\subsubsection{Demographics}

Sixty-three participants ( 15 males, 48 females, age 25 to 53 years, $M=32.59, S D$ $=6.62$ years) completed the study. There was a large range of working experience represented in the sample (range 0-21 years). The distribution was skewed, with the most participants working a relatively short period for the Swedish Migration Agency $(M d n=2-3$ years, Mode $=1-2$ years). Thirty-five of the participants were case officers, and are in that function responsible for interviewing asylum applicants. One participant was a case officer for minors. The other 27 participants were decision makers, who decide on the granting of a refugee status based on the casefile including transcripts of the interviews. 25 of them had previously been a case officer and were thus experienced in interviewing in the asylum procedure as well.

\subsection{Vignettes}

The credibility assessment in asylum cases tends to center on two elements. First, the origin of the applicant (i.e., the nationality and hometown) has to be deemed credible in order to assess the risk that the applicant faces upon a return to that country (EMN, 2013). Second, if the origin of the applicant is known, the persecution story (i.e., what has happened to the asylum seeker in the country of origin that instigated the flight) has to be found credible (UNHCR, 2013). We wanted to represent both cases that center on the origin claim and cases that center on the claim of persecution in the present study. Hence, two vignettes described cases in which evidence for the origin of the applicant was absent, and two vignettes described cases in which evidence for the persecution of the 
applicant(s) was absent. We designed two different vignettes within each type of case to examine whether there is a thematic overlap in the questions formulated in response to vignettes that had the same investigative focus (i.e., credibility of origin vs. persecution story) but were otherwise diverse. All vignettes differed from each other in terms of nationality, sex, and age of the applicant(s). Furthermore, in the origin vignettes we alternated between an urban (vignette 1) and a rural background (vignette 2 ), and in the vignettes focusing on persecution we changed the ground for fear of persecution from membership of a social group (vignette 3) to political views (vignette 4).

As such, we designed four different fictitious case vignettes (see appendices A-D for the vignettes' text): vignette 1 , in which the origin of a Southern-Sudanese woman fleeing with her children was questioned; vignette 2 , in which the origin of an Eritrean young man was questioned; vignette 3, in which the persecution story an Afghan Sikh family fleeing victimization and extortion by the Taliban was questioned; and vignette 4 , in which the persecution story of a Turkish young man who flees after participating in protests against Erdogan was questioned. To make sure that the vignettes were realistic, they were first checked by an experienced Swedish case officer who did not further participate in the study.

The four vignettes had a similar structure (see also Appendices A-D). They started with a brief paragraph about the applicant(s) identity, origin, and motive for fleeing. The story continued with a paragraph with more information about the flight (in the origin cases), or about what had happened in the country of origin (in the persecution cases). Finally, the relevant country of origin information (COI) was provided, and the absence of evidence was made explicit. The vignettes concluded with a task description for the participant in which the focus of the case was explicated.

\subsection{Procedure and materials}

The study was designed with the online survey software Qualtrics. The asylum officials were invited to participate by means of an e-mail, including a link to the study. The study was fully translated to Swedish. Participants were informed that they were allowed to leave the study at any point if they wished so.

After participants consented to participation, they were randomly assigned to one of the four vignette conditions: 17 participants read vignette 1; 18 participants 
read vignette 2; 18 participants read vignette 3 ; and 12 participants read vignette 4. Immediately after the participants had read the vignette for the first time they were asked to rate on a scale from 0 to 100 to what extent they thought the story of the asylum seeker was plausible. The plausibility rating was followed-up by a task to encourage deeper processing of the story. The asylum officials had to read the story a second time and highlight 5 aspects of the story that they wanted to elaborate on in the interview (see Appendices A-D for the phrases that could be highlighted).

Now, the participants were asked to formulate five questions that they would like to ask the asylum seeker to assess the veracity of the claim about origins or persecution. These questions formed the input for the main analyses of the study. We only asked the participants to formulate a limited number of questions for two reasons. First, by only formulating five questions the officials could focus on what they thought were the most relevant aspects in the story to assess the credibility of the claim. Consequently, their answers gave us an idea of what the officials typically find important elements to assess claims about origin and persecution even though we could not analyze full interviews. Second, considering the high workload that migration boards currently face, we wanted to limit the time that asylum officials had to spend on the study in order to minimize interference with their everyday work.

Next, participants were asked several metacognitive questions about the questions they had formulated. Specifically, they were asked to rate on a scale from 0 to 100 to what extent they felt confident that these questions would help them to assess the veracity of the claims, to what extent they had based the questions on knowledge rather than intuition, and to what extent they expected their colleagues to ask the same questions. They were also asked to rate on a scale from 0 to 100 to what extent they thought that the answers to their questions might be affected by contextual factors, such as circumstances of the interview (e.g., time-pressure, or stress induced by the interview), characteristics of the interviewee, characteristics of the interviewer, the way in which questions are asked, and the mediation of an interpreter.

Before continuing to the last part of the study, participants were asked to make a judgment about the asylum status of the applicant. Specifically, they were asked to rate on a scale from 0 to 100 to what extent they would be inclined to grant an international protection status to the applicant, based on the available information. In the last part of the study, participants were asked several demographic questions ${ }^{1}$. 


\subsection{Question coding}

The questions formulated by the asylum officials in response to the vignette were subsumed to the following analyses.

\subsubsection{Style}

Initially two styles were distinguished, based on existing literature (e.g., Moston \& Engelberg, 1993; Vrij et al., 2006) but slightly reformulated to better fit with interviewing practice in the asylum procedure. Information gathering questions allow asylum seekers to describe their actions and experiences in their own words. The interviewer seeks information and clarification of previously provided information. An accusatory style of questioning communicates disbelieve and distrust in the asylum seeker's story. The interviewer seeks to confirm skepticism. A third style was discovered during the analyses: the burden communication style. These questions explicitly communicate the burden of proof to the asylum seeker. The questions stipulate that it is the responsibility of the applicant to establish the veracity of his claims.

\subsubsection{Type}

After the questions were coded in terms of their style, questions that required multiple responses were identified and were split into multiple single questions. For example, the question "Tell me about the documents that were handed over to the smuggler, how they have been issued and what they looked like?", was split into one question about how the documents were issued, and one questions about what the documents looked like.

All the single questions were then typified with codes adapted from Thoresen et al. (2006) and were similar to Johnson et al. (in press). Five types of questions were distinguished. Questions allocated to the open or cued recall category prompted a free recall. These questions did not delimit the answer except in a general way. Cued recall questions sometimes also included specific contextual cues or details, either introduced by the interviewee or by the interviewer to refocus the attention on specific details, aspects or situations, or to request additional information.

The second category, the limited cued recall category, held questions that delimited the answer, for example because there could logically only be one correct answer. The questions in the limited cued recall category did not require or 
stimulate a lengthy response, but rather a short answer. Examples of questions in this category were: "Where did you live?" and "When did it happen?".

Two types of closed questions were distinguished. Yes/no questions were questions that merely requested a yes or a no, and no further explanation. For example: "Did you go to the market?". Questions that could potentially be answered with yes or no but were clearly intended to invite the interviewee to provide an extensive answer are coded as open-ended questions (e.g., "Can you describe..."). Forced choice questions included utterances that gave explicit or implicit options from which the interviewee should choose.

The last category of questions that was identified were suggestive questions. Questions were allocated to this type when they were stated in such a way that the interviewer strongly communicated what response was expected, asked for a clarification or confirmation of information not previously disclosed by the asylum seeker, or quoted the asylum seeker incorrectly.

\subsubsection{Theme}

The thematic analyses followed the procedure recommended by Braun and Clarke (2006). The first step of the analysis was to generate a code for each question that captured the essence of the content. For example, the question "Tell me something about your husband's job as a politician?" would be initially coded as 'husband's job'. Hereafter codes were collated into potential themes and subthemes. The structure of themes was then refined multiple times to reach an optimal solution with good homogeneity within the themes and enough heterogeneity between themes. Once the optimal structure was reached, meaning was given to each theme and the themes were described.

\subsection{Inter-rater reliability}

To minimize subjectivity in the coding of questions, a second coder was asked to code all the questions. For theme inter-rater reliability measurement, we gave the second coder the thematic structure and explanation of the themes, and asked her to categorize all the questions according to that coding scheme. The outcomes of the inter-rater reliability analyses are presented in Table $1^{2}$. A third coder clarified differential outcomes. A few questions were assigned to a different theme $(n=2)$ 
or subtheme $(n=2)$ by all three coders, and where coded as miscellaneous because no consensus was reached.

Table 1. Outcomes and classification of the inter-rater reliability analyses for each vignette.

\begin{tabular}{llll}
\hline Vignette & Analysis & $\mathrm{K}$ & Classification $^{1}$ \\
\hline \multirow{4}{*}{1} & Style & 1.00 & Perfect agreement \\
& Single/multiple & .96 & Almost perfect agreement \\
& Type & .86 & Almost perfect agreement \\
& Theme & .86 & Almost perfect agreement \\
\hline \multirow{4}{*}{2} & Style & .82 & Almost perfect agreement \\
& Single/multiple & .68 & Substantial agreement \\
& Type & .97 & Almost perfect agreement \\
& Theme & .93 & Almost perfect agreement \\
\hline \multirow{3}{*}{3} & Style & .66 & Substantial agreement \\
& Single/multiple & .79 & Substantial agreement \\
& Type & .79 & Substantial agreement \\
& Theme & .89 & Almost perfect agreement \\
\hline \multirow{4}{*}{4} & Style & .30 & Fair agreement \\
& Single/multiple & .79 & Substantial agreement \\
& Type & .92 & Almost perfect agreement \\
& Theme & .85 & Almost perfect agreement \\
\hline
\end{tabular}

${ }^{1}$ The Kappa statistics were classified according to the classification of Landis and Koch (1977).

\section{RESULTS}

\subsection{Question style and type}

The large majority, 92\%, of the 325 formulated questions was posed in an information gathering style. Only $2 \%(n=8)$ of the questions was accusatory in style, with most accusatory questions $(n=4)$ being formulated in response to Vignette 4. Burden communication questions comprised $3 \%$ of all questions $(n=10)$, and they were mostly asked $(n=7)$ in response to Vignette 2 .

Of the 325 questions 56 contained multiple ideas. The 387 questions that resulted after splitting the multiple questions into single questions were mostly categorized as open or cued recall questions, with $75 \%$ of all the questions falling under that type. Of the remaining questions, $11 \%$ was categorized as limited cued recall questions ( $n=43$ ), and $8 \%$ of the questions was closed yes/no questions ( $n$ $=32$ ). Vignette 2 and 4 together accounted for a large proportion of all the closed 
questions ( $n=25 ; 78 \%$ ). There was one forced choice question and two questions were suggestive.

\subsection{Thematic analyses}

The results from the thematic analyses including a description of the themes for each vignette are displayed in Figure 1-5. Questions that did not fit any theme - some were too general and some did not connect to any other questions - were placed in a miscellaneous category. Similarly, if questions were too general to fit to a specific subtheme, they were categorized as 'no subtheme'.

There was a considerable overlap in the kind of questions that asylum officials formulated when the origins of the asylum seeker were questioned (see Figure 1). Both in response to Vignette 1 and Vignette 2 the majority of the questions (72\% and $69 \%$ respectively) were about the life of the asylum seeker in the country of origin, identity documents, or the flight from the country of origin to Europe. From Figure 2 and 3, it becomes clear that also several of the subthemes under these three overlapping themes are similar. This shows that when the credibility of the origin of the asylum seeker is assessed, asylum officials tend to formulate similar questions, even though the cases are different (i.e., difference in nationality, sex, age, and rural/urban background). The other questions in these cases were casespecific.

In cases where the credibility of the persecution narrative was assessed there was less overlap in the questions (see Figure 1). Two themes seemed to be recurring in these cases. In response to both vignettes questions were formulated about the risks that the asylum seekers would face upon a return to the country, and about evidence (documentation/proof) or the lack thereof to support their story. The recurring themes in the vignettes about persecution only comprised a minority of the questions ( $11 \%$ and $18 \%$ respectively). The large majority of the questions in response to both Vignette 3 and Vignette 4 were case specific. Questions in response to vignette 3 for example addressed the victimization by the Taliban, the abduction of the father, and the family's social group (see Figure 4). In response to vignette 4 , questions were mostly about how the Turkish authorities had persecuted the man and what he did in the protests against Erdogan (see Figure 5). 


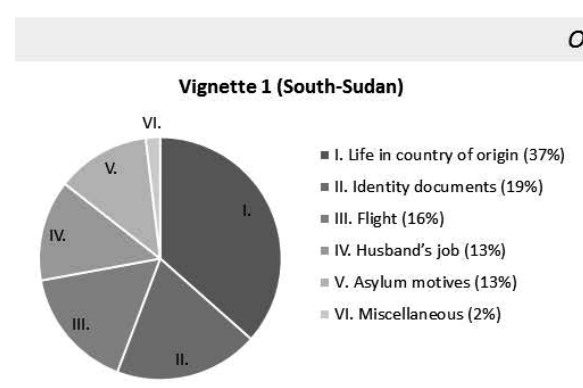

Origins

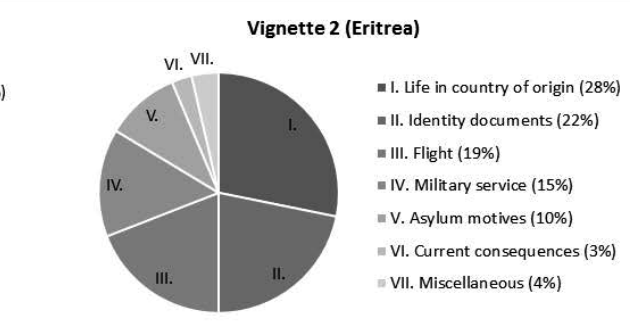

Persecution
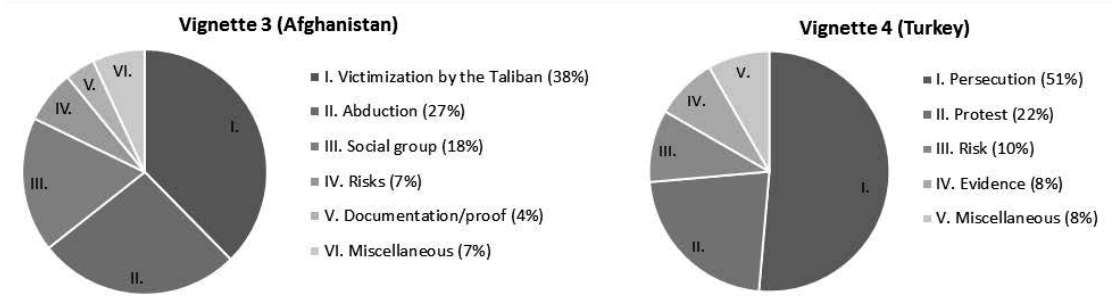

Figure 1. The thematic structure for each of the vignettes with the corresponding percentages of questions that were allocated to each theme.

\subsection{Confidence ratings and contextual influences}

A MANOVA with vignette as a between subjects' factor and the three confidence questions as dependent variables showed that there were no differences between the groups on the confidence ratings $F(9,144)=0.32, p=.97$, Wilk's $\Lambda=$ 0.95. On average the asylum officials were relatively confident that their questions would aid the credibility assessment, with a mean of $67.08(S D=18.23)$ on a scale from 0 - 100. Our participants also reported that the questions were based on knowledge rather than intuition ( $M=66.80, S D=17.32$ ), and that they expected their colleagues to ask similar questions ( $M=71.88, S D=19.54)$. 


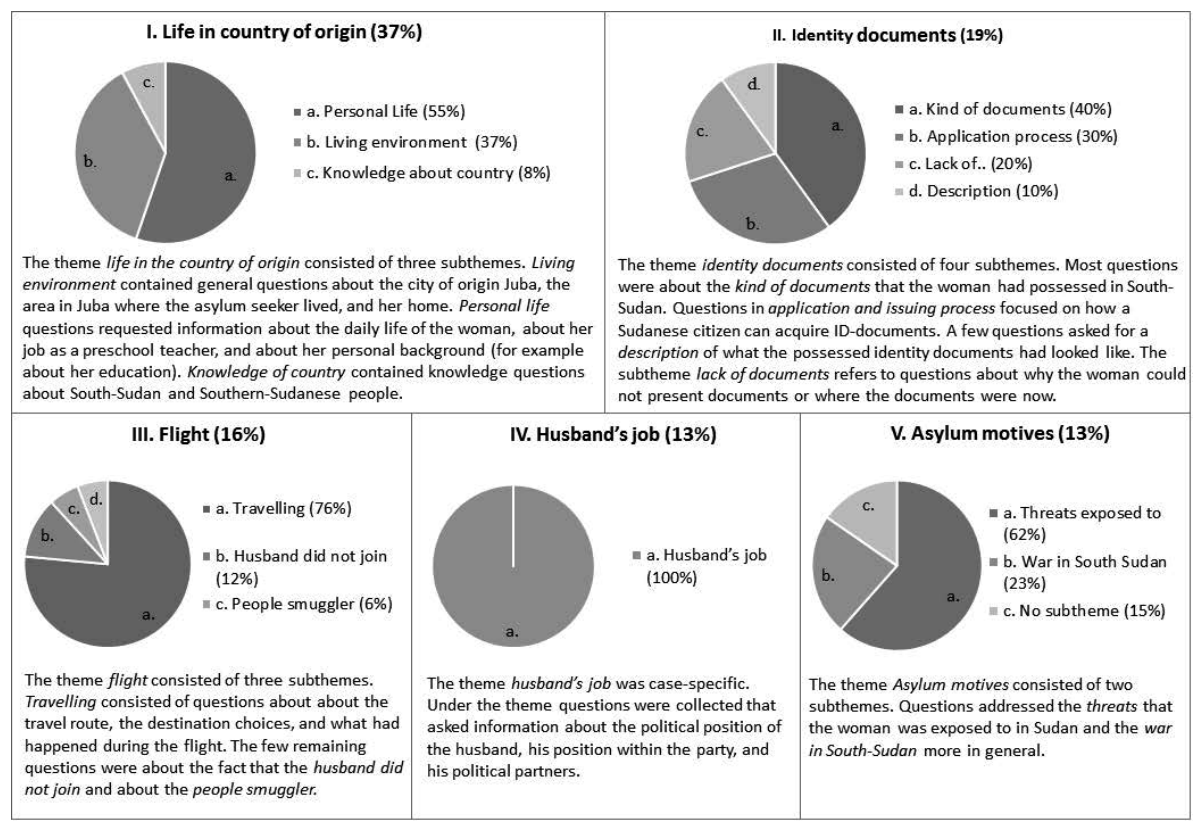

Figure 2. Description of the themes and subthemes that captured the questions formulated in response to Vignette 1, with corresponding percentages of questions that were allocated to each subtheme.

A Repeated Measures ANOVA with vignette as the between subjects factor and the five contextual influences as the within subjects variable yielded a main effect of the contextual influences, $F(4,58)=23.64, p<0.001, \eta p 2=.62$. Pairwise comparisons showed that our participants felt that characteristics of the interviewee ( $M=70.49, S D=19.38)$, the way questions are asked $(M=74.60, S D=16.64)$, and the intervention of a translator $(M=74.34, S D=16.27)$ would influence the responses to the questions more than characteristics of the interviewer $(M=58.71$, $S D=18.82)$, and the circumstances of the interview $(M=59.60, S D=20.89)$. 


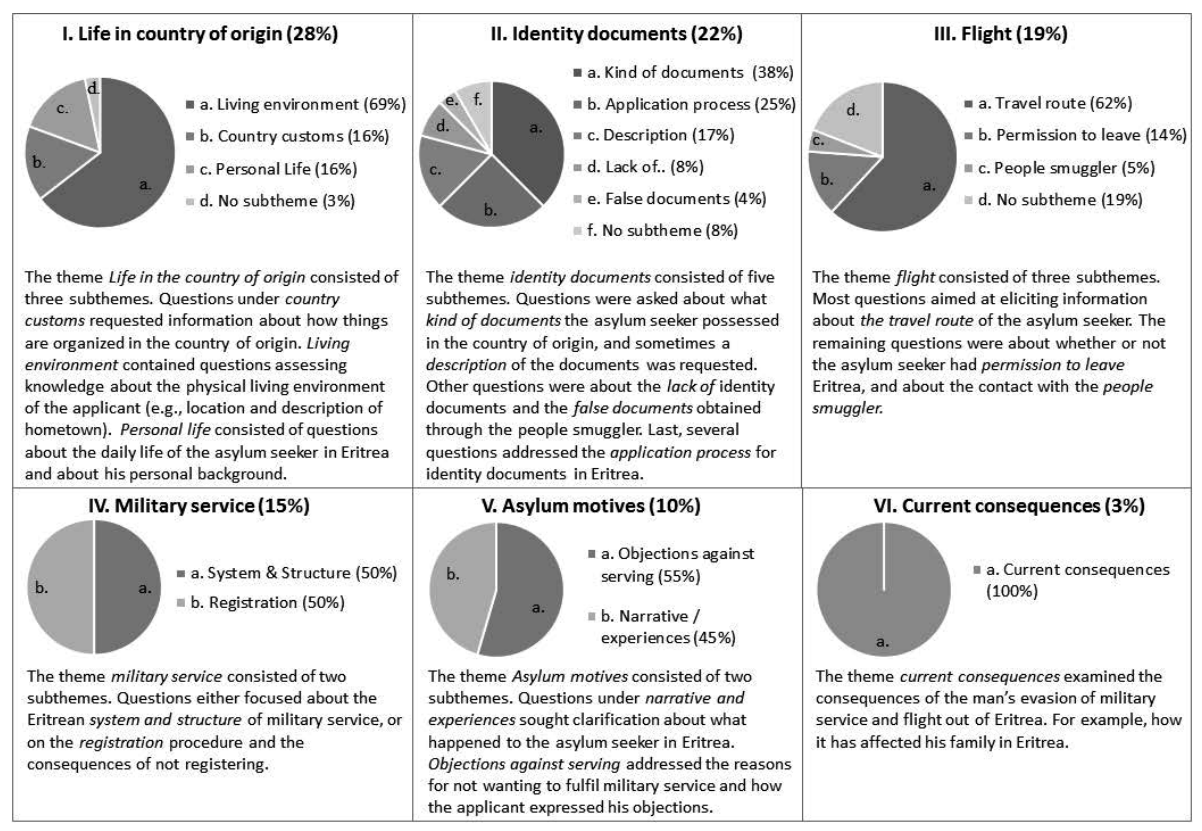

Figure 3. Description of the themes and subthemes that captured the questions formulated in response to Vignette 2, with corresponding percentages of questions that were allocated to each subtheme.

\subsection{Plausibility and asylum judgments}

In general participants found the vignette stories plausible, with mean ratings ranging from 60.92 to 74.29 . An ANOVA on plausibility ratings with vignette as the between subjects factor showed no significant differences between the plausibility ratings, $F(4,65)=2.08, p=.09$. There was, however, a significant difference in the extent to which participants were inclined to grant a refugee status to the asylum seeker, $F(3,61)=9.95, p<.001, \eta_{p}{ }^{2}=.33$. Post-hoc comparisons showed that participants who responded to Vignette 4 were significantly less likely to grant asylum than participants who responded to the other vignettes (all $p$ 's $<0.003$ ). The corresponding means are displayed in Table 2. 


\begin{tabular}{|c|c|c|c|}
\hline \multicolumn{2}{|c|}{ I. Victimization by the Taliban (38\%) } & \multicolumn{2}{|r|}{ II. Abduction (27\%) } \\
\hline \multicolumn{2}{|c|}{$\begin{array}{l}\text { The theme victimization by the Taliban consisted of four subthemes. Most } \\
\text { questions were about what happened during- and the motives for the attacks } \\
\text { and killings, and about why the attacks started after the release of the father } \\
\text { (i.e., the timing). Question about extortion focused on why the family needed } \\
\text { protection and on the process of the extortion; when and by whom they were } \\
\text { extorted. The subtheme family specific contained questions about whether } \\
\text { there could be other reasons than membership of a social group for the } \\
\text { attacks. Several questions addressed threats by the Taliban more in general. }\end{array}$} & \multicolumn{2}{|c|}{$\begin{array}{l}\text { The theme abduction consisted of four subthemes. The subtheme } \\
\text { experiences/narrative was comprised of questions about the experiences of } \\
\text { the father during his kidnapping. Questions about how and when the } \\
\text { kidnapping came about were subsumed under the subtheme sequence of } \\
\text { events. The subtheme ransom contained questions related to the } \\
\text { negotiations about the payment of the ransom and the demands that the } \\
\text { Taliban made in relation to the ransom. Questions regarding the reasons of } \\
\text { the Taliban to abduct the father comprised a separate subtheme }\end{array}$} \\
\hline III. Social group (18\%) & \multicolumn{2}{|c|}{ IV. Risks (7\%) } & V. Documentation/proof (4\%) \\
\hline $\begin{array}{l}\text { = a. Sikhs in Afghanistan } \\
(45 \%) \\
=\text { b. Sikh religion (44\%) } \\
=\text { c. Community ( } 11 \%)\end{array}$ & b. & $\begin{array}{l}\text { a. Alternative } \\
\text { protection (57\%) } \\
\text { b. Risked treatment } \\
(43 \%)\end{array}$ & $\begin{array}{l}=\text { a. Identification }(50 \%) \\
=\text { b. Proof }(50 \%)\end{array}$ \\
\hline $\begin{array}{l}\text { The theme social group consisted of three } \\
\text { subthemes. Questions about how the Sikhs are } \\
\text { viewed in Afghanistan both in general and more } \\
\text { specifically by the Taliban were pooled. Other } \\
\text { questions were about the Sikh religion and about } \\
\text { the relationship of the family to the Sikh } \\
\text { community. }\end{array}$ & $\begin{array}{l}\text { The theme risks consiste } \\
\text { first subtheme assessed } \\
\text { family would risk upon a } \\
\text { The subtheme alternativ } \\
\text { questions about the pos } \\
\text { protection by Afghan au } \\
\text { to diminish the risks fac }\end{array}$ & $\begin{array}{l}\text { I of two subthemes. The } \\
\text { what treatment the } \\
\text { return to Afghanistan. } \\
\text { e protection consisted of } \\
\text { sibilities of getting } \\
\text { thorities or other parties, } \\
\text { ed in Afghanistan. }\end{array}$ & $\begin{array}{l}\text { The theme documentation / proof consisted of } \\
\text { two subthemes related to documentation. } \\
\text { Questions were about whether the family could } \\
\text { provide proof for either their persecution story, } \\
\text { or for their social identity (gathered under } \\
\text { identification). }\end{array}$ \\
\hline
\end{tabular}

Figure 4. Description of the themes and subthemes that captured the questions formulated in response to Vignette 3, with corresponding percentages of questions that were allocated to each subtheme.

To examine whether the initial plausibility judgment could predict the judgment about refugee status, a regression analysis was conducted. The snap-judged plausibility predicted the extent to which asylum official estimated the chances of granting a refugee status to the asylum seeker, $t(63)=3.41, p<.002$. The model with only plausibility as a predictor was significant, $F(1,63)=11.63, p<.002, \mathrm{R}^{2}$ adjusted $=.14$, and the plausibility judgment explained $14 \%$ of the variance in the judgment to grant or reject a refugee status. 


\section{Persecution (51\%)}

The theme persecution consisted of six subthemes. Questions about the arrest were both about the accusations or reasons for the arrest and about how the man was arrested. Questions about the release from prison inquired about why the man was released even though the authorities later expressed interest in him again, and also about his life after the release. The subtheme detention consisted of questions about the time the applicant spent in prison. These could be very general or more specific, for example about

interrogations and the treatment he received. The subtheme him specific captured questions about why the authorities were interested in the applicant specifically and not in all the other people involved in the protests. Home searches contained questions about the invasion of the applicants' apartment. The subtheme actors consisted of questions about the actors of persecution (i.e., the Turkish authorities) and about how the applicant knew that they had instigated the persecution.

\section{Protest (22\%)

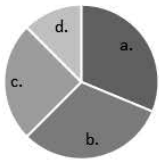 \\ - a. Facebook (31\%) \\ = b. Political activities (31\%) \\ = c. Involvement $(25 \%)$ \\ ind. Motives (13\%)}

The theme protest consisted of four subthemes. The subtheme Facebook was comprised of questions about the Facebook messages and why these were deleted. The subtheme political activities captured questions about past political activities and opinions. Questions about the applicant's involvement in the protests and about how the he motivated his family and friends to participate fell under the subtheme involvement. Other questions explored the applicant's motives to protest.

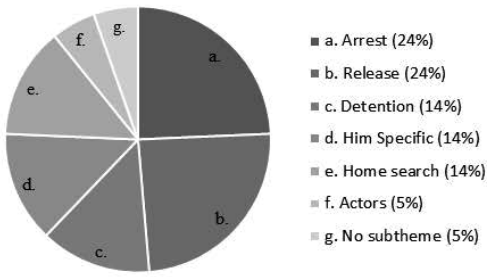

IV. Evidence (8\%)

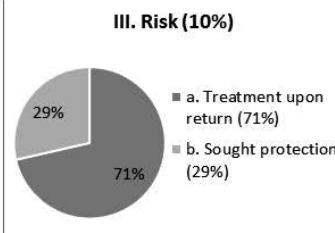

The theme risk consisted of two subthemes. Some questions specifically targeted the treatment that the applicant would risk upon a return. Other question were asked to assess whether the applicant had ever tried to- or could seek help or protection in Turkey.

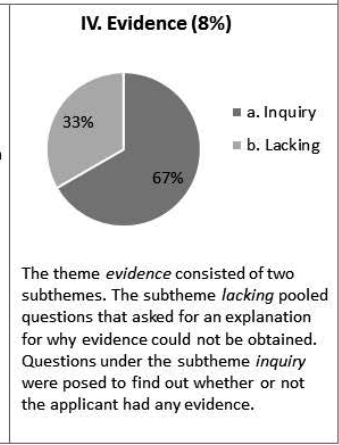

Figure 5. Description of the themes and subthemes that captured the questions formulated in response to Vignette 4, with corresponding percentages of questions that were allocated to each subtheme.

Table 2. Descriptive statistics of plausibility judgments and likelihood to grant a refugee status for each of the four vignette stories.

\begin{tabular}{lllllll}
\hline \multirow{2}{*}{ Condition } & \multirow{2}{*}{$N$} & \multicolumn{2}{c}{ Plausibility judgment } & & \multicolumn{2}{c}{ Granting refugee status } \\
\cline { 7 - 8 } \cline { 7 - 7 } & & $M$ & $S D$ & & $M$ & SD \\
\hline Vignette 1 (Sudan) & 17 & 74.29 & 13.40 & & $63.12^{\mathrm{a}}$ & 27.93 \\
Vignette 2 (Eritrea) & 18 & 77.50 & 15.99 & & $66.33^{\mathrm{a}}$ & 29.82 \\
Vignette 3 (Afghanistan) & 18 & 74.00 & 14.31 & & $76.78^{\mathrm{a}}$ & 20.43 \\
Vignette 4 (Turkey) & 12 & 60.92 & 22.97 & & $26.17^{\mathrm{b}}$ & 22.23 \\
Total & 65 & 72.63 & 17.07 & & 60.97 & 30.56 \\
\hline
\end{tabular}

${ }^{a, b}$ Post-hoc tests showed that means with the superscript a differed significantly from means with the superscript $b$ at the $p<.003$ level. 


\section{DISCUSSION}

The aim of the present paper was to examine how asylum officials interview to assess the credibility of asylum seekers' claims. We evaluated the type, style, and themes of interview questions formulated by Swedish asylum officials in response to fictitious case vignettes. Two main conclusions can be drawn. First, Swedish asylum officials at least know that they should predominantly ask open questions in an information gathering style to elicit information from asylum seekers. Second, when the origins of the asylum seeker are assessed, Swedish asylum officials seem to rely primarily on questions that assess knowledge about life in the country of origin, identity documents, and the flight. Such a thematic overlap was not found when the interview was held to assess the credibility of claims about persecution.

\subsection{Questions style and type}

We found that Swedish asylum officials primarily formulated questions in the information gathering style, as opposed to the accusatory or burden communication style. The likelihood that an interviewer will elicit ample and accurate information with information gathering questions is higher than with accusatory questions (Vrij et al., 2014; Vrij et al., 2006). The questions formulated by the asylum officials were primarily open or cued recall questions. Only a small proportion of the questions was typified as closed, and almost none were forced choice or suggestive questions. This finding is promising since open and cued recall questions elicit the most, and most accurate, information in investigative interviews (e.g., Bull, 2010; Jacob Cohen, 1968; Fisher et al., 2011; Memon \& Bull, 1991; Memon et al., 1994; Milne \& Bull, 2006). We must be cautious in concluding that asylum officials ask predominantly open and information gathering questions in practice. It may be possible that our results overestimate the prevalence of information gathering and open questions in asylum interviews.

The present study was an imitation of a real asylum case. Our set-up is void of one essential factor: the interaction between the applicant and the official. The consequence of the absence of interaction in the current study is that asylum officials have unlimited time to think about what questions they want to ask. They do not have to respond quickly to what the asylum seeker has said, or think about a follow-up questions while listening to the answer. Asking open questions is dif- 
ficult and cognitively demanding (Memon et al., 1994). It may be the case that in real asylum interviews, asylum officials lack the time or cognitive recourses to formulate open questions, and instead ask more closed questions.

Another reason that the proportion of open-ended questions may be overestimated is the number of questions the case officials were asked to formulate. Our participants were asked to create only five questions, which may have limited the types of questions they would ask. For example, a typical interview tends to start with a few open type questions, but questions become more closed as the interview progresses (e.g.,Fisher, Geiselman, \& Raymond, 1987; Wright \& Alison, 2004). The style and type of questioning may also change during the interview as an effect of the interviewee's answers. In the present study, the asylum officials did not receive answers to their questions. We do not know whether the style and type of questions would change in quality depending on the answer given.

All the vignettes were deemed as plausible in the eyes of the asylum officials. It is possible that the style of questioning could also become more skeptical or accusatory if the official thinks that the asylum seeker's story is unlikely to begin with. That is, the beliefs of the interviewer may influence the style of questioning in investigative interviews. Previous research in a police investigation context has for example shown that people formulate more guilt presumptive questions when they think the suspect is guilty, as opposed to believing in the suspect's innocence (Hill, Memon, \& McGeorge, 2008). Thus, to be more correct in the interpretation one could say that the results indicate that asylum officials mostly ask open and information gathering questions at the start of the interview and when the applicant's story seems relatively plausible at first sight.

The large proportion of open ended questions formulated by the participants in our study does imply that Swedish asylum officials at least know that they should ask open questions to obtain accurate information. This interpretation is in line with our finding that asylum officials think that the way in which questions are asked influences what information is obtained in the interview. Knowing how one should set-up an interview, however, does not guarantee that asylum officials will also translate that knowledge or intentions into practice. Research has shown that translating knowledge and intentions into effective practice is often difficult (Sheeran, 2002). To examine whether the asylum officials' knowledge is also systematically incorporated in practice, it would be valuable to study real asylum 
interviews. That way, the questions across different cases can be investigated, all the questions in an interview can be analyzed.

The identification of a burden communication style, although presented in only a few questions, is interesting and it may be explained by the standard of proof in asylum law. It is up to the asylum seeker to establish a well-founded fear of persecution (Asylum Procedure Directive, 2013; Qualification Directive, 2011), and asylum authorities merely have the duty to assess the relevant elements of the application in cooperation with the asylum seeker. With questions in the burden communication style, asylum officials possibly want to emphasize that the main responsibility lies with the applicant, and thus that the initiative to make their claims believable also lies with them. Whether such questions are effective is a different matter. There is currently no research regarding burden communication questions and if they elicit valuable information; however, our estimation is that they would not. Questions that communicate the burden of proof implicitly emphasize the different positions of the interviewer and interviewee. Thereby, the questions may negatively influence the rapport between the interviewer and the interviewee; one of the important requirements for effective investigative interviews (e.g., Fisher et al., 2011; Memon, Meissner, \& Fraser, 2010; Vrij et al., 2014).

\subsection{Recurring themes in origin cases}

Besides mapping the type and style of questions formulated by Swedish asylum officials, the second aim of this study was to analyze the kind of questions that are typically asked to assess the credibility of asylum claims. We were looking for the presence of typical question categories that may recur in an asylum interview. The presence of such categories would make it possible to evaluate whether the questions request knowledge that people can ordinarily be expected to have when taking into account how human memory functions. In cases where the asylum officials focused on examining the veracity of claims about persecution, we only found a few similar themes that were also small in size. Most of the questions formulated in response to the persecution cases were case-specific. For these questions it will be difficult to assess whether the questions are answerable for veracious individuals, as targeted memory may differ from case to case.

We did find a set of questions that were typically formulated in cases where the origin of the asylum seeker was questioned. In the two different origin cases, many 
questions were formulated about objects and places in the living environment of the asylum seeker. Questions also focused on country customs and history, and what identity documents looked like in the country of origin. The questions implied that asylum officials held the assumption that persons truly originating from a specific country or area should have ample knowledge about that area, its history, its customs, and frequently encountered objects. Whether that assumption holds true is questionable when taking into account how human memory functions. Events that are routine or objects we encounter regularly, are not necessarily encoded and stored in memory in great detail (e.g., Conway \& Pleydell-Pearce, 2000; Knudsen, 2007). For example, the question "Please describe what your passport looked like?" may seem valid to assess the credibility of a claim about origins, but it may be difficult to answer in sufficient detail. It would really depend on how much attention people normally pay to the lay-out of their passport.

Our participants were generally confident that their questions aided the credibility assessment. Future studies will have to provide support for whether that confidence is justified through empirical evaluation of typically asked questions and if they truly help to discriminate between truthful and fabricated accounts.

\subsection{Limitations and future directions}

As previously mentioned, our thematic structures resulted from a limited number of questions. Because asylum officials formulated only five questions, the questions were broad in content and sometimes even contained statements about what the asylum official would like to ask (e.g., , Posing general knowledge questions about Eritrea), rather than a real question. In a full real-life interview several more specific and concrete questions would most likely be asked, which would allow for a more in depth analysis of which questions are normally asked. Nevertheless, the results provided the first global overview of the themes that are typically addressed in asylum interviews to assess the credibility of claims about origins and persecution.

Another limitation of the present study was the difficulty of coding individual questions for style. Previous research has focused on the style of a full interview as well as the proportion of open and closed questions contained in the interview (Hartwig, Granhag, \& Vrij, 2005; Vrij et al., 2014; Vrij et al., 2006; Williamson, 1993). Although we attempted to code the style of individual questions, it was difficult 
because a question may be interpreted differently depending on how it was asked (i.e., in what tone), or in context to previously asked questions and responses. This difficulty was also reflected in the low inter-rater reliability for style in Vignette 4. In future studies, it would be preferable to use video or audio recordings of interviews for the analysis of question style, or at least interview transcripts.

A final direction for future research concerns the relationship between plausibility ratings and the final decision to grant a refugee status. We found that an initial snap judgment of plausibility regarding the asylum story predicted the final decision of the asylum officials. These findings could imply that the first judgment of plausibility biases the subsequent assessment of the claim, in the sense that asylum officials seek to confirm their first impression. Such a confirmation bias has been repeatedly found in police interviews and criminal investigations (e.g., Ask \& Granhag, 2005; Hill et al., 2008; Kassin, Goldstein, \& Savitsky, 2003; Nickerson, 1998). Note however, that in the present study the participants did not receive any additional information between the plausibility judgment and the eventual judgment. They only had the time to think more about the story, and to formulate questions; therefore, more research is needed to draw the conclusion that asylum officials are prone to a confirmation bias. For example, an experiment in which asylum officials receive affirmative, neutral or contradictory information between the two judgments, to investigate whether plausibility functions as an anchor for the eventual decision to grant or reject a refugee status.

\section{CONCLUSION}

The assessment of credibility is inevitable in the asylum procedure. Statements of the asylum seeker are oftentimes the only available evidence besides general information about the situation in the country of origin. It is important to take into account how the statements were elicited in order to decide whether or not the statements of the asylum seeker should be deemed credible. A first step to a careful credibility assessment, is to make sure that the methods of questioning are of a high standard. For instance, by asking open questions in an information gathering style and asking questions that only a truthful asylum seeker, and not a deceptive asylum seeker, can answer. 
The present study is the first to systematically evaluate the style, type and kind of questions formulated by asylum officials to assess the credibility of a claim about origin or persecution. Our results are promising. We found three recurring themes in the questions for the cases that focused on claims about origins. Especially the prevalence of questions belonging to the theme life in the country of origin implies that asylum officials hold the assumption that a credible claimant should have ample knowledge about the area or origin, its history, and its customs. The question that remains unanswered is whether it reasonable or not to expect a genuine asylum seeker to reproduce such knowledge. Swedish asylum officials also tend to formulated primarily open questions in an information gathering style. Even though we do not know whether the same proportions of open and information gathering would be found in full interviews, the results do indicate that Swedish asylum officials at the very least know how a careful interview should be set-up. 


\section{REFERENCES}

Ask, K., \& Granhag, P. A. (2005). Motivational sources of confirmation bias in criminal investigations: the need for cognitive closure. Journal of Investigative Psychology and Offender Profiling, 2, 43-63. doi:10.1002/jip.19

Asylum Procedure Directive 2013/32/EU, L3180/60 C.F.R. (2013).

Barclay, C. R., \& Subramaniam, G. (1987). Autobiographical memories and self-schemata. Applied Cognitive Psychology, 1, 169-182. doi: 10.1002/acp.2350010303

Bluck, S., \& Habermas, T. (2000). The life story schema. Motivation \& Emotion, 24, 121-147.

Bögner, D., Brewin, C., \& Herlihy, J. (2009). Refugees' experiences of home office interviews: A qualitative study on the disclosure of sensitive personal information. Journal of Ethnic and Migration Studies, 36, 519-535. doi: 10.1080/13691830903368329

Bond, J. (2012). Excluding justice: The dangerous intersection between refugee claims, criminal Law, and 'guilty' asylum seekers. International Journal of Refugee Law, 24, 37-59. doi: 10.1093/ijrl/eer039

Braun, V., \& Clarke, V. (2006). Using thematic analysis in psychology. Qualitative Research in Psychology, 3, 77-101. doi: 10.1191/1478088706qp063oa

Bull, R. (2010). The investigative interviewing of children and other vulnerable witnesses: Psychological research and working/professional practice. Legal and Criminological Psychology, 15, 5-23. doi: 10.1348/014466509X440160

Byrne, R. (2007). Assessing testimonial evidence in asylum proceedings: Guiding standards from the international criminal tribunals. International Journal of Refugee Law, 19, 609-638. doi: 10.1093/ijrl/eem056

Cohen, J. (1968). Weighted kappa: Nominal scale agreement provision for scaled disagreement or partial credit. Psychological Bulletin, 70, 213-220. doi: 10.1037/h0026256

Cohen, J. (2001). Questions of credibility: omissions, discrepancies and errors of recall in the testimony of asylum seekers. International Journal of Refugee Law, 13, 293-309.

Conway, M. A., \& Pleydell-Pearce, C. W. (2000). The construction of autobiographical memories in the self-memory system. Psychological review, 107, 261-288. doi: 10.1037/0033-295X.107.2.261

Doornbos, N. (2004). Gescheiden werelden: De beoordeling van geloofwaardigheid van vluchtverhalen [Separate worlds: the assessment of credibility of flight stories]. Amsterdams Sociologisch Tijdschrift, 31, pp. 80-112.

European Migration Network [EMN]. (2013). Establishing Identity for International Protection: Challenges and Practices. Brussels: European Commission.

Eurostat Press Office. (2015). Asylum in the EU: The number of asylum applicants in the EU jumped to more than 625000 in 2014 (53/2015) [Press release]. Retrieved from http://ec.europa.eu/eurostat/web/products-press-releases/-/3-20032015-BP

Ewens, S., Vrij, A., Leal, S., Mann, S., Jo, E., \& Fisher, R. P. (2014). The effect of interpreters on eliciting information, cues to deceit and rapport. Legal and Criminological Psychology, Early view (Online Version of Record published before inclusion in an issue), n/a-n/a. doi: 10.1111/lcrp.12067

Fisher, R. P., Geiselman, R. E., \& Raymond, D. S. (1987). Critical analysis of police interview techniques. Journal of Police Science and Administration, 15, 177-185.

Fisher, R. P., Milne, R., \& Bull, R. (2011). Interviewing cooperative witnesses. Current Directions in Psychological Science, 20, 16-19. doi: 10.1177/0963721410396826 
Goodman, S. R. (2013). Asking for too much: The role of corroborating evidence in asylum proceedings in the United States and United Kingdom. Fordham International Law Journal, 36, 1733-1766.

Graham, B., Herlihy, J., \& Brewin, C. R. (2014). Overgeneral memory in asylum seekers and refugees. Journal of Behavior Therapy and Experimental Psychiatry, 45, 375-380. doi: http://dx.doi.org/10.1016/j.jbtep.2014.03.001

Granhag, P. A., Strömwall, L. A., \& Hartwig, M. (2005). Granting asylum or not? Migration board personnel's beliefs about deception. Journal of Ethnic and Migration Studies, 31, 29-50. doi: 10.1080/1369183042000305672

Gyulai, G. (2013). The evidentiary framework of credibility assessment. In G. Gyulai (Ed.), Credibility assessment in asylum procedures: a multidisciplinary training manual (pp. 9-20). Budapest, Hungary: Hungarian Helsinki Comittee.

Hartwig, M., Granhag, P. A., \& Vrij, A. (2005). Police interrogation from a social psychology perspective. Policing and Society, 15, 379-399.

Henkel, L. A. (2013). Do older adults change their eyewitness reports when re-questioned? The Journals of Gerontology Series B: Psychological Sciences and Social Sciences, 69, 356-365. doi: 10.1093/geronb/gbt071

Herlihy, J., Jobson, L., \& Turner, S. (2012). Just tell us what happened to you: Autobiographical memory and seeking asylum. Applied Cognitive Psychology, 26, 661-676. doi: 10.1002/acp.2852

Herlihy, J., Scragg, P., \& Turner, S. (2002). Discrepancies in autobiographical memories implications for the assessment of asylum seekers: repeated interviews study. British Medical Journal, 324, 324-327. doi: 10.1136/bmj.324.7333.324

Herlihy, J., \& Turner, S. (2006). Should discrepant accounts given by asylum seekers be taken as proof of deceit? Torture, 16, 81-92.

Herlihy, J., \& Turner, S. W. (2009). The psychology of seeking protection. International Journal of Refugee Law, 21, 171-192. doi: 10.1093/ijrl/eep004

Hill, C., Memon, A., \& McGeorge, P. (2008). The role of confirmation bias in suspect interviews: A systematic evaluation. Legal and Criminological Psychology, 13, 357-371. doi: $10.1348 / 135532507 \times 238682$

Horselenberg, R., Merkelbach, H., Crombag, H. F. M., \& Van Bergen, S. (2010). Getuigen helpen herinneren [Helping witnesses to remember]. In P. J. Van Koppen, H. Merkelbach, M. Jelicic, \& J. W. De Keijser (Eds.), Reizen met mijn rechter [Travelling with my judge] (pp. 487-508). Deventer: Kluwer.

IND-Werkinstructie nr. 2010/14 (AUB): Beoordeling geloofwaardigheid en zwaarwegendheid [INS-work instruction nr. 2010/14 (AUB): Assessment of credibility and substantiality] (2010).

Inter-Parliamentary Union [IPU]. (2001). Refugee Protection: A guide to international refugee law. Geneva: Inter-Parliamentary Union \& Office of the UNHCR.

Johnson, M., Magnussen, S., Thoresen, C., Lønnum, K., Burrel, L. V., \& Melinder, A. (in press). Beste practice recommendations still fail to result in action: a national 10 -year followup study of investigative interviews in CSA cases. Psychology Crime and Law.

Kagan, M. (2002). Is truth in the eye of the beholder - objective credibility assessment in refugee status determination. Georgetown Immigration Law Journal, 17, 367-416.

Kassin, S. M., Goldstein, C. C., \& Savitsky, K. (2003). Behavioral confirmation in the interrogation room: On the dangers of presuming guilt. Law and Human Behavior, 27, 187-203. doi:10.1023/A:1022599230598 
Knudsen, E. I. (2007). Fundamental Components of Attention. Annual Review of Neuroscience, 30, 57-78. doi: doi:10.1146/annurev.neuro.30.051606.094256

Koser, K. (2011). The smuggling of refugees. In D. Kyle \& R. Koslowski (Eds.), Global human smuggling: Comparative perspectives (pp. 256 - 272). Baltimore: The John Hopkins University Press.

Levine, L., \& Edelstein, R. (2009). Emotion and memory narrowing: A review and goal-relevance approach. Cognition \& Emotion, 23, 833-875. doi: 10.1080/02699930902738863

Memon, A., \& Bull, R. (1991). The Cognitive Interview: Its origins, empirical support, evaluation and practical implications. Journal of Community \& Applied Social Psychology, 1, 291-307. doi: 10.1002/casp.2450010405

Memon, A., Holley, A., Milne, R., Koehnken, G., \& Bull, R. (1994). Towards understanding the effects of interviewer training in evaluating the cognitive interview. Applied Cognitive Psychology, 8, 641-659. doi: 10.1002/acp.2350080704

Memon, A., Meissner, C. A., \& Fraser, J. (2010). The cognitive interview: A meta-analytic review and study space analysis of the past 25 years. Psychology, Public Policy, and Law, 16, 340-372. doi:10.1037/a0020518

Milne, R., \& Bull, R. (2006). Interviewing victims of crime, including children and people with intellectual disabilities. In M. Kebbel \& G. Davies (Eds.), Practical psychology for forensic investigations and prosecutions (pp. 7-24). Chichester: John Wiley \& Sons Ltd.

Moston, S., \& Engelberg, T. (1993). Police questioning techniques in tape recorded interviews with criminal suspects. Policing and Society, 3, 223-237. doi: 10.1080/10439463.1993.9964670

Nickerson, R. S. (1998). Confirmation bias: A ubiquitous phenomenon in many guises. Review of General Psychology, 2, 175-220. doi:10.1037/1089-2680.2.2.175

Noll, G. (2005a). Introduction: Re-mapping evidentiary assessment in asylum procedures. In N. Gregor (Ed.), Proof, evidentiary assessment and credibility in asylum procedures (pp. 1-12). Leiden, the Netherlands: Koninklijke Brill NV.

Noll, G. (2005b). Salvation by the grace of state? explaining credibility assessment in the asylum procedure. In N. Gregor (Ed.), Proof, evidentiary assessment and credibility in asylum procedures (pp. 197-214). Leiden, the Netherlands: Koninklijke Brill NV.

Pillemer, D. B. (2001). Momentous events and the life story. Review of General Psychology, 5, 123-134. doi: 10.1037/1089-2680.5.2.123

Qualification Directive 2011/95/EU [Recast QD 2004], L336/09 C.F.R. (2011).

Rassin, E., \& Candel, I. (2010). Suggestie tijdens het verhoor [Suggestion during the interview]. In P. J. Van Koppen, H. Merkelbach, M. Jelicic, \& J. W. De Keijser (Eds.), Reisen met mijn rechter [Travelling with my judge] (pp. 509-528). Deventer: Kluwer.

Rousseau, C., Crépeau, F., Foxen, P., \& Houle, F. (2002). The complexity of determining refugeehood: A multidisciplinary analysis of the decision-making process of the Canadian Immigration and Refugee Board. Journal of Refugee Studies, 15, 43-70. doi: 10.1093/ $\mathrm{jrs} / 15.1 .43$

Sheeran, P. (2002). Intention-Behavior Relations: A Conceptual and Empirical Review. European Review of Social Psychology, 12, 1-36. doi: 10.1080/14792772143000003

Smeets, T. (2011). Acute stress impairs memory retrieval independent of time of day. Psychoneuroendocrinology, 36, 495-501. doi: http://dx.doi.org/10.1016/j. psyneuen.2010.08.001 
Smeets, T., Jelicic, M., Peters, M. J. V., Candel, I., Horselenberg, R., \& Merckelbach, H. (2006). 'Of course I remember seeing that film'-how ambiguous questions generate crashing memories. Applied Cognitive Psychology, 20, 779-789. doi: 10.1002/acp.1205

Snook, B., Luther, K., Quinlan, H., \& Milne, R. (2012). Let 'em talk!: A field study of police questioning practices of suspects and accused persons. Criminal Justice and Behavior, 39, 1328-1339. doi: 10.1177/0093854812449216

Sweeney, J. A. (2009). Credibility, proof and refugee law. International Journal of Refugee Law, 21, 700-726. doi: 10.1093/ijrl/eep027

Szypszak, A. (2000). Where in the World is Dr. Detchakandi: A Story of Fact Investigation Part II: Refugess and Asylum--Clinical Essay. Immigration and Nationality Law Review, 21, 125-138.

Thoresen, C., Lønnum, K., Melinder, A., Stridbeck, U., \& Magnussen, S. (2006). Theory and practice in interviewing young children: A study of Norwegian police interviews 19852002. Psychology, Crime \& Law, 12, 629-640. doi: 10.1080/10683160500350546

UNHCR. (2003). Background Note on the Application of the Exclusion Clauses: Article 1F of the 1951. Geneva: UNHCR.

United Nations. (1951). The 1951 convention relating to the status of refugees. Geneva: United Nations.

United Nations High Commissioner for Refugees. (2013). Beyond proof, credibility asessment in EU asylum systems. Brussels: UNHCR.

Landis, J. R., \& Koch, G. G. (1977). The measurement of observer agreement for categorical data. Biometrics, 33, 159-174. doi:10.2307/2529310

Vrij, A., \& Granhag, P. A. (2012). Eliciting cues to deception and truth: What matters are the questions asked. Journal of Applied Research in Memory and Cognition, 1, 110-117. doi: http://dx.doi.org/10.1016/j.jarmac.2012.02.004

Vrij, A., Granhag, P. A., \& Mann, S. A. (2010). Good liars. Journal of Psychiatry \& Law, 38, 77-98.

Vrij, A., Hope, L., \& Fisher, R. P. (2014). Eliciting reliable information in investigative interviews. Policy Insights from the Behavioral and Brain Sciences, 1, 129-136. doi: $10.1177 / 2372732214548592$

Vrij, A., Mann, S., \& Fisher, R. P. (2006). Information-gathering vs accusatory interview style: Individual differences in respondents' experiences. Personality and Individual Differences, 41, 589-599. doi: http://dx.doi.org/10.1016/j.paid.2006.02.014

Wettergren, $\AA$. ., \& Wikström, H. (2013). Who is a refugee? Political subjectivity and the categorisation of Somali asylum seekers in Sweden. Journal of Ethnic and Migration Studies, 40, 566-583. doi: 10.1080/1369183X.2013.830502

Williamson, T. M. (1993). From interrogation to investigative interviewing; strategic trends in police questioning. Journal of Community \& Applied Social Psychology, 3, 89-99.

Wright, A. M., \& Alison, L. (2004). Questioning sequences in canadian police interviews: Constructing and confirming the course of events? Psychology, Crime \& Law, 10, 137154. doi:10.1080/1068316031000099120 


\section{APPENDIX A}

English Translation of Vignette 1. Bold Phrases Could Be Highlighted in the Highlighting Exercise.

A female asylum seeker claims to originate from Juba, the capital of South Sudan. She was a teacher in a primary school and her husband was a politician. Because of his job they were endangered during the war, and they decided to flee to North Sudan.

During their flight they were shot at, and another car was destroyed by a roadside bomb. When they arrived in the north her husband told her that she had to flee to Egypt with her 2 children (she was pregnant of a third child). From there she travelled with the help of a people smuggler to Europe by airplane. Her husband was supposed to come two months later, but she hasn't heard from him since.

Because of the time pressure under which she left Sudan, the woman does not have any evidence for her origins. Furthermore, she claims to have handed in her identity documents to the smuggler, and to have travelled to Europe with false documents.

It is known from Country of Origin Information (COI) that the situation in South Sudan is indeed very dangerous for politicians and their close family. Furthermore, Southern Sudanese people are often the target of discrimination, arrests, threats and violence by North Sudanese authorities (among which the police and security services), so Northern Sudan would not be a safe place to settle for a Southern Sudanese woman either.

However, an important question arising from her story is whether the woman is truly originating from South Sudan. This is why in the detailed interview you want to investigate whether the woman truly originates from South Sudan. 


\section{APPENDIX B}

English Translation of Vignette 2. Bold Phrases Could Be Highlighted in the Highlighting Exercise.

An 18-year-old asylum seeker claims to originate from Dukambiya, a small village in the south of Eritrea. He fled Eritrea because he does not want to fulfil his obligatory military service. He claims that his brother was arrested 5 years ago when he refused to serve the army, and that he subsequently disappeared. Still, because the man has conscientious objections against serving, he decided not to register at the registration office when he turned eighteen.

At first, he hoped that the authorities would not find out. However, one night he heard uproar outside and his mother came running in the room. She was panicked,explained that there was a raid to find deserters, and urged him to flee. He managed to outrun the police-forces and after walking for two days he crossed the border with Ethiopia. From there he travelled with help of a people smuggler by truck via Sudan to Egypt, from where he flew to Europe.

Because he did not plan his flight, he has no evidence for his origins. He claims to have handed in his identity documents to the smuggler and to have travelled to Europe with false documents.

It is known from Country of Origin Information (COI) that ad-hoc raids are often held to arrest deserters in Eritrea. Deserters face prison time, and detained deserters often disappear. Furthermore, people who flee the country to evade military service also face prison time, and still have to fulfil their obligatory military service when they return.

However, an important question arising from his story is whether the man is truly originating from Eritrea. This is why in the detailed interview you want to investigate whether the man truly originates from Eritrea. 


\section{APPENDIX C}

English Translation of Vignette 3. Bold Phrases Could Be Highlighted in the Highlighting Exercise.

An Afghan family consisting of a father and mother in their 50's and a son in his 20's flee to Europe together. They claim to fear their lives because the Taliban threatens their lives and the Afghan government is not able to protect them.

They used to live in Jalalabad and owned a small clothes shop there. They claim that every day the Taliban would come to ask for money in exchange for protection. The family needed protection because they belonged to the Sikhs, a religious minority. The Taliban men would bring large weapons and if there was not enough money they would use the weapons to beat the father and son up. One day, the Taliban kidnapped the father and demanded a ransom in exchange for his release. Only after two months the son was able to pay this money, in between his father was being tortured.

After his release the Taliban began attacking the family and other Sikhs, because they felt that Sikhs do not belong in Afghanistan. Many family members were killed. That is when the family sold their shop and used a people smuggler to get away. They travelled via Peshawar and Dubai to a European country, in which they now ask for protection.

It is known from Country of Origin Information (COI) that Sikhs in Afghanistan often have to fear people in their environment. They experience discrimination and are sometimes violently harassed. The Afghan government does not offer protection against the harassment.

However, the family does not have evidence for their claims of harassment by the Taliban.

This is why in the detailed interview you want to investigate whether the family is veracious about their past experiences, and their fear for the Taliban. 


\section{APPENDIX D}

English Translation of Vignette 4. Bold Phrases Could Be Highlighted in the Highlighting Exercise.

A Turkish 25-year-old man claims to have fled his hometown Istanbul because he fears persecution by the Turkish authorities.

In the end of May and beginning of June 2013 he participated in the protests at the Taksim square in Istanbul against the authoritarian policies of premier Erdogan. The police used tear gas and rubber bullets to quell the protests. This made the man angry. Therefore, he tried to motivate his friends and family to protest against the governing-style of Erdogan through his Facebook page. A day later a police force invaded his apartment and he was arrested. $\mathrm{He}$ claims to have been repeatedly beaten by prison guards during his time in detention, and when he complained about this he was put in solitary confinement.

After two months he was released. Hoping to end this horrible chapter of his life he continued his studies and was very careful in what he said to whom. However, since his release his house has been repeatedly searched by authorities, and he has been threatened with a trial if he would provoke any more protests against the government in the future. The man claims to fear persecution in the future, and feels that his right to freedom of speech is violated. Furthermore, he feels that the Turkish government was the instigator of this injustice.

It is known from Country of Origin Information (COI) that the protest actions in May 2013 led to a tough response of the Turkish government including arrests of provokers of the protests. However, evidence for the man's participation in the protests or his arrest is lacking. For example, the Facebook massage was deleted, and he claims that he never got an official arrest warrant.

This is why in the detailed interview you want to investigate whether the man is veracious about his past experiences and his fear for the Turkish authorities.

\section{FOOTNOTES}

${ }^{1}$ All the materials, including the specific formulation of the meta-cognitive-, contextual-, and demographic questions, can be provided by the first author upon request.

${ }^{2}$ Note from Table 1 that for the analysis of style in vignette 4 only fair agreement between the first and second coder was reached. The inconsistencies were solved with a third coder. Still we will keep the relatively low inter-rater reliability in mind when interpreting the results, and we discuss this more in depth in the discussion section. 


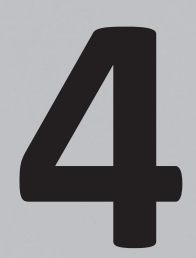

\section{Establishing Origin: Analysing Questions in Asylum} Interviews

This chapter has been accepted for publication as: van Veldhuizen, T. S., Maas, R. P. A. E., Horselenberg, R., \& van Koppen, P. J. (in press) Establishing origin: Analysing questions in asylum interviews. Psychiatry, Psychology, and Law. 


\section{ABSTRACT}

In the absence of evidence, asylum seekers are interviewed to assess the credibility of their story. Few studies have examined whether questions asked in such interviews stimulate the applicant to give lengthy, detailed, and accurate answers. We analysed the style, type, and content of the questions asked to assess a claim about origin in 40 case files from the Dutch Immigration Service. A large proportion of the questions were closed and fact-checking questions. Less than one-fifth of questions were open or cued recall questions. The results also showed that to assess the credibility of origin, knowledge questions are posed about the applicant's immediate living environment, flight to Europe, identity documents, country of origin, and personal background. Possibilities for increasing the quantity and quality of information obtained in asylum interviews are discussed. Future research should validate the assumption that truthful claimants have ample knowledge about their country and town of origin.

Keywords: investigative interviewing; asylum procedure; credibility assessment; question style; question type; question content; origin claims 


\section{INTRODUCTION}

Interviewing practice in the European asylum procedure is largely understudied (Van Veldhuizen, Horselenberg, Landström, Granhag, \& Van Koppen, in press). This is surprising, given that the oral statements of asylum seekers carry much weight in determining refugee status due to a general scarcity of evidence in asylum cases (e.g., United Nations High Commissioner for Refugees [UNHCR], 2013). In contrast, much is known about the most effective interviewing techniques to elicit information from witnesses, suspects, and victims of crimes (e.g., Fisher \& Geiselman, 2010; Fisher, Milne, \& Bull, 2011; Milne \& Bull, 2006; Tekin et al., 2015; Vrij, Hope, \& Fisher, 2014). In the present study, we applied that knowledge to evaluate the interviewing practice in asylum cases.

\subsection{Interviewing asylum seekers}

Despite the differences between the refugee status determination and criminal context (Noll, 2005), asylum interviews share characteristics with police interviews (Herlihy \& Turner, 2009). Asylum seekers are essentially eye-witnesses of their own life (Herlihy, Jobson, \& Turner, 2012; Herlihy \& Turner, 2009). In order to appear credible, they have to give detailed and consistent statements about their identity, origin and past experiences, for which they have to search their autobiographical memory (Cameron, 2010; Herlihy et al., 2012; UNHCR, 2013; Van Veldhuizen, Horselenberg, \& Van Koppen, 2016). Hence, similar to interviews with eyewitnesses, one objective of asylum interviews should be to enhance accurate memory recall. Concurrently, asylum interviews share characteristics with suspect interviews (Doornbos, 2006). Although for different reasons than suspects in police interviews, asylum seekers may be motivated to lie during their interview (Beneduce, 2015). By lying about their identity, origin or flight motives they hope to increase their chances of acquiring a refugee status. Asylum officials have to decide to believe the applicant's statements or not, before assessing whether the applicant is eligible for asylum (UNHCR, 2013). Consequently, as is the case in suspect interviews (e.g., DePaulo \& Morris, 2004), detecting deception seems an important element of asylum interviews (Herlihy et al., 2012).

Lastly, besides being treated as eyewitness and suspect, an asylum seeker may be considered a victim with corresponding vulnerabilities. Many asylum seekers 
have witnessed or experienced horrific events in their country of origin or at some point during the flight (UNHCR, 2011). They may suffer from post-traumatic stress, and as a consequence their ability to provide detailed and coherent statements may be compromised (Graham, Herlihy, \& Brewin, 2014; Herlihy \& Turner, 2007; Moore \& Zoellner, 2007). Even without post-traumatic stress, the asylum interview may be a stressful experience (Bögner, Brewin, \& Herlihy, 2009; Sourander, 2003). Such stress should be minimized as it may impair memory recall (Smeets, 2011).

Asylum interviews thus are complex. Asking the right questions can help to elicit accurate information, make the applicant feel comfortable, and elicit information on the basis of which the credibility of the asylum story can be assessed.

\subsection{Best practice in investigative interviewing}

\subsubsection{Question style}

How the interviewer approaches the interviewee with his questions matters. Information gathering questions are preferred over accusatory questions. With an information gathering style, the interviewer is searching for the truth in an open and non-confrontational way, whereas the accusatory style is characterized by confirmatory questions, posed to elicit a confession (Hartwig, Granhag, \& Vrij, 2005; Vrij et al., 2014; Vrij, Mann, \& Fisher, 2006). More comprehensive and accurate narratives are obtained in information gathering interviews than in accusatory interviews (Hartwig et al., 2005; Vrij et al., 2014), even from reluctant suspects (Meissner, Redlich, Bhatt, \& Brandon, 2012). In an accusatory interview the interviewee can also become anxious, defiant and uncooperative, which hinders the working alliance between the interviewer and interviewee. The information gathering style, in contrast, promotes rapport-building, makes the interviewee feel respected, and reduces stress (Vanderhallen, Vervaeke, \& Holmberg, 2011; Vrij et al., 2006).

That does not mean, however, that information gathering questions are easy to answer for liars. They are more cognitively demanding than accusatory questions because they encourage liars to provide more detail than they may have prepared for (Vrij et al., 2006). Accusatory questions can be easily answered with short denials and do not require much thinking of a lying interviewee. In addition, interviews in the information gathering style also yield more diagnostic information about 
the truthfulness of the suspect (Meissner et al., 2012; Vrij et al., 2006; Vrij, Mann, Kristen, \& Fisher, 2007).

\subsubsection{Question type}

In general, open questions are preferred to other questions types (e.g., Clarke \& Milne, 2001; Thoresen, Lønnum, Melinder, Stridbeck, \& Magnussen, 2006; Walsh \& Bull, 2010, 2012). They invite an interviewee to give a long answer in his own words and usually elicit more and more accurate information from the interviewee than closed or direct questions that only require a short answer (e.g., Bull, 2010; Fisher et al., 2011; Milne \& Bull, 2006; Snook, Luther, Quinlan, \& Milne, 2012). Forced-choice and suggestive questions may steer the answers of the interviewee into a particular direction and may undermine the answers' validity (Horselenberg, Merkelbach, Crombag, \& Van Bergen, 2010; Snook et al., 2012; Thoresen et al., 2006).

The use of open questions may also be important for rapport-building (Walsh \& Bull, 2012). Asking many direct questions implicitly conveys the message that the interviewee should limit his answers to a few words. Asking open questions, in contrasts, shows that the interviewer is interested in the interviewee's story and communicates that the interviewee is in control of the flow of information (Fisher, 1995).

The last advantage of asking open questions is that it may be more challenging for liars to give long answers than for truth-teller. Truth-tellers are forthcoming most of the time and can rely on their memory to give elaborate answers (Granhag, Hartwig, Giolla, \& Clemens, 2014; Hartwig, Granhag, Stromwall, \& Doering, 2010; Strömwall, Hartwig, \& Granhag, 2006). Liars are typically less forthcoming. They like to keep their story simple and to give concise answers with limited detail, because giving a rich but false statement puts them at risk of contradicting themselves and the evidence in the case (Strömwall et al., 2006). In response to closed questions they can probably successfully maintain this strategy without arousing suspicion, yet the strategy may be more difficult to maintain in response to open questions that invite the interviewee to elaborate on their previous statements (Vrij, 2004) (although fact checking probes may lead to more statement-evidence inconsistencies, cf. Hartwig et al., 2011). 


\subsubsection{Question content}

Besides question style and type, the content of the questions asked should also be considered. In asylum cases, a lack of knowledge about the hometown- and country, and undetailed and vague statements may infringe on the applicant's credibility (UNHCR, 2013). However, if questions are asked about events, places or objects that the applicant does not possess knowledge of, it is unreasonable to expect correct, let alone extensive, answers.

Human memory is selective; people generally attend to and store information that is novel, distinct or otherwise salient rather than to ordinary or expected information (Conway \& Pleydell-Pearce, 2000; Knudsen, 2007; Levine \& Edelstein, 2009). As such, memories for ordinary information or the periphery of an event may be less pronounced. Memories are also malleable and can be sabotaged even without conscious awareness (Loftus, 2005). They fade over time (Wagenaar, 1986), and people can fail to access a memory due to stress (Smeets, 2011) or ineffective retrieval cues (Smith \& Vela, 2001; Tulving \& Thomson, 1973). Hence, an incorrect, short or vague statement can be indicative of a lack of knowledge or genuine memory errors, just as well as being indicative of deception.

\subsection{Interviewing practice of asylum officials}

To obtain as much valid information as possible for a credibility assessment in asylum cases, asylum officials should ask predominantly information gathering and open questions, and refrain from asking suggestive and forced choice questions. Questions should address topics the applicant can be expected to have knowledge about. Before it can be examined to what extent the questions in asylum interviews address knowledge and memories that truthful applicants with a properly functioning memory may be expected to have, however, it has to be established what kind of questions typically are asked.

To our knowledge, only one empirical study has previously focused on the style, type, and content of questions asked by asylum officials (Van Veldhuizen et al., in press). Van Veldhuizen and colleagues asked Swedish asylum officials to respond to one out of four fictitious case vignettes presenting an asylum seeker's claim. The applicant in the vignette had no evidence for either his or her origin (in 2 vignettes), or could not corroborate his persecution story with evidence (in the 2 other vignettes). De asylum officials formulated five questions that they would like 
to ask to assess the claim about origin or persecution. Results show that asylum officials predominantly formulated open questions in an information gathering style. Furthermore, to assess the credibility of a claim about origin, asylum officials tended to formulate questions that assess knowledge about the life in the country of origin, identity documents, and the flight. They seem to assume that persons truly originating from a specific country or area should have ample knowledge about that area, its history, its customs, and frequently encountered objects. Such a set of typical questions was not found when the persecution story was the central element of the credibility assessment.

The findings pertaining to the proportion of information gathering and open questions were promising, but there were several limitations to the study. The asylum officials only formulated a limited number of questions in response to a fictitious case without any time restrictions. In a real interview more questions are asked and there is an ongoing interaction between the interviewee and the interviewer. As such, the interviewer has limited time to think about the next question. The authors concluded that although asylum officials seem to have knowledge about best practice of investigative interviewing and seem to use knowledge about one's hometown to assess the credibility of claims about origin, more research is needed to draw conclusions about the actual interviewing practice in asylum cases.

\subsection{The Present Study}

In the current study, we sought to replicate previous findings with an archival study at the Dutch Immigration and Naturalisation Service (INS). We analysed the style, type, and content of the questions asked in asylum interviews and evaluated whether they facilitate the credibility assessment by eliciting a high quantity of accurate information. Compared to previous research (Van Veldhuizen et al., in press) we expected more closed questions since interviews tend to start with a few open questions and become more closed as the interview proceeds (Fisher, Geiselman, \& Raymond, 1987; Wright \& Alison, 2004). In line with previous findings (Van Veldhuizen et al., in press) we expected to find that asylum officials use a similar set of knowledge questions to assess the credibility of an applicant's origin, regardless of any differences in nationality, and background of the applicant. Cases were selected in which the applicant could not corroborate his origin with evidence. 


\section{METHOD}

\subsection{Case selection}

Forty case files from the Dutch INS were selected with a purposeful sampling procedure. A list was created of all applications filed in 2014 in which the asylum seeker initially could not provide (authentic) documents to corroborate his origin, which ensured homogeneity in presence of evidence. We selected applicants who claimed to be from Eritrea or Sudan to ensure variation in applicant background. For each nationality we further split the list into granted and rejected cases to ensure variation in case outcome. We randomly selected 10 cases from each list to add up to 40 cases in total. With the random selection in the final step, we intended to obtain a high variation of cases within each group.

\subsection{Case characteristics}

\subsubsection{The applicants}

The asylum seekers were on average $24.45(S D=5.38)$ years old at the time of applying. Of the Eritrean applicants, 10 were male and 10 were female. Seventeen of the Sudanese applicants were male ( 3 female). Most Eritrean applicants ( $n=$ 19) were Tigrinya people and were Coptic Orthodox Christians, whereas only 1 applicant was a Muslim belonging to the Tigre people. The Sudanese applicants had 11 different ethnicities but were all Muslims. Most applicants from Eritrea claimed to come from a village $(n=14)$, rather than a city $(n=5)$; one applicant explained that her town of origin was too large for a village but too small for a city. Sudanese applicants equally often came from a city and a village.

\subsubsection{The interviewers}

Eighty-five asylum officials were involved in the 106 interviews from which the questions were selected (see also Table 1). As a result of the diversity of interviewers, our findings are likely reflective of the general interviewing practice of Dutch asylum officials.

Asylum officials with a permanent position receive training provided by the knowledge centre of the INS, and follow at least three basic e-learning modules from the European Training Curriculum offered by the European Asylum Support 
Office [EASO] (ACVZ, 2016). The three modules are 'Evidence Assessment', 'Inclusion', and 'Interviewing Techniques'. In the module about interviewing techniques, the appropriate structure of an interview is addressed (EASO, 2014a). In line with the best practices in investigative interviewing discussed in the introduction, the importance of rapport building, an information gathering style and a free recall phase are taught. Different types of questions (e.g., open vs. closed) and their effectiveness are not discussed in the module. Asking open questions is encouraged in the EASO practical guide about personal interviews (2014b), but it is unclear to what extent the instrument informs the training of Dutch asylum officials.

\subsubsection{Content and length of the procedure.}

In the Dutch procedure, asylum applicants are interviewed several times (see Table 1). The first interview and substantial interview are prerequisites to decide on a case and are therefore conducted in all cases. The application interview and additional interviews are not always conducted.

The average number of days between the asylum application and the first interview was $58(S D=29)$. The average time that was taken to reach a decision was 44 days, but the length of the asylum procedure varied greatly $(S D=53)$. The length of the asylum procedure did not predict the odds of the case being granted or rejected, $p>.30$.

Table 1 Overview of the focus of different interviews in the Dutch asylum procedure and the number of different interviewers that conducted each type of interview within the sample.

\begin{tabular}{llcc}
\hline Interview & Focus & $\begin{array}{c}\mathrm{N} \\
\text { Interviews }\end{array}$ & $\begin{array}{c}\mathrm{N} \\
\text { Interviewers }\end{array}$ \\
\hline Application interview & $\begin{array}{l}\text { Identity, travel route (Dublin } \\
\text { requirements), origin }\end{array}$ & 25 & 20 \\
First interview* & Identity, origin, nationality, travel route & 40 & 38 \\
Substantial interview** & $\begin{array}{l}\text { Clarification first interview, flight } \\
\text { motives }\end{array}$ & 40 & 37 \\
Additional interview & $\begin{array}{l}\text { Clarification of substantial elements } \\
\text { (e.g., origin or flight motives) }\end{array}$ & 1 & 1 \\
\hline
\end{tabular}

Note: an asterisk indicates that the interview is a prerequisite for deciding on a case. Other interviews are optional.

\subsubsection{The credibility of origin}

In all cases, the credibility of the applicant's origin was assessed in an interview. In Eritrean cases, the credibility of origin also formed the main input for the INS 
decision. In the rejected cases the origin of the applicant was contested, whereas in the granted cases the origin claim was deemed credible. In Sudanese cases, the origin of the applicant was not decisive for the asylum status. Sudanese applicants also had to establish a genuine fear of persecution in Sudan to be eligible to an asylum status.

Of the 10 Eritrean cases in which the applicant's origin was contested by the INS, in 6 cases the origin claim later proved to be truthful (either before or during the appeal procedure). In these six cases, the applicant presented authentic identity documents that he had not possessed at the start of the procedure, but had collected from family members in the country of origin in the course of the procedure. The documents invalidated the outcome of the credibility assessment.

For two Sudanese rejections the outcome of the appeal was unknown at the time of our analyses. The other rejections were all appealed but withstood judicial review.

\subsection{Selection of questions}

All interviews were verbalized in transcripts in a question-answer style and divided into several sections to organize the different topics addressed in the interviews. In total, 3735 questions were extracted from the transcripts ( $N=1782$ for Eritrean cases; $N=1953$ for Sudanese cases).

Most questions $(\approx 90 \%)$ were asked in the application interview and the first interview. Questions were extracted from sections that were directly related to the country, region, and place of origin, including questions about (documentary) evidence for their origin or their outward journey, questions about the last address in the country of origin, and questions about origin and recent leave. Questions about the travel route were also included, even though one could argue that these questions are asked to determine which country is responsible for handling the asylum application (in the context of the Dublin regulation, Dublin Regulation, 2003). They were nevertheless included because previous research implied that questions about the travel route are also used to assess the credibility of claims about origin (Van Veldhuizen et al., in press). Questions about personal data and ethnicity were also extracted because they were sometimes used to assess the veracity of the origin claim. Questions under the headings family members, religion, and marital status were not systematically included. As an exception, individual 
questions about these topics that were asked under the origin-related headings were included in the analyses. From substantial interviews, only those questions were selected that asked for clarifications of the statements made in the first interview and were directly related to origin or identity documents.

The number of questions pertaining to origin in each file ranged from 46 to 160. On average each file contained $93(S D=30)$ origin-related questions. The number of origin-related questions in Eritrean cases were somewhat lower $(M=89, S D=$ 30) than in the Sudanese cases $(M=98, S D=30)$.

Seventy-one questions were not included in the analyses because they were utterances rather than questions. Most were statements about an observation that the interviewer made (e.g., 'You first said $X$, now you say $Y^{\prime}$ ) or an action of the interviewer (e.g., 'I repeat the question'). Hence, a total of 3664 questions formed the input for the main analyses.

\subsection{Question coding}

The questions selected from the case files were coded for style, type, and content.

\subsubsection{Style}

We used the same definitions to code the questions for style as Van Veldhuizen et al. (in press), and similar to their study we distinguished three different styles. Information gathering questions allow asylum seekers to describe their actions and experiences in their own words. The interviewer is open-minded and seeks information and clarification of previously provided information. An accusatory style of questioning communicates disbelieve and distrust in the asylum seeker's story. The interviewer seeks to confirm scepticism. Burden communication questions explicitly communicate the burden of proof to the asylum seeker. They stipulate that it is the applicant's responsibility to establish the veracity of his claims. All questions were coded by two coders who reached a substantial agreement, Cronbach's $\alpha=$ .64. Inconsistencies were resolved by a third coder (except for 1 question, which therefore was excluded).

'Why questions' were difficult to code. They could be interpreted differently depending on intonation. Asking why someone made a choice can come across as sceptical (i.e., 'Why would you do that?'), but 'why questions' can be asked just 
as well with the intention to gather information about the reasons behind certain actions. To resolve the difficulties, we took into account the context in which the question was asked (i.e., previous questions and answers). If the context could not abate the ambiguity, we coded the questions as information gathering.

\subsubsection{Type}

Of all questions, 3559 (97\%) contained only one idea and could be used for further analyses without any changes. The other 105 questions (3\%) contained multiple ideas and were split into multiple questions, resulting in 3771 questions that were subsumed to the type, and content analyses.

Following Van Veldhuizen et al. (in press) five types of questions were distinguished. Open or cued recall questions prompt a free recall, and do not delimit the answer except in a general way. Cued recall questions include specific contextual cues or details, either introduced by the interviewee or by the interviewer, to refocus the attention on specific details, aspects or situations, or to elaborate and elicit additional information. The question 'Can you describe the church that you just mentioned?' is an example of a cued recall question.

Limited cued recall questions delimit the answer, for example because there can logically only be one correct answer. They can also be called fact-checking questions, and do not require or stimulate a lengthy response, but rather a short answer. Examples of questions in this category are: 'Where did you live?' and 'Which villages surrounded your hometown?'

Yes/no questions are closed questions that merely request a affirmative or disconfirming answer without any further explanation, for example: 'Did you go to the market?' Another type of closed questions, forced choice questions, gives explicit or implicit options from which the interviewee should choose (e.g., 'Is there much vegetation or are there only buildings in the area?').

Lastly, suggestive questions strongly communicate what response is expected, ask for a clarification or confirmation of information not previously disclosed by the asylum seeker, or quote the asylum seeker incorrectly. For example the question 'Not originally from another country?' is suggesting that the applicant named the wrong country when asked for the origins of his tribe.

All questions were typified by two coders who reached a substantial agreement, Cronbach's $\alpha=.79$. Inconsistencies were resolved by a third coder. 


\subsubsection{Content}

The content of the questions was analysed thematically (Braun \& Clarke, 2006). Two separate thematic structures were made for Eritrean and Sudanese cases to examine the thematic overlap in origin-related questions asked to applicants from different claimed nationalities. The initial structures were made corraboratively by two researchers. The questions were first sorted broadly by topic. The different topics were collated into potential themes and subthemes. The structure of themes was refined multiple times to reach an optimal structure with sufficient homogeneity within the themes and sufficient heterogeneity between the themes to categorize the questions. Finally, the themes were described.

The two resulting thematic structures were provided to a third researcher, who coded all the questions in 10 randomly picked files (5 Eritrean files; 5 Sudanese files). An almost perfect agreement between the first two researchers combined and the third coder was reached for the Eritrean cases (Cronbach's $\alpha=.85$ ) and a substantial agreement was reached for the Sudanese cases (Cronbach's $\alpha=.70$ ), indicating that the thematic structures adequately described the content of the questions.

\section{RESULTS}

\subsection{Question style}

Of the 3664 questions, $97 \%$ were posed in the information gathering style. Only a small proportion constituted accusatory questions (2\%) and even fewer questions $(<1 \%, n=15)$ were asked in the burden communication style. The proportions of question style differed depending on case outcome, $\chi^{2}(2)=13.60, p<.002$. Standardized residuals showed that burden communication questions were less often than expected asked in granted cases $(0.1 \%, z=-2.27, p<.025)$, and more often than expected in rejected cases $(0.7 \%, z=2.33, p<.01)$. There were no differences in the distribution of information gathering and accusatory questions.

\subsection{Question type}

Eighteen percent of all questions ( $N=3771)$ were open questions. A larger proportion of the questions delimited the answer of the applicant, either by re- 
questing a short or factual answer (36\%) or by merely asking for a yes-no response (42\%). Of the remaining questions, $3 \%$ was coded as forced choice questions and $1 \%$ was considered to be suggestive. The distribution of question type is illustrated in Figure 1.

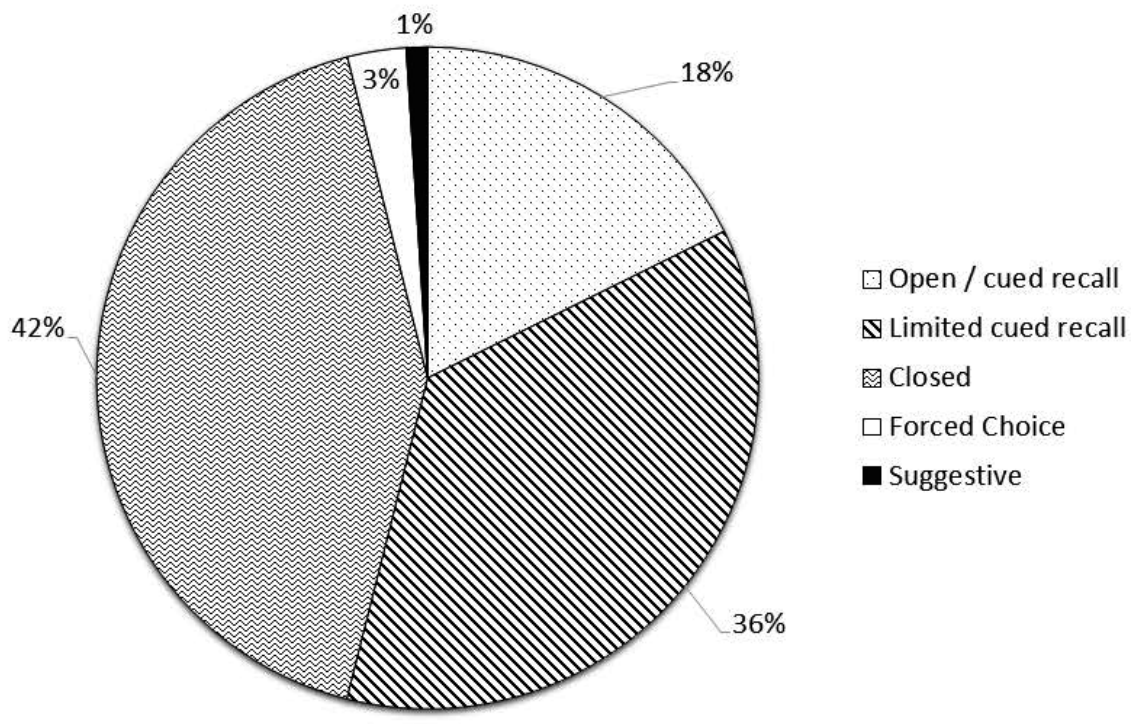

Figure 1. Pie chart of the question type distribution with corresponding percentages $(N=3771)$.

The distribution of question type differed for cases with different outcomes, $\chi^{2}(4)=12.52, p<.02$. An inspection of the standardized residuals yielded, however, that compared to what would be expected none of the question types was over- or underrepresented in either rejected or granted cases.

The average ratio of yes-no questions to open questions was $2.68(S D=1.03)$, indicating that on average for each open question 2 to 3 closed questions were asked. An ANOVA showed that the ratio of open-ended versus closed questions was the same for rejected and granted cases, $F(1,38)=1.97, p>.16$.

\subsection{Thematic analyses}

The two thematic structures describing the content of the questions asked in Eritrean and Sudanese cases are similar (see Figures $2 \& 3$ ). In both types of cases, questions were asked about the living environment, the flight, documents, the applicant's personal background, and the country of origin. In Eritrean interviews 
an additional theme was identified concerning the specific standpoint of the applicant (not further discussed in detail). Questions were coded as miscellaneous if they were too general to fit one of the themes, or if they were singletons in the sense that they did not recur in other interviews. Despite the minor differences in subthemes between Eritrean and Sudanese cases, the questions collated under the themes were relatively similar in both types of cases.

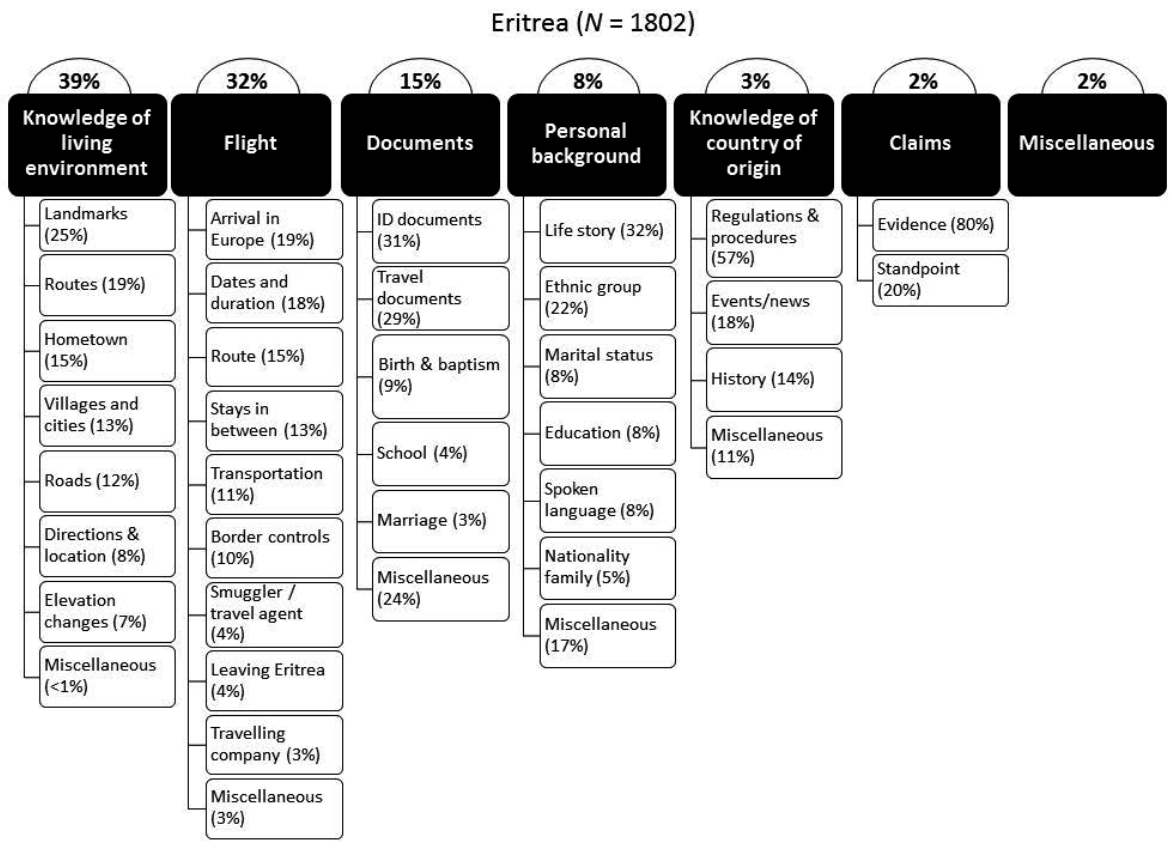

Figure 2. Thematic structure describing the content of the questions asked in the Eritrean cases. Subthemes are displayed below each theme. The themes and subthemes are organized based on their size (i.e., their occurrence in the interviews).

\subsubsection{Knowledge of the living environment}

The theme knowledge of living environment contained questions that assessed the applicant's autobiographical and semantic memory about his direct living environment in the country of origin. This could either be the place where the applicant grew up or the place where the applicant had lived prior to fleeing the country. Questions were asked about things visible in that particular environment, as well as its defining characteristics and geography. For example, a considerable proportion of the questions in both Eritrean and Sudanese cases addressed knowledge 
about landmarks, such as water sources, mountains, churches or specific buildings or facilities. Other questions sought information about surrounding villages and cities, and routes to and from specific points in the environment. Many Sudanese applicants had lived in a refugee camp inside their home country (internal dislocation) for a long time. In those cases, questions were often asked about the camps as if this had been their hometown. Typical for the Eritrean cases were questions about elevation changes in the environment and names and characteristics of specific roads.

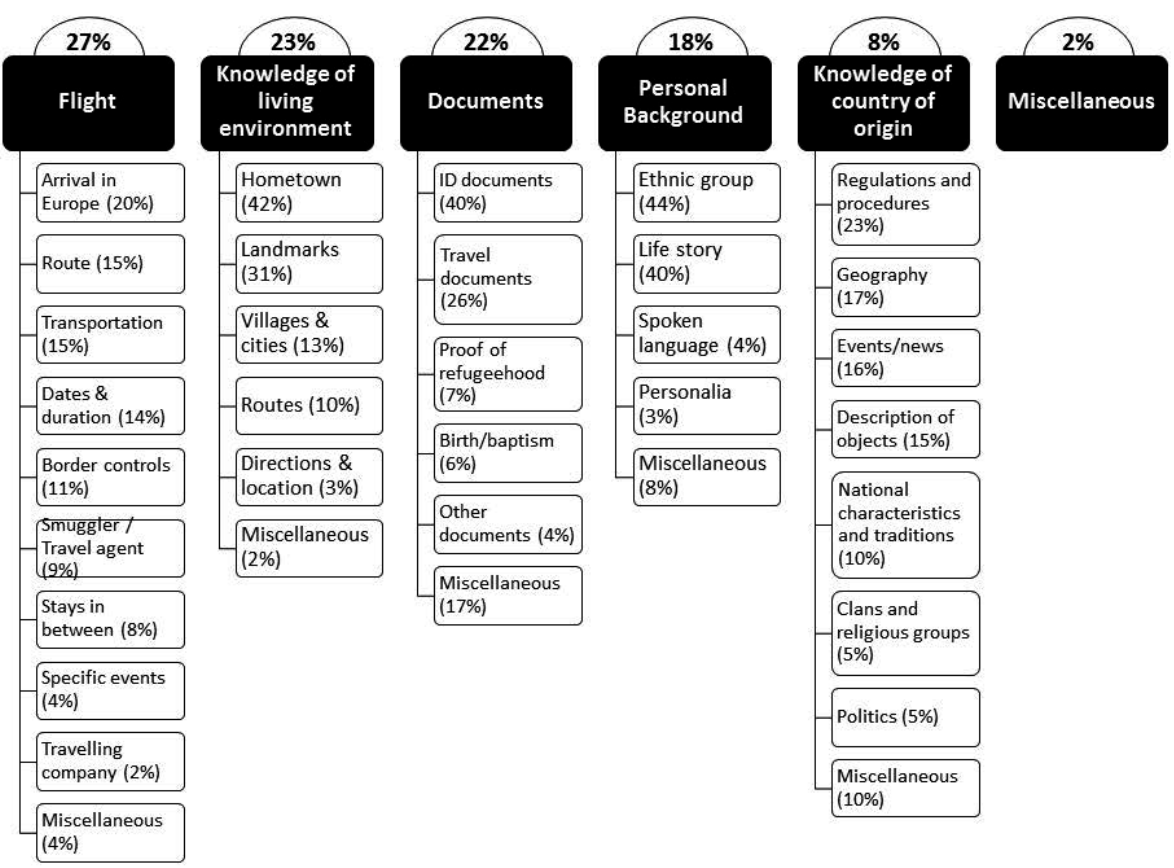

Figure 3. Thematic structure describing the content of the questions asked in the Sudanese cases. Subthemes are displayed below each theme. The themes and subthemes are organized based on their size (i.e., their occurrence in the interviews).

\subsubsection{Flight}

Questions subsumed under the theme flight referred to the period between leaving the country of origin and arriving in Europe. Many questions focused, for example, on the route taken to Europe, the moment of arrival in Europe, the means of transportation used, and the smuggler or travel agent. In both Eritrean and 
Sudanese cases, we found a considerable proportion of questions ( $18 \%$ and $14 \%$ respectively) about specific dates and the duration of events.

\subsubsection{Documents}

The theme documents comprised questions about the documents that the asylum seeker (had) possessed. Applicants were often asked whether they had possessed identity documents or travel documents, and where these documents were now. Sometimes applicants were asked for a description of their identity documents. Other documents that could potentially substantiate their origin, such as marriage certificates, baptism documents, or school passes were also regularly addressed.

\subsubsection{Personal background}

Questions about the life of the applicant in the country of origin, and his or her social identity were combined in the theme personal background. These questions focused on gathering information and assessing knowledge about the applicant's own ethnic background. With other questions an image was sketched of the applicant's life story. For example, questions were asked about where the applicant had lived at specific times during his life, major life events, and his educational and professional background. Questions about language and the nationality of family members were also collated under personal background.

\subsubsection{Knowledge of country of origin}

Questions about the country of origin, rather than the direct living environment, also constituted a theme. The questions tested autobiographical and semantic memory about the home country. Most questions addressed customs and formal proceedings in the country of origin. Applicants were, for example, asked how the military service is organised or how identity documents are obtained in the country of origin. Questions about recent events or news from the country of origin were also regularly asked. Sudanese applicants were sometimes also asked other questions about the country of origin, for example about politics, clans and ethnic groups other than one's own social group, geography, and national characteristics and traditions. They were also asked to describe Sudanese objects, such as vehicles, money, or the flag. 


\subsubsection{Differences between Eritrean and Sudanese cases}

A closer inspection of the proportion of questions constituting each theme shows that the themes are represented differently in the Eritrean and Sudanese cases. Whereas in Eritrean cases 39\% of the questions assessed knowledge of the living environment, that topic was less often addressed in Sudanese cases with $23 \%$. In contrast, in Sudanese cases more attention was paid to the personal background of the applicant ( $18 \%$ as opposed to $8 \%$ in Eritrean cases) and knowledge of the country of origin ( $8 \%$ as opposed to $3 \%$ in Eritrean cases). The different emphasis may be explained by the observation that Sudanese applicants often lived in refugee camps for a considerable time prior to fleeing to Europe, which made their memory for their original living environment less recent.

\subsection{Other observations}

During the coding of questions, some questions stood out because the interviewer's approach seemed either helpful or unhelpful for the applicant to provide a good statement. Several examples will be given below. Note that these are examples that are not necessarily exemplary of the general interviewing style, neither did they recur in each interview.

\subsubsection{Cultural misunderstandings.}

One dialogue illustrated the cultural differences between the interviewer (I) and interviewee $(A)$ :

I: How could you explain to me where I could find your house? I go to Jukma, and then...?

A: When you arrive, you ask the very first person where I live, and then you will be given directions.

I: But there isn't a kind of explanation like 'I live behind the Mosque, just before the hill...?'

A: That we do have. We have very tall trees, so a tree will be indicated.

I: And about your house, can you give such an explanation about that? 
A: There are no trees where I lived with my wife. There is a draw-well close by.

Initially, the answer given by the interviewee did not match the intentions of the interviewer. The interviewer could have stopped there and concluded that the interviewee was vague about where he lived, which would be a negative credibility finding. Instead, the interviewer notices that there might be a difference in how directions are provided in the interviewer's and interviewee's culture and that the applicant may not understand what sort of answer is expected. The interviewer adequately clarifies what information he is searching for. The interviewer eventually elicits the information that there was a draw-well close to the house of the applicant.

\subsubsection{Intuitive assessments}

In asylum cases the language barrier is normally resolved by an interpreter who translates the interview. Sometimes, however, there is no interpreter who speaks the dialect or tribal language of the applicant, and the interview is instead conducted in one of the official languages of the claimed country of origin. Below a dialogue is depicted from such an interview, in which the interviewer tries to assess the applicant's proficiency in the tribal language to inform the credibility assessment:

I: Could you please translate the following sentences for me in your tribal language Fur?

I: "The house is green"

A: Don [House]; Kerro [Green] (phonetic representation)

Since the INS had no Fur speaking interpreter and since the answers were not audio-recorded but merely reported phonetically, the applicant's answers could not be verified. Hence, the answers could not proof or disproof the applicant's origin. Thereby, the question only seems to serve an intuitive assessment of the credibility of the origin claim.

\subsubsection{Complicated questions}

Most questions were posed in clear language and understandable. Sometimes, however, questions were hard to understand. For example: 
"My question was about the West. Imagine that you are in Merandi. The sun rises in the East. You stand with your back towards the direction in which the sun rises. Then you look towards the West. Could you now describe what you see then?"

In order to answer the question correctly, someone has to (1) understand what the interviewer is asking for (i.e., a description of the visible environment from a specific point of view), (2), have a basic understanding of compass points, and (3) conjecture correctly in which direction one ought to look according to the interviewer. In case an unsatisfactory answer is given, for example an inaccurate or a vague description, it will be difficult to rule out that the lack of detail or accuracy was caused by a misconception rather than dishonesty.

\subsubsection{Questions inviting speculation}

Some questions seemed to encourage applicants to give an answer, even if they did not know the answer. At times, the interviewers invited the applicant to speculate: 'Why didn't your father tell you more about that, you think?' At other times they stimulated the applicant to estimate or guess to follow-up an 'I don't know' answer, for instance by asking 'Could you give an estimation?' Asking such questions can convey the message that guessing is alright, also in response to other questions (Fisher, 2010).

\section{DISCUSSION}

The current study is the first in which the style, type, and content of questions asked in real-life asylum interviews are examined. Results show that Dutch asylum officials predominantly ask information gathering questions and only scarcely employ an accusatory or burden communication style. We also found that interviews mainly consist of closed and fact-checking questions, whereas open questions occur less frequent. The analyses of question content revealed that asylum officials assess the credibility of origin claims by testing the applicant's knowledge about the claimed country and area of origin. The findings are evaluated in the light of knowledge about best practice in investigative interviewing. 
Question style was coded to examine how asylum officials approach the interviewees (open-mindedly or sceptically). In line with findings of the vignette study by Van Veldhuizen et al. (in press) we found that most questions are asked in an information gathering style. Using an information gathering approach is good practice, since such a way of questioning generally elicits more accurate information (Hartwig et al., 2005; Vrij et al., 2014) and more cues to deception from interviewees (Meissner et al., 2012; Vrij et al., 2007) than an accusatory approach. In the meantime an information gathering style also makes interviewees feel comfortable (Vanderhallen et al., 2011; Vrij et al., 2006).

The distribution of different question types in the interviews painted a different picture. Dutch asylum officials primarily ask closed and fact-checking questions, thereby delimiting the answers of applicants. No room is given to the asylum seeker to provide a free narrative about his origin. A different balance, with more open-ended than closed questions, would be preferable as these questions generally enhance memory recall and accuracy (Bull, 2010; Fisher, 2010; Milne \& Bull, 2006). Posing more open questions can also positively affect the rapport building between the interviewer and interviewee (Walsh \& Bull, 2012). On a positive note, forced choice and suggestive questions seem to be asked only sporadically.

A greater proportion of open questions was asked in response to fictitious case vignettes (Van Veldhuizen et al., in press). A possible explanation for the divergent findings is that asylum officials are aware that they should ask open questions and are capable of doing so under the controlled circumstances of a vignette study, but that the high cognitive demand of a real interview impairs them to do so in practice. Asking open questions is more cognitively demanding than asking closed questions and requires practice (Memon, Holley, Milne, Koehnken, \& Bull, 1994).

The content of the questions was studied to examine whether asylum officials use a typical set of questions in their credibility assessment of origin. The overlapping themes in the Eritrean and Sudanese case files indicated that, in order to assess origin, asylum officials test the applicants' knowledge about their immediate living environment, the country of origin (for example about customs, news facts, national symbols, and objects) and their descent. Thereby, asylum officials seem to assume that people who genuinely originate from the claimed country of origin have ample knowledge about that country, their hometown, and their ethnic background. 
The question is whether people have such extensive knowledge about their country and town of origin. In 6 out of the 10 Eritrean cases in which the origin claim was contested by the INS after a 'knowledge test', documentary evidence could later prove the origin of the applicant. This implies that truthful applicants may not always be able to answer the knowledge questions satisfactory. Asylum officials may overestimate the capacities of human memory. Take for example the substantial number of questions asking for specific dates or the duration of events. People are generally very poor at remembering such information (Friedman, 2004), and may not be able to answer those questions correctly. Another example is that people may not be able to give a very detailed description of commonly used objects such as their identity documents and the local currency because the specific layout of objects like money is not particularly relevant (Nickerson \& Adams, 1979).

We also identified interviewing tactics that either help or hinder the elicitation of an accurate narrative. We argue that there are risks associated with using the answers to complex questions and questions that invite speculation in a credibility assessment, because when an incorrect answer is given to such questions memory errors and misconceptions cannot be ruled out (Fisher, 2010). Additionally, questions of which the answers can only be intuitively assessed will not result in evidence that can be used to build a case. In contrast, an open mind and alertness to cultural differences can help elicit more accurate narratives (Powell \& Bartholomew, 2003). As has been suggested by previous research, cultural differences may influence the specificity of asylum seekers' statements (Jobson, 2009) and effective communication (e.g., Doornbos, 2006), and may hamper the assessment of truthfulness (Taylor, Larner, Conchie, \& van der Zee, 2014). The example in the current study shows that cultural misunderstandings indeed occur easily, but its consequences can be minimised when interviewers are sensitive to cultural differences and willing to adjust their questions to the applicant.

\subsection{Strengths and limitations}

By analysing questions asked in real cases instead of questions that asylum officials formulated in response to fictitious case vignettes (as did Van Veldhuizen et al., in press) a further insight into what happens in practice is achieved. One advantage of using interview transcripts is that the questions were asked in a realistic setting and affected by factors such as time pressure, the presence of an 
interpreter and the working relationship with the applicant, but without having an extra person observing the interview present in the room. As such, the actual interviewing practice could be evaluated without the potential influence of social desirability induced by the presence of a researcher.

Another advantage of using transcripts was that the context in which the question was asked (i.e., its relation to previous questions and answers) could be taken into account. Within the context, it became easier to code the questions for style. This advantage was reflected in a higher inter-rater agreement for style than in previous research (cf. Van Veldhuizen et al., in press).

A possible downside of using transcripts is that they are made during the interview, and may not always give a verbatim representation of what has been said. However, since the questions are written down before they are translated by the interpreter, we think that the questions are a relatively good rendition of what has been asked by the interviewer. It is by contrast impossible to determine to what extent the questions were also literally translated to the applicant. That is, even when the interviewer poses an open question, the interpreter may translate this into a closed question thereby (unintendedly) delimiting the answer of the applicant. The answers of the applicants were not studied in the present study, but when assessing credibility it should be taken into account that a translation may also affect the kind of answer that is elicited (see also Ewens et al., 2014).

We decided to code individual questions for style, rather than coding the style of the interview as a whole. One of the often-used indicators in coding the style of a full interview is the balance of open versus closed questions, with a high proportion of the latter being indicative of an accusatory style (see e.g., Vrij et al., 2006). Although in the current sample the questions were mostly non-sceptical and therefore coded as information gathering, most of the interviews would probably be coded as accusatory considering the high proportion of closed questions. However, in our operationalization of style and type a clear distinction was made between the two concepts, with the former referring to the way in which the interviewer approaches the interview and the latter referring to the technical characteristics of questions. As such we think that both our results concerning style and type are meaningful.

In the results for style and type, the number of accusatory questions and suggestive questions may have been slightly underestimated because the utterances 
that were statements rather than questions were not analysed. Many of those 71 utterances confronted the applicant with an inconsistency and would probably be coded as accusatory. Other utterances stated 'I repeat the question' and would have been coded as suggestive if analysed. Since this only affects approximately $2 \%$ of the total number of questions, including those questions would not affect the results or the interpretation thereof.

\subsection{Recommendations and future research}

Comparing the findings with scientific knowledge about best practice in investigative interviewing gives rise to several recommendations for practice and future research. To start with, although the style of questioning was generally in line with best practice, the working alliance between interviewer and interviewee may be even further improved by reformulating 'why' questions into 'what' questions. Take for example the question 'Why did you only decide to leave the country on 7 November 2011?' Depending on the manner in which the question is asked, it may be an information gathering or rather a sceptical accusatory question. We would advise reformulating the questions, for example into 'What was the immediate cause for your decision to leave the country on 7 November 2011?'.

Second, asking more open questions will facilitate the assessment of comprehensiveness of a statement. In asylum cases, the applicant's credibility is sometimes undermined by vague statements that lack detail. It is questionable whether that is justified if the observation results of an interview with a disproportionate number of closed questions. If a comprehensive account is expected from the applicant, then the questions asked should also invite the applicant to elaborate. The Dutch court pointed this out in the case of a Somali woman seeking asylum. The judge explicated that if the officials wanted to obtain more elaborated answers fewer closed question should have been used in the interview ("AWB-13_18748," 2013, p. 5).

To increase the proportion of open questions throughout asylum interviews, additional practical training of asylum officials might be needed. We have insufficient insight into the training that asylum officials receive to provide concrete recommendations for improvements. Considering that asylum officials do seem to know that it is best practice to pose open questions (Van Veldhuizen et al., in press), there may not be a problem in the acquisition of knowledge and skill in 
the training, but rather there may be difficulties with applying that knowledge in practice. However, more research - for example focusing on the effectiveness of the training that asylum officials receive - is needed to justify this conclusion.

Third, the validity of the information obtained in the interview may be further improved by incorporating a do-not-guess instruction, emphasizing that interviewees should not guess when they do not know the answer (Fisher, 2010). We encountered different questions that invited the asylum seeker to speculate or give estimations in their answers, and also closed questions seem to stimulate guessing (Waterman, Blades, \& Spencer, 2001). If interviewees start guessing it is difficult to assess to what extent their statements reflect their actual knowledge. Inaccurate answers and inconsistencies may arise from wrong guesses.

Fourth, including a free recall invitation in the interview may also elicit more comprehensive narratives about origin. That way, the interviewee gets the opportunity to tell about his country of origin and living environment without being interrupted (Davis, McMahon, \& Greenwood, 2005; Memon, Meissner, \& Fraser, 2010). A free recall phase is beneficial for several reasons (e.g., more accurate recall, more time to search memory, interviewee's own words and concepts are used, Powell, 2002). A free recall phase is already used by the INS to elicit the persecution story in substantial interviews. The following instruction is used: 'You will now get the opportunity to tell in your own words about the immediate reasons for you to leave your country of origin. I want to ask you to tell as much as possible in a chronological order, and where you can, to include names, places, and dates'.

A similar invitation for free recall may also help the asylum official to tailor the follow-up questions to the experiences and memory of the asylum seeker. In current INS practice, a frame of reference seems to be used to determine what level of comprehensiveness can be expected of the applicant. The frame of reference consists of a short description of the course of life and educational background of the applicant, for instance: 'Young, unmarried man who partly completed primary education. Can read and write. No other education. Worked as farmer with horse and carriage.' The content of the questions, however, seems to be guided mostly by the available Country of Origin Information and the set of questions that are typically asked to assess the credibility of origin claims. The asylum official might locate a river close to the claimed village of origin and therefore asks questions about that river. The risk associated with this approach is that when the applicant 
cannot provide comprehensive statements about the river, it is difficult to determine whether the lack of comprehensiveness is the result of a lie about origin or a genuine lack of knowledge about the river. By eliciting a free narrative about the area of origin, in contrast, the interviewer obtains leads about places and concepts that the applicant has knowledge of. If the applicant spontaneously mentions the river in his free narrative, the asylum official can elaborate on the river in the remainder of the interview.

More scientific knowledge about what people generally know about their country and town of origin would also be valuable. Just like we know that that human memory for certain details, such as peripheral visual details (Conway \& Pleydell-Pearce, 2000) and temporal details (i.e., time and duration, Friedman, 2004 ) is notoriously poor, there may be information about our environment that we typically do or do not remember. Future research could focus on what knowledge truthful claimants generally do and do not have about their hometown. Also, the validity of the knowledge questions typically asked to assess origin could be tested, with validity referring to the extent to which they accurately discriminate between people who are truthful and people who are lying about their origin.

\section{CONCLUSION}

To our knowledge, this is the first study to systematically evaluate the questions asked in real-life asylum cases. Asylum officials seem to assume that testing the knowledge of asylum seekers about their home country aids the credibility assessment of a claim about origin. Asylum seekers are expected to provide much information and details about their living environment, their descent, and their country more in general. When asking for such knowledge and detail, two preconditions should be fulfilled by the immigration service. First, interviewing techniques should be utilized that give the applicant the opportunity to satisfy the requirements of comprehensiveness and high detail. That is the questions asked should be predominantly open and information gathering to encourage the applicant to give comprehensive statements. Second, only knowledge that a genuine applicant can be reasonably be expected to have should be addressed. Looking at current interviewing practice in the asylum procedure, a better balance of open 
versus closed questions in combination with a free recall invitation can increase the amount and accuracy of information obtained for a credibility assessment. In the meantime, more empirical studies are needed to examine what people typically know about their origin. 


\section{REFERENCES}

ACVZ. (2016). De geloofwaardigheid gewogen. Een advies over het onderzoeken, integraal beoordelen en toetsen van verklaringen in de asielprocedure. [Assessing credibility: an advisory report on the examination, integrated assessment and review of asylum seekers' accounts in support of their applications]. De Hague: ACVZ. Retrieved from https://acvz.org/ on September 11, 2016.

AWB-13_18748, No. ECLI:NL:RBLIM:2013:12106 (District Court Limburg, the Netherlands 2013).

Beneduce, R. (2015). The moral economy of lying: Subjectcraft, narrative capital, and uncertainty in the politics of asylum. Medical Anthropology, 34, 551-571. doi:10.1080/014 59740.2015.1074576

Bögner, D., Brewin, C., \& Herlihy, J. (2009). Refugees' experiences of home office interviews: A qualitative study on the disclosure of sensitive personal information. Journal of Ethnic and Migration Studies, 36, 519-535. doi:10.1080/13691830903368329

Braun, V., \& Clarke, V. (2006). Using thematic analysis in psychology. Qualitative Research in Psychology, 3, 77-101. doi:10.1191/1478088706qp063oa

Bull, R. (2010). The investigative interviewing of children and other vulnerable witnesses: Psychological research and working/professional practice. Legal and Criminological Psychology, 15, 5-23. doi:10.1348/014466509X440160

Cameron, H. E. (2010). Refugee status determinations and the limits of memory. International Journal of Refugee Law, 22, 469-511. doi:10.1093/ijrl/eeq041

Clarke, C., \& Milne, R. (2001). National evaluation of the PEACE investigative interviewing course (PRAS/149). Retrieved from London:

Conway, M. A., \& Pleydell-Pearce, C. W. (2000). The construction of autobiographical memories in the self-memory system. Psychological review, 107, 261-288. doi:10.1037/0033-295X.107.2.261

Davis, M. R., McMahon, M., \& Greenwood, K. M. (2005). The efficacy of mnemonic components of the cognitive interview: towards a shortened variant for time-critical investigations. Applied Cognitive Psychology, 19, 75-93. doi:10.1002/acp.1048

DePaulo, B. M., \& Morris, W. L. (2004). Discerning lies from truths: Behavioural cues to deception and the indirect pathway of intuition. In P. A. Granhag \& L. Strömwall (Eds.), The detection of deception in forensic contexts (pp. 15-40). New York: Cambridge University Press.

Doornbos, N. (2006). Op verhaal komen: Institutionele communicatie in de asielprocedure [Telling your story: Institutional communication in the asylum procedure]. Nijmegen, the Netherlands: Wolf Legal Publishers (WLP).

Dublin Regulation 343/2003, L050/01 C.F.R. (2003).

EASO. (2014a). EASO e-learning platform. European Asylum Curriculum. Module 6: Interview techniques. Retrieved from https://ceac.easo.europa.eu/eac/

EASO. (2014b). EASO Practical guid: Personal interview. Retrieved from Malta: http://www. asylumlawdatabase.eu/sites/www.asylumlawdatabase.eu/files/aldfiles/EASO_TheImplementation-of-Art-15c-QD-in-EU-Member-States.pdf

Ewens, S., Vrij, A., Leal, S., Mann, S., Jo, E., \& Fisher, R. P. (2014). The effect of interpreters on eliciting information, cues to deceit and rapport. Legal and Criminological Psychology, Early view (Online Version of Record published before inclusion in an issue), n/a-n/a. doi:10.1111/lcrp.12067 
Fisher, R. P. (1995). Interviewing victims and witnesses of crime. Psychology, Public Policy, and Law, 1, 732-764. doi:10.1037/1076-8971.1.4.732

Fisher, R. P. (2010). Interviewing cooperative witnesses. Legal and Criminological Psychology, 15, 25-38. doi:10.1348/135532509X441891

Fisher, R. P., \& Geiselman, R. E. (2010). The Cognitive Interview method of conducting police interviews: Eliciting extensive information and promoting Therapeutic Jurisprudence. International Journal of Law and Psychiatry, 33, 321-328. doi:10.1016/j. ijlp.2010.09.004

Fisher, R. P., Geiselman, R. E., \& Raymond, D. S. (1987). Critical analysis of police interview techniques. Journal of Police Science and Administration, 15, 177-185.

Fisher, R. P., Milne, R., \& Bull, R. (2011). Interviewing cooperative witnesses. Current Directions in Psychological Science, 20, 16-19. doi:10.1177/0963721410396826

Friedman, W. J. (2004). Time in autobiographical memory. Social Cognition, 22, 591-605. doi:10.1521/soco.22.5.591.50766

Graham, B., Herlihy, J., \& Brewin, C. R. (2014). Overgeneral memory in asylum seekers and refugees. Journal of Behavior Therapy and Experimental Psychiatry, 45, 375-380. doi:http://dx.doi.org/10.1016/j.jbtep.2014.03.001

Granhag, P. A., Hartwig, M., Giolla, E. M., \& Clemens, F. (2014). Suspects' Verbal CounterInterrogation Strategies. In P. A. Granhag, A. Vrij, \& B. Verschuere (Eds.), Detecting Deception (pp. 293-313). Chichester: John Wiley \& Sons, Ltd.

Hartwig, M., Granhag, P. A., Stromwall, L., \& Doering, N. (2010). Impression and information management: On the strategic self- regulation of innocent and guilty suspects. The Open Criminology Journal, 3, 10-16.

Hartwig, M., Granhag, P. A., Stromwall, L., Wolf, A. G., Vrij, A., \& Hjelmsäter, E. R. a. (2011). Detecting deception in suspects: verbal cues as a function of interview strategy. Psychology, Crime \& Law, 17, 643-656. doi:10.1080/10683160903446982

Hartwig, M., Granhag, P. A., \& Vrij, A. (2005). Police interrogation from a social psychology perspective. Policing and Society, 15, 379-399.

Herlihy, J., Jobson, L., \& Turner, S. (2012). Just tell us what happened to you: Autobiographical memory and seeking asylum. Applied Cognitive Psychology, 26, 661-676. doi:10.1002/acp.2852

Herlihy, J., \& Turner, S. W. (2007). Asylum claims and memory of trauma: sharing our knowledge. The British Journal of Psychiatry, 191, 3-4. doi:10.1192/bjp.bp.106.034439

Herlihy, J., \& Turner, S. W. (2009). The psychology of seeking protection. International Journal of Refugee Law, 21, 171-192. doi:10.1093/ijrl/eep004

Horselenberg, R., Merkelbach, H., Crombag, H. F. M., \& Van Bergen, S. (2010). Getuigen helpen herinneren [Helping witnesses to remember]. In P. J. Van Koppen, H. Merkelbach, M. Jelicic, \& J. W. De Keijser (Eds.), Reizen met mijn rechter [Travelling with my judge] (pp. 487-508). Deventer: Kluwer.

Knudsen, E. I. (2007). Fundamental components of attention. Annual Review of Neuroscience, 30, 57-78. doi:doi:10.1146/annurev.neuro.30.051606.094256

Levine, L., \& Edelstein, R. (2009). Emotion and memory narrowing: A review and goal-relevance approach. Cognition \& Emotion, 23, 833-875. doi:10.1080/02699930902738863

Loftus, E. F. (2005). Planting misinformation in the human mind: A 30-year investigation of the malleability of memory. Learning \& Memory, 12, 361-366. doi:10.1101/Im.94705

Meissner, C., Redlich, A., Bhatt, S., \& Brandon, S. (2012). Interview and interrogation methods and their effects on investigative outcomes. Campbell systematic reviews, Article 13. doi:doi:10.4073/csr.2012.13 
Memon, A., Holley, A., Milne, R., Koehnken, G., \& Bull, R. (1994). Towards understanding the effects of interviewer training in evaluating the cognitive interview. Applied Cognitive Psychology, 8, 641-659. doi:10.1002/acp.2350080704

Memon, A., Meissner, C. A., \& Fraser, J. (2010). The cognitive interview: A meta-analytic review and study space analysis of the past 25 years. Psychology, Public Policy, and Law, 16, 340-372. doi:10.1037/a0020518

Milne, R., \& Bull, R. (2006). Interviewing victims of crime, including children and people with intellectual disabilities. In M. Kebbel \& G. Davies (Eds.), Practical psychology for forensic investigations and prosecutions (pp. 7-24). Chichester: John Wiley \& Sons Ltd.

Moore, S. A., \& Zoellner, L. A. (2007). Overgeneral autobiographical memory and traumatic events: An evaluative review. Psychological Bulletin, 133, 419-437. doi:10.1037/00332909.133.3.419

Nickerson, R. S., \& Adams, M. J. (1979). Long-term memory for a common object. Cognitive Psychology, 11, 287-307. doi:http://dx.doi.org/10.1016/0010-0285(79)90013-6

Noll, G. (2005). Introduction: Re-mapping evidentiary assessment in asylum procedures. In N. Gregor (Ed.), Proof, evidentiary assessment and credibility in asylum procedures (pp. 1-12). Leiden, the Netherlands: Koninklijke Brill NV.

Powell, M. B. (2002). Specialist Training in Investigative and Evidential Interviewing: Is it Having Any Effect on the Behaviour of Professionals in the Field? Psychiatry, Psychology and Law, 9, 44-55. doi:10.1375/pplt.2002.9.1.44

Powell, M. B., \& Bartholomew, T. (2003). Interviewing and assessing clients from different cultural backgrounds: Guidelines for all forensic professionals. In David Carson \& R. Bull (Eds.), Handbook of Psychology in Legal Contexts (pp. 625-643). Chichester, Engeland: John Wiley \& Sons, Ltd.

Smeets, T. (2011). Acute stress impairs memory retrieval independent of time of day. Psychoneuroendocrinology, 36, 495-501. doi:http://dx.doi.org/10.1016/j. psyneuen.2010.08.001

Smith, S. M., \& Vela, E. (2001). Environmental context-dependent memory: a review and meta-analysis. Psychonomic bulletin \& review, 8, 203-220. doi:10.3758/BF03196157

Snook, B., Luther, K., Quinlan, H., \& Milne, R. (2012). Let 'em talk!: A field study of police questioning practices of suspects and accused persons. Criminal Justice and Behavior, 39, 1328-1339. doi:10.1177/0093854812449216

Sourander, A. (2003). Refugee families during asylum seeking. Nordic Journal of Psychiatry, 57, 203-207. doi:10.1080/08039480310001364

Strömwall, L. A., Hartwig, M., \& Granhag, P. A. (2006). To act truthfully: Nonverbal behaviour and strategies during a police interrogation. Psychology, Crime \& Law, 12, 207-219. doi:10.1080/10683160512331331328

Tekin, S., Granhag, P. A., Strömwall, L., Giolla, E. M., Vrij, A., \& Hartwig, M. (2015). Interviewing strategically to elicit admissions from guilty suspects. Law and Human Behavior, 39, 244-252. doi:10.1037//hb0000131

Thoresen, C., Lønnum, K., Melinder, A., Stridbeck, U., \& Magnussen, S. (2006). Theory and practice in interviewing young children: A study of Norwegian police interviews 19852002. Psychology, Crime \& Law, 12, 629-640. doi:10.1080/10683160500350546

Tulving, E., \& Thomson, D. M. (1973). Encoding specificity and retrieval processes in episodic memory. Psychological review, 80, 352-373. doi:10.1037/h0020071 
UNHCR. (2011). Handbook and guidelines on procedures and criteria for determining refugee status under the 1951 Convention and the 1967 Protocol relating to the status of refugees. Geneva: UNHCR.

United Nations High Commissioner for Refugees. (2013). Beyond proof, credibility asessment in EU asylum systems. Retrieved from Brussels:

Van Veldhuizen, T. S., Horselenberg, R., Landström, S., Granhag, P. A., \& Van Koppen, P. J. (in press). Interviewing asylum seekers: A vignette study on the questions asked to assess credibility of claims about origin and persecution'. Journal of Investigative Psychology and Offender Profiling.

Van Veldhuizen, T. S., Horselenberg, R., \& Van Koppen, P. J. (2016). Proving identity, origin, and persecution: Credibility assessment in the EU asylum procedure. Manuscript submitted for publication.

Vanderhallen, M., Vervaeke, G., \& Holmberg, U. (2011). Witness and suspect perceptions of working alliance and interviewing style. Journal of Investigative Psychology and Offender Profiling, 8, 110-130.

Vrij, A. (2004). Why professionals fail to catch liars and how they can improve. Legal and Criminological Psychology, 9, 159-181. doi:10.1348/1355325041719356

Vrij, A., Hope, L., \& Fisher, R. P. (2014). Eliciting reliable information in investigative interviews. Policy Insights from the Behavioral and Brain Sciences, 1, 129-136. doi:10.1177/2372732214548592

Vrij, A., Mann, S., \& Fisher, R. P. (2006). Information-gathering vs accusatory interview style: Individual differences in respondents' experiences. Personality and Individual Differences, 41, 589-599. doi:http://dx.doi.org/10.1016/j.paid.2006.02.014

Vrij, A., Mann, S., Kristen, S., \& Fisher, R. P. (2007). Cues to deception and ability to detect lies as a function of police interview styles. Law and Human Behavior, 31, 499-518. doi:10.1007/s10979-006-9066-4

Wagenaar, W. A. (1986). My memory: A study of autobiographical memory over six years. Cognitive Psychology, 18, 225-252. doi:http://dx.doi.org/10.1016/00100285(86)90013-7

Walsh, D., \& Bull, R. (2010). What really is effective in interviews with suspects? A study comparing interviewing skills against interviewing outcomes. Legal and Criminological Psychology, 15, 305-321. doi:10.1348/135532509X463356

Walsh, D., \& Bull, R. (2012). Examining rapport in investigative interviews with suspects: Does its building and maintenance work? Journal of Police and Criminal Psychology, 27, 73-84. doi:10.1007/s11896-011-9087-x

Waterman, A. H., Blades, M., \& Spencer, C. (2001). Interviewing children and adults: the effect of question format on the tendency to speculate. Applied Cognitive Psychology, 15, 521-531. doi:10.1002/acp.741

Wright, A. M., \& Alison, L. (2004). Questioning sequences in canadian police interviews: Constructing and confirming the course of events? Psychology, Crime \& Law, 10, 137154. doi:10.1080/1068316031000099120 


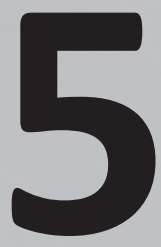

\section{The Provenance of Émigrés:}

The Validity of Measuring

Knowledge of Places

This chapter has been published as:

van Veldhuizen, T. S., Horselenberg, R., Stel, M., Landström, S., Granhag, P. A., \& van Koppen, P. J. (2017). The provenance of émigrés: The validity of measuring knowledge of places. Psychology, Crime \& Law, 23, 553-674. doi:10.1080/106831 6X.2017.1284219 


\section{ABSTRACT}

Establishing the origin of those seeking asylum is essential but difficult as asylum seekers often cannot corroborate their origin claim with documents. The aim of the present study was to assess whether asking knowledge questions, sketch questions and impossible questions are valid methods to determine the veracity of an origin claim. Participants ( $N=105)$ from Tilburg (truth-tellers), Maastricht (partial liars) and Gothenburg (full liars) were asked to convince an interviewer that they originated from Tilburg. Half of them prepared and half of them did not prepare themselves for the interview. They were asked 10 knowledge questions typically asked to assess the credibility of origin claims, 4 impossible questions and 1 sketch question. Participants from Tilburg answered more questions correctly than participants from Maastricht and Gothenburg. Performance also improved with preparation. Even though the results did provide some support for the validity of assessing claims about origin by asking knowledge questions, the differences between the groups were modest, and it was impossible to correctly identify all truth-tellers and liars. Changing the output modality from verbal answering to sketching contributed to the credibility assessment of origin claims, whereas impossible questions were not discriminatory.

Keywords: Credibility assessment, origin claims, asylum procedure, hometown knowledge, unexpected questions 


\section{INTRODUCTION}

Immigration boards have to assess each asylum claim individually (Qualification Directive, 2011). They have to find answers to questions, such as 'Is this man truly gay, and was he therefore persecuted in Senegal?', and 'Could not the Afghan government protect this family from being terrorized by the Taliban?' Note that besides a question about flight motives another element is enclosed: the nationality of the applicant. Origin, referring to both the applicant's nationality and hometown, is an essential element in all asylum cases (Consterdine, Pendry, \& McKinlay, 2013). In order to establish whether the asylum seeker has a genuine fear of persecution, the applicant's origin has to be established. Only then can the asylum story be tested against what is known about the political and human rights situation in the country of origin.

In some cases, origin itself may even constitute a reason for asylum (EASO, 2015). If mere presence in a country may put someone in life-threatening situations, for example due to indiscriminate violence and armed conflicts, EU countries may decide to temporarily grant a protection status to all asylum seekers from that country (Article 15C, Qualification Directive, 2011). Examples of countries to which such policies have been applied are Afghanistan, Iraq, Somalia and Syria (EASO, 2015). In other countries, such as Eritrea, the flight itself may impose a threat on the asylum seeker upon return, because fleeing the country is considered a crime (UK Home Office, 2013).

Proving or disproving claims about origin is not always easy. Determining the country of origin of an applicant is relatively straightforward when someone has a passport or other identity documents. If the documents are authentic, the nationality of the applicant can be established with a reasonable degree of certainty (IND werkinstrcutie nr. 2010/14). However, many asylum seekers cannot provide proof of who they are and where they came from (European Migration Network [EMN], 2013). A lack of proof may be due to several reasons. Asylum seekers may have never possessed identity documents, they may have handed over their documents to smugglers, their documents may be lost or destroyed during the flight, or their documents are forged (Doornbos, 2004; Noll, 2005; van Liempt \& Doomernik, 2006). Between 2007 and 2011 the proportion of undocumented asylum seekers 
ranged from $25 \%$ in Latvia to $94 \%$ in Sweden and Norway (EMN, 2013). For these asylum seekers a credibility assessment of their claim about origin is inevitable.

To establish the credibility of an origin claim, immigration boards pose a set of questions to the asylum seeker about the country and region of origin (Doornbos, 2006; EMN, 2013). Two recent studies showed that, in order to assess the veracity of origin claims, asylum officials ask questions about the applicant's immediate living environment, flight, identity documents, personal background, and country of origin (van Veldhuizen, Horselenberg, Landström, Granhag, \& van Koppen, 2016; van Veldhuizen, Maas, Horselenberg, \& van Koppen, 2016). Applicants may, for example, be asked to name certain landmarks in their city of origin, to describe the route from one place to another, how identity documents can be acquired and what they look like, and what events took place in the country of origin prior to their flight. The applicant's answers to those questions are compared to available information about the country of origin that the authorities assemble in country of origin information (COI) reports (Doornbos, 2006; EMN, 2013; United Nations High Commissioner for Refugees [UNHCR], 2013). If the applicant is able to answer most of the questions, and if the answers are consistent with $\mathrm{COI}$, the origin claim will likely be deemed credible (UNHCR, 2013).

Asylum officials seem to hold the assumption that somebody who truly originates from a specific country or area should also hold ample knowledge about that environment, its customs, and frequently encountered objects (van Veldhuizen, Horselenberg, Landström, et al., 2016; van Veldhuizen, Maas, et al., 2016). This assumption is related to two indicators often used to assess the credibility of statements in the asylum procedure, namely sufficiency of detail and consistency with available specific and general information (UNHCR, 2013).

When considering the capacities of human memory, it is questionable whether this assumption is valid. If the assumption is valid, you would expect truthful applicants to be able to answer a large proportion of the knowledge questions accurately and in detail. In contrast, applicants who lie about their origin should not be able to provide equally accurate and detailed answers. Several memory limitations may conceal this difference between truth-tellers and liars (van Veldhuizen, Horselenberg, \& van Koppen, 2016). First, questions may address knowledge that the applicant does not have because the information was never attended to, or stored, in the first place. People have to pay attention to information in order to 
store it in memory (Chun \& Turk-Browne, 2007; Conway \& Pleydell-Pearce, 2000; Cowan, 1988; Knudsen, 2007). Hence, asking questions about a specific church, river or village in the environment is only sensible if the applicant has memories about those locations. Similarly, in order to be able to provide a statement about the local currency, an applicant has to have used that money. Even if the applicant has used money in his or her home country, it is questionable how much attention has been paid to its lay-out, and thus how detailed the description of the money would be (Nickerson \& Adams, 1979). Second, questions may address episodic knowledge which, despite previously being held by the applicant, has faded by the time of questioning. Memory becomes weaker over time, and the more time passes between the formation of memory and the retrieval, the less likely it is that the applicant will be able to provide a rich statement (Janssen, Rubin, \& St. Jacques, 2011; Nørby, 2015; Wagenaar, 1986). Third, there may be factors hindering retrieval at the time of the interview. If the used retrieval cues diverge from how the information was stored in memory, it may be difficult for the applicant to provide an answer (Smith \& Vela, 2001; Tulving \& Thomson, 1973). For example, an applicant who was a store owner in his country of origin probably stored a mental image of the store from the owner's perspective. As a result, a more comprehensive description of the store may be obtained by asking 'Standing behind the counter and looking into the store, what did you see?' than by asking 'What would I see if I entered your store?' In addition, the stress induced by the interview setting and high stake situation may also hinder a truth-teller to provide a detailed account, since stress impairs memory retrieval (Buss, Wolf, Witt, \& Hellhammer, 2004; Deffenbacher, Bornstein, Penrod, \& McGorty, 2004; Smeets, 2011).

The differences between truth-tellers and liars may be further reduced if liars prepare for the interview. Liars who know that they are expected to have knowledge about their country and area of origin may search for information beforehand, thereby accumulating their knowledge about the alleged country of origin and closing in on truth-tellers.

These factors together will make it more difficult to find questions that truthtellers, but not liars, will be able to answer. Because of these concerns, we tested the validity of the assumption that somebody who truly originates from a specific town also has ample knowledge about that town. Our aim was to examine to what extent truth-tellers can be expected to answer questions about their hometown 
correctly, and to what extent liars are able to improve their performance by preparing for the interview. Correspondingly, our main research question was whether the questions typically used to assess claims about origin are valid, in the sense that they help to distinguish truth-tellers from liars, even when liars prepare for the interview. Despite hypothesizing truth-tellers to be comparatively more knowledgeable about the alleged hometown, we did not expect the currently employed method of credibility assessment to be sufficiently sensitive and specific. Hence, we examined whether a decision criterion could be formulated on the basis of which most genuine applicants would be correctly identified (high sensitivity), whereas few of the lying applicants would be mistakenly identified as genuine (high specificity) (Altman \& Bland, 1994). An additional aim was to develop a new experimental paradigm to evaluate the validity of knowledge questions to assess the veracity of an origin claim.

A secondary purpose was to explore whether lie detection tools that have been found to be effective in law enforcement settings could also be effective in the context of assessing origin claims. In recent years, a cognitive approach to lie detection has been developed (Vrij, Fisher, Mann, \& Leal, 2008; Vrij, Granhag, Mann, \& Leal, 2011). The basic idea behind the approach is that lying is more cognitively demanding than telling the truth, and that liars and truth-tellers use different strategies when being interviewed. Many different techniques can be used to exploit these differences between truth-tellers and liars, and to improve the detection of deception. Examples are increasing cognitive load, encouraging interviewees to say more, and asking unanticipated questions (e.g., Nahari, Vrij, \& Fisher, 2014a; Vrij, Fisher, Mann, \& Leal, 2006; Vrij \& Granhag, 2012; Vrij, Granhag, et al., 2011; Vrij et al., 2009; Vrij, Mann, Leal, \& Fisher, 2010; Vrij, Mann, et al., 2008).

We explored the effectiveness of two different techniques in the assessment of the veracity of origin claims. First, we changed the output modality from providing a verbal answer to drawing a sketch. Previous research has shown that liars and truth-tellers tend to provide an equal number of details when verbally describing an event or the lay-out of a location. In contrast, when asked to draw or sketch the situation or location, liars provide fewer details in the sketch than truth-tellers (Roos af Hjelmsäter, Öhman, Granhag, \& Vrij, 2014; Vrij, Mann, Leal, \& Fisher, 2011). The rationale behind changing the output modality is that liars normally anticipate to answer verbally; asking them to make a sketch is therefore unexpected. 
The benefit of asking unexpected questions is that liars rehearse a story, in which they anticipate to be asked certain questions. They include enough details in their story to appear credible. As long as the questions are expected, this strategy helps liars. When they are asked something unexpected, however, they are less flexible than truth-tellers. Whereas truth-tellers can rely on their memory, liars have to improvise, resulting in less accurate and less detailed answers (Leins, Fisher, \& Vrij, 2012; Leins, Fisher, Vrij, Leal, \& Mann, 2011; Roos af Hjelmsäter et al., 2014). Hence, we hypothesized that changing the output modality would be effective to assess the veracity of origin claims, because truth-tellers can rely on their memory for a place in their home-town, whereas liars probably do not anticipate a sketch question, and therefore may not focus on the lay-out of places during preparation.

Second, we included impossible questions in the interview. In addition to being unexpected, these questions would also be irrelevant, resulting in even truth-tellers not being expected to know the answers. The technique was inspired by a study from Liu et al. (2010), who asked lying and truth-telling children event-irrelevant questions that were difficult - but not impossible - to answer. They asked, for example, 'What did you have in your pocket when you were stung by a bee?' The results showed that lying participants tried to answer these questions more often than truth-tellers. The reasoning behind this is that truth-tellers hold a so-called illusion of transparency (Granhag \& Hartwig, 2008; Kassin, 2005). They think that everybody can read their inner state, and will consequently know that they are telling the truth. As such, truth-tellers feel confident enough to admit that they do not know the answer to a question. Liars, in contrast, employ different strategies to maintain their image (Hartwig, Granhag, Stromwall, \& Doering, 2010). They do not want to appear avoidant, and may therefore be inclined to answer even very difficult questions. We explored the merit of this theory in the context of assessing credibility of origin claims, by posing knowledge questions that are practically impossible to answer correctly (e.g., 'What are the geographical coordinates of Tilburg?'). It was hypothesized that truth-tellers would dare to indicate that they could not answer an impossible question more often than liars. 


\section{METHOD}

\subsection{Participants and design}

A total of 105 participants (52 male; 53 female) were allocated over a 3 (origin: Tilburg vs. Maastricht vs. Gothenburg) ' 2 (preparation: prepared vs. unprepared) quasi-experimental design. All participants had to convince the interviewer that they originated from Tilburg in the Netherlands. Participants from Maastricht and Gothenburg had never visited Tilburg before participating in the study, which was important to preclude that their answers to questions about Tilburg were based on a genuine memory trace. Hence, participants from Tilburg were truth-tellers ( $N$ =42), participants from Maastricht in the Netherlands were partial liars because they could rely on their memory for questions about the Netherlands, but not for questions about Tilburg $(N=24)$, and participants from Gothenburg in Sweden were full liars $(N=39)$. Within each origin condition, participants were randomly assigned to a preparation condition. Participants from Tilburg had been living there for at least a full year ( $\max =27$ years, mode $=3$ years, $M d n=5$ years). One participant from Tilburg was excluded from the analyses because he did not have the Dutch nationality.

Participants from Tilburg $(M=21.90, S D=2.29)$ were younger than participants from Gothenburg $(M=26.82, S D=5.67)$ and Maastricht $(M=28.54, S D=15.1)$. Age was therefore included in the main analyses as a covariate, but it had no influence on any of the analyses reported in the result section. Most participants had finished their secondary education (64.42\%) and were enrolled in a bachelor university programme, $7.69 \%$ of the participants had finished a vocational training, 3.85\% had a diploma from a university of applied sciences, $14.42 \%$ had a BA university degree, and $7.69 \%$ had a MA university degree. The participants rated their English proficiency as good with a mean of $7.13(S D=1.15)$ on a scale from 1 (very poor) to 9 (excellent), and there were no group differences in self-reported English proficiency, $p s>.18$.

\subsection{Rewards and motivation}

We used different rewards at the three locations in order to comply with university rules. Participants in Gothenburg were all included in a raffle to win an Asus Tablet 8.0. Participants in Maastricht and Tilburg could choose between being 
included in a raffle for an Asus Tablet 8.0, receiving a monetary compensation in the form of a $€ 7.50$ gift voucher, or earning a partial course credit. Despite the different rewards, all participants were equally motivated to convince the interviewer, $H(2)=0.43, p>.80$, with a score of $6.80(S D=1.63)$ on a scale from 1 (not at all motivated) to 9 (very motivated). Nevertheless, we decided to include motivation as a covariate because of the unequal variances across the origin groups. Motivation did not affect any of the findings reported in the result section.

\subsection{Procedure and materials}

Participants were recruited in Tilburg, Maastricht and Gothenburg to participate in a study about persuasiveness. They were informed that their main task would be to convince an interviewer about their origin and that they might be asked to lie during the study. Participants signed a consent form and chose a reward for their participation. The study was conducted in English to ensure that all the participants had the same disadvantage of speaking a second language. We also believed that, compared to interviewing the participants in their native language, this would improve external validity of the study, because when interviewed through an interpreter (as is done in asylum interviews) or in a second language, people provide less detailed answers than in their mother tongue (Ewens et al., 2014).

Next, the participants were told that they had to convince an interviewer that they originated from Tilburg in the Netherlands, where they had lived until recently. The principle investigator also explicated whether the participant had to lie or tell the truth. The participants were reinforced by explaining that, depending on their performance in the interview their reward would be doubled (i.e., they were told that if they were persuasive either their monetary reward would be doubled, their chances of winning the tablet would be doubled, or they would receive a double course-credit), or they would have to write an additional statement about their origin. They were asked to fill out their demographic variables and to rate their own English proficiency before continuing.

All participants were told that the interview would be about Dutch habits and traditions, the history of Tilburg and the landmarks in and around the city, and the street plan and geography of Tilburg. Participants in the preparation condition then prepared for the interview with the help of the internet. Google Chrome history viewer showed that they mostly used Wikipedia, Google Maps, and the 
municipality's website for preparation. The participants in the control condition played computer games (Super Mario, Sudoku, Tetris or Space Bubbles). There was an effect of origin on the extent to which the participants who prepared tried to find as much information as possible during the preparation phase, $F(2,49)=3.83$, $p<.03, \eta_{p}{ }^{2}=.14$. Participants from Tilburg $(M=6.24, S D=1.45)$ reported trying less hard than participants from Maastricht $(M=7.55, S D=1.44), p<.05$, but tried equally hard as participants from Gothenburg $(M=7.10, S D=1.25), p=.15$. People from Maastricht and Gothenburg did not differ in their self-reported efforts to search for information, $p=1$. With the means ranging from 6.24 to 7.55 on a 9-point Likert-scale, regardless of their origin, all participants in the preparation condition reported that they had tried relatively hard to find as much information as possible during the preparation time.

After 20 minutes of preparation or playing games, the principle investigator asked participants to fill out a short questionnaire with four questions about the extent to which participants felt ready for the interview (Cronbach's $\alpha=0.81$ ). Participants were then escorted to the interview room (in Gothenburg and Maastricht), or the interviewer was asked to enter the room, and the principle investigator left (in Tilburg).

The interviewers (three different interviewers at each location) followed a strict protocol. They never probed and were given strict instructions about how to respond to questions from the interviewee. The interview consisted of 10 questions typically asked to assess origin claims in the asylum procedure (van Veldhuizen, Horselenberg, Landström, et al., 2016; van Veldhuizen, Maas, et al., 2016), and were therefore considered to be typical questions. Four questions were impossible questions, and for one question we changed the output modality from verbal answering to sketching. An overview of the questions and the order in which they were asked can be found in Table 1.

Participants returned to the principle investigator to complete the final parts of the study. Participants in the preparation condition filled out the preparation questionnaire, consisting of four questions measuring the satisfaction with their preparation. All participants were asked to fill out the post interviewing questionnaire, which started off with questions about their experiences in the interview, motivation and estimations of their own success. For all interview questions, they were then asked to rate to what extent they had anticipated them before the 
interview, and to what extent they felt the questions were relevant to assess the veracity of an origin claim. Participants were thanked for their participation and debriefed.

Table 1 A listing of the questions that were included in the interview in order of appearance in the interview. Behind each question the question type can be found.

\begin{tabular}{|c|c|c|}
\hline No. & Question & Type \\
\hline 1 & $\begin{array}{l}\text { What is the primary religious affiliation in the Netherlands? Please do } \\
\text { not take into account atheists or non-religious people? }\end{array}$ & Typical \\
\hline 2 & Historically, which industry is Tilburg famous for? & Typical \\
\hline $3 A$ & Do you possess a Dutch passport or identification card? & Typical \\
\hline 3B & Please describe in as much detail as possible your Dutch passport to me & Typical \\
\hline 4 & What are the three largest cities surrounding Tilburg? & Typical \\
\hline 5 & What are the geographical coordinates of Tilburg? & Impossible \\
\hline 6 & Please describe as precisely as possible the flag of Tilburg & Typical \\
\hline 7 & Which famous Dutch painter was educated in Tilburg? & Typical \\
\hline 8 & $\begin{array}{l}\text { Imagine that you are standing at City Hall Square, in Dutch called } \\
\text { Stadhuisplein. Someone asks directions by foot to Hill Square, in Dutch } \\
\text { called De Heuvel, how would you explain the route to them? }\end{array}$ & Typical \\
\hline 9 & $\begin{array}{l}\text { How much do the inhabitants of Tilburg on average appreciate the } \\
\text { landscape in their neighbourhoods on a scale from 1, very poor, to 10, } \\
\text { excellent? }\end{array}$ & Impossible \\
\hline 10 & $\begin{array}{l}\text { Please name as many city districts of the municipality of Tilburg as you } \\
\text { know }\end{array}$ & Typical \\
\hline 11 & Please describe as precisely as possible a 20 Euro note & Typical \\
\hline 12 & $\begin{array}{l}\text { How many inhabitants of } 80 \text { years and older did Tilburg have at the 1st } \\
\text { of January 2014? }\end{array}$ & Impossible \\
\hline 13 & $\begin{array}{l}\text { Which important landmark of Tilburg borders directly at the City Hall } \\
\text { Square (Stadhuisplein)? }\end{array}$ & Typical \\
\hline 14 & $\begin{array}{l}\text { Hill square, or in Dutch: the Heuvel, is an important landmark of Tilburg. } \\
\text { Please make a sketch of the square on this form }\end{array}$ & Sketch \\
\hline 15 & Now please with this pen, add all the lampposts in the sketch & Impossible \\
\hline
\end{tabular}

\subsection{Ethics}

The study was approved by the Ethical Review Committee Psychology and Neuroscience (ERCPN) of Maastricht University. In line with ERCPN policies, participants were debriefed orally and in writing.

\subsection{Coding and scoring of interview questions}

All questions were coded by two coders. ${ }^{1}$ The inter-rater reliability was calculated by computing Cohen's Kappa ( $\mathrm{k}$ ) for dichotomous interview items and intra- 
class correlations (ICC) for continuous variables. A third coder clarified differential outcomes.

\subsubsection{Typical questions}

For all the typical questions a score between 0 and 1 was awarded. Answers to questions $1,2,7,8$ and 13 could be either correct (score $=1$ ) or incorrect (score $=0)$. The average inter-rater agreement for these items was $K=0.85$. Answers to questions 4, 6 and 10 could also be partially correct. To compute a relative score for questions 3 and 4 , the number of detail that Dutch people can normally provide in their descriptions of these objects was taken into account. We conducted a pilot study in which 46 Dutch participants described a 20 euro note and their identity documents; 33 participants described their passport and 12 participants described their ID card. The number of details given in the current study was divided by the maximum number of reported details in the pilot study, which was 9 details for the 20 euro note $(M=3.76, S D=1.92), 13$ details for the passport $(M=6.18, S D=2.93)$ and 7 details for the ID card $(M=3.83, S D=1.80)$. The average ICC for the questions with a continuous score was 0.94 .

While coding, we realized that the participants in Tilburg often confused Stadhuisplein (Town Hall Square) with Willemsplein (William's square), which is adjacent to Stadhuisplein. They tried to provide directions from there (question 8) or named a landmark bordering that square (question 13). An independent coder also coded questions with a more lenient approach. As such each participant was awarded both a regular score and a lenient score. The total performance was computed with the regular scores, but the analyses were also conducted with the lenient scores.

\subsubsection{Impossible questions}

For the impossible questions we coded whether or not the participants tried to answer the question or guess, and whether any doubt about the usefulness of the question was voiced. For each impossible question we therefore had an answering score of 0 (no answer) or 1 (answer given) and an expressed doubt score of 0 (no doubt) or 1 (expressed doubt). For the answering score, the average inter-rater agreement was substantial with $K=0.68$. Because expressed doubt turned out to be an unreliable measure with $K=0.51$, we could not interpret those scores and did not analyse them further. 


\subsubsection{Sketch question}

For the sketch question the number of correct details in each sketch was counted. The count comprised the score for that question. The ICC for the two coders was 0.99 .

\section{RESULTS}

\subsection{Validity of typical questions}

\subsubsection{Manipulation checks}

An ANOVA on readiness for the interview was conducted to assess whether prepared participants would also feel more ready for the interview. The analysis yielded a main effect of origin, $F(2,97)=39.55, p<.001, \eta_{p}{ }^{2}=.45$. Participants from Tilburg felt more ready for the interview $(M=5.98, S D=1.06)$ than participants from Maastricht $(M=4.08, S D=1.65), p<.001$, and Gothenburg $(M=3.54, S D=$ 1.16), $p<.001$. Preparation did not affect readiness for the interview, nor was there an interaction between preparation and origin for interview readiness, $p s>.25$.

\subsubsection{Performance on the interview}

An ANCOVA on the overall performance in terms of correct answers during the interview, with origin and preparation as independent variables and age and motivation as covariates, yielded a significant main effect of origin, $F(2,95)=64.36$, $p<.001, \eta p 2=.58$, and a main effect of preparation, $F(1,95)=22.70, p<.001$, $\eta p 2=.19$, but no interaction effect, $p=.73$. The results are displayed in Figure 1. Participants who prepared for the interview provided more correct answers, resulting in higher interview scores $(M=3.97, S D=1.75)$ than participants in the control condition $(M=2.77, S D=1.80)$. Independent of preparation, participants from Gothenburg scored lower $(M=1.88, S D=1.31)$ on the interview than participants from Maastricht $(M=3.27, S D=1.37), p<.001$, who in turn scored lower than participants from Tilburg $(M=4.96, S D=1.87), p<.001$. The effects did not change after conducting the same analyses with the sum score that included the lenient scores for the questions related to Town Hall Square. Truth-tellers seem to 
have more knowledge about the town they claim to be from than liars. Liars can, however, enhance their performance on the interview by preparing.

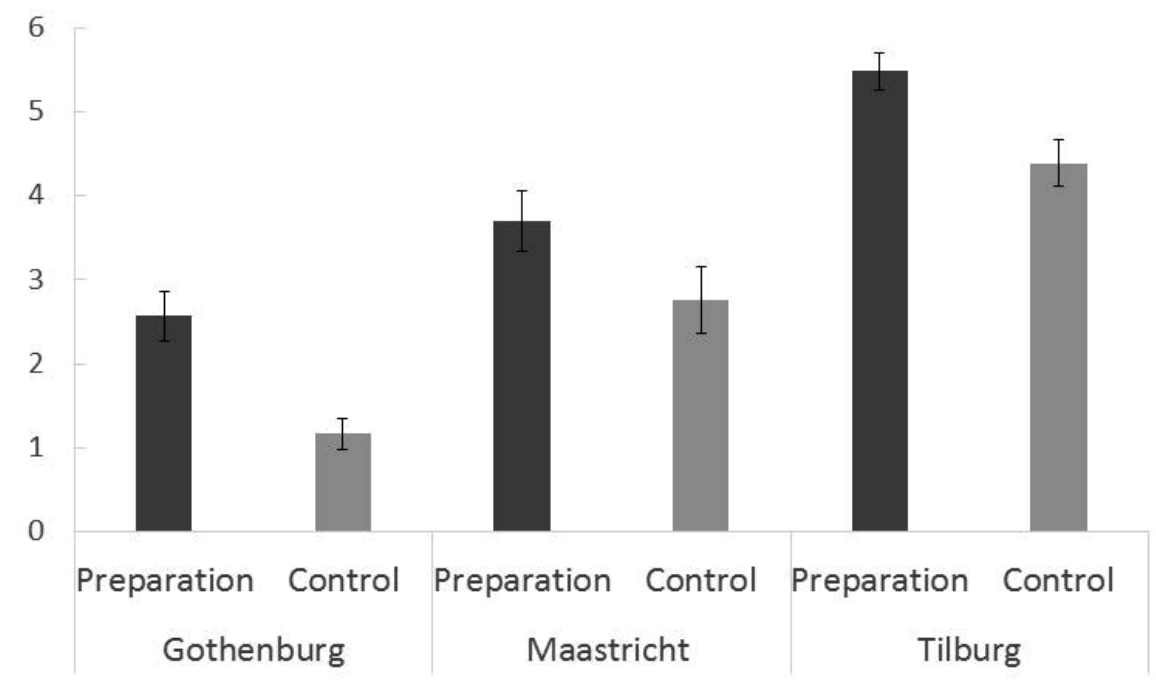

Figure 1. Mean performance scores disaggregated by origin and preparation conditions. Total scores could range from 0.00 to 10.00. Error bars represent standard errors corresponding to the group means.

3.1.2.1 Sensitivity and specificity of the interview. In an actual interview, the veracity of an individual claim has to be assessed. The percentages of applicants who would be identified as truthful are given for different cut-off values in Table 2. It is not possible to adopt a cut-off value that results in a $100 \%$ correct classification of both truth-tellers and liars. With a cut-off value of two correct answers perfect sensitivity is reached, but $70 \%$ of the prepared liars would also pass the test, resulting in a specificity of only $30 \%$. In contrast, a cut-off score of five correct answers results in perfect specificity, but then $63 \%$ of the unprepared truth-tellers would be falsely identified as liars, resulting in a sensitivity of only $37 \%$. Thus, accurately differentiating between individual truth-tellers and liars based on knowledge about the hometown seems difficult. 
Table 2 Percentages of participants in each condition who would 'pass' the origin interview for different cut-off performance scores on the interview.

\begin{tabular}{ccccccc}
\hline & \multicolumn{2}{c}{ Gothenburg } & \multicolumn{2}{c}{ Maastricht } & \multicolumn{2}{c}{ Tilburg } \\
\hline $\begin{array}{c}\text { Cut-off } \\
\text { value }\end{array}$ & $\begin{array}{c}\text { Control } \\
\%\end{array}$ & $\begin{array}{c}\text { Preparation } \\
\%\end{array}$ & $\begin{array}{c}\text { Control } \\
\%\end{array}$ & $\begin{array}{c}\text { Preparation } \\
\%\end{array}$ & $\begin{array}{c}\text { Control } \\
\%\end{array}$ & $\begin{array}{c}\text { Preparation } \\
\%\end{array}$ \\
\hline 8 & & & & & & 0.0 \\
7 & & & & & 0.0 & 9.5 \\
6 & & & 0.0 & 0.0 & 5.3 & 28.6 \\
5 & & 0.0 & 9.1 & 15.4 & 36.9 & 66.7 \\
4 & 0.0 & 15.0 & 18.2 & 38.5 & 63.2 & 95.2 \\
3 & 5.3 & 35.0 & 36.4 & 76.9 & 78.9 & 100.0 \\
2 & 10.6 & 70.0 & 72.7 & 84.6 & 100.0 & 100.0 \\
1 & 57.9 & 90.0 & 100.0 & 100.0 & 100.0 & 100.0 \\
\hline
\end{tabular}

3.1.2.2 Performance on individual questions. It was also explored whether certain questions in the interview were more discriminatory than others. Since there were no significant interaction effects between origin and preparation for any of the questions, all $p s>.05$, the focus will be on the main effects.

For the questions with a continuous outcome, ANOVAs or - if the assumption of equal variances across groups was violated - Kruskal-Wallis and Mann-Whitney $\mathrm{U}$-Tests were conducted. The results, as can be seen in Table 3, show that even though questions 6 (description of the Tilburg flag) and 10 (the naming of town districts) did discriminate between people from Gothenburg and Tilburg, they could not discriminate between people from Maastricht and Tilburg. Furthermore, preparation enhanced performance on these questions. Therefore, these questions do not seem to be valid.

Question 11 (naming three surrounding cities) seems valid. Most participants in Tilburg could name all three cities correctly, and their score on this question was significantly higher than the scores of people from Maastricht and Gothenburg. Preparation did not enhance performance on this question.

Since questions 3 (describing identity documents) and 4 (describing the 20 Euro note) were about Dutch objects, people from Maastricht should have been able to rely on their memory for these questions and answer these questions truthfully. Indeed, people from Maastricht and Tilburg could describe the 20 Euro note in equal detail, and their descriptions were significantly more detailed than those from people from Gothenburg, where the local currency is the Swedish Krona. Contrary to expectations, participants in Tilburg gave a more detailed description of 
their identity documents than people from both Maastricht and Gothenburg. Thus, in the description of the identity documents, an unexpected difference between the participants from Tilburg and Maastricht emerged.

For questions with dichotomous outcomes, logistic regression analyses were conducted in which participants from Tilburg were compared to participants from Gothenburg (GOT vs. TIL) and Maastricht (MAAS vs. TIL). The results (see Table 4) showed that performance on the questions about religion and history could be predicted by preparation. Correct answers on the other questions could not be predicted by preparation, and were more valid to distinguish between truth-tellers and liars. The odds that participants from Gothenburg and Maastricht would correctly name Van Gogh as the painter who was educated in Tilburg were respectively $82 \%$ and 79\% lower than the odds that participants from Tilburg would answer that question correctly. Similarly, with the lenient coding scheme described in the method section, the odds that participants from Tilburg would provide correct directions in response to question 8 were approximately 95\% higher than for participants from Maastricht and Gothenburg. The scores obtained with the strict coding scheme were analysed with chi-squared analyses and followed a similar pattern. Accurate directions were more often than expected given by people from Tilburg, $z=4.40, p<.001$, and less often than expected by people from Gothenburg, $z=-2.80, p<.01$, and Maastricht, $z=-2.20, p<.05$. Question 13 (naming a landmark) did not result in any significant differences between the origin groups when a strict coding scheme was used. With a more lenient coding scheme, the odds that participants from Gothenburg and Maastricht named a correct landmark were $99 \%$ and $76 \%$ lower than the odds that participants from Tilburg gave a correct answer.

Table 3 Means, standard deviations, and test outcomes of the scores on the questions with a continuous score between 0 and 1 broken down for origin and preparation.

\begin{tabular}{llcccccccccccc}
\hline & Question & \multicolumn{2}{c}{ Gothenburg } & \multicolumn{2}{c}{ Maastricht } & \multicolumn{2}{c}{ Tilburg } & \multicolumn{4}{c}{ Control } & \multicolumn{3}{c}{ Preparation } \\
\hline No. & Type & $M$ & $S D$ & $M$ & $S D$ & $M$ & $S D$ & Origin & $M$ & $S D$ & $M$ & $S D$ & Prep. \\
\hline 3 & ID documents & $0.16^{\mathrm{a}}$ & 0.11 & $0.25^{\mathrm{a}}$ & 0.1 & $0.43^{\mathrm{a}}$ & 0.12 & $p<.001$ & 0.26 & 0.14 & 0.25 & 0.13 & n.s. \\
4 & 20 Euro & $0.19^{\mathrm{a}, \mathrm{b}}$ & 0.16 & $0.31^{\mathrm{a}}$ & 0.15 & $0.34^{\mathrm{b}}$ & 0.14 & $p<.001$ & 0.30 & 0.17 & 0.25 & 0.16 & n.s. \\
6 & Flag* & $0.09^{\mathrm{a}}$ & 0.28 & 0.08 & 0.15 & $0.21^{\mathrm{a}}$ & 0.31 & $p<.04$ & 0.05 & 0.14 & 0.21 & 0.33 & $p<.005$ \\
10 & Districts* & $0.13^{\mathrm{a}}$ & 0.18 & 0.23 & 0.24 & $0.33^{\mathrm{a}}$ & 0.21 & $p<.001$ & 0.15 & 0.22 & 0.30 & 0.18 & $p<.001$ \\
11 & Cities* & $0.03^{\mathrm{a}}$ & 0.13 & $0.65^{\mathrm{a}}$ & 0.33 & $0.94^{\mathrm{a}}$ & 0.15 & $p<.001$ & 0.51 & 0.45 & 0.56 & 0.45 & n.s. \\
\hline
\end{tabular}

Note: Superscripts in rows indicate which origin groups scored significantly differently from each other. Means with the same superscript differ. Asterisks indicate that for these variables Levene's test was significant. For these variables we used Kruskal-Wallis tests to assess the ef- 
fect of origin, and followed up with three Mann-Whitney U-tests. For the follow-up we used a Bonferroni correction. The effects of origin were assessed with a Mann Whitney $U$ test.

Means, standard deviations, and test outcomes of the scores on the questions with a continuous score between 0 and 1 broken down for origin and preparation.

Table 4 Percentages of correct answers and corresponding odd ratios on the dichotomous questions for the origin groups and preparation groups.

\begin{tabular}{|c|c|c|c|c|c|c|c|c|c|}
\hline \multicolumn{2}{|r|}{ Question } & \multicolumn{3}{|c|}{ Origin } & \multicolumn{2}{|c|}{$\operatorname{Exp}(B)$} & \multicolumn{2}{|c|}{$\begin{array}{l}\text { Preparation } \\
\text { condition }\end{array}$} & \multirow{2}{*}{$\begin{array}{c}\text { Exp (B) } \\
\text { Preparation } \\
\text { vs. control }\end{array}$} \\
\hline No. & Type & $\begin{array}{c}\text { GOT } \\
\%\end{array}$ & $\begin{array}{c}\text { MAAS } \\
\%\end{array}$ & $\begin{array}{l}\text { TIL } \\
\%\end{array}$ & $\begin{array}{c}\text { GOT } \\
\text { vs. TIL }\end{array}$ & $\begin{array}{l}\text { MAAS } \\
\text { vs. TIL }\end{array}$ & $\begin{array}{c}\text { Control } \\
\%\end{array}$ & $\begin{array}{c}\text { Preparation } \\
\%\end{array}$ & \\
\hline 1 & Religion & 36 & 63 & 59 & 0.26 & n.s. & 38 & 63 & 2.96 \\
\hline 2 & History & 56 & 67 & 88 & 0.11 & 0.18 & 51 & 89 & 9.77 \\
\hline 7 & Painter & 33 & 38 & 66 & 0.17 & 0.20 & 40 & 54 & n.s. \\
\hline \multirow[t]{2}{*}{8} & Dir_strict & 0 & 0 & 51 & \multicolumn{2}{|c|}{$\begin{array}{c}p<.001, V= \\
.62^{*}\end{array}$} & 20 & 20 & n.s. ${ }^{*}$ \\
\hline & Dir_lenient & 8 & 8 & 68 & 0.05 & 0.05 & 34 & 30 & n.s. \\
\hline \multirow{2}{*}{13} & LM_strict & 3 & 8 & 15 & n.s. & n.s. & 4 & 13 & n.s. \\
\hline & LM_lenient & 18 & 33 & 68 & 0.10 & 0.24 & 46 & 63 & n.s. \\
\hline
\end{tabular}

Note: GOT stands for Gothenburg, MAAS stands for Maastricht, and TIL stands for Tilburg. The asterisk indicates that a chi-squared analysis was conducted to assess group differences, because complete separation prevented the use of logistic regression analyses.

\subsection{Alternative lie detection techniques}

\subsubsection{Manipulation checks}

An ANOVA on self-rated cognitive demand with preparation and origin as independent variables yielded no effects, all $p s>$.38. Truth-teller and liars found the interview equally demanding with a mean score of $6.05(S D=1.90)$ on a scale from 1 (not at all) to 9 (very much).

As intended, unanticipated questions were truly experienced as unanticipated. A mixed measures ANOVA with question type (typical vs. unanticipated questions) as a within-subjects variable and origin and preparation as between-subject variables yielded a significant interaction effect between question type and preparation $F(1,96)=4.41, p=.038, \eta_{p}^{2}=.04$. The typical questions were somewhat anticipated, regardless of whether participants were prepared $(M=5.10, S D=$ $0.15)$ or unprepared $(M=5.38, S D=0.16), F(1,96)=1.69, p=.18$. Unanticipated questions were always less expected than the typical questions, but even less 
expected for participants who prepared $(M=2.95, S D=0.17)$ than for participants who did not prepare $(M=3.76, S D=0.18), F(1,96)=11.25, p=.001, \eta_{p}^{2}=.11$. Thus, it is unlikely that participants prepared for the questions that were intended to be unanticipated.

A mixed measures ANOVA with question type as a within-subjects variable and origin and preparation as between-subjects variables only yielded a significant main effect of question type, $F(1,98)=225.56, p<.001, \eta_{p}{ }^{2}=.70$, indicating that questions intended as typical were rated to be more relevant to assess truthfulness of an origin claim $(M=6.43, S D=0,93)$ than impossible questions $(M=3.68$, $S D=1.76)$. The mean of 3.68 on a 9-point scale shows that, as intended, people perceived the impossible questions as moderately irrelevant.

\subsubsection{Changing output modality}

Because the assumption of equal variances was violated, a Kruskal-Wallis test was used to assess the relation between group membership and number of details in the drawing of Hill Square. Origin was significantly related to the number of correct details in the sketch, $H(2)=67.31, p<.001$. Mann-Whitney U-tests with a Bonferroni correction (criterion: $\alpha=.017$ ) yielded that participants from Tilburg drew more details in the sketch $(M=5.63, S D=3.27)$ compared to participants from Gothenburg $(M=0.13, S D=0.47), U=113.00, z=-7.11, p<.001, r=-.79$, and participants from Maastricht $(M=0.25, S D=0.68), U=79.00, z=-5.80, p<.001$, $r=-.72$. The drawings of people from Gothenburg and Maastricht were equally detailed, $U=427.50, p=.29$. Preparation had no effect on the number of detail in the sketches, $U=1324.00, p=.85$. Based on the drawings, the origin groups could be accurately distinguished from each other.

\subsubsection{Impossible questions}

An ANOVA with origin and preparation as independent variables on the eagerness to answer impossible questions showed that, contrary to our expectations, there were no differences between truth-tellers and liars in the eagerness to answer impossible questions. All participants were equally eager to answer the impossible questions, regardless of their origin, preparation or their interaction, ps $>.17$. On average participants tried to answer $70 \%(S D=15 \%)$ of the impossible 
questions. Most participants ( $n=71,68 \%$ ) tried to answer three of the four impossible questions.

\section{DISCUSSION}

We found some support for the validity of asking knowledge questions about the hometown and country as a tool for credibility assessment of origin claims. Truthful participants had more knowledge about the alleged hometown than lying participants. These results seem promising, but there are several reasons to be cautious to conclude that the questions typically asked in asylum interviews can help to determine whether an individual applicant is veracious. The number of questions that truth-tellers are able to answer correctly is modest, and liars can come close to truth-tellers by preparing for the interview.

\subsection{Validity of typical questions}

Overall, people from Tilburg (truth-tellers) performed better on the interview than people from Maastricht (partial liars), who in turn outperformed people from Gothenburg (full liars). At first sight, the assumption that individuals who truly originate from a specific town or area have ample knowledge about that place seems to be valid. Despite the group differences, however, the unprepared truth-tellers had only limited knowledge about their hometown. On average, they only answered less than half of the questions correctly. In addition, unprepared truth-tellers only gave one or two correct answers more than prepared liars. It is questionable whether this difference is sufficient to be able to recognize a truthtelling or lying applicant in an asylum interview.

A remedy could be to eliminate ineffective questions and to focus on the most discriminatory questions. For example, the ability to describe a 20-euro note was unaffected by preparation for the interview, and as intended people from Tilburg and Maastricht were able to provide more detailed answers than people from Gothenburg. The question thereby seems to be a relatively effective question to detect truthfulness. Yet, the descriptions from participants in both Tilburg and Gothenburg were neither very detailed, nor were they very far apart. It will be hard to correctly identify an individual as a truth-teller or a liar based on the little 
information in the answers, and taking into consideration the small difference between them. Truth-tellers did not give very detailed descriptions. They would for example state that the 20 euro note is rectangular, blue and has the number 20 on it. Of these three details, the rectangular shape and the fact that the number 20 is on the banknote may also be logically inferred by people who have never seen the 20-euro note (Nickerson \& Adams, 1979). Thus even the questions that were statistically speaking discriminatory, may not always be effective for individual decision making.

\section{Truth about origin claim}

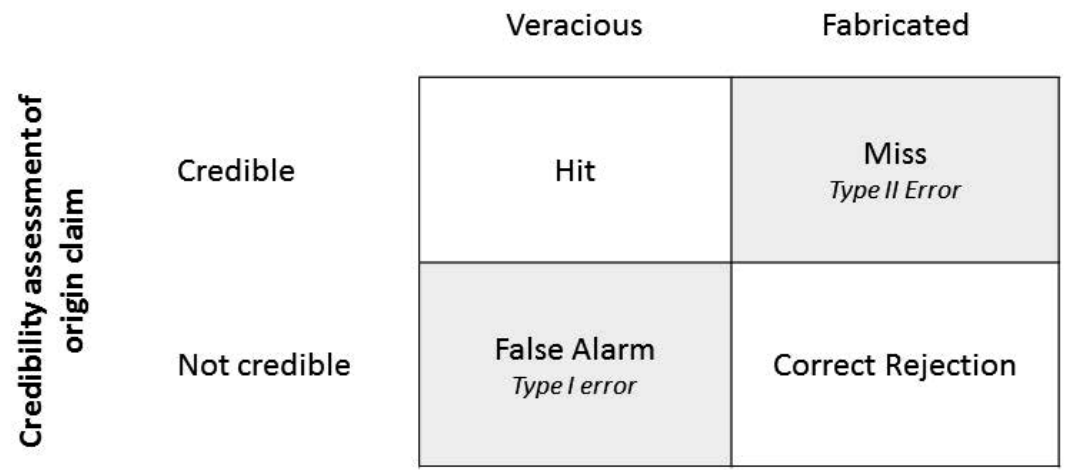

Figure 2. An illustration of possible outcomes in the credibility assessment of a claim about origin in terms of signal detection theory.

Besides only knowing the answer to a modest number of questions, truthtelling participants also did not give a particularly detailed description of common Dutch objects. The low number of details could indicate that people have limited knowledge about these objects, or that they do not recall or report all the knowledge that they have. A limited knowledge about common objects is not too surprising, because people probably only pay attention to and remember characteristics that are relevant when using the object (Chun \& Turk-Browne, 2007; Nickerson \& Adams, 1979), such as the colour blue to quickly distinguish a 20-euro note from other banknotes.

Moreover, people may not report all the knowledge that they have in an interview setting. In the pilot study, people gave a slightly more detailed description of a 20 euro note and their identification documents than in the current study. Possible 
explanations for underreporting in the present study may be that, even for truthful participants, the interview was quite stressful, and that the stress induced by the interview impaired memory recall (Deffenbacher et al., 2004; Smeets, 2011). The stress experienced by applicants in real asylum interviews may be even higher (e.g., Bögner, Brewin, \& Herlihy, 2009). Hence, stress is a factor that should be taken into account when evaluating the detail in asylum seekers' statements. An alternative explanation for underreporting is that the instructions about how much detail was required were unclear, and that the detail of the descriptions would improve with clear instructions to report everything (e.g., Memon, Meissner, \& Fraser, 2010).

People may also appear less knowledgeable than they are when there is a misunderstanding about concepts. In the interview, two questions were asked in relation to Stadhuisplein. We realized that people from Tilburg often thought that the interviewer was referring to Willemsplein. In common parlance, those squares are often considered one square. The answers to the questions about Stadhuisplein may therefore strictly speaking be incorrect, even though the participant does have knowledge about the environment. Terminological misunderstandings can easily occur and could potentially lead to an incorrect assessment of the knowledge of an applicant about his hometown.

Unclear instructions or terminological misunderstandings should be avoided as much as possible, as they may obscure the differences in knowledge about the alleged hometown that exist between truth-tellers and liars. To correctly assess how knowledgeable a person is about his hometown and commonly used objects, it may be beneficial to provide clear instructions about the comprehensiveness that is expected of answers, and to include a free recall phase in the interview about origin. Instructions that encourage the interviewee to report everything they know may help to obtain more information by reinforcing the memory of truth-tellers (Memon et al., 2010). It could also magnify differences between truth-tellers and liars, because truth-tellers want to be forthcoming whereas liars may want to keep their story concise (Granhag, Hartwig, Giolla, \& Clemens, 2014). Explicitly communicating that the goal of the interview is to elicit as much verifiable information as possible prompts truth-tellers to provide more verifiable details, whereas liars tend to be unable to do so (Nahari et al., 2014a; Nahari, Vrij, \& Fisher, 2014b). Future research could examine the effectiveness of such instructions in the context of assessing the veracity of origin claims. 
A free recall phase could also reinforce truth-telling applicants to say more. A free recall allows the interviewee to identify topics that he or she has knowledge of and is able to talk about. This will provide the interviewer with topics that can be questioned further. In current asylum interviews, questions are mainly asked about places and objects that the interviewer deems relevant. It is uncertain whether truth-telling applicants have knowledge about these places and objects, and too little information is elicited to assess the credibility of their origin claim. A free recall phase helps the interviewer to adjust the questions asked to the applicants' experiences and life in the country of origin. Moreover, the terms provided by the interviewee in the free recall phase can be used in the remainder of the interview, thereby reducing the chances of terminological misunderstandings.

Truth-tellers may also be identified more easily with recognition tasks rather than recall tasks. Recognition is generally easier for people than recall, because it requires less depth of processing of the information (e.g., Yonelinas, 2001). Correspondingly, it may be easier for truthful asylum applicants to pick the correct banknote from five different notes, than to describe that banknote in detail from memory (Nickerson \& Adams, 1979). For a lying applicant, who has never seen the banknote, this may be more difficult. In order for the recognition task to be valid, the task has to be unbiased just like line-up procedures for eye-witness identifications (e.g., Brewer \& Palmer, 2010; Wells \& Olson, 2003). Consider, for example, a recognition task with the 20 euro banknote. In a valid recognition task, there should be at least 5 alternatives, such that an identification of the real 20 euro note due to chance is highly unlikely (Brewer \& Palmer, 2010). The alternatives should also be plausible alternatives, meaning that none of the banknotes should stand out (Brewer \& Palmer, 2010). In addition, a lying applicant should never have seen the actual 20 euro note, because vague familiarity with the object may lead to a correct identification that is not indicative of truthfulness (Brewer \& Palmer, 2010). Other conditions for a valid recognition task include that the instructions are unbiased (i.e. not steering the interviewee into a particular direction) and that the test-taker does not know the correct answer (Brewer \& Palmer, 2010). Meeting all these conditions may not always be feasible in an asylum interview. Yet, if conducted properly, recognition tasks could potentially be a useful tool for a credibility assessment. Whether or not it is possible to distinguish between truthful 
and fabricated origin claims based on recognition tasks should be tested in future research.

\subsection{Effectiveness of other lie detection techniques}

In line with previous research (Leins et al., 2012; Roos af Hjelmsäter et al., 2014), changing the output modality was an effective technique to exploit differences between truth-tellers and liars. The participants from Tilburg drew more detailed sketches than participants from Maastricht and Gothenburg, who mostly produced sketches without a single correct detail. The benefits of using drawings in asylums interviews can be twofold. Besides aiding the recognition of fabricated origin claims, drawings may also help truth-tellers to remember more correct details (Dando, Wilcock, Behnkle, \& Milne, 2010; Dando, Wilcock, \& Milne, 2009).

On a cautious note, it must be acknowledged that all of our participants were from Northern Europe and relatively highly educated. There is some evidence suggesting that ecological and cultural differences influence the development of spatial awareness (Berry, 1971; Segall, Campbell, \& Herskovits, 1963). Before using drawings as a tool in the credibility assessment in asylum cases, it should be examined whether people from non-western cultures have an equal ability to draw a 2D visual representation of a physical environment as our western participants.

The use of impossible questions did not help to distinguish truth-tellers from liars. In contrast with prior research (Liu et al., 2010), all participants seemed to be eager to answer and give an estimation or guess. It should be noted that our impossible questions differed from the questions used by Liu and colleagues in one important respect: the accuracy or truthfulness of the answers to the questions that Liu et al. (2010) used could not be validated, whereas the answers to the questions we used were, in principle, verifiable. As a consequence, truthful participants in Liu et al.'s study may have felt more confident to admit not knowing the answer compared to our participants, because the interviewer could not know the answer either. Truth-tellers in the current study might have felt that admitting to lack this publicly available knowledge would infringe on their persuasiveness. Speaking against this reasoning is the finding that the impossible question of which the answer could in principal most easily be checked, that is, "What are the geographical coordinates of Tilburg?", was the question to which most truthful participants admitted not knowing the answer. In contrast, the questions to which 
the answers were less easily accessible (e.g., "How do the inhabitants of Tilburg on average appreciate the landscaping in their neighbourhood?") more often elicited an answer or a guess. Nevertheless, it might be worthwhile to test the validity of different kinds of impossible questions in the context of credibility assessments of origin claims in future studies.

Alternatively, the impossible questions may not have elicited differential responses from truth-tellers and liars in the current study because our truth-tellers experienced a high cognitive load. Whereas liars are normally thought to be higher mentally taxed than truth-tellers (Vrij, Fisher, et al., 2008; Vrij, Granhag, et al., 2011), our truth-tellers and liars found the interview equally cognitively demanding. Due to the difficulty that truth-tellers experienced in the interview, they may have been as eager to show off their knowledge as our lying participants. Although the high cognitive demand experienced by the truth-tellers is atypical compared to other lie detection studies, it may correspond to the factual situation in the asylum procedure. Truthful asylum seekers probably experience a high cognitive demand, due to cultural differences, language differences, and the high stakes associated with the outcomes of the interview (UNHCR, 2013). Combined with the burden of proof, that lies with asylum seekers rather than with authorities (Qualification Directive, 2011), this may instigate truthful asylum seekers to answer each question and guess if they can. It should therefore be emphasized in asylum interviews that it is better to admit to not know an answer than to guess.

\subsection{Strengths and limitations}

The present study was the first experimental study to assess the validity of questions typically asked in asylum interviews. One advantage of using a quasiexperimental paradigm was that we could approach the ground truth about origin. In order to test what people who rely on genuine memory know about their hometown, we used participants whose origin could be established with a reasonable degree of certainty. Another advantage was that we could control for the fact that liars may prepare. In a natural setting, there is no way of knowing to what extent asylum seekers have prepared for the interview.

Being the first study of its kind there were also some methodological limitations. Firstly, we relied on self-reports to establish the origin of the participants. As such, we cannot be completely certain about their origin. We dealt with this 
limitation by already asking participants about their origin during their recruitment, before they knew that origin had a central place in the study. At that time, participants had no obvious reason to lie about their origin. In a replication of the study, participants could be asked to bring identification documents to the study to establish the ground truth with complete certainty.

Similarly, we used self-reports to establish whether our lying participants had ever visited Tilburg. Participants could potentially have lied. To minimize the chance of lying, participants were asked whether they had ever visited Tilburg prior to informing them about the purpose of the study. In Maastricht, we asked potential participants to fill out a pre-study questionnaire on which they had to indicate which of the 10 largest Dutch cities they had ever visited. Only those who did not tick the box next to Tilburg were invited for participation in the study. There was no reason to lie about a visit to Tilburg, and we assume that our participants were truthful about this matter. Still, the results should be interpreted with this limitation in mind.

Secondly, the interviewers and the coders were not blind to the origin condition. It could be the case that coders were more lenient or stricter if they knew that a participant was lying. A difficulty with blind coding was that coders could have inferred from the videos where the interview was conducted, for example, due to the fact that the interview rooms were different at the different test-locations, but also because of differences in English accents of people from Gothenburg, Maastricht and Tilburg. We used strict coding schemes to account for this issue and believe that this minimized the potential influence of the coders' knowledge on the scores as much as possible.

A third limitation of the current study was that we conducted it among populations who do not share a language. In real asylum interviews, someone who would claim to be from the Netherlands without speaking a word of Dutch, would not be very credible. Our Swedish participants would therefore not be very credible in a real asylum interview. As we used strict coding schemes, we do not think that the scoring of the participants' answers was in any way influenced by the language differences. However, future studies may design a more realistic setting by using truth-tellers and liars who share a language, for instance Spanish-speaking Chileans and Spanish speaking Ecuadorians. If interviewees share a mother tongue, an 
interpreter may also be introduced to the experiment to translate the interviews. With an interpreter, the ecological validity of the study can be further increased.

Fourth, it proved difficult to find people in Maastricht who had never visited Tilburg. As a result we only had a limited number of participants in the partial liars' condition. Because of the small sample of partial liars, we checked whether the results would change without this group. The results were similar if the group was excluded from the analyses, but the results regarding partial liars should nevertheless be interpreted with caution.

Finally, the process of preparation was simplified. Preparation did not make people feel more ready for the interview. Delving into the preparation experiences, it was revealed that especially liars found preparation difficult, and they indicated that they had too little time to prepare. Perhaps the preparation phase confronted liars with all the information that they did not have, and overwhelmed them rather than making them feel more prepared. In real life, liars may prepare for a longer period of time. Yet even with the limited preparation time, preparation did improve performance on the interview.

\section{CONCLUSION}

In conclusion, asylum officials seem to rightfully assume that truth-tellers have more knowledge about their hometown than liars. However, even though truthtellers may be able to outperform liars in an interview, they generally seem to have limited knowledge about their surroundings and they sometimes report less than they know. In addition, the difference between liars and truthful applicants can be reduced by the liars preparing for the interview. As such, it seems very difficult to determine whether or not individual applicants are veracious about their origin, based on the questions that we evaluated. Note that this was the first study to examine the validity of knowledge questions for the purpose of credibility assessments and to explore the possible application of cognitive lie detection techniques to the asylum context. More research with more culturally diverse samples is necessary to support the conclusions drawn above. Future research should also look into ways in which the sensitivity and specificity of the credibility assessment of claims about origin can be improved. Nevertheless, the results show that there 
is some merit in the currently employed techniques, but that immigration boards should be careful to equate limited knowledge about one's hometown to lying. Even people who are veracious about where they came from, do not have a perfect memory about their country and town of origin.

\section{FOOTNOTES}

1. The specific coding schemes can be provided by the first author upon request.

\section{REFERENCES}

Altman, D. G., \& Bland, J. M. (1994). Diagnostic tests 1: sensitivity and specificity. BMJ: British Medical Journal, 308, 1552-1552.

Bögner, D., Brewin, C., \& Herlihy, J. (2009). Refugees' experiences of home office interviews: A qualitative study on the disclosure of sensitive personal information. Journal of Ethnic and Migration Studies, 36, 519-535. doi:10.1080/13691830903368329

Bond, J. (2012). Excluding justice: The dangerous intersection between refugee claims, criminal Law, and 'guilty' asylum seekers. International Journal of Refugee Law, 24, 37-59. doi:10.1093/ijrl/eer039

Berry, J. W. (1971). Ecological and cultural factors in spatial perceptual development. Canadian Journal of Behavioural Science, 3, 324-336. doi:10.1037/h0082275

Brewer, N., \& Palmer, M. A. (2010). Eyewitness identification tests. Legal \& Criminological Psychology, 15, 77-96. doi:10.1348/135532509X414765

Buss, C., Wolf, O. T., Witt, J., \& Hellhammer, D. H. (2004). Autobiographic memory impairment following acute cortisol administration. Psychoneuroendocrinology, 29, 10931096. doi:http://dx.doi.org/10.1016/j.psyneuen.2003.09.006

Chun, M. M., \& Turk-Browne, N. B. (2007). Interactions between attention and memory. Current Opinion in Neurobiology, 17, 177-184. doi:http://dx.doi.org/10.1016/j. conb.2007.03.005

Consterdine, E., Pendry, L., \& McKinlay, P. (2013). Establishing identity for international protection: challenges and practices. National contribution from the United Kingdom. Brussels: European Migration Network.

Conway, M. A., \& Pleydell-Pearce, C. W. (2000). The construction of autobiographical memories in the self-memory system. Psychological review, 107, 261-288. doi:10.1037/0033-295X.107.2.261

Cowan, N. (1988). Evolving conceptions of memory storage, selective attention, and their mutual constraints within the human information-processing system. Psychological Bulletin, 104, 163-191.

Dando, C., Wilcock, R., Behnkle, C., \& Milne, R. (2010). Modifying the cognitive interview: countenancing forensic application by enhancing practicability. Psychology, Crime \& Law, 17, 491-511. doi:10.1080/10683160903334212 
Dando, C., Wilcock, R., \& Milne, R. (2009). The cognitive interview: the efficacy of a modified mental reinstatement of context procedure for frontline police investigators. Applied Cognitive Psychology, 23, 138-147. doi:10.1002/acp.1451

Deffenbacher, K. A., Bornstein, B. H., Penrod, S. D., \& McGorty, E. K. (2004). A meta-analytic review of the effects of high stress on eyewitness memory. Law and Human Behavior, 28, 687-706. doi:10.1007/s10979-004-0565-x

Doornbos, N. (2004). Gescheiden werelden: De beoordeling van geloofwaardigheid van vluchtverhalen [Separate worlds: the assessment of credibility of flight stories]. Amsterdams Sociologisch Tijdschrift, 31, 80-112.

Doornbos, N. (2006). Op verhaal komen: Institutionele communicatie in de asielprocedure [Telling your story: Institutional communication in the asylum procedure]. Nijmegen, the Netherlands: Wolf Legal Publishers (WLP).

EASO. (2015). EASO The implementation of Article 15(c) QD in EU Member States. Retrieved from Malta: http://www.asylumlawdatabase.eu/sites/www.asylumlawdatabase.eu/ files/aldfiles/EASO_The-Implementation-of-Art-15c-QD-in-EU-Member-States.pdf

European Migration Network [EMN]. (2013). Establishing Identity for International Protection: Challenges and Practices. Brussels: European Commission.

Ewens, S., Vrij, A., Leal, S., Mann, S., Jo, E., \& Fisher, R. P. (2014). The effect of interpreters on eliciting information, cues to deceit and rapport. Legal and Criminological Psychology, Early view (Online Version of Record published before inclusion in an issue), n/a-n/a. doi:10.1111/lcrp.12067

Granhag, P. A., \& Hartwig, M. (2008). A new theoretical perspective on deception detection: On the psychology of instrumental mind-reading. Psychology, Crime \& Law, 14, 189200. doi:10.1080/10683160701645181

Granhag, P. A., Hartwig, M., Giolla, E. M., \& Clemens, F. (2014). Suspects' Verbal CounterInterrogation Strategies. In P. A. Granhag, A. Vrij, \& B. Verschuere (Eds.), Detecting Deception (pp. 293-313): Chichester: John Wiley \& Sons, Ltd.

Hartwig, M., Granhag, P. A., Stromwall, L., \& Doering, N. (2010). Impression and information management: On the strategic self- regulation of innocent and guilty suspects. The Open Criminology Journal, 3, 10-16.

IND-Werkinstructie nr. 2010/10 (AUB): Wijze van opstarten van onderzoek en/of het stellen van vragen bij onderzoek tijdens de asielprocedure [INS-Work instruction nr. 2010/10 (AUB): Way of starting research and/or posing questions in assessments during the asylum procedure], (2010).

Janssen, S. M. J., Rubin, D. C., \& St. Jacques, P. L. (2011). The temporal distribution of autobiographical memory: changes in reliving and vividness over the life span do not explain the reminiscence bump. Memory \& Cognition, 39, 1-11. doi:10.3758/ s13421-010-0003-x

Kassin, S. M. (2005). On the psychology of confessions: Does innocence put innocents at risk? , 60, 215-228. doi:10.1037/0003-066X.60.3.215

Knudsen, E. I. (2007). Fundamental components of attention. Annual Review of Neuroscience, 30, 57-78. doi:doi:10.1146/annurev.neuro.30.051606.094256

Leins, D., Fisher, R. P., \& Vrij, A. (2012). Drawing on liars' lack of cognitive flexibility: Detecting deception through varying report modes. Applied Cognitive Psychology, 26, 601-607. doi:10.1002/acp.2837

Leins, D., Fisher, R. P., Vrij, A., Leal, S., \& Mann, S. (2011). Using sketch drawing to induce inconsistency in liars. Legal and Criminological Psychology, 16, 253-265. doi:10.1348/135532510X501775 
Liu, M., Granhag, P. A., Landström, S., Hjelmsaeter, E. R. a., Strömwall, L., \& Vrij, A. (2010). Can you remember what was in your pocket when you were stung by a bee?': Eliciting cues to deception by asking the unanticipated. Open Criminology Journal, 3, 31-36. doi:10.2174/1874917801003010031

MacMillan, N. A. (2002). Signal Detection Theory. In H. Pashler \& S. Yantis (Eds.), Stevens' Handbook of Experimental Psychology. pp. 43-90. New York: John Wiley \& Sons, Inc.

Martin, S., Schoenholtz, A. I., \& Fisher, D. (2005). The impact of asylum on receiving countries. In G. J. Borjas \& J. Crisp (Eds.), Poverty, International Migration and Asylum (pp. 99-120). London: Palgrave Macmillan UK.

Memon, A., Meissner, C. A., \& Fraser, J. (2010). The cognitive interview: A meta-analytic review and study space analysis of the past 25 years. Psychology, Public Policy, and Law, 16, 340-372. doi:10.1037/a0020518

Nahari, G., Vrij, A., \& Fisher, R. P. (2014a). Exploiting liars' verbal strategies by examining the verifiability of details. Legal and Criminological Psychology, 19, 227-239. doi:10.1111/j.2044-8333.2012.02069.x

Nahari, G., Vrij, A., \& Fisher, R. P. (2014b). The verifiability approach: Countermeasures facilitate its ability to discriminate between truths and lies. Applied Cognitive Psychology, 28, 122-128. doi:10.1002/acp.2974

Nickerson, R. S., \& Adams, M. J. (1979). Long-term memory for a common object. Cognitive Psychology, 11, 287-307. doi:http://dx.doi.org/10.1016/0010-0285(79)90013-6

Noll, G. (2005). Introduction: Re-mapping evidentiary assessment in asylum procedures. In N. Gregor (Ed.), Proof, evidentiary assessment and credibility in asylum procedures (pp. 1-12). Leiden, the Netherlands: Koninklijke Brill NV.

Nørby, S. (2015). Why forget? On the adaptive value of memory loss. Perspectives on Psychological Science, 10, 551-578. doi:10.1177/1745691615596787

Qualification Directive 2011/95/EU [Recast QD 2004], L336/09 C.F.R. (2011).

Roos af Hjelmsäter, E., Öhman, L., Granhag, P. A., \& Vrij, A. (2014). 'Mapping' deception in adolescents: Eliciting cues to deceit through an unanticipated spatial drawing task. Legal and Criminological Psychology, 19, 179-188. doi:10.1111/j.2044-8333.2012.02068.x

Segall, M. H., Campbell, D. T., \& Herskovits, M. J. (1963). Cultural differences in the perception of geometric illusions. Science, 139(3556), 769-771.

Smeets, T. (2011). Acute stress impairs memory retrieval independent of time of day. Psychoneuroendocrinology, 36, 495-501. doi:http://dx.doi.org/10.1016/j. psyneuen.2010.08.001

Smith, S. M., \& Vela, E. (2001). Environmental context-dependent memory: a review and meta-analysis. Psychonomic bulletin \& review, 8, 203-220. doi:10.3758/BF03196157

Tulving, E., \& Thomson, D. M. (1973). Encoding specificity and retrieval processes in episodic memory. Psychological review, 80, 352-373. doi:10.1037/h0020071

UK Home Office. (2013). Eritrea: Country of origin information report. Retrieved from Croydon, UK: http://www.ecoi.net/file_upload/1226_1379594014_eritrea-coireport-2013-09-18.pdf

United Nations. (1951). The 1951 convention relating to the status of refugees. Geneva: United Nations.

United Nations High Commissioner for Refugees [UNHCR]. (2013). Beyond proof, credibility asessment in EU asylum systems. Brussels: UNHCR.

van Liempt, I., \& Doomernik, J. (2006). Migrant's Agency in the Smuggling Process: The Perspectives of Smuggled Migrants in the Netherlands. International Migration, 44, 165-190. doi:10.1111/j.1468-2435.2006.00383.x 
van Veldhuizen, T. S., Horselenberg, R., Landström, S., Granhag, P. A., \& van Koppen, P. J. (2016). Interviewing asylum seekers: A vignette study on the questions asked to assess credibility of claims about origin and persecution. Journal of Investigative Psychology and Offender Profiling. Advance online publication. doi:10.1002/jip.1472

van Veldhuizen, T. S., Horselenberg, R., \& Van Koppen, P. J. (2016). Proving identity, origin, and persecution: Credibility assessment in the EU asylum procedure. Manuscript submitted for publication.

van Veldhuizen, T. S., Maas, R. P. A. E., Horselenberg, R. \& Van Koppen, P. J. (2016). Establishing origin: Analysing questions in asylum interviews. Manuscript submitted for publication.

Verkuyten, M. (2004). Emotional reactions to and support for immigrant policies: Attributed responsibilities to categories of asylum seekers. Social Justice Research, 17, 293-314. doi:10.1023/B:SORE.0000041295.83611.dc

Vrij, A., Fisher, R., Mann, S., \& Leal, S. (2006). Detecting deception by manipulating cognitive load. Trends in Cognitive Sciences, 10, 141-142. doi:http://dx.doi.org/10.1016/j. tics.2006.02.003

Vrij, A., Fisher, R., Mann, S., \& Leal, S. (2008). A cognitive load approach to lie detection. Journal of Investigative Psychology and Offender Profiling, 5, 39-43. doi:10.1002/ jip.82

Vrij, A., \& Granhag, P. A. (2012). Eliciting cues to deception and truth: What matters are the questions asked. Journal of Applied Research in Memory and Cognition, 1, 110-117. doi:http://dx.doi.org/10.1016/j.jarmac.2012.02.004

Vrij, A., Granhag, P. A., Mann, S., \& Leal, S. (2011). Outsmarting the liars: Toward a cognitive lie detection approach. Current Directions in Psychological Science, 20, 28-32. doi:10.1177/0963721410391245

Vrij, A., Leal, S., Granhag, P., Mann, S., Fisher, R., Hillman, J., \& Sperry, K. (2009). Outsmarting the liars: The benefit of asking unanticipated questions. Law and Human Behavior, 33, 159-166. doi:10.1007/s10979-008-9143-y

Vrij, A., Mann, S., Leal, S., \& Fisher, R. (2010). 'Look into my eyes': can an instruction to maintain eye contact facilitate lie detection? Psychology, Crime \& Law, 16, 327-348. doi:10.1080/10683160902740633

Vrij, A., Mann, S., Leal, S., \& Fisher, R. (2011). Is anyone there? Drawings as a tool to detect deceit in occupation interviews. Psychology, Crime \& Law, 18, 377-388. doi:10.1080/ 1068316X.2010.498422

Vrij, A., Mann, S. A., Fisher, R. P., Sharon, L., Milne, R., \& Bull, R. (2008). Increasing cognitive load to facilitate lie detection: The benefit of recalling an event in reverse order. Law and Human Behavior, 32, 253-265. doi:10.2307/25144624

Wagenaar, W. A. (1986). My memory: A study of autobiographical memory over six years. Cognitive Psychology, 18, 225-252. doi:http://dx.doi.org/10.1016/00100285(86)90013-7

Wells, G. L., \& Olson, E. A. (2003). Eyewitness Testimony. Annual Review of Psychology, 54, 277-295. doi:doi:10.1146/annurev.psych.54.101601.145028

Yonelinas, A. P. (2001). Components of episodic memory: The contribution of recollection and familiarity. Philosophical Transactions: Biological Sciences, 356, 1363-1374. 



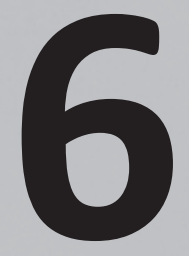

What We Have Learned about

Effective Assessments in Asylum

Cases 



\section{THE VALIDITY OF CURRENT METHODS OF CREDIBILITY ASSESSMENT}

In the EU assessment for asylum, documental evidence is often lacking and the judgement of the asylum official is substantially relied upon. In the current thesis I consider the validity of the assessment procedures used in the European asylum system. Specifically, I examine the extent to which these methods can discriminate between honest and fabricated asylum claims. The four studies presented in chapters two through five provide evidence to call the validity of the European asylum assessment system into question. The credibility assessment is vulnerable to memory errors of honest applicants, personal bias of assessors and manipulation by dishonest applicants. In addition, currently-employed interview techniques may not facilitate the efforts of honest applicants to provide a credible account. Having said that, the studies showed that with more effective questioning strategies and with a deliberate (rather than rigorous) evaluation of asylum seekers' statements, the validity of credibility assessment can be increased.

In the remainder of this chapter, I first discuss the findings of the four studies presented in this thesis, with respect to the validity of credibility assessments in the EU asylum procedure. I then examine the scope and generalizability of these findings. Finally, I consider practical implications of the current research. Specifically, I focus on what we have learned about effective interviewing and decisionmaking practices in asylum cases. In that discussion, I also identify opportunities for future research.

\subsection{Summary of findings}

The review of EU policy and regulation for credibility assessment in Chapter 2 demonstrated that immigration authorities evaluate asylum seekers' statements with five indicators: sufficiency of detail, consistency within statements, consistency with other evidence (e.g., country of origin information, COI), consistency with other witnesses, and plausibility. Although each of these indicators has received empirical support, there is also evidence that undermines each one's validity. There are various circumstances under which little detail, inconsistency, or implausibility (i.e., negative credibility findings) may be the result of factors other than deceit, for example, the questions asked, the style in which they were asked, 
memory errors and limitations, individual and cultural differences all play a part. Considering that asylum officials often hold stereotypical beliefs and assumptions about how credible and non-credible accounts are presented (Granhag, Strömwall, \& Hartwig, 2005; Herlihy, Gleeson, \& Turner, 2010), and that as an uncertain decision context, in the asylum procedure stereotypes and rules of thumb are likely to be employed to reduce cognitive complexity (Colwell, 2005; Porter \& ten Brinke, 2009; Tversky \& Kahneman, 1974), there is a danger that asylum assessors will apply credibility indicators too rigorously and without sufficient consideration for confounding factors. Indeed, recent research on asylum decisions suggests that the procedure used to arrive at such decisions is often lacking in objectivity and motivation (Millbank, 2009; Sweeney, 2016).

As was argued in Chapter 2, to prevent overly-rigorous application of credibility indicators in the assessment of asylum claims, at least two conditions should be met. First, questions in asylum interviews should stimulate statements that meet the credibility requirements. That is, questions should evoke an elaborate and accurate narrative, rather than short answers from which accuracy is difficult to assess. Second, asylum officials should scrutinize all possible explanations for a negative credibility finding, such as a lack of detail or inconsistency in the account. From this reasoning, it follows that to focus only on the methods used to evaluate the credibility of asylum seekers' statements, is insufficient. As the questions used will affect the quantity and quality of information obtained, it is just as important to examine the statements as it is to examine the questions (Oxburgh, Myklebust, \& Grant, 2010; Snook, Luther, Quinlan, \& Milne, 2012).

For this reason, I have concentrated on style, type and content of questions typically used in asylum interviews in Chapters 3 and 4 . In both the vignette study (in Chapter 3) and in real life interviews (in Chapter 4), assessors framed questions in the information-gathering style. This is positive, considering that informationgathering questions generally elicit more elaborate and accurate answers in investigative interviews than other questions (Vrij, Hope, \& Fisher, 2014; Vrij, Mann, \& Fisher, 2006). Asylum officials also seem to know that asking open questions constitutes best practice in investigative interviewing as they largely formulated open questions in response to the vignettes. However, applying that knowledge in actual interviews appears to be difficult, as is evidenced by the large proportion of closed and fact-checking questions ( $>75 \%)$ in interview transcripts. This is 
not a surprising finding. Research from the law enforcement context shows that asking open questions is cognitively demanding, and that training in interviewing techniques does not always lead to the desired improvements in practice (Memon, Bull, \& Smith, 1995; Memon, Holley, Milne, Koehnken, \& Bull, 1994).

Although not surprising, that propensity with which officials rely on closed questions is significant; closed and fact-checking questions limit the information obtained (Fisher, 2010; Snook et al., 2012; Thoresen, Lønnum, Melinder, Stridbeck, \& Magnussen, 2006) and accuracy may be compromised (Milne \& Bull, 2006; Waterman, Blades, \& Spencer, 2001). An interview primarily consisting of closed questions may be a prominent factor in a lack of detail, knowledge or inaccuracies in an applicant's responses, rather than dishonesty. Using credibility indicators as detail and specificity or consistency with COI (i.e., accuracy of the statements) to assess the credibility of a claim evoked through closed questions therefore is precarious.

In addition to question style and type, question content also affects the statements obtained in an interview. A closer look at the topics addressed in asylum interviews reveals a set of questions typically used by asylum officials in the assessment of an origin claim. These questions are evident across variations in nationality claim, applicant's personal background or flight story. In particular, asylum officials test the applicant's knowledge of the place, local customs and common objects of the specific country, area and town that they claim to originate from. Such a standardised interviewing strategy is not apparent in the assessment of claims of persecution. To assess a persecution claim, asylum officials tend to formulate case-specific questions thematically organized around the grounds for the asylum application (e.g., persecution due to religion or political opinion). Thus, to assess origin asylum applicants are subjected to an origin knowledge test with similar questions regardless of case characteristics, whereas persecution claims are assessed differently depending on the nature of the claim.

The experimental study in Chapter 5 indicates that the assumptions underlying the testing of origin knowledge is-at least to some extent-valid. People with a genuine origin claim do indeed know more about the claimed town of origin than people that fabricate their origin claim. Despite having more knowledge than liars, however, even truth-tellers seem to have limited knowledge about their home environment. Furthermore, liars can acquire knowledge about their claimed hometown and diminish the differences with truth-tellers by preparing for the 
interview. Given that liars often plan their lies (Clemens, Granhag, \& Strömwall, 2013; Granhag, Hartwig, Giolla, \& Clemens, 2014; Leins, Fisher, \& Ross, 2013), this method for credibility assessment may be especially vulnerable to deception. A set of direct and fact-checking questions about the claimed country, area and town of origin, may not be sufficient to effectively distinguish between genuine and fabricated origin claims. Accordingly, this study demonstrated the origin knowledge test to have low diagnostic utility.

The fact that people have limited knowledge about their home environment should be taken into account in the credibility assessment of origin claims. If one wants to assess the truth of an origin claim, the questions should be adjusted to what people do know. One way in which this can be accomplished is by asking applicants to speak freely on everything that they remember about their home environment (New Zealand Police, 2012). I will discuss how this may be achieved in Implications for Practice and Future Research.

An alternative avenue for credibility assessment is to utilise interviewing methods that take advantage of the different interviewing strategies used by truthtellers and liars. In the criminal context for example, asking unexpected questions has been shown to elicit cues of deception (Lancaster, Vrij, Hope, \& Waller, 2013; Vrij et al., 2009). The first type of unexpected questions that could be valuable are impossible questions. This is because liars may be more likely to guess at impossible questions than are truth-tellers (Liu et al., 2010). Liars do not like to admit ignorance, because they do not want to appear being avoidant (Hartwig, Granhag, Stromwall, \& Doering, 2010). Truth-tellers however, often falsely believe that the interviewer can easily recognize their truthfulness (Granhag \& Hartwig, 2008), and may be more confident to give an 'I do not know' response (Liu et al., 2010). Comparing these expectations with the findings presented in Chapter 5 of the current thesis, this hypothesis is not supported in the context of assessment for origin claims. Regardless of their truthfulness, all participants in the experimental study guessed at impossible questions. Based on these findings, asking impossible questions - at least in the form in which I studied it-does not seem to be a valid tool for the credibility assessment of an origin claim.

A second type of unanticipated questions could be useful in the assessment of origin claims. This type involves questions that require an answer in a different output modality. That is, questions that do not require a verbal response but 
instead ask the interviewee to draw or sketch an answer. People usually do not expect to be asked to sketch an answer in an interview (Leins, Fisher, \& Vrij, 2012; Leins, Fisher, Vrij, Leal, \& Mann, 2011; Roos af Hjelmsäter, Öhman, Granhag, \& Vrij, 2014) and consequently, even liars who have prepared their answers, must improvise. Improvising is difficult for liars because they tend to be less flexible than truth-tellers, who can rely on memory (Leins et al., 2012). As such, the drawings of truth-tellers should be more detailed than those of liars. The findings in Chapter 5 were in line with previous research (Leins et al., 2011; Roos af Hjelmsäter et al., 2014). When asked to make a sketch of a central square in the claimed hometown, truth-tellers' drawings contained more correct details compared to those of fabricators. Drawings could be a useful tool in the credibility assessment of origin claims, however more research needs to be conducted to affirm these findings, especially among non-Western populations.

In summary, in order to support their origin claim, asylum applicants must describe where they come from and how they arrived in Europe. They are not invited to provide an elaborate narrative about their origin, instead, they are mainly asked closed and fact-checking questions that invite the applicant to provide short answers. The questions asked investigate the applicant's knowledge of their hometown, of their living environment and of their country of origin. Their answers are evaluated by means of five credibility indicators. Regarding origin claims, sufficient detail and knowledge of the country and town of origin (i.e., the accuracy of the answers) often form the basis for the credibility judgement.

At least three critical remarks can be made about the validity of this interviewing strategy and credibility assessment. First, although the assumption that genuine applicants provide more elaborate and detailed statements about their hometown than do lying applicants may have some merit, if the interrogations of the asylum official does not encourage applicants to provide an elaborate and detailed account, it is unlikely that the interview will also yield such a distinction. Second, the assumption that someone who genuinely originates from a specific place has more knowledge about that place than does someone who is falsely claiming to originate from there may be true, however, it must be kept in mind that even truthful claimants can possess only limited knowledge of their direct living environment. In addition, lying claimants may come across as more knowledgeable because they prepare for an interview. Third, including in the situation that an 
applicant has extensive knowledge of his home environment and the questions asked invite an elaborate response and cue the right memory, other factors may impair the accuracy of the information obtained and the detail in the statements. For example, stress imposed by the interview may hamper memory recall (Smeets, 2011) or the interpreter's translation may systematically affect the account. The interpreter may not correctly translate the questions or translation may alter the question style, type or content (Keselman, Cederborg, Lamb, \& Dahlström, 2008, 2010), the interpreter may make errors in the translation of information given by the applicant, thereby decreasing an answer's accuracy (Keselman et al., 2010), and, due to the presence of an interpreter, the applicant may spontaneously provide a less-detailed account (Ewens et al., 2014; Ewens, Vrij, Mann, \& Leal, 2015). These influences on the validity of credibility assessments should be considered when designing refugee status determination processes. In the following sections, I present effective interviewing and decision making methods that could mitigate these influences and examine the extent to which they are likely to support or hinder credibility.

\section{SCOPE AND GENERALIZABILITY}

Before discussing what we have learned throughout this thesis about effective interviewing and decision-making practice in the asylum procedure, however, the scope and generalizability of the research must be considered. This dissertation is the first empirical work that focusses on interviewing practice in the context of credibility assessments in the European asylum procedure. With these studies, I provide insight into the challenges associated with the collection and assessment of evidence in asylum cases. Given the high workload that the accelerating number of people seeking asylum in Europe impose on immigration boards (Eurostat, 2016), the high uncertainty under which asylum officials must decide (Noll, 2005), and the potentially-negative consequences associated with incorrect decisions (Bond, 2012; Inter-Parliamentary Union [IPU], 2001), it is surprising that until now this topic has been neglected by researchers. There is an urgent need for further research into effective interviewing and decision-making practice in the asylum context. 
As the credibility assessment in asylum procedures has received little scientific attention, there are still many unexplored topics. As a starting point, three lines of research that would increase our knowledge base about current practice and could yield new methods for the credibility assessment were therefore proposed in Chapter 2. I argued for research evaluating current interviewing practice, investigating the transparency and objectivity in current decision making, and exploring alternative methods for credibility assessments. In this thesis I mainly focused on the first topic by systematically studying methods of questioning in asylum interviews and by testing the validity of those methods. The areas of decision making and alternative methods for credibility assessments were only briefly touched upon and are largely left to explore. However, also along the lines of the current research much knowledge should still be gained.

By focusing on specific topics (i.e., assessing origin claims) I delimited the scope of the thesis. In addition, because I deemed it important to base the studies in practice, I was dependent on the co-operation of immigration boards. As such, the scope of the present research was more limited than I had hoped for. For instance, it could be argued that the results of the current study only apply to Sweden and the Netherlands, as these are the two countries in which interviewing practice was studied. Other countries were approached to participate in the Vignette study (e.g., Belgium and Germany) but declined to cooperate. For the archival study a further limitation was the language of the interview transcripts; only Dutch or English interviews could be studied.

Although the four studies presented in this thesis are limited by geographical location and language, it is likely that there is substantial overlap between the interviewing and decision-making practice in Sweden and the Netherlands with other European countries. First, as asylum procedures in EU countries are guided by the same policies and regulations, all countries must adopt the same minimum standards for the examination of asylum applications (Asylum Procedure Directive, 2013). Second, immigration authorities around the world use similar indicators to assess the credibility of asylum seekers' statements (Mackey \& Barnes, 2013; Qualification Directive, 2011; United Nations High Commissioner for Refugees [UNHCR], 2013). Third, in most EU countries, the assessment of origin is conducted in a specific part of the interview or in a separate interview (European Migration Network, 2013; IGC, 2012). Across EU countries, questions about an applicant's 
home country are a key method for establishing identity. Finally, the interviewing and decision-making practice may be similar because most EU countries use the training modules provided by the European Asylum Support Office (EASO) to train their case workers (Asylum Procedure Directive, 2013; EASO, 2014). Thus, while replicating our findings in countries beyond the Netherlands and Sweden would be valuable, the findings obtained here are likely to have substantial generalizability to other countries.

The scope of the thesis narrowed from an original focus on all credibility assessments for asylum, to solely the credibility assessment of origin claims. This shift arose on finding that asylum officials employ a specific strategy when assessing the legitimacy of an origin claim. The strategy to assess truthfulness by testing knowledge about the home environment seems to be widely employed, as it was used by both Swedish and Dutch asylum officials and in interviews with a variety of applicants. Moreover, origin is a central element in all asylum cases (Consterdine, Pendry, \& McKinlay, 2013), evidence for origin claims often is scarce in the asylum procedure (European Migration Network, 2013), and asylum seekers can be motivated to lie about their origin to increase their chances of acquiring asylum (Beneduce, 2015). For these reasons I chose to examine the extent to which the origin knowledge test is a valid indicator of fabricated asylum narratives. Future research could investigate whether there is also a typical strategy employed by asylum officials to assess the credibility of a persecution claim. A fruitful avenue may be to focus on persecution claims that are based on similar grounds. For example, it is conceivable that two individuals who claim to have fled their home country because of their religion will be asked similar questions regardless of their nationality or personal background. An interesting study would therefore constitute the thematic analysis of the questions asked in, for instance, conversion cases from different countries of origin (with a similar set-up as the study discussed in Chapter 3). If the cases represent a wide spectrum of applicants (male or female, young or old, tight or loose family structures), such a study could yield information about the strategies employed to assess the credibility of a conversion from one religion to another, after which the validity of that strategy could be tested. Having said that, most of the conclusions drawn below on what constitutes effective interviewing- and decision making practice in the asylum context, could also apply to the assessment of persecution claims rather than origin claims only. 
A final critique to the current thesis concerns recommendations for practice. Although I have been critical of current credibility assessments, I do not offer an alternative method that undeniably leads to correct determinations. This lack of recommendations is largely owing to the complex context in which asylum officials operate. Officials must make decisions based on very little evidence (e.g., Gyulai, 2013; Kagan, 2002; Noll, 2005), knowing that their decision has great consequences for the parties involved (Bond, 2012; Inter-Parliamentary Union [IPU], 2001; Larsaeus, 2004). The uncertain decision context is a key feature of asylum cases and identifying a perfectly reliable and valid measure appropriate to the vast variety of asylum cases is unrealistic. Rather, the findings discussed here provide knowledge that can guide the design of future asylum assessment procedures and facilitate the work of asylum officials. Specifically, I discuss the implications of the current thesis by explaining how appropriate interviewing and decision-making methods can contribute to effective credibility assessment.

\section{IMPLICATIONS FOR PRACTICE AND FUTURE RESEARCH}

The studies discussed in the current thesis demonstrate that, in order to effectively assess credibility, memory capacity should be taken into consideration, both in the elicitation and evaluation of asylum seekers' statements. Implications for practice and for future research are discussed in relation to the two main conclusions drawn from the present thesis. First, asylum interviews should be conducted such that applicants are stimulated to provide elaborate and accurate narratives. Second, when evaluating asylum seekers' statements, considering the particularities of the asylum context, officials should keep an open mind to alternative explanations before reaching a conclusion on the truthfulness of a statement.

\subsection{Eliciting elaborate and accurate answers}

As has been repeatedly argued throughout this thesis, asking more open as opposed to closed- and fact-checking questions could increase the quantity and quality of information obtained in asylum interviews. To achieve this, asylum officials could be trained to ask more open questions. As the studies demonstrated, although asylum officials know which type of questions are effective, they experi- 
ence difficulties applying that knowledge in real-life interviews. Therefore, training should concentrate on transferring this knowledge to practice. To what extent current training already focuses on transfer is unclear, the effectiveness of additional training is therefore uncertain.

The cognitive load imposed on asylum officials during the interview may also inhibit asking open questions. Interrogation is a cognitively demanding task and asking open questions is more cognitively demanding than asking closed questions (Memon et al., 1994). Asylum officials must divide their mental resources over at least four simultaneous tasks: they must (1) formulate questions, (2) check to some extent that the interpreter is correctly translating the question to the applicant, (3) actively listen to the applicant's answer, and (4) process and write down the applicant's response for the interview transcript (IGC, 2012; UNHCR, 2013). During the fourth task, they should also already be formulating the next question. Furthermore, they must remain sensitive to cultural differences and be alert to identify statements that need clarification. Consequently, including in interviews lacking in open questions, most asylum officials are already under substantial cognitive load.

Using electronic means to record the interview and splitting tasks over two asylum officials could reduce cognitive load, which may encourage interviewers to ask more open-ended questions. Recording the interview would allow transcription to take place after the interview; the two officials could split the other tasks. One official could take notes during the interview to identify topics for further questioning, this would allow the other to focus on questioning and listing to the applicant. This solution is very costly and is certainly not always efficient (Horselenberg \& Van Koppen, 2011), and more cost- and time-efficient ways to encourage officials to ask more open questions are valuable. I argue that structuring the interview around a free recall invitation could impel the interviewer to ask more open questions throughout the interview.

\subsubsection{Eliciting a free recall}

If the interview about origin begins with a free recall invitation, the remainder of the interview can be adjusted to the information elicited with the free recall (see also the free recall model described in New Zealand Police, 2012). The following instructions could be used: 
One objective in this interview is to establish where you come from. You have told us that you come from [village] in [country]. I have never been there, but I would like to know as much as possible about your home environment. Please tell me everything you remember about [village] and the environment.

In response to this question, interviewees can search their memory and tell in their own words and pace about their past living environment. Based on the length and depth of the answer and the words chosen by the interviewee, the interviewer can estimate the general language and cognitive abilities of the interviewee. This information can be used to tailor the remainder of the interview to the applicant's abilities. An additional goal of the free recall phase is to identify topics that the applicant has knowledge of and that can be addressed in the remainder of the interview. During a short break after the free recall phase, the interviewer can evaluate the applicant's free recall and identify topics for the remainder of the interview.

Following the free recall model (see Figure 1, New Zealand Police, 2012), the interviewer invites the applicant to elaborate on relevant topics. When, for example, the applicant mentions a large mosque in the city-centre of his hometown, the interviewer can follow-up by asking, 'In your description of your homeenvironment, you mentioned a mosque. Please tell me more about that mosque.' The interviewer then continues with open prompts (e.g., 'Can you tell me more about the services that were held at the mosque?') and some factual or clarifying questions (e.g., 'Which colour were the walls of the mosque?'). Before closing the questioning phase about the mosque, the interviewer summarizes the statements about the mosque, checks whether he understood the interviewee correctly, and asks the interviewee if there is anything he would like to add about the mosque. Now, a new topic can be introduced with a cued-recall invitation (e.g., 'You also told me that you walked from home to school each day, can you tell me more about that?'). In the free recall model, the interviewer is directed to start with an open question each time a new topic is introduced.

If necessary, an additional free recall invitation can be used to elicit further information. For example, if the applicant's response to the free recall invitation is not as elaborate as hoped for and yields too few topics for further questioning, or if the interviewer wants to investigate other domains of the applicant's life. An additional free recall instruction may be: 'I would also like to know more about 
your life in [country]. Please tell me about your daily life in [village]. What did a typical day look like?' or 'If I, who has never been to [village] would come to visit you, what would you show me in the town?'.

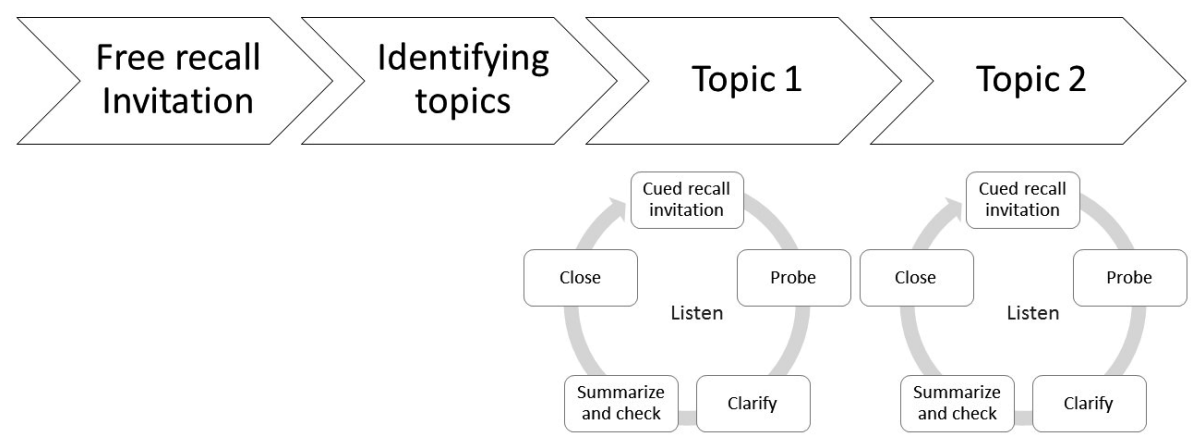

Figure 1. The free recall model for investigative interviews. This model starts with a free recall invitation, followed up by a cued recall phase for each topic identified in the applicant's response. This figure has been adapted from Leksås and Kapferer (2016) and the New Zealand Police (2012, p. 65).

Note that the initial free- and cued recall invitations differs from the additional open follow-up questions. The former ask the applicant to either 'tell about', 'explain about', or 'describe' an event or the environment; these are referred to as TED questions (Boon, Odinot, Horselenberg, \& Geijsen, 2016; Oxburgh et al., 2010) and are the most open-ended invitations. The follow-up questions are more directive, and are often grouped as the ' $5 \mathrm{Wh}+$ how' questions; questions beginning with what, why, when, who, where or how (Oxburgh et al., 2010). Wh + how questions also invite applicants to answer in their own words and may be considered open questions, however they generally elicit a less elaborate response than do TED questions (Boon et al., 2016; New Zealand Police, 2012; Oxburgh et al., 2010).

The free recall model only works if the applicant is willing and able to talk. In the asylum procedure, there is a high likelihood that the applicant is cooperative. After all, burden of proof lies with the applicant (Qualification Directive, 2011); applicants who want to be considered for international protection must present a convincing argument and refusing to co-operate will damage their case. Some asylum seekers, however, may not make full disclosures; this is often owing to a distrust of government officials following negative experiences with authorities in their home country (Bögner, Brewin, \& Herlihy, 2009; UNHCR, 2013). Although in 
such cases a free recall session may not succeed in eliciting an elaborate account, specific and closed questions are likely to be even less effective because they restrict the applicant's control over the flow of information (Fisher \& Geiselman, 2010). The best way to go forward with a distrusting applicant is to make rapport a priority (Milne \& Bull, 1999; Powell \& Bartholomew, 2003). Once rapport between the interviewer and applicant has been established, a free recall invitation and open questions are more likely to elicit a substantial response than are other types of questions (Fisher \& Geiselman, 2010).

In other situations, the applicant may be willing but unable to provide an elaborate response, for example due to limited intellectual or linguistic ability. It is worthwhile to note that while people with learning disabilities often give less extensive free narratives, the accuracy of their statements is generally not impaired (Milne \& Bull, 2001). Asking as many open-ended questions as possible is forthwith advisable, including in the case of learning or linguistic impairment (Bull, 2010). Furthermore, if the applicant is unable to answer open questions completely, asking either/or questions is generally more effective than asking yes/no questions. Either/or questions result in more accurate answers in interviews with people with limited mental abilities (Heal \& Sigelman, 1995). A good strategy to assess whether the intellectual abilities of the applicant are sufficient to participate in the interview is to start the interview with neutral and non-threatening topics about which most people will be able to contribute something to (Bull, 2010). For example, in place of starting the interview by asking for a description of their hometown or to explain their reasons for fleeing the country of origin, the interviewer could begin with a general and much less complex question such as, at home, how would they normally have dinner. The length of their response and the words used inform the interviewer of the applicant's conversational abilities.

Besides the possibility of eliciting more accurate information than can a more directed interviewing technique (e.g., Milne \& Bull, 1999; Milne \& Bull, 2001; New Zealand Police, 2012; Powell \& Snow, 2007), another advantage of the free recall model to the country of origin interview is that it minimises the risk of asking questions about a place of which the interviewee has no knowledge. Instead, the interviewer can build on the applicant's own claims to knowledge. For example, when the interviewee (in response to the free recall invitation) spontaneously mentions a place, building, or experience, the interviewer can be confident to explore this 
as a topic that this applicant has knowledge of. Instead of using COI to prepare knowledge questions beforehand, the interviewee can be asked to elaborate on the topics he himself identified and the forthcoming statements subsequently can be verified with COI.

\subsubsection{The verifiability approach}

The free recall invitation also facilitates the verifiability approach. This approach has proven a valid tool for identifying truth-tellers in criminal contexts (Nahari \& Vrij, 2014; Nahari, Vrij, \& Fisher, 2014a, 2014b). The theory behind the approach is that even though truth-tellers' and liars' accounts may on average be equally detailed, truth-tellers provide more details of which the accuracy can be validated with information from other sources. The verifiability approach is therefore only applicable if there is evidence against which the accuracy of statement details could be checked. The interviewee must believe that the interviewer can verify the statements, otherwise a lying interviewee might provide false details.

Owing to the need to identify details, the verifiability approach will often not be useful to assess the credibility of a persecution claim. Only rarely will the events that have caused the asylum seeker's flight have been reported in the news or in NGO reports (ACCORD, 2013). For example, even though COI may report raids in Eritrea to arrest evaders, reports of one specific raid in a small rural village in Eritrea probably do not exist. Although details in the stories provided by Eritrean asylum seekers about the raids often cannot be verified, details of the applicant's living environment are often verifiable (EMN, 2013). The verifiability approach may therefore be useful for origin assessments.

Another precondition for using the verifiability approach is that a spontaneous narrative must be elicited. Closed-and cued-recall questions often directly ask for verifiable answers (e.g., 'What was the colour of the mosque?'), rather than allowing the interviewee to spontaneously come up with such details. When free recall questions are asked, however, truthful statements and fabricated statements can be compared on the number of spontaneously provided verifiable details about the home environment.

One of the strengths of the verifiability approach is its resistance against countermeasures. For example, when suspects are informed that the interviewer is searching for verifiable details, liars are unable to provide more verifiable details, 
whereas the number of verifiable details in the truth-tellers' statements, increases (Nahari, Vrij, et al., 2014b). This instruction may, however, be less effective in origin interviews. If lying asylum seekers are aware that the interviewer is searching for verifiable details, they may prepare these details before being interviewed.

The appropriateness of the verifiability approach to the credibility assessment in asylum cases should therefore be tested before being applied in practice. Testing is further advised owing to research showing that this approach is ineffective in the insurance context (Nahari, Leal, Vrij, Warmelink, \& Vernham, 2014). To start with, it needs to be studied whether - similar to suspect statements (Nahari, Vrij, et al., 2014a, 2014b) - truthful asylum narratives indeed contain more verifiable details than do fabricated narratives. A study could be conducted in which participants are invited to provide a narrative about their claimed home environment by means of the free-recall instruction proposed above. Similar to the study presented in Chapter 5, a 3 (truthfulness: truth-tellers vs. partial liars vs. full liars) x 2 (preparation: prepared vs. unprepared) design could be used. This design allows for three analyses: first, the truthful narratives can be compared to fabricated narratives on spontaneously provided verifiable details; second, the narratives of unprepared truth-tellers will yield information about what people typically know about their home-environment and what they deem relevant information to convince someone of their origin; and third, by monitoring the preparation phase and by studying the narratives of prepared liars, information can be gathered about how liars typically prepare for origin interviews. To increase the value of the study, the study could be conducted among populations which are highly represented in the current population of asylum seekers. An interesting addition - perhaps for followup research - would be to tell all participants before the preparation phase that their narratives will be judged on verifiable details. By instructing the liars, the susceptibility of the verifiability approach to counter measures in the context of the assessment of origin claims can be assessed.

If the verifiability approach proofs effective in the asylum context then the detail indicator could be satisfied using this approach, and perhaps reformulated. Asylum officials could be instructed to assess the extent to which an applicant spontaneously provides verifiable details in response to a free narrative invitation. 


\subsubsection{Establishing ground-rules}

Introducing a free recall invitation in the origin interview may require substantial change to the interview structure. Other techniques for stimulating an elaborate and accurate account, such as setting clear ground-rules for the interview, can be more easily implemented. Examples of often-used ground rules are: the interviewee should only talk about events that happened to him personally, rather than events that he heard about from other people; the interviewee should correct the interviewer when he is mistaken; the interviewer is naïve as to what has happened to the interviewee; the interviewee should always ask for clarification or explanation if they are unclear (Brubacher, Poole, \& Dickinson, 2015; Lamb, Orbach, Hershkowitz, Esplin, \& Horowitz, 2007; Orbach et al., 2000).

Particular to the asylum procedure, an additional ground rule is that at any point that the interviewee does not understand the interpreter he should provide notice. Two other instructions, namely the report everything instruction and the do not guess or I do not know instruction, can also be introduced with the ground rules to stimulate elaborate and accurate answering (e.g., Brubacher et al., 2015; Memon, Meissner, \& Fraser, 2010).

3.1.3.1 The 'report everything' instruction. As the name of this instruction implies, interviewees are instructed to report everything that they remember, even though it might seem trivial or irrelevant, and even when the information is partial or incomplete (Geiselman, Fisher, MacKinnon, \& Holland, 1986). This instruction is given as interviewees may edit their answers and leave out details because they think they are not important. By reporting partial or incomplete information, other relevant information or details may be triggered, thereby further enhancing recall (Geiselman et al., 1986; Milne \& Bull, 2002)

This instruction can be easily implemented in interviews, and the technique is regarded useful by police officers (Kebbell, Milne, \& Wagstaff, 1999). In addition, as it increases the amount of correct information recalled during the interview, it is one of the most effective components of the cognitive interview (Davis, McMahon, \& Greenwood, 2005; Memon et al., 2010; Milne \& Bull, 2002). Besides giving a report everything instruction at the start of the interview, it is beneficial to repeat this instruction several times throughout the interview, especially before a free recall phase or a cued recall question (Memon et al., 2010). 
Asylum seekers are likely to be uncertain of which information is relevant to the immigration board (Kagan, 2002) and in this case, the report everything instruction may encourage them to tell anything that comes to mind. Reporting everything that comes to mind at an early stage in the procedure may also result in a more credible account, because it may reduce the number of commissions (i.e., details in a second interview that were not mentioned before). Commissions may negatively affect credibility by undermining the consistency of the account (UNHCR, 2013). In sum, the report everything instruction is a relatively simple measure to encourage asylum applicants to provide an as complete narrative as possible.

3.1.3.2 The do not guess instruction. The second instruction, referred to as the do not guess instruction or I do not know instruction, may also increase accurate recall. One prerequisite of an accurate narrative is that the interviewee admits to not understanding a question or being unsure of an answer (Brubacher et al., 2015; Fisher, 2010; Lamb et al., 2007; Memon et al., 2010). This is for the reason that, as it becomes unclear which answers are based on genuine memory and which are based on guesses or hunches, determining the validity of statements is difficult for the assessor.

In a review of research into the effectiveness of the do not guess instruction in child interviews, evidence indicates that this instruction increases the number of I do not know responses and the accuracy of the answers under two conditions (Brubacher et al., 2015). First, the instruction must be specific and preferably practiced at the beginning of the interview. Second, the instruction should be combined with the instruction to report everything because the interviewer is naïve as to what has happened. Without the report everything instruction, children overuse the I do not know response, thereby also reducing the quantity of correct answers. In addition, the do not guess instruction should be emphasised throughout the interview (Memon et al., 2010).

A do not guess instruction may be valuable in asylum interviews for two reasons. First, as asylum officials sometimes ask questions that invite speculation, they implicitly communicate that speculation or guessing is acceptable (as I found in Chapter 4); the do not guess instruction may remind both the interviewee and the asylum official that speculation should be avoided. Second, the findings in Chapter 5 demonstrate that in high-stake situations respondents will be intent to answer questions, even in the case that they are almost impossible to answer cor- 
rectly. These findings imply that, owing to the importance of the decision made, particularly in the asylum context guessing is likely to occur. When using the do not guess instruction, asylum officials should also keep in mind in their credibility assessment that I do not know responses are not an indication of fabrication. In fact, if anything, admitting to a lack of memory seems to be indicative of truthfulness rather than deceit (Porter \& Yuille, 1996).

\subsection{Being open-minded to multiple explanations}

The preceding discussion pertained to techniques for eliciting a larger quantity of (and more accurate) information in interviews. Asking appropriate questions eliminates some alternative explanations for shortcomings in the applicant's testimony. When an interviewee provides vague and general statements in response to free- and cued-recall questions concerns for question type and style no longer apply. Alternative explanations for a negative credibility finding may, however, still hold. For instance, errors at any stage of memory formation and retrieval will influence unspecific answers, inaccuracies and inconsistencies (Cohen, 2001; Herlihy, Jobson, \& Turner, 2012).

To make the right decision in as many cases as possible, asylum officials should therefore keep an open mind while assessing credibility. Once an asylum official forms a hypothesis about an asylum seeker's truthfulness, the risk arises that, throughout the remainder of the interview, and in the evaluation of the applicant's statements, the official will only seek to confirm their hypothesis and will unintentionally ignore information that supports the alternative hypotheses. This phenomenon, known as tunnel vision, is well documented in the context of criminal investigations (Ask \& Granhag, 2005; Findley \& Scott, 2006; Hill, Memon, \& McGeorge, 2008; Kassin, 2005; Kassin, Goldstein, \& Savitsky, 2003; Kerstholt \& Eikelboom, 2007; Meissner \& Kassin, 2002; Rassin, 2010). Tunnel vision is grounded in several psychological mechanisms. One mechanism is confirmation bias; once the impression of guilt is formed, all evidence is evaluated in light of this presumption of guilt (Crombag, 2010; Kassin, 2005). Investigators may search for evidence that confirms their perception, pay more attention to incriminating evidence than exonerating evidence, and interpret ambiguous evidence as indicative of guilt rather than of innocence (Nickerson, 1998). Confirmation bias is reinforced by belief perseverance (Crombag, 2010); people want to retain their belief, 
despite any opposing evidence (Koehler, 1991). Evidence disconfirming the belief may never be identified, ignored, or wrongly interpreted. Not surprisingly, tunnel vision is an influential factor in many wrongful convictions (Crombag, van Koppen, \& Wagenaar, 2009; Findley \& Scott, 2006; van Koppen, 2011).

The risk of a tunnel vision can be reduced. A confirmation bias can be counteracted by actively trying to disconfirm one's own hypothesis, by formulating counterarguments, or by consciously considering evidence pointing away from the first impression (e.g., Nickerson, 1998; O’Brien, 2009). A strategy in which one tries to disconfirm one's own hypothesis, although complex (O'Brien, 2009), corresponds to the way in which empirical scientists strive to find truth. Following Karl Popper (Dienes, 2008), in any search for knowledge, it is more necessary to attempt to falsify the original hypothesis than it is to seek verification. A hypothesis remains 'true' only as long it is not rejected.

Applied to the asylum context, if an asylum official identifies shortcomings in an applicant's statements, the first impression is likely to be that the story is untrue. However, this first impression may be false. For example, the lack of detail or inconsistency in the story was the result of an honest mistake (Cohen, 2001). In practice, the combination of the uncertain decision context of the asylum procedure and the psychological mechanisms that put people at risk of tunnelling, may make it difficult to keep an open mind during the credibility assessment (Nickerson, 1998; Tversky \& Kahneman, 1974). However, a tool that may promote well-considered assessment is scenario thinking.

\subsubsection{Scenario thinking}

Scenario thinking encourages asylum officials to actively formulate alternative explanations for their initial findings and consider evidence disconfirming their first impressions (Bex, van Koppen, Prakken, \& Verheij, 2010; Van Koppen, 2011, 2013). In each asylum case, the central question is whether or not the applicant is eligible for international protection (see Figure 2). Two hypotheses can be formed: the null, that the applicant has a genuine fear of persecution in the country of origin, and the alternative, that the applicant does not have a genuine fear of persecution in the country of origin. To determine which hypothesis is more likely to be true, evidence is needed about the applicant's identity, origin and past experiences. Given the general scarcity of documentary evidence to support identity, origin, 
and persecution claims, for each of those elements two new hypotheses can be formed. For the origin claim, for example, the two hypotheses are that the origin claim is truthful or that the origin claim is fabricated. Asylum officials should seek information or evidence that supports or refutes these hypotheses.

At first sight the hypotheses are simple statements. However, a comprehensive story must be formed around each hypothesis, also called a scenario (van Koppen, 2011). A scenario may, for instance, describe where the applicant is from, the applicant's life in the country of origin, and his or her flight to Europe. In order to determine which hypothesis or scenario is more likely to be true, the evaluation should concentrate on the extent to which the evidence in the case can be predicted by the different scenarios. Evidence that would only be found if the truth scenario is valid and not if the fabrication scenario is valid, would prove the truth scenario beyond doubt. For example, an authentic passport corroborating the applicant's identity and origin cannot be predicted by the fabrication scenario. In reality, however, evidence of that strength is frequently unavailable.

In the example in Figure 2, three pieces of evidence are collected during the interview that can be indicative of the truthfulness or fabrication of the origin claim. Initially, it might appear that each piece of evidence clearly contributes to the credibility assessment. For example, the lack of knowledge about buses aligns with the fabrication scenario, in contrast, knowledge about the renovation of a church is more consistent with the truthful scenario. Nevertheless, unlike the passport and birth certificate in the example above, it is also possible to use these pieces of evidence to support the opposing scenario. Alternative explanations should be explored before concluding that evidence undermines or corroborates the asylum story. This is also referred to as the falsification and verification phase.

Consider Evidence 1. The applicant may be unable to describe the buses in his claimed hometown because he is lying about his origin. Alternatively, the applicant may never have taken the bus or might not be able to recall their layout, for example due to stress imposed by the interview or the presence of the interpreter. The interviewer could then ask additional questions to assess the likelihood of alternative explanations. He could ask, for example, 'Can you tell me more about how you travelled through town?' and follow up with 'What means of transportation did you normally use?' If the applicant always travelled on foot because there was no money for any form of public transportation, this may explain the lack of 
knowledge. The alternative explanation would render Evidence 1 as having low diagnostic value, as it can no longer discriminate between the truth and fabrication scenario. If the applicant occasionally travelled by bus, the interviewer must inquire further to explore other explanations (e.g., a failing memory). As alternative explanations are verified or falsified, the diagnostic value of each piece of evidence increases or decreases.

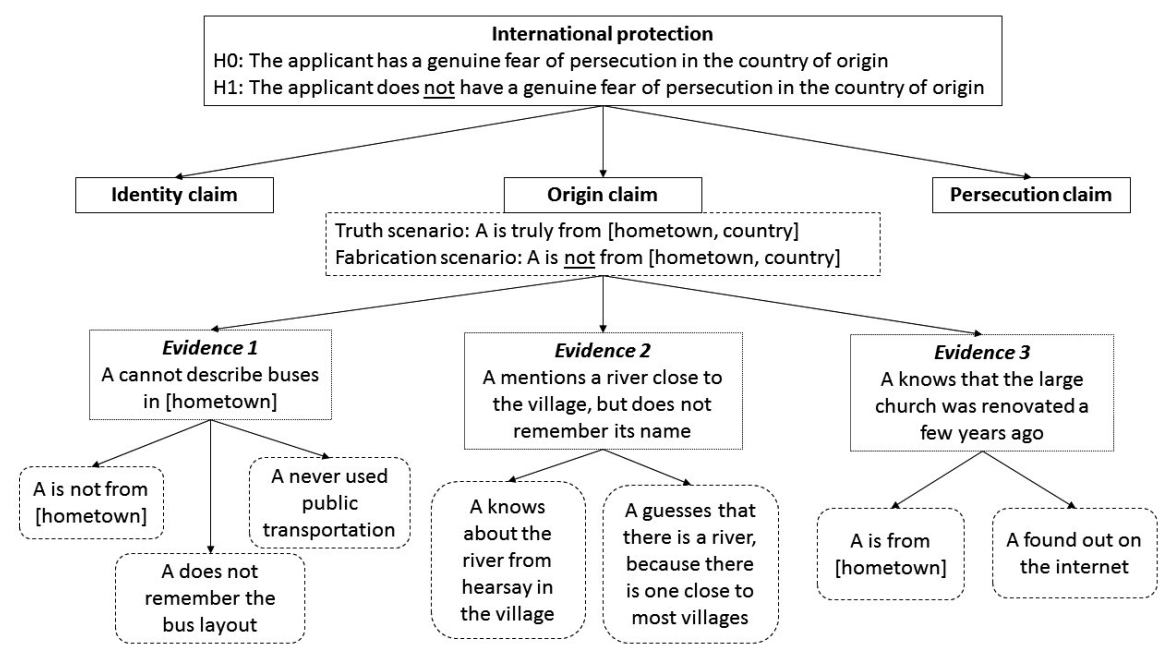

Figure 2. An example of scenario thinking applied to the credibility assessment of an origin claim. 'A' refers to applicant.

Scenario thinking should not exclusively be applied to negative credibility findings. Including for presumably positive findings, alternative explanations should also be considered. For example, although the information that a church was renovated a few years ago, may be convincing at first sight, yet it does not automatically imply truthfulness. This information may easily be found on the internet and used to appear credible. In other words, the knowledge about the renovation may also be predicted by the fabrication scenario, if that scenario holds that the applicant has prepared for the interview.

After all reasonable explanations for a specific finding have been explored, value can be attached to each piece of evidence. A conclusion can be drawn about the extent to which the evidence is predicted by each scenario, and thereby, which scenario is more likely to be true (Bex et al., 2010; van Koppen, 2011). Asylum 
officials are encouraged to devise solid arguments as to why one scenario is more likely than another. By clarifying which explanations for the evidence have been considered and why they are accepted or rejected, the credibility assessment becomes more deliberate and transparent.

\subsubsection{Evidence framing matrix}

By scrutinizing alternative scenarios, the interview also becomes more strategic. The interviewer tries to elicit information that either confirms or rejects alternative explanations, without revealing which information he is searching for. A tool that may aid this process is the evidence framing matrix (Granhag, Strömwall, Willén, \& Hartwig, 2013). The evidence framing matrix - developed within the gradual revelation of evidence paradigm (Dando, Bull, Ormerod, \& Sandham, 2015; Hartwig, Granhag, Strömwall, \& Vrij, 2005)-is a tool designed to tactically confront an interviewee with inconsistencies in his statements and available evidence. The rationale behind the evidence framing matrix is that by framing inconsistencies in different ways, different responses can be elicited from the interviewee. By using the matrix, the interviewer facilitates truth-tellers to diminish discrepancies between their accounts and the evidence by providing them with an additional opportunity to search their memory, while inciting liars to magnify the discrepancies between their accounts and the evidence (Granhag et al., 2013).

The evidence framing matrix is illustrated with an example in Figure 3. The example refers to a Chinese Uyghur woman who has reported a home address in China that according to Google Maps, does not exist. Typically, as described in Chapter 4, such inconsistencies are discussed with the applicant in a rather confrontational manner. The asylum official often states the inconsistency without asking a question but in a way that still demands a response. An example is: 'You said that you lived at this address, but this address does not exist on Google Maps.' Several problems may arise from such a confrontation. First, the approach of the interviewer may be perceived as accusatory and this may negatively affect interviewing dynamics (Vanderhallen, Vervaeke, \& Holmberg, 2011; Vrij et al., 2006). Second, the interviewer may reveal all the information that they have. As a lying applicant may fabricate an answer to fit the evidence and a truthful asylum seeker may be able to explain the discrepancy, both explanations would probably 
fit the evidence equally well. Consequently, the confrontational style risks eliciting answers that will not aid distinction between deception and a truthful account.

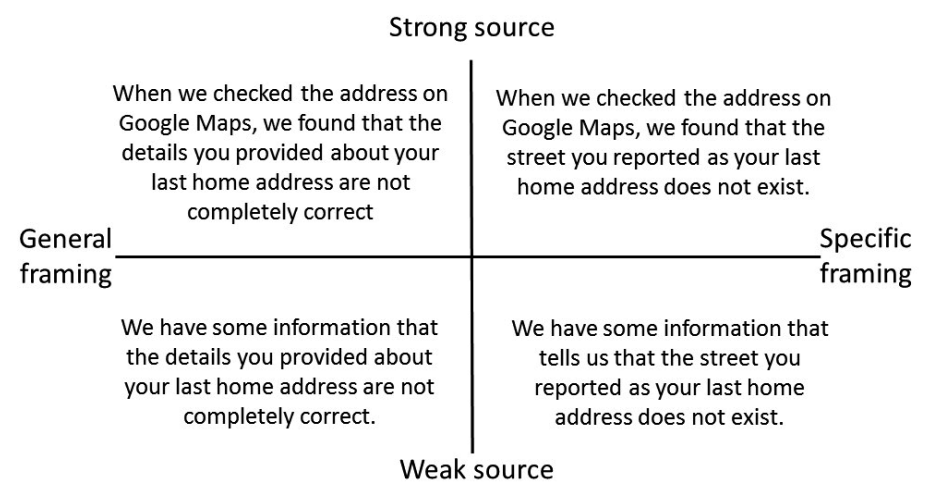

Figure 3. An application of the Evidence Framing Matrix (Granhag et al., 2013) to the assessment of a statement-evidence discrepancy in an asylum case.

This problem can be avoided by framing the specificity of the discrepancy and the perceived strength of the evidence (Granhag et al., 2013). The discrepancy can be presented either in general terms (e.g., 'the details in the address do not seem to be completely correct') or in specific terms (e.g. 'the address you provided does not exist'). The strength of the evidence can be framed as coming from a weak source (e.g. 'We have some information that...) or a strong source (e.g., 'Google maps showed...). Framing a discrepancy as unspecific and the evidence as weak would then result in the following question: 'We have found some information that the details you provided about your last address are not completely correct. Can you think of anything that explains this?'.

The above question is information-gathering in style, and therefore may have a positive effect on the working relationship (Vanderhallen et al., 2011). Furthermore, if truthful, the Uyghur woman is given the opportunity to search her memory for an explanation for the allegedly wrong address. She may for example explain, 'I might have given you the historic street name; on current maps the modern names may be used'. If this information proves accurate, she will be able to provide a rather 
spontaneous alternative explanation that renders her explanation more convincing than in a situation in which she knew the exact discrepancy. If the Uyghur woman is lying, this way of framing the discrepancy may pose a dilemma. She does not know what evidence the interviewer holds. As such, she could either leave the statement unchanged, keeping the statement-evidence discrepancy intact, alternatively, she could change her statement. Changing her statement would risk magnifying discrepancies by providing an explanation that also does not fit the evidence.

The situation outlined in the previous paragraph is an ideal situation. In practice, truthful individuals may be unable to remember anything further, and the lying individual may not change the statement. When using the evidence matrix, the interviewer can move to another quadrant of the matrix to make the source of the information stronger or the framing more specific (Granhag et al., 2013). The truthful interviewee is given the opportunity to search her memory once more, and the lying interviewee is presented with another dilemma. Still, a truthful interviewee may be unable to think of an alternative explanation, for example because he lacks the accurate knowledge or because the evidence is incorrect (i.e., the information on Google Maps may be inaccurate). Therefore, using the evidence framing matrix does not exempt the asylum official from remaining critical to his own hypothesis about the discrepancy.

The evidence framing matrix seems a promising and practical method to tactically confront an interviewee with statement-evidence inconsistencies in a non-accusatory manner. Research on the effectiveness of the evidence framing matrix to elicit cues to truthfulness and deceit is however still limited to one study (Granhag et al., 2013; but also see Luke et al., 2013 for a unidimensional test of the general-to-specific framing of evidence). Future research could aim to validate the matrix as a tool to aid credibility assessments in the asylum context. For instance, a study could be designed in which truth-tellers and liars (truth-tellers and liars could be appointed in the same way as in Chapter 5) are interviewed about their origin. They are invited to provide a free narrative about their home-environment. After providing the narrative, a short break is taken during which the facts and descriptions provided by the participants are checked against external sources. If the participant's account is fully in line with the evidence, the participant is excused. If discrepancies between the account and the evidence are found, the interview continues. In the second part of the interview, the interviewer confronts 
the participant with one discrepancy between his account and the evidence either in a confrontational style, or tactically following the evidence framing matrix. As such a 2 (truthfulness: truth-teller vs. liar) x 2 (approach: confrontational vs. evidence framing) design is employed. Similar to Granhag et al. (2013) responses of the truth-tellers and liars can be compared on the amount of statement-evidence inconsistency (how well the statements correspond to the evidence from external sources before and after the second part of the interview) and on within-statement inconsistency (the extent to which statements changes during the second part of the interview). If the evidence framing matrix is a valid tool for addressing inconsistencies, truth-tellers' statements should be more consistent with the evidence than statements of liars and their consistency should increase during the second part of the interview, whereas liars' statements should remain equally (in)consistent or become less consistent with the evidence.

\subsubsection{Plausibility judgments}

Asylum officials should also be aware that their personal knowledge and experience influences how they perceive the statements of asylum seekers. As outlined in Chapter 2, the plausibility assessment is especially affected by the official's own background.

The exact definition of plausibility remains unclear (UNHCR, 2013). Sometimes, plausibility is defined as the extent to which a story is believable. However, when plausibility becomes synonymous with believability, it becomes essentially another term for credibility. As plausibility is identified as a distinct indicator of credibility in the qualification directive (Qualification Directive, 2011), a different definition should be used to prevent circular reasoning. A second definition of plausibility is the extent to which a story is reasonable, likely or probable, or in line with 'common sense'. With this operationalisation of plausibility, however, the assessment seems to be largely based on intuition and strongly affected by the assessor's personal perceptions of what is reasonable or likely (UNHCR, 2013).

To assess how plausibility is determined in practice and whether it is a distinct indicator of credibility, we conducted a correlational study (Maegherman, Van Veldhuizen, Horselenberg, \& Van Koppen, 2016). Five vignettes presented a Syrian persecution claim, an Eritrean origin claim, a car crash eyewitness account, an alleged drug dealer's (suspect) statement, and an alleged child sexual abuse 
(CSA) victim's statement. Each vignette contained statements from two subsequent interviews, and a short summary of the evidence in the case. Participants rated each five vignettes on four indicators: detail, internal consistency, consistency with evidence and plausibility. We aimed to make each vignette equally detailed, internally (in)consistent, and consistent with evidence.

The results show that even though we attempted to make each story equally detailed, and internally- and externally-consistent, the stories were rated differently. Specifically, the statements of the drug dealer and of the Eritrean asylum seeker were perceived to be least-detailed, least-consistent and least-plausible. The Syrian asylum seeker's narrative, in turn, was perceived as the most detailed, consistent and plausible. Ratings for the witness' and CSA victim's statements were somewhere in between. Despite the differences between the stories, ratings for the four credibility indicators correlated with each other, implying that the indicators are interrelated.

Strong correlations between indicators raised the question whether any of the indicators can be objectively measured in a credibility assessment. These correlations imply that the indicators are all based on one anchoring judgment. The anchor judgment seems to depend on the topic of the story rather than measurable differences; the Eritrean asylum seeker and the suspect were found less credible, regardless of the actual quality of their statements. If this interpretation of the results is correct, an intuitive judgment about the believability of the asylum narrative would influence the final decision in the case, regardless of the evidence obtained during the interview.

Indeed, in Chapter 3, I found that a snap-judgment of plausibility predicted the final judgment about asylum in the case. Also, $22 \%$ of Swedish asylum officials in a study by Granhag, et al (2005) reported that even though their decisions were based on facts, their intuition could influence the direction of the investigation. The conclusion that intuition drives the credibility assessment is, however, premature. In the vignette study, there was no evidence of a relationship between the initial plausibility rating and the final judgment, and neither does the correlational study described here allow for any causal inferences. More research is necessary to investigate the extent to which an initial judgement might influence the evaluation of evidence to predict a final judgment. 
An investigation into the influence of such expectancy effects is currently being conducted. In this experiment, I designed two versions of the same vignette, one more plausible than the other. Judges, asylum officials, and lay-people will be asked to read one of the vignettes and then provide a snap-judgment about its plausibility. They will then be presented with seven pieces of evidence: two negative credibility findings, two positive credibility findings and three ambiguous pieces of evidence that could be explained either positively or negatively. For each piece, they will be asked to rate whether it would negatively or positively affect the credibility of the story, and how important they consider this information to the credibility assessment. Thereafter, participants estimate the likelihood that they would grant a refugee status to this applicant. The design enables assessment of the extent to which an initial plausibility judgement may affect the final decision in a case, and to what extent this relationship is mediated through two components of confirmation bias (Nickerson, 1998), namely: selective attention processes (i.e., the relative importance attached to confirming and disconfirming information) and expectancy dependant perception (i.e., the extent to which ambiguous information is interpreted as confirming or disconfirming evidence). If expectancy effects do bias decision making processes in the asylum context, the assessment procedure will need to be restructured to prevent intuitive plausibility judgements from evolving into tunnel vision. As argued earlier, scenario thinking could become a beneficial tool.

\section{CONCLUSION}

In his book, How I Developed a Talent for Life, former asylum seeker Rodaan Al Galidi states that during his asylum procedure in the Netherlands he learned that a neat lie is better than the messy truth (Al Galidi, 2016). In the current thesis I have demonstrated that the truth can indeed be messy. Truthful recollections of past experiences can be incomplete, inconsistent and inaccurate because of the malleable and reconstructive nature of human memory (e.g., Loftus, 2005; Vredeveldt, van Koppen, \& Granhag, 2014). Compared to truths, partly or completely fabricated narratives can be relatively consistent and convincing (Granhag \& Strömwall, 2001). As such, it is often difficult to distinguish truth from fabrication. 
As the European asylum system is based in the principle of non-refoulement, EU member states have a duty to minimize the chances of wrongfully returning an asylum seeker to their country of origin (European Parliament, 1999; UNHCR, 2001, §16; see also the case of M.S.S. v. Belgium and Greece, §54-56). Migration boards should strive to correctly identify as many genuine asylum seekers as possible, despite the difficult task of identifying truth in the complex and uncertain asylum context. Besides the general difficulty to separate genuine from fabricated stories, this process is further complicated by the scarcity of evidence to corroborate asylum seekers' claims (Kagan, 2002; Noll, 2005). Neither do asylum officials receive feedback about the accuracy of previous assessments, on which they can evaluate their own work (Doornbos, 2006). It is not surprising that asylum officials report that assessing credibility is the foremost obstacle to coming to a decision (Granhag et al., 2005), and that clear decision criteria are sought as bases for credibility assessment (UNHCR, 2013).

I have been critical of the five credibility indicators used to evaluate asylum seekers' statements because-when applied rigorously-it is likely that ordinary memory limitations such as forgetting, changing recollections or mistakes are confused with or mistaken for signs of fabrication. Nevertheless, currently there are no other methods that will lead to the correct conclusion in all cases. Thus, instead of dismissing the credibility indicators, I call for methods to improve the credibility assessment within the current framework. That is, I seek interviewing and decision-making methods that lead to a better identification of genuine refugees and non-genuine applicants based on the existing credibility indicators.

In discussing the practical implications of the current thesis, I concentrate on factors that are within the control of the migration board. To increase the correct identification of legitimate asylum claims-or sensitivity-of credibility assessments, I call for interviewing techniques that will assist genuine asylum seekers to provide more detailed and accurate narratives, such that their stories become more complete and thereby, convincing. Second, I advocate an open-minded evaluation of asylum seekers' statements, in which the messiness of truths is considered and taken into consideration. I further considered how these techniques may hinder liars to appear credible. As such, the proposed methods also contribute to the correct identification of illegitimate asylum claims-or specificity-of the credibility assessment. For example, while genuine asylum seekers may be able to provide 
more complete narratives including more (verifiable) details when asked the right questions, as liars often work to keep their story short and simple, they may not be able to do so (Nahari, Vrij, et al., 2014b; Strömwall, Hartwig, \& Granhag, 2006). With the tactics proposed here, it is possible to clarify truthful narratives while also reducing the extent to which fabricated narratives are convincing. However, despite our advances in this area, distinguishing between legitimate and illegitimate asylum claims is likely to remain a demanding task.

Each year hundreds of thousands of individuals apply for asylum in Europe (Eurostat, 2016). In most of these cases, the results of a credibility assessment will decide the case (Gyulai, 2013; Noll, 2005). Making a correct decision all cases is impossible. However, with a constant endeavour to employ the best interviewing and decision-making techniques, the system can ensure an increasing probability of correct determinations. Asking the right questions in asylum interviews and being open minded when evaluating asylum seekers' statements in relation to other evidence in the case will be key to effective credibility assessment. 


\section{REFERENCES}

ACCORD. (2013). Researching country of origin information - Training manual. Retrieved from Vienna, Austria: http://www.coi-training.net/handbook/Researching-Countryof-Origin-Information-2013-edition-ACCORD-COI-Training-manual.pdf

Al Galidi, R. (2016). Hoe ik talent voor het leven kreeg [How I developed a talent for life]. Amsterdam: Jurgen Maas.

Ask, K., \& Granhag, P. A. (2005). Motivational sources of confirmation bias in criminal investigations: the need for cognitive closure. Journal of Investigative Psychology and Offender Profiling, 2, 43-63. doi:10.1002/jip.19

Asylum Procedure Directive 013/32/EU, L3180/60 C.F.R. (2013).

Beneduce, R. (2015). The moral economy of lying: Subjectcraft, narrative capital, and uncertainty in the politics of asylum. Medical Anthropology, 34, 551-571. doi:10.1080/014 59740.2015.1074576

Bex, F. J., van Koppen, P. J., Prakken, H., \& Verheij, B. (2010). A hybrid formal theory of arguments, stories and criminal evidence. Artificial Intelligence and Law, 18, 123-152. doi:10.1007/s10506-010-9092-x

Bögner, D., Brewin, C., \& Herlihy, J. (2009). Refugees' experiences of home office interviews: A qualitative study on the disclosure of sensitive personal information. Journal of Ethnic and Migration Studies, 36, 519-535. doi:10.1080/13691830903368329

Bond, J. (2012). Excluding justice: The dangerous intersection between refugee claims, criminal Law, and 'guilty' asylum seekers. International Journal of Refugee Law, 24, 37-59. doi:10.1093/ijrl/eer039

Boon, R., Odinot, G., Horselenberg, R., \& Geijsen, K. (2016). Van verhoor naar forensish interview. Naar een effectieve interviewstandaard voor de politie [From interrogation to forensic interview. Towards an effective interviewing standard for the police]. Tijdschrift voor de Politie, 78(4), 20-25.

Brubacher, S. P., Poole, D. A., \& Dickinson, J. J. (2015). The use of ground rules in investigative interviews with children: A synthesis and call for research. Developmental Review, 36, 15-33. doi:http://dx.doi.org/10.1016/j.dr.2015.01.001

Bull, R. (2010). The investigative interviewing of children and other vulnerable witnesses: Psychological research and working/professional practice. Legal and Criminological Psychology, 15, 5-23. doi:10.1348/014466509X440160

Clemens, F., Granhag, P. A., \& Strömwall, L. A. (2013). Counter-interrogation strategies when anticipating questions on intentions. Journal of Investigative Psychology and Offender Profiling, 10, 125-138. doi:10.1002/jip.1387

Cohen, J. (2001). Questions of credibility: omissions, discrepancies and errors of recall in the testimony of asylum seekers. International Journal of Refugee Law, 13, 293-309.

Colwell, L. H. (2005). Cognitive heuristics in the context of legal decision making. American Journal of Forensic Psychology, 23(2), 17-41.

Consterdine, E., Pendry, L., \& McKinlay, P. (2013). Establishing identity for international protection: challenges and practices. National contribution from the United Kingdom. European Migration Network.

Crombag, H. F. M. (2010). Over tunnelvisie [About tunnel vision]. In P. J. Van Koppen, H. Merkelbach, M. Jelicic, \& J. W. De Keijser (Eds.), Reizen met mijn rechter [Travelling with my judge] (pp. 387-399). Deventer: Kluwer.

Crombag, H. F. M., van Koppen, P. J., \& Wagenaar, W. A. (2009). Dubieuze zaken: De psychologie van strafrechtelijk bewijs (5e ed.) [Dubious cases: The psychology of criminal 
evidence (5th ed.)] (L. Criminal, Criminology, \& R. N. P. V. S. n. geprogr Eds.). Amsterdam: Olympus.

Dando, C. J., Bull, R., Ormerod, T. C., \& Sandham, A. L. (2015). Helping to sort the liars from the truth-tellers: The gradual revelation of information during investigative interviews. Legal and Criminological Psychology, 20, 114-128. doi:10.1111/Icrp.12016

Davis, M. R., McMahon, M., \& Greenwood, K. M. (2005). The efficacy of mnemonic components of the cognitive interview: towards a shortened variant for time-critical investigations. Applied Cognitive Psychology, 19, 75-93. doi:10.1002/acp.1048

Dienes, Z. (2008). Understanding psychology as a science: An introduction to scientific and statistical inference. New York: Palgrave Macmillan.

Doornbos, N. (2006). Op verhaal komen: Institutionele communicatie in de asielprocedure [Telling your story: Institutional communication in the asylum procedure]. Nijmegen, the Netherlands: Wolf Legal Publishers (WLP).

EASO. (2014). EASO training curriculum. Retrieved from Luxemboug: https://www.easo. europa.eu/sites/default/files/public/BZ0413152ENC.pdf

EMN. (2013). Establishing Identity for International Protection: Challenges and Practices. Brussels: European Commission.

European Migration Network. (2013). Establishing Identity for International Protection: Challenges and Practices. Brussels: European Commission.

European Parliament. (1999). Tampere European council 15 and 16 october 1999: Presidency conclusions. Retrieved from http://www.europarl.europa.eu/summits/tam_en.htm

Eurostat. (2016). Asylum and first time asylum applicants - annual aggregated data (rounded). Luxembourg: European Commission.

Ewens, S., Vrij, A., Leal, S., Mann, S., Jo, E., \& Fisher, R. P. (2014). The effect of interpreters on eliciting information, cues to deceit and rapport. Legal and Criminological Psychology, Early view (Online Version of Record published before inclusion in an issue), n/a-n/a. doi:10.1111/lcrp.12067

Ewens, S., Vrij, A., Mann, S., \& Leal, S. (2015). Using the reverse order technique with nonnative speakers or through an interpreter. Applied Cognitive Psychology, n/a-n/a. doi:10.1002/acp.3196

Findley, K. A., \& Scott, M. S. (2006). The multiple dimensions of tunnel vision in criminal cases. Wisconsin Law Review, 2, 291-397.

Fisher, R. P. (2010). Interviewing cooperative witnesses. Legal and Criminological Psychology, 15, 25-38. doi:10.1348/135532509X441891

Fisher, R. P., \& Geiselman, R. E. (2010). The Cognitive Interview method of conducting police interviews: Eliciting extensive information and promoting Therapeutic Jurisprudence. International Journal of Law and Psychiatry, 33, 321-328. doi:10.1016/j. ijlp.2010.09.004

Geiselman, R. E., Fisher, R. P., MacKinnon, D. P., \& Holland, H. L. (1986). Enhancement of eyewitness memory with the cognitive interview. The American Journal of Psychology, 99, 385-401. doi:10.2307/1422492

Granhag, P. A., \& Hartwig, M. (2008). A new theoretical perspective on deception detection: On the psychology of instrumental mind-reading. Psychology, Crime \& Law, 14, 189200. doi:10.1080/10683160701645181

Granhag, P. A., Hartwig, M., Giolla, E. M., \& Clemens, F. (2014). Suspects' Verbal CounterInterrogation Strategies. In P. A. Granhag, A. Vrij, \& B. Verschuere (Eds.), Detecting Deception (pp. 293-313). Chichester: John Wiley \& Sons, Ltd. 
Granhag, P. A., \& Strömwall, L. A. (2001). Deception detection: Examining the consistency heuristic. In C. M. Breur, M. M. Kommer, J. F. Nijboer, \& J. M. Reijntjes (Eds.), New trends in criminal investigation and evidence (pp. 309-321). Antwerpen: Intresentia.

Granhag, P. A., Strömwall, L. A., \& Hartwig, M. (2005). Granting asylum or not? Migration board personnel's beliefs about deception. Journal of Ethnic and Migration Studies, 31, 29-50. doi:10.1080/1369183042000305672

Granhag, P. A., Strömwall, L. A., Willén, R. M., \& Hartwig, M. (2013). Eliciting cues to deception by tactical disclosure of evidence: The first test of the Evidence Framing Matrix. Legal and Criminological Psychology, 18, 341-355. doi:10.1111/j.2044-8333.2012.02047.x

Gyulai, G. (2013). The evidentiary framework of credibility assessment. In G. Gyulai (Ed.), Credibility assessment in asylum procedures: a multidisciplinary training manual (pp. 9-20). Budapest, Hungary: Hungarian Helsinki Comittee.

Hartwig, M., Granhag, P. A., Stromwall, L., \& Doering, N. (2010). Impression and information management: On the strategic self- regulation of innocent and guilty suspects. The Open Criminology Journal, 3, 10-16.

Hartwig, M., Granhag, P. A., Strömwall, L. A., \& Vrij, A. (2005). Detecting deception via strategic disclosure of evidence. 29, 469-484. doi:10.1007/s10979-005-5521-x

Heal, L. W., \& Sigelman, C. K. (1995). Response biases in interviews of individuals with limited mental ability. Journal of Intellectual Disability Research, 39, 331-340. doi:10.1111/j.1365-2788.1995.tb00525.x

Herlihy, J., Gleeson, K., \& Turner, S. (2010). What assumptions about human behaviour underlie asylum judgments? International Journal of Refugee Law, 22, 351-366. doi:10.1093/ijrl/eeq027

Herlihy, J., Jobson, L., \& Turner, S. (2012). Just tell us what happened to you: Autobiographical memory and seeking asylum. Applied Cognitive Psychology, 26, 661-676. doi:10.1002/acp.2852

Hill, C., Memon, A., \& McGeorge, P. (2008). The role of confirmation bias in suspect interviews: A systematic evaluation. Legal and Criminological Psychology, 13, 357-371. doi:10.1348/135532507X238682

Horselenberg, R., \& Van Koppen, P. J. (2011). Een opname van het verhoor is de verbalisants beste vriend [A tape of the interrogation is the policeman's best friend]. Tijdschrift voor de Politie, 73(5), 23-26.

IGC. (2012). Asylum procedures. Report on policies and practices in IGC participating states 2012. Geneva: Inter-governmental Consultations on Migration Asylum and Refugees.

Inter-Parliamentary Union [IPU]. (2001). Refugee Protection: A guide to international refugee law. Retrieved from Geneva: http://www.ipu.org/pdf/publications/refugee_en.pdf

Kagan, M. (2002). Is truth in the eye of the beholder - objective credibility assessment in refugee status determination. Georgetown Immigration Law Journal, 17, 367-416.

Kassin, S. M. (2005). On the psychology of confessions: Does innocence put innocents at risk? , 60, 215-228. doi:10.1037/0003-066X.60.3.215

Kassin, S. M., Goldstein, C. C., \& Savitsky, K. (2003). Behavioral confirmation in the interrogation room: On the dangers of presuming guilt. Law and Human Behavior, 27, 187-203. doi:10.1023/A:1022599230598

Kebbell, M. R., Milne, R., \& Wagstaff, G. F. (1999). The cognitive interview: A survey of its forensic effectiveness. Psychology, Crime \& Law, 5, 101-115. doi:10.1080/10683169908414996

Kerstholt, J. H., \& Eikelboom, A. R. (2007). Effects of prior interpretation on situation assessment in crime analysis. Journal of Behavioral Decision Making, 20, 455-465. doi:10.1002/bdm.570 
Keselman, O., Cederborg, A.-C., Lamb, M. E., \& Dahlström, Ö. (2008). Mediated communication with minors in asylum-seeking hearings. Journal of Refugee Studies, 21, 103-116. doi:10.1093/jrs/fem051

Keselman, O., Cederborg, A.-C., Lamb, M. E., \& Dahlström, Ö. (2010). Asylum-seeking minors in interpreter-mediated interviews: what do they say and what happens to their responses? Child \& Family Social Work, 15, 325-334. doi:10.1111/j.13652206.2010.00681.x

Koehler, D. J. (1991). Explanation, imagination, and confidence in judgment. Psychological Bulletin, 110, 499-519. doi:10.1037/0033-2909.110.3.499

Lamb, M. E., Orbach, Y., Hershkowitz, I., Esplin, P. W., \& Horowitz, D. (2007). Structured forensic interview protocols improve the quality and informativeness of investigative interviews with children: A review of research using the NICHD Investigative Interview Protocol. Child Abuse \& Neglect, 31, 1201-1231. doi:10.1016/j.chiabu.2007.03.021

Lancaster, G. L. J., Vrij, A., Hope, L., \& Waller, B. (2013). Sorting the liars from the truth tellers: The benefits of asking unanticipated questions on lie detection. Applied Cognitive Psychology, 27, 107-114. doi:10.1002/acp.2879

Larsaeus, N. (2004). The relationship between safeguarding internal security and complying with international obligations of protection. The unresolved issue of excluded asylum seekers. Nordic Journal of International Law, 73, 69-97. doi:doi:http://dx.doi. org/10.1163/157181004323056392

Leins, D. A., Fisher, R. P., \& Ross, S. J. (2013). Exploring liars' strategies for creating deceptive reports. Legal and Criminological Psychology, 18, 141-151. doi:10.1111/j.20448333.2011.02041.x

Leins, D. A., Fisher, R. P., \& Vrij, A. (2012). Drawing on liars' lack of cognitive flexibility: Detecting deception through varying report modes. Applied Cognitive Psychology, 26, 601-607. doi:10.1002/acp.2837

Leins, D. A., Fisher, R. P., Vrij, A., Leal, S., \& Mann, S. (2011). Using sketch drawing to induce inconsistency in liars. Legal and Criminological Psychology, 16, 253-265. doi:10.1348/135532510X501775

Leksås, J., \& Kapferer, S. (2016) Reflections on the Link between the Interview and Assessment of Credibility [PowerPoint presentation]. Presented at the expert meeting about credibility assessment in asylum context at the University of Gothenburg, Sweden at March 3, 2016

Liu, M., Granhag, P. A., Landström, S., Hjelmsaeter, E. R. a., Strömwall, L., \& Vrij, A. (2010). Can you remember what was in your pocket when you were stung by a bee?': Eliciting cues to deception by asking the unanticipated. Open Criminology Journal, 3, 31-36. doi:10.2174/1874917801003010031

Loftus, E. F. (2005). Planting misinformation in the human mind: A 30-year investigation of the malleability of memory. Learning \& Memory, 12, 361-366. doi:10.1101/Im.94705

Luke, T. J., Hartwig, M., Brimbal, L., Chan, G., Jordan, S., Joseph, E., . . Granhag, P. A. (2013). Interviewing to Elicit Cues to Deception: Improving Strategic Use of Evidence with General-To-Specific Framing of Evidence. Journal of Police and Criminal Psychology, 28, 54-62. doi:10.1007/s11896-012-9113-7

Mackey, A., \& Barnes, J. (2013). Assessment of credibility in refugee and subsidiary protection claims under the EU Qualification Directive: Judicial criteria and standards. Retrieved from Haarlem, the Netherlands: http://www.refworld.org/docid/557028564.html

Maegherman, E., Van Veldhuizen, T., Horselenberg, R., \& Van Koppen, P. J. (2016). Detailed, consistent, and plausibile: A vignette study on the relationship between plausibility and other credibility indicators. 
Meissner, C. A., \& Kassin, S. M. (2002). "He's guilty!": Investigator bias in judgments of truth and deception. Law and Human Behavior, 26, 469-480. doi:10.2307/1394522

Memon, A., Bull, R., \& Smith, M. (1995). Improving the quality of the police interview: Can training in the use of cognitive techniques help? Policing and Society, 5, 53-68. doi:1 $0.1080 / 10439463.1995 .9964710$

Memon, A., Holley, A., Milne, R., Koehnken, G., \& Bull, R. (1994). Towards understanding the effects of interviewer training in evaluating the cognitive interview. Applied Cognitive Psychology, 8, 641-659. doi:10.1002/acp.2350080704

Memon, A., Meissner, C. A., \& Fraser, J. (2010). The cognitive interview: A meta-analytic review and study space analysis of the past 25 years. Psychology, Public Policy, and Law, 16, 340-372. doi:10.1037/a0020518

Millbank, J. (2009). 'The ring of truth': A case study of credibility assessment in particular social group refugee determinations. International Journal of Refugee Law, 22, 1-33. doi:10.1093/ijrl/een040

Milne, R., \& Bull, R. (1999). Investigative Interviewing: psychology and practice. Chichester: Wiley.

Milne, R., \& Bull, R. (2001). Interviewing witnesses with learning disabilities for legal purposes. British Journal of Learning Disabilities, 29, 93-97. doi:10.1046/j.14683156.2001.00139.x

Milne, R., \& Bull, R. (2002). Back to basics: a componential analysis of the original cognitive interview mnemonics with three age groups. Applied Cognitive Psychology, 16, 743753. doi:10.1002/acp. 825

Milne, R., \& Bull, R. (2006). Interviewing victims of crime, including children and people with intellectual disabilities. In M. Kebbel \& G. Davies (Eds.), Practical psychology for forensic investigations and prosecutions (pp. 7-24). Chichester: John Wiley \& Sons Ltd.

M.S.S. v. Belgium and Greece. (21 January 2011). Application no. 30696/09. Strasbourg: European Court of Human Rights

Nahari, G., Leal, S., Vrij, A., Warmelink, L., \& Vernham, Z. (2014). Did Somebody See It? Applying the Verifiability Approach to Insurance Claim Interviews. Journal of Investigative Psychology and Offender Profiling, 11, 237-243. doi:10.1002/jip.1417

Nahari, G., \& Vrij, A. (2014). Can I borrow your alibi? The applicability of the verifiability approach to the case of an alibi witness. Journal of Applied Research in Memory and Cognition, 3, 89-94. doi:http://dx.doi.org/10.1016/j.jarmac.2014.04.005

Nahari, G., Vrij, A., \& Fisher, R. P. (2014a). Exploiting liars' verbal strategies by examining the verifiability of details. Legal and Criminological Psychology, 19, 227-239. doi:10.1111/j.2044-8333.2012.02069.x

Nahari, G., Vrij, A., \& Fisher, R. P. (2014b). The verifiability approach: Countermeasures facilitate its ability to discriminate between truths and lies. Applied Cognitive Psychology, 28, 122-128. doi:10.1002/acp.2974

New Zealand Police. (2012). Investigative Interviewing Doctrine. Retrieved from Wellington: https://fyi.org.nz/request/244/response/2484/attach/4/Investigative\%20interviewing\%20doctrine.pdf

Nickerson, R. S. (1998). Confirmation bias: A ubiquitous phenomenon in many guises. Review of General Psychology, 2, 175-220. doi:10.1037/1089-2680.2.2.175

Noll, G. (2005). Introduction: Re-mapping evidentiary assessment in asylum procedures. In N. Gregor (Ed.), Proof, evidentiary assessment and credibility in asylum procedures (pp. 1-12). Leiden, the Netherlands: Koninklijke Brill NV. 
O'Brien, B. (2009). Prime suspect: An examination of factors that aggravate and counteract confirmation bias in criminal investigations. Psychology, Public Policy, and Law, 15, 315-334. doi:10.1037/a0017881

Orbach, Y., Hershkowitz, I., Lamb, M. E., Sternberg, K. J., Esplin, P. W., \& Horowitz, D. (2000). Assessing the value of structured protocols for forensic interviews of alleged child abuse victims. Child Abuse \& Neglect, 24, 733-752. doi:http://dx.doi.org/10.1016/ S0145-2134(00)00137-X

Oxburgh, G. E., Myklebust, T., \& Grant, T. (2010). The question of question types in police interviews: A review of the literature from a psychological and linguistic perspective. International Journal of Speech Language and the Law, 17, 45-66. doi:10.1558/ijsll. v17i1.45

Porter, S., \& ten Brinke, L. (2009). Dangerous decisions: A theoretical framework for understanding how judges assess credibility in the courtroom. Legal and Criminological Psychology, 14, 119-134. doi:10.1348/135532508X281520

Porter, S., \& Yuille, J. C. (1996). The language of deceit: An investigation of the verbal clues to deception in the interrogation context. Law and Human Behavior, 20, 443-458. doi:10.1007/BF01498980

Powell, M. B., \& Bartholomew, T. (2003). Interviewing and assessing clients from different cultural backgrounds: Guidelines for all forensic professionals. In David Carson \& R. Bull (Eds.), Handbook of Psychology in Legal Contexts (pp. 625-643). Chichester, Engeland: John Wiley \& Sons, Ltd.

Powell, M. B., \& Snow, P. C. (2007). Guide to questioning children during the freenarrative phase of an investigative interview. Australian Psychologist, 42, 57-65. doi:10.1080/00050060600976032

Qualification Directive 2011/95/EU [Recast QD 2004], L336/09 C.F.R. (2011).

Rassin, E. (2010). Blindness to alternative scenarios in evidence evaluation. Journal of Investigative Psychology and Offender Profiling, 7, 153-163. doi:10.1002/jip.116

Roos af Hjelmsäter, E., Öhman, L., Granhag, P. A., \& Vrij, A. (2014). 'Mapping' deception in adolescents: Eliciting cues to deceit through an unanticipated spatial drawing task. Legal and Criminological Psychology, 19, 179-188. doi:10.1111/j.2044-8333.2012.02068.x

Smeets, T. (2011). Acute stress impairs memory retrieval independent of time of day. Psychoneuroendocrinology, 36, 495-501. doi:http://dx.doi.org/10.1016/j. psyneuen.2010.08.001

Snook, B., Luther, K., Quinlan, H., \& Milne, R. (2012). Let 'em talk!: A field study of police questioning practices of suspects and accused persons. Criminal Justice and Behavior, 39, 1328-1339. doi:10.1177/0093854812449216

Strömwall, L. A., Hartwig, M., \& Granhag, P. A. (2006). To act truthfully: Nonverbal behaviour and strategies during a police interrogation. Psychology, Crime \& Law, 12, 207-219. doi:10.1080/10683160512331331328

Sweeney, J. A. (2016). A 'credible' response to persons fleeing armed conflict. In M. Happold \& M. Pichou (Eds.), The Protection of Persons Fleeing Armed Conflict and Other Situations of Violence. (pp. 81-103). Brussels: Larcier.

Thoresen, C., Lønnum, K., Melinder, A., Stridbeck, U., \& Magnussen, S. (2006). Theory and practice in interviewing young children: A study of Norwegian police interviews 19852002. Psychology, Crime \& Law, 12, 629-640. doi:10.1080/10683160500350546

Tversky, A., \& Kahneman, D. (1974). Judgment under Uncertainty: Heuristics and Biases. Science, 185, 1124-1131. doi:10.1126/science.185.4157.1124 
UNHCR. (2001). Note on international protection. A/AC.96/951. Retrieved from New York: http://www.refworld.org/docid/3bb1c6cc4.html

UNHCR. (2013). Beyond proof, credibility asessment in EU asylum systems. Retrieved from Brussels:

van Koppen, P. J. (2011). Overtuigend bewijs: Indammen van rechterlijke dwalingen [Convincing evidence: Reducing the number of miscarriages of justice]. Amsterdam: Nieuw Amsterdam.

Van Koppen, P. J. (2013). Gerede twijfel: Over bewijs in strafzaken. [Reasonable doubt: About evidence in criminal cases]. Amsterdam: De Kring.

Vanderhallen, M., Vervaeke, G., \& Holmberg, U. (2011). Witness and suspect perceptions of working alliance and interviewing style. Journal of Investigative Psychology and Offender Profiling, 8, 110-130.

Vredeveldt, A., van Koppen, J. P., \& Granhag, P. A. (2014). The inconsistent suspect: A systematic review of different types of consistency in truth tellers and liars. In R. Bull (Ed.), Investigative Interviewing (pp. 183-207). New York, NY: Springer New York.

Vrij, A., Hope, L., \& Fisher, R. P. (2014). Eliciting reliable information in investigative interviews. Policy Insights from the Behavioral and Brain Sciences, 1, 129-136. doi:10.1177/2372732214548592

Vrij, A., Leal, S., Granhag, P., Mann, S., Fisher, R., Hillman, J., \& Sperry, K. (2009). Outsmarting the liars: The benefit of asking unanticipated questions. Law and Human Behavior, 33, 159-166. doi:10.1007/s10979-008-9143-y

Vrij, A., Mann, S., \& Fisher, R. P. (2006). Information-gathering vs accusatory interview style: Individual differences in respondents' experiences. Personality and Individual Differences, 41, 589-599. doi:http://dx.doi.org/10.1016/j.paid.2006.02.014

Waterman, A. H., Blades, M., \& Spencer, C. (2001). Interviewing children and adults: the effect of question format on the tendency to speculate. Applied Cognitive Psychology, 15, 521-531. doi:10.1002/acp.741 



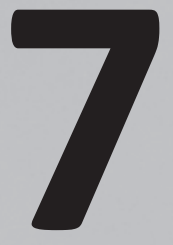

About the Relevance of All This:

Why, Who, What and How? 



\section{RELEVANCE}

The recent influx of asylum seekers in the EU has generated much debate about how member states should conduct asylum assessments (European Council, 2016). The effort put into asylum procedures by politicians, the public and the media is not surprising considering that the outcomes of the procedures have consequences for society as a whole. Almost everyone directly or indirectly benefits from an effective asylum system. State authorities have to protect their self-image and balance their duty to honour fundamental human rights by offering protection to those who genuinely need it and the wish to restrict entry for those who abuse a generous system to improve their living standards or with harmful intentions (Stern, 2014). The public also has an interest in the outcomes of asylum procedures; granting access to applicants with illegitimate claims may cause unrest or misbalance in society (Bond, 2012). That may, in turn, also have negative consequences for genuine refugees, as they will encounter more negative attitudes in their new country if the public feels that the asylum system is ineffective (Verkuyten, 2004). In addition, they may be confronted with the perpetrators of the crimes they fled from if the assessment cannot filter perpetrators of human right violations from victims. Finally, genuine applicants' main interest in effective asylum systems is that they are correctly being recognized as such.

Determining eligibility is not easy. Asylum assessments are almost always complicated by a lack of documentary evidence (Noll, 2005) and not all asylum seekers are completely honest in their application (Beneduce, 2015). Assessing credibility of the applicant's oral statements therefore is key in most asylum cases. These assessments are prone to distortion due to memory errors, dishonesty, or assessors' biases. Following from the high numbers of people seeking asylum in Europe and the high stakes associated with asylum determinations, ensuring that credibility assessments are conducted effectively and justly is important. Research examining to what extent current assessments are likely to yield correct decisions and where they can be improved is invaluable in this regard. 


\section{TARGET GROUPS}

The results presented in the thesis are relevant to different target groups ranging from actual users of the gained knowledge, to people who may be affected by changes that occur as a result of the current research. The first target group that may benefit from the current research are asylum officials, who conduct interviews and decide on cases on a daily basis. Asylum officials report credibility assessments to be the most challenging aspect of their work, and have expressed a need for more knowledge about effective assessments both in past research (Granhag, Strömwall, \& Hartwig, 2005) and in personal responses to the vignette study in Chapter 3. This thesis will offer them insight about how questions asked in interviews affect the credibility of statements and how the most valuable information for credibility assessments can be elicited from both truthful and deceptive asylum seekers.

However, although the thesis is of interest to individual officials who wish to acquire more knowledge about effective interviewing and decision making in the asylum context, a second - and surely more influential - target group is national and international institutions designing policy instructions and training instruments for asylum officials. By harmonizing work instructions for asylum officials in the EU along the lines of scientific knowledge about best practice in interviewing and decision-making, asylum assessments will become more evidence-based and less dependent on the individual interviewer or decision-maker. Hence, in this thesis I focused on the factors in asylum procedures that influence the validity of credibility assessments and are controlled by migration boards (i.e., system factors, Brewer \& Wells, 2011). The discussion of challenges and opportunities in current asylum assessments can inform future policy instructions and interview training. For example, policies issued by national authorities could require asylum officials to provide the asylum seeker with clear report everything and do not guess instructions (Brubacher, Poole, \& Dickinson, 2015) and to employ a free recall model of interviewing (New Zealand Police, 2012). With a systematic implementation of these interviewing tactics, more accurate information will be obtained. Training centres (for example at the national level, but also the UNHCR and EASO training centres), should focus on the implementation of these techniques under high cognitive load.

A third target group is what I propose to call the evaluators of decisions, that is, lawyers and refugee law judges. Both lawyers and refugee law judges evaluate 
- although from different perspectives - whether or not the migration board's decision is just and sufficiently motivated. Evidence about the validity of the different methods of questioning employed in credibility assessments, as provided in this thesis, will assist lawyers and judges to evaluate whether the migration boards' judgements are justified considering the nature of the questions asked in the interviews.

Lastly, as argued above, the current thesis also is essential to genuine refugees and other members of society. Effective asylum assessments allow genuine asylum seekers to present their claim more efficiently and convincingly, whereas they hinder deceptive claimants in their efforts to appear credible, thus reducing error.

\section{ACTIVITIES AND PRODUCTS}

From the beginning of the PhD trajectory I have reached out to practitioners and organizations in the field of asylum assessments to gain understanding of the challenges they encounter in their daily work. I started by interviewing asylum lawyers and refugee law judges, as well as asylum officials, litigators and policy makers at the Belgian, Swedish, and Dutch migration board. In addition, I attended an asylum interview to personally experience the interview dynamics. From these activities arose an ongoing exchange of valuable knowledge and important experiences with people in the field.

Concretely, the exchange resulted in cooperation from the Swedish and Dutch migration board in the empirical studies presented in Chapter 3 and 4, allowing me to study actual interviewing practice. In return, I have on several occasions presented my research findings to enhance understanding of effective interviewing and decision making in asylum cases from a legal psychological perspective. For example, I gave lectures for policy makers and asylum officials at the Swedish Migration Board and the Norwegian Directorate for Immigration. Both lectures were filmed and spread within the organization. Additionally, in the Netherlands I presented the research to the Research and Analysis Centre of the Immigration and Naturalization Service (INS), to country of origin specialists of the INS, and to asylum officials at the INS application centre in Den Bosch. 
Besides giving lectures, I was invited to have an advisory role in two projects. First, in March 2016 I participated in an expert meeting at the University of Gothenburg organized in the context of the development of a new evidence-based decision aid for credibility assessments in asylum cases. The tool was published in Swedish in March 2017 (Granhag, Landström, \& Nordin, 2017). Second, in May 2016, a report from the Dutch Advisory Committee on Migration Affairs (ACVZ, 2016) was published on how the assessment of the credibility of asylum seekers' accounts could be improved in practice. The research was commissioned by the State Secretary for Security and Justice. Along with lawyers, judges, and NGO representatives, who participated in expert meetings, I was interviewed to obtain a legal psychological perspective on the research question. The main conclusion drawn in the report is that, although considerable improvements were observed in credibility assessments, additional improvements in the gathering of information and in the assessment of credibility are necessary. In addition, the ACVZ calls for an investment in permanent training and professionalization of asylum officials. These conclusions fit well with the conclusions drawn in the current thesis, and were largely endorsed by the State Secretary.

I also proactively built bridges between psychological science and legal practice. For instance, to enhance a further understanding of how psychological processes may affect credibility assessments, I provided several asylum lawyers and asylum officials with an annotated bibliography of publications that are of interest to them. In addition, to be able to disseminate my work to a broader audience published my empirical articles in an open-access format whenever possible. That way, the research findings are freely accessible to anyone who is interested.

\section{INNOVATION}

Besides the fact that credibility assessments in asylum procedures are understudied compared to the criminal context, by providing a systematic evaluation of methods of questioning in asylum cases the current thesis is innovative in at least two other ways. The first innovation pertains to the combination of methodologies used to investigate the main research question. So far most psychological research into asylum assessments consisted of policy and literature reviews in which psy- 
chological knowledge about memory processes was applied to the different indicators used in credibility determinations (see e.g., Herlihy, Jobson, \& Turner, 2012; Herlihy \& Turner, 2007). Although the current thesis started with a similar review to identify challenges in practice and gaps in the existing literature, it was followed by empirical studies employing both qualitative and quantitative methodologies. The approach of studying current practice with a vignette methodology (in Chapter $3)$, as well as using an experimental paradigm to assess the validity of currently employed methods of credibility assessment (in Chapter 5 ) is unique in this context. With the experimental study in chapter 5 , we also developed a new paradigm for assessing the validity of origin tests. Although the analysis of real-life cases in Chapter 4 may methodologically speaking be less innovative, it is nevertheless filling a gap in existing literature, as a systematic evaluation of the questions in actual asylum interviews had not been conducted before.

The second important innovation concerns the substantive focus of the thesis. Until now, the relatively few empirical studies into asylum assessments have predominantly focused on how individual differences may affect the applicant's credibility (such as trauma and post-traumatic stress, see for example Rogers, Fox, \& Herlihy, 2015). Such studies are invaluable as they inform decision makers of the factors that should be taken into account while assessing credibility of oral statement. In the current thesis, however, a different perspective was chosen by focusing on variables that systematically affect the quality of oral statements and are controlled by the asylum official. That is, I concentrated on the question of how asylum procedures can be optimized when taking into account general memory processes rather than individual differences.

\section{PLANNING AND REALISATION}

As was explained under activities and products, the dissemination of the insights provided in this thesis is already ongoing. In addition, several activities are currently being planned.

First, once the thesis has been published, the Research and Analysis Centre of the INS will prepare an internal policy note concerning the main findings and how these should be implemented in practice. I will keep in touch with my contact per- 
son at the INS to give my input on that note. Naturally, the thesis will also be send out to my contacts at NGO's in the field of asylum (such as the training division of the EASO and the UNHCR), and other European migration boards.

Second, to encourage other scholars to conduct further research in this area and to promote more evidence-based practice among practitioners, a mixed symposium will be organised on 21 September 2017. At the symposium, challenges and future directions in asylum assessments will be discussed from a legal psychological perspective. To that end, the results of the research will be placed in a broader context, and a debate will be instigated about how the knowledge provided by the research can realistically be implemented in current practices and what additional knowledge is required to further optimize asylum assessments in the future.

Surrounding the symposium and the public defence on 22 September 2017, we will also generate media attention for the research. A press release will be send out the week prior to the defence, and local and national media will be invited to attend the symposium or defence as well.

Third, I am exploring the possibility to organise a Post Academic training ('PAO-onderwijs') for asylum lawyers focusing on interviewing tactics and memory processes that affect credibility assessments. Not only must lawyers become better equipped to evaluate the quality of INS interviews and decisions through such a training, it will also prepare lawyers for their own fact-finding interviews with asylum seekers. I have already spoken to several lawyers to identify questions that would be valuable to address. Next steps are to inventory whether there is a wider interest in such a PAO training, and whether it is possible to organise within the next year. 


\section{REFERENCES}

ACVZ. (2016). De geloofwaardigheid gewogen. Een advies over het onderzoeken, integraal beoordelen en toetsen van verklaringen in de asielprocedure. [Assessing credibility: an advisory report on the examination, integrated assessment and review of asylum seekers' accounts in support of their applications]. De Hague: ACVZ Retrieved from https://acvz.org/.

Beneduce, R. (2015). The moral economy of lying: Subjectcraft, narrative capital, and uncertainty in the politics of asylum. Medical Anthropology, 34, 551-571. doi:10.1080/014 59740.2015.1074576

Bond, J. (2012). Excluding justice: The dangerous intersection between refugee claims, criminal Law, and 'guilty' asylum seekers. International Journal of Refugee Law, 24, 37-59. doi:10.1093/ijrl/eer039

Brewer, N., \& Wells, G. L. (2011). Eyewitness identification. Current Directions in Psychological Science, 20, 24-27. doi:10.1177/0963721410389169

Brubacher, S. P., Poole, D. A., \& Dickinson, J. J. (2015). The use of ground rules in investigative interviews with children: A synthesis and call for research. Developmental Review, 36, 15-33. doi:http://dx.doi.org/10.1016/j.dr.2015.01.001

European Council. (2016). EU-Turkey statement, 18 march 2016 (144/16) [Press release]. Retrieved from http://www.consilium.europa.eu/en/press/press-releases/2016/03/18eu-turkey-statement/

Granhag, P. A., Landström, S., \& Nordin, A. (2017). Värdering av muntliga utsagor: ett venteskapligt baserat beslutsstöd för migrationsärenden [Evaluating oral statements: an evidence-based decision aid for asylum cases]. Retrieved from Gothenburg:

Granhag, P. A., Strömwall, L. A., \& Hartwig, M. (2005). Granting asylum or not? Migration board personnel's beliefs about deception. Journal of Ethnic and Migration Studies, 31, 29-50. doi:10.1080/1369183042000305672

Herlihy, J., Jobson, L., \& Turner, S. (2012). Just tell us what happened to you: Autobiographical memory and seeking asylum. Applied Cognitive Psychology, 26, 661-676. doi:10.1002/acp.2852

Herlihy, J., \& Turner, S. W. (2007). Asylum claims and memory of trauma: sharing our knowledge. The British Journal of Psychiatry, 191, 3-4. doi:10.1192/bjp.bp.106.034439

New Zealand Police. (2012). Investigative Interviewing Doctrine. Retrieved from Wellington: https://fyi.org.nz/request/244/response/2484/attach/4/Investigative\%20interviewing\%20doctrine.pdf

Noll, G. (2005). Introduction: Re-mapping evidentiary assessment in asylum procedures. In N. Gregor (Ed.), Proof, evidentiary assessment and credibility in asylum procedures (pp. 1-12). Leiden, the Netherlands: Koninklijke Brill NV.

Rogers, H., Fox, S., \& Herlihy, J. (2015). The importance of looking credible: the impact of the behavioural sequelae of post-traumatic stress disorder on the credibility of asylum seekers. Psychology, Crime \& Law, 21, 139-155. doi:10.1080/1068316X.2014.951643

Stern, R. (2014). "Our Refugee Policy is Generous": Reflections on the Importance of a State's Self-Image. Refugee Survey Quarterly, advance access. doi:10.1093/rsq/hdt020

Verkuyten, M. (2004). Emotional reactions to and support for immigrant policies: Attributed responsibilities to categories of asylum seekers. Social Justice Research, 17, 293-314. doi:10.1023/B:SORE.0000041295.83611.dc 
Summaries, Acknowledgements, $\&$ Curriculum Vitae 



\section{ENGLISH SUMMARY}

In the EU assessment for asylum, documental evidence is often lacking. As such, the assessment is substantially reliant on the asylum official's judgment about the credibility of the asylum seeker's statements. The procedure is therefore vulnerable to memory errors, manipulation by dishonest applicants and the personal bias of assessors. I examined to what extent currently-employed interviewing methods in asylum assessments are likely to facilitate or hinder the credibility of statements and present possibilities for mitigating the influence of memory errors, lying and biases. The main research question henceforth was to what extent are the methods used to assess credibility in the asylum procedure valid, in the sense that they can discriminate between truthful and fabricated asylum claims'?

The first step towards answering the main question entailed an examination of how credibility assessments are generally conducted in practice. In Chapter 2 the legal rules and regulations and policy guidelines that guide credibility assessments in the EU were reviewed, and evaluated based on psycho-legal research about the capacities of human memory and the detection of deception. The review yielded five often-used credibility indicators: sufficiency of detail and specificity, internal consistency, consistency with information from external sources, consistency with other witnesses, and plausibility. The evaluation of these indicators indicated that although a lack of detail, consistency or plausibility may point to a fabrication in the statements of asylum seekers, such shortcomings in a statement may also arise from memory limitations and ineffective interviewing techniques. Consequently - when using these indicators in practice - honest asylum seekers should be facilitated in their efforts to provide a credible narrative by asking effective questions.

From the policy review arose the question to what extent current interviewing practice stimulates detailed, consistent and accurate answering. In the vignette study among Swedish asylum officials in Chapter 3 the style, type and content of questions asked to assess credibility were therefore studied. The study demonstrated that Swedish asylum officials mainly formulate open and information gathering questions which likely elicit more elaborate and accurate answers than closed and accusatory questions. The results further showed that when assessing an origin claim, asylum officials ask a typical set of questions testing the applicant's knowledge about their home environment. The officials thereby seem to assume 
that honest applicants should have ample knowledge about their country and town of origin, its culture and customs, and frequently encountered objects.

A downside of the vignette study was that the questions were formulated in response to fictitious cases without interaction with an interviewee, and were therefore decontextualized. To draw conclusions about actual interviewing practice in asylum procedures the questions in 40 real-life cases of the Dutch immigration service were analysed (in the archival study in Chapter 4). In all cases, origin was established through an interview due to a lack of corroborating documents. The analyses yielded that, although Dutch asylum officials primarily employ an information gathering style, they predominantly pose closed and fact-checking questions and thereby likely elicit short answers. In line with the vignette study, the analyses of question content demonstrated that in the origin assessment asylum officials test the applicants' knowledge of their home environment.

Because both the vignette study and the archival study indicated that asylum officials use an origin-knowledge test to assess the credibility of origin claims, the validity of this method was evaluated in an experimental study in Chapter 5 . People from Tilburg (truth-tellers), Maastricht (partial liars) and Gothenburg (full liars) all had to convince an interviewer that they originated from Tilburg. They were led to believe that if successful, their participation reward would be doubled. To account for any preparation that dishonest applicants may do before an asylum interview, half of the participants could prepare for the interview (experimental condition) and half completed a filler-task (control condition). In the interview their knowledge of Tilburg and the Netherlands was tested with 10 questions typical for the asylum interview. The results imply that truth-tellers do have more knowledge about the claimed hometown than liars. However, even honest participants have only limited knowledge about their home environment; most truth-tellers answered less than half of the questions correctly. On top of that, liars can diminish the differences with truth-tellers by preparing for the interview. As such, the sensitivity and specificity of the origin-knowledge test proved low.

In Chapter $5 \mathrm{I}$ also explored the applicability of alternative methods that have proven effective for detecting truths and lies in suspect interviews. Asking impossible questions did not lead to an effective categorization of truth-tellers and liars; both groups equally often tried to answer these questions by guessing. Asking participants to sketch the lay-out of a central square, in contrast, did provide diag- 
nostic information. Truth-tellers provided more accurate details in their sketches than liars. The use of sketches in asylum interviews needs further testing among different populations, but could be a valuable addition to the credibility assessment of origin claims.

Finally, the results of the four studies were synthesized and discussed in Chapter 6. I concluded that the current thesis calls the validity of the European asylum assessment system into question. The questions typically asked in asylum interviews do not seem to facilitate honest applicants in providing a credible statement or effectively hinder liars in their effort to appear credible. A set of direct and factchecking questions about the claimed country, area and town of origin, may not be sufficient to effectively distinguish between genuine and fabricated origin claims. Nonetheless, with more effective questioning strategies that promote elaborate and accurate answering and with a deliberate and open-minded evaluation of asylum seekers' statements, the validity of credibility assessment can be increased. Using a free-recall model for investigative interviewing, and employing scenario thinking in the evaluation of asylum seekers' statements may be valuable in that regard.

The studies presented in this thesis were the first focused explicitly on the validity of interviewing techniques in the asylum procedure. Both the interviewing and decision making practice in the European asylum procedure could benefit from more empirical research. Further research is needed to validate current interviewing techniques, to identify hurdles in the evaluation of statements and other evidence, and to search for new and effective methods of credibility assessments. 



\section{DUTCH SUMMARY (SAMENVATTING)}

Bij het beoordelen van asielzaken in de EU is documentenbewijs vaak niet voorhanden. Daarom is de beoordeling veelal afhankelijk van het oordeel van de asielambtenaar over de geloofwaardigheid van de verklaringen van de asielzoeker. De procedure is hierdoor kwetsbaar voor geheugenfouten, manipulatie door onoprechte aanvragers en persoonlijke denkfouten van de beoordelaars. Ik onderzocht in hoeverre huidige methoden voor geloofwaardigheidsbeoordelingen in de asielprocedure de geloofwaardigheid van verklaringen bevorderen of juist hinderen en ik presenteer mogelijkheden om de invloed van geheugenfouten, leugenachtigheid en denkfouten op geloofwaardigheidsbeoordelingen te verminderen. De voornaamste onderzoeksvraag was daarom: tot op welke hoogte zijn de gebruikte methoden om geloofwaardigheid te beoordelen in asielprocedures valide, in de zin dat zij een onderscheid kunnen maken tussen waarachtige en verzonnen asielverhalen?

De eerste stap om de hoofdvraag te kunnen beantwoorden bestond uit een verkenning van hoe geloofwaardigheid beoordeeld wordt in de praktijk. In hoofdstuk 2 werden daarom de wettelijke voorschriften en beleidsrichtlijnen die richting geven aan de geloofwaardigheidsbeoordelingen in de EU geëvalueerd op basis van rechtspsychologisch onderzoek naar de capaciteit van het menselijk geheugen en leugendetectie. Dit leverde vijf veelgebruikte geloofwaardigheidsindicatoren op: voldoende detail en specificiteit, interne consistentie, consistentie met informatie van externe bronnen, consistentie met andere personen en getuigen, en plausibiliteit. De evaluatie van deze indicatoren toonde aan dat, ook al kan een gebrek aan detail, consistentie of plausibiliteit wijzen op onwaarachtigheden in de verklaringen van asielzoekers, dergelijke tekortkomingen ook kunnen ontstaan door beperkingen van het geheugen en ineffectieve interviewtechnieken. Derhalve zouden - wanneer de indicatoren in de praktijk gebruikt worden - eerlijke asielzoekers geholpen moeten worden om hun verhaal op een geloofwaardige manier te vertellen door effectieve vragen te stellen en zouden de beperkingen van het geheugen in overweging genomen moeten worden bij de beoordeling van hun verklaringen.

Uit de beleidsverkenning rees de vraag in welke mate huidige interviewmethoden het geven van gedetailleerde, consistente en accurate antwoorden ook 
stimuleert. In de vignettenstudie in hoofdstuk 3 werd daarom de stijl, het type en de inhoud van vragen geformuleerd door Zweedse asielambtenaren bestudeerd. De studie liet zien dat Zweedse asielambtenaren voornamelijk open en informatie verzamelende vragen formuleren, waarop waarschijnlijk meer uitgebreide en meer accurate antwoorden gegeven worden dan gesloten en beschuldigende vragen. De resultaten toonden verder dat asielambtenaren bij het onderzoeken van herkomst een typische set van vragen stellen waarmee zij de aanvragers kennis van de thuisomgeving toetsen. De ambtenaren lijken te veronderstellen dat eerlijke aanvragers ruime kennis bezitten over hun land en stad van origine, de lokale cultuur en gebruiken en veel voorkomende objecten.

Een nadeel van de vignettenstudie was dat de vragen geformuleerd werden in reactie op fictieve zaken en zonder interactie met de geïnterviewde. Daardoor werden de vragen uit de context gehaald. Om conclusies te kunnen trekken over de daadwerkelijke vraagstelling in asielgehoren werden de vragen in 40 echte zaken van de Nederlandse immigratiedienst geanalyseerd (in de archiefstudie in hoofdstuk 4). In alle zaken werd herkomst vastgesteld door het stellen van vragen, omdat deze niet met documenten bewezen kon worden. De analyses toonden aan dat Nederlandse asielambtenaren, ondanks dat zij doorgaans een informatie verzamelende stijl hanteren, overwegend gesloten en feitelijke vragen stellen die waarschijnlijk korte antwoorden oproepen. In lijn met de uitkomsten van de vignettenstudie liet de inhoudelijke analyse van de vragen zien dat asielambtenaren ten behoeve van de herkomstbeoordeling de kennis van de aanvrager over de thuisomgeving toetsen.

Omdat zowel de vignettenstudie als de archiefstudie indiceren dat asielambtenaren een herkomstkennistoets gebruiken om de geloofwaardigheid van herkomstclaims te onderzoeken, werd de validiteit van deze methode onderzocht in een experimentele studie in hoofdstuk 5. Mensen uit Tilburg (waarheidsvertellers), Maastricht (gedeeltelijke leugenaars) en Gotenburg (leugenaars) moesten een interviewer overtuigen dat zij uit Tilburg kwamen. Hen werd verteld dat hun beloning voor deelname verdubbeld zou worden als zij succesvol waren. Rekening houdend met een eventuele voorbereiding van onoprechte asielaanvragers voor het asielgehoor, mocht de helft van de participanten zich voorbereiden voor het interview (experimentele conditie) terwijl de andere helft een 'fillertask' uitvoerde (controle conditie). In het interview werd de kennis van Tilburg en Nederland getest 
met 10 vragen die typisch zijn voor het asielgehoor. De resultaten impliceren dat waarheidsvertellers inderdaad meer kennis hebben over de vermeende thuisstad. Echter, zelfs eerlijke mensen hebben slechts beperkte kennis over hun thuisomgeving; de meeste waarheidsvertellers beantwoordden minder dan de helft van de vragen correct. Daar komt nog bij dat leugenaars de verschillen met waarheidsvertellers kunnen verkleinen door zich voor te bereiden op het interview. Daarmee bleek de sensitiviteit en specificiteit van de herkomstkennistoets laag te zijn.

In hoofdstuk vijf onderzocht ik eveneens de toepassing van alternatieve methoden die effectief zijn gebleken om waarheid en leugens te detecteren in het verdachtenverhoor. Het stellen van onmogelijke vragen leidde niet tot een effectieve categorisatie van waarheidsvertellers en leugenaars; beide groepen probeerden even vaak te antwoorden door te gokken. De vraag aan participanten om de lay-out van een centraal plein te schetsen leverde daarentegen wel diagnostische informatie op. Waarheidsvertellers tekenden meer accurate details in hun schetsen dan leugenaars. Het gebruik van schetsen in asielgehoren moet nog verder onderzocht worden in andere populaties, maar zou een waardevolle toevoeging kunnen zijn voor het onderzoeken van de geloofwaardigheid van herkomst.

Tenslotte werden de resultaten van de vier studies gesynthetiseerd en besproken in hoofdstuk 6. Ik concludeerde dat op basis van dit proefschrift de validiteit van het Europese systeem voor het onderzoeken van asielverhalen twijfelachtig is. De vragen die doorgaans worden gesteld in asielgehoren lijken eerlijke aanvragers niet te faciliteren in het geven van geloofwaardige verklaringen, noch hinderen zij leugenaars bij hun inspanning om geloofwaardig over te komen. Een set van directe en feitelijke vragen over het vermeende land, gebied, en de vermeende stad van herkomst is wellicht niet toereikend om effectief een onderscheid te kunnen maken tussen waarachtige en verzonnen herkomstclaims. Daar staat tegenover dat de validiteit van de geloofwaardigheidsbeoordeling kan worden vergroot met meer effectieve vraagstrategieën die het geven van uitgebreide en accurate antwoorden stimuleren en met een weloverwogen en onbevooroordeelde evaluatie van de verklaringen van asielzoekers. Een interview model gebaseerd op het vrije relaas en het gebruik van scenario's bij het evalueren van verklaringen kunnen daarbij waardevol zijn.

In dit proefschrift worden voor het eerst studies gepresenteerd die expliciet focussen op de validiteit van interviewtechnieken in de asielprocedure. Zowel de 
praktijk van interviewen als van beslissen in Europese asielprocedures zou baat hebben bij meer empirisch onderzoek. Vervolgonderzoek is nodig om huidige vraagtechnieken te valideren, om obstakels bij het evalueren van verklaringen en ander bewijs te identificeren en om te zoeken naar nieuwe effectieve methoden voor geloofwaardigheidsbeoordelingen. 


\section{SWEDISH SUMMARY (SAMMANFATTNING)}

De allra flesta europeiska asylutredningar är beroende av Migrationsverkets handläggares bedömning av tillförlitligheten i asylsökandens utsaga. Detta eftersom bevisning i form av dokument som kan styrka den sökandes berättelse ofta saknas. Processen är därför sårbar för såväl naturliga minnesfel hos de sökande som lögner från oärliga sökande samt handläggares subjektiva fördomar. Inom ramen för denna avhandling har jag undersökt i vilken utsträckning de metoder som idag används vid bedömning av asylsökandes tillförlitlighet hjälper eller stjälper sökande att ge tillförlitliga utsagor. Med andra ord, om dessa metoder minskar eller ökar inflytandet av minnesfel, lögner och subjektiva fördomar. Den huvudsakliga forskningsfrågan var därmed; i vilken utsträckning är de metoder som används för att bedöma sökandes tillförlitlighet i asylprocessen valida i det avseende att de kan skilja på sanna och fabricerade utsagor?

Det första steget i att besvara denna fråga bestod i en granskning av hur tillförlitlighetsbedömningar går till i praktiken. I kapitel 2 granskades de rättsliga regler och de riktlinjer som styr tillförlitlighetsbedömningar inom EU. Dessa utvärderades utifrån rättspsykologisk forskning om lögner och människans minnesförmåga.

Genom granskningen identifierades fem vanligt förekommande markörer för tillförlitlighet: tillräcklig detaljrikedom och specificitet, konstans med avseende på överensstämmelse med information från externa källor med andra vittnen, samt rimlighet. Granskningen av dessa markörer visade att även om detaljfattigdom, bristande överrensstämmelse eller rimlighet kan indikera att en asylsökandes utsaga är fabricerad, så kan dessa brister i en utsaga också vara resultatet av bristande minnesförmåga eller ineffektiva intervjutekniker. Vid användandet av dessa markörer i praktiken bör man alltså underlätta för ärliga asylsökande att lämna tillförlitliga utsagor genom att ställa ändamålsenliga frågor.

Utifrån granskningen av riktlinjerna uppkom frågan om i vilken grad de intervjumetoder som idag används bidrar till detaljrika, konstanta och korrekta svar. I kapitel 3 presenteras en vinjettstudie som undersökte vilken frågestil, frågetyp och frågeinnehåll som används av svenska handläggare på Migrationsverket för att bedöma tillförlitlighet. Studien visade att svenska handläggare framför allt formulerar öppna och informationssamlande frågor, vilka brukar leda till mer utförliga och korrekta svar jämfört med slutna och konfrontativa frågor. Studien visade 
också att när de utreder den sökandes ursprungsland så ställer Migrationsverkets handläggare standardfrågor för att testa den asylsökandes kunskap om sin hemmiljö. Handläggarna verkar härmed förutsatta att ärliga sökanden har omfattande kunskap om sitt ursprungsland och sin hemstad, dess kultur och sedvanor, samt de föremål som ofta kan anträffas i detta land.

En nackdel med vinjettstudien var att frågorna formulerades utifrån fiktiva fall utan interaktion med en samtalspartner vilket gjorde att frågorna saknade ett sammanhang. För att kunna dra slutsatser om faktisk intervjupraxis analyserades frågor i 40 verkliga fall från det Holländska Migrationsverket (inom ramen för arkivstudien i kapitel 4). I samtliga fall fick ursprung fastställas genom en intervju då dokumentation som kunde stödja den sökandes påståenden saknades. Analyserna visade att, även om Holländska migrationshandläggare framförallt använde sig av en informationssamlande frågestil, så ställde de i huvudsak slutna och faktakontrollerande frågor. Något som sannolikt resulterar i korta svar från de sökande. I linje med resultaten från vinjettstudien, så visade analyserna av frågeinnehållet att handläggare, i utredningen kring den sökandens ursprung, testar sökandens kunskap om sin hemmiljö.

Resultaten från både vinjett- och arkivstudien antydde att migrationshandläggare använder ett kunskapstest för att bedöma tillförlitligheten i asylsökandes berättelse om sitt ursprung. Därför testades validiteten i denna metod i ett experiment i kapitel 5. Personer från Tilburg (sanningssägare), Maastricht (delvisa lögnare) och Göteborg (fullständiga lögnare) försökte alla övertyga en intervjuare om att de kom från Tilburg. Deltagarna motiverades att göra väl ifrån sig genom att de erbjöds dubbelt så hög ersättning för sitt deltagande om de lyckades övertyga intervjuaren. För att motsvara de eventuella förberedelser oärliga sökanden kan göra före en asylintervju, så fick hälften av deltagarna möjlighet att förbereda sig för intervjun (experimentgruppen) medan den andra hälften gjorde en utfyllnadsuppgift (kontrollgruppen). I intervjun testades deltagarnas kunskaper om Tilburg och Nederländerna med 10 frågor som är typiska för asylintervjun. Resultaten visade att sanningssägare hade mer kunskap om den påstådda hemstaden, jämfört med lögnare . Dock så hade även sanningssägarna begränsad kunskap om sin hemstad; de flesta sanningssägare svarade rätt på mindre än hälften av frågorna. Dessutom minskade skillnaderna mellan sanningssägare och lögnare genom förberedelser 
inför intervjun. Känsligheten och specificiteten i kunskapstestet av den sökandes ursprung visade sig således vara låg.

I kapitel 5 utforskade jag också tillämpbarheten av alternativa metoder som visat sig vara effektiva för att identifiera skillnader mellan sanningssägare och lögnare i förhör med misstänkta. Att ställa omöjliga (dvs irrelevanta och icke förväntade) frågor ledde inte till någon effektiv kategorisering av sanningssägare och lögnare. Detta eftersom båda grupperna i lika hög utsträckning försökte svara på sådana frågor genom att gissa. Att be deltagare att skissa upp en planritning av ett centralt torg i Tilburg visade sig dock ge diagnostisk information. Sanningssägare inkluderade fler korrekta detaljer i sina skisser, jämfört med lögnare. Användandet av skisser i asylintervjuer behöver testas ytterligare i olika populationer men skulle på sikt kunna utgöra ett värdefullt bidrag till dem har att bedöma tillförlitligheten i den sökandes utsaga om sitt ursprung.

Slutligen sammanställdes och diskuterades resultaten av de fyra studierna $i$ kapitel 6. Slutsatsen av den aktuella avhandlingen är att validiteten i de metoder som används för asylbeslut i Europa kan ifrågasättas. De frågor som vanligtvis ställs i asylintervjuer tycks varken underlätta för ärliga sökanden att lämna en tillförlitlig utsaga eller på ett effektivt sätt hindra lögnare i deras försök att framstå som tillförlitliga. Direkta och faktakontrollerade frågor om den sökandes påstådda ursprungsland och hemort, tycks inte vara tillräckligt för att på ett effektivt sätt kunna särskilja mellan sanna och falska utsagor om den sökandes ursprung. Validiteten i tillförlitlighetsbedömningar kan dock förbättras genom en kombination av mer effektiva frågetekniker som bidrar till utförliga och korrekta svar och noga övervägda och fördomsfria utvärderingar av asylsökandes utsagor. Användandet av fri återgivning i asylintervjun och beaktandet av alternativa scenarier inför bedömningen av asylsökandes utsagor kan vara användbart i detta avseende.

Studierna som ingår i denna avhandling är de första som specifikt syftar till att undersöka validiteten i asylintervjuer. Både intervju- och beslutsfattandeprocessen i den europeiska asylprocessen skulle gynnas av ytterligare forskning. Mer forskning behövs för att validera nuvarande intervjutekniker, för att identifiera svårigheter $\mathrm{i}$ värderingen av utsagor och annan bevisning, samt för att identifiera nya och effektiva metoder för tillförlitlighetshetsbedömningar i asylärenden. 



\section{ACKNOWLEDGEMENTS}

Before starting my PhD in September 2013, I was a social psychologist who knew little about legal psychology, let alone law. The only thing I knew was that I am strongly motivated by fairness in my own life, and that I wanted to pursue a PhD only if the research would have a direct practical relevance. When I saw the call for the Erasmus Mundus Joint Doctorate program in Legal Psychology (EMJD-LP), I was immediately enthusiastic about the program as a whole and especially about the topic of my proposal: 'Proving claims of asylum seekers: measuring knowledge of people and places'.

During our very first week, at the EMJD-summer school and EAPL conference in fabulous Coventry, I was a little overwhelmed and impressed with my fellow EMJD PhD-students, because of their knowledge and prior experiences in this field of research. At the same time, however, the conference and the interactions in-between talks further sparked my interest in legal psychology and I remember feeling very lucky to start my own research in this field. Now, almost four years later, I consider myself a legal psychologist with at least a basic knowledge of law and legal proceedings, still enthusiastic about the topic of my thesis, and more than ever fascinated by legal psychology as a discipline. As clichés are often true, I daresay that during this process I not only grew as a researcher, but I also came to know myself a little bit better. Of course - to throw in a second cliché - I could not have done this by myself, and several people need to be properly thanked for their share in this process.

First of all I want to thank my main supervisors, Peter van Koppen and Robert Horselenberg. As befits good supervisors, they started off our first meeting by providing a vivid example of how a prominent principle in legal psychology works in real life, namely: belief perseverance. As attentive readers of my thesis will have read in Chapter 6, belief perseverance is a mechanism underlying tunnel vision and is defined as 'maintaining a belief despite new information that firmly contradicts it'. Let me explain how this went a bit more. On my CV I mentioned playing korfball for almost all my life. Peter and Robert, holding a stereotypical view that only people with black stockings (read: Reformed Christians) play korfball, asked me during my first meeting whether I indeed was a strong believer. Even though I made very clear that this is not the case, the belief frequently turned up in the 
following years. Upon arrival in Maastricht, it turned out that my close colleagues Ricardo and André also thought I was a professing Christian, and at any occasion that I would actually wear black stockings or mention playing against a team from a Christian village, confirmation bias - the tendency to search for, interpret, favour, and recall information in a way that confirms one's pre-existing beliefs - would kick in and the belief would persevere.

But these were not the only examples of legal psychological principles in action that Peter and Robert set, and certainly not their only contribution to my PhD trajectory. Peter, for example, never misses an opportunity to tell juicy stories about interesting cases, which makes working with him and especially having lunch with him a lot of fun. In the beginning he would often add to his stories "but Tanja, don't you know this case, seriously?" leaving me feeling stupid. But after a while I got familiar with his repertoire and the discussions became even more interesting. Upon hearing that Peter was my supervisor, other people often asked: "but isn't he extremely tough on you"? Well, yes, he sometimes is, but describing Peter merely as a tough supervisor is definitely selling him short. He is direct and honest, but his comments are often valuable and if you disagree with him based on arguments, there is always room for a good discussion to find a fitting solution. Moreover, Peter's interest in me went beyond my research. Each supervisory meeting started with the questions: "How are you?", "How is Wouter and how are your nieces and nephews?", and "Are you still having fun with all of this?". Only after discussing these questions and any local gossip, we started talking about research. When I was in my mid-PhD crisis and had trouble writing anything down, he urged me to take some time off rather than setting deadlines, apparently knowing that distance and perspective was what I needed most at that point. Without Peter's support, both academically and personally, I think this thesis would have looked very differently.

Robert has functioned as my First Aid for Doctoral Students contact-person. He ends most of his e-mails with 'Zwaai!' (English: Wave!), which in my eyes is descriptive of his personality. He is always energetic and outgoing, and most importantly very approachable. With him I could literally discuss anything, and without him I truly doubt whether I would have completed my PhD. The way he started his emails was probably even more important in that respect. He often began his e-mail, especially when I had just completed a dreaded task or met a major deadline, with something that is valuable to any PhD-student: a compliment. He sensed flawlessly 
when I was overwhelmed, and always managed to cheer me up, make me focus on my accomplishments, and motivate me to keep on going. But not only was Robert good for compliments, social activities, walks through Maastricht, and 'slap geouwehoer', he also contributed greatly to the contents of my thesis; from developing research questions and study-designs, to data-collections and the way it has been written down. More than anyone he saw the need for legal psychological research in the asylum context, and he was as involved in the project as I was. One way in which this became plainly visible, is by his proposal to capture the progress of the final stages of my project with Scrum. With Scrum, each time a small task is completed a yellow sticky note is replaced with a green one. His investment was reflected by the size of the diagram; the schedule covered a full wall in his office, and his office became greener and greener. We jokingly said that in order to obtain your PhD, you have to move from jaundice to 'greendice' (In Dutch: van geelzucht naar groenzucht). Without Robert I would probably still be yellowish right now.

I also want to thank my two other supervisors, Pär Anders Granhag and Sara Landström. Both based in Gothenburg, they were mostly watching the process from a distance. When needed, however, they were always very quick with their feedback to study designs and papers. They offered a different perspective, and as such their feedback was very valuable. During my six months abroad in Sweden, we had more intensive contact. Both of their doors were always open for questions or discussions. Their doors were also open when I was feeling down. Despite having wonderful colleagues and loving the city, I was feeling homesick. Both Pär Anders and Sara have been incredibly supportive during this time, which made it a little bit easier to cope with.

Other people who helped me cope with difficult times were my colleagues, friends, and now paranymphs: Nathalie and Ricardo. Nathalie and I started within the EMJD program on the same sunny day in Coventry. I was super nervous and seriously considered dropping out before even starting. Luckily I met Nathalie in the hotel on the first evening, and we clicked immediately. We soon became close friends, and I stayed over at Nathalie's place many nights to reduce the number of train-rides. We shared hotel rooms during conferences (especially Saint-Petersburg was memorable), and during our time in Gothenburg we even shared an apartment and undertook many adventures together. We went to the gym almost 6 days a week, went hiking and canoeing, but most of all, Nathalie helped me to get the 
most out of our time in Sweden, despite my homesickness. I think it is safe to say that we saw each other's ups and downs during the whole PhD process and it is only fitting that we both complete the process at roughly the same time, celebrating both defence days together, as each other's paranymphs.

Ricardo was one of my direct colleagues in the law faculty in Maastricht. We soon had a good working relationship, which evolved in a friendship over time. An important moment has been the winter school in Gothenburg in December 2013, in which Ricardo participated. We had so much fun with the Swedish language, for example pronouncing 'var så god' (meaning: 'here you go' or 'no problem') as 'was je goed' (meaning: 'clean yourself properly' in Dutch), and I remember that I could not stop laughing when Ricardo tried to get free wine because he thought 'gratis' in Swedish was the same as 'tack' (meaning: thank you). As a result of that week in Gothenburg we introduced 'fika' in Maastricht. We discussed a lot during our coffee breaks: feedback from our supervisors, Peter's forbidden words, statistics, but also life. Taking the train to Maastricht always was more pleasant when I knew my Fika-buddy would be in the office! This is also why I was really happy that Ricardo agreed to be my paranymph, and supported me in the process towards my defence.

But many more colleagues positively contributed to my PhD-life. I will mention a few by name, knowing that my list will surely be incomplete. To start with colleagues in Maastricht. First, André de Zutter, who made sure that no day at the office was boring, silent or the same. André always is full of energy and may seem bold, but deep down has a small heart and is a very helpful colleague. Chantal Meertens is another colleague that I cannot thank enough. She took care of so many administrative issues, booked so many cabs, flights, and hotels, and was always available for a nice talk or coffee. Lastly, Claire van den Eeden, strictly speaking not a colleague in Maastricht but in Amsterdam. I really appreciated our exchanges during our feet-on-the-table sessions in Eindhoven.

Then, my fellow EMJD-candidates - too many to name all - made each summer and winter school and many conferences memorable. One of them, however, needs to be mentioned explicitly. Serra probably is one of the toughest people I met during the past years. She may be small in size but stands up for what she thinks is important, and as such is a very loyal friend. We had much fun together, especially during conferences in Iceland and London, but I know I can also always 
call or e-mail her to just shamelessly complain about anything. Serra will always listen, but also tell me to suck it up and move forward.

In addition I also want to thank all my colleagues from Sweden. During our first few days in the CLIP-group in Gothenburg, Nathalie and I probably had seven fika's each day, because everybody wanted to make sure we felt welcome. I need to specifically mention Emelie Ernberg, who has translated the summary of this dissertation into Swedish because my own Swedish does not reach much further than 'Tack så mycket Emelie'! But also Renate, our Dutch Swedish colleague with whom we spent many hours in the office at the department and who - as she so eloquently put it herself upon our goodbyes - put a layer of Dutch gravy on the Swedish meatballs! And perhaps most important in this category is Helen. She feels like extended family. During our 6 months in Gothenburg, she helped us with basically everything we needed. Helen, Patric and their kids welcomed us in their home on multiple occasions. We can always stay at their place when visiting Gothenburg. Their friendship and hospitality has no limits.

As a last group of colleagues, I need to thank several research assistants who helped me collecting and analysing data. First, Mikaela Magnusson who translated responses for the vignette study and conducted interviews in the Tilburg study. Second, Enide Maegherman, who became involved in the final stages of my project by collecting data and proofreading English texts. In September 2017, she will start in the EMJD program herself. I cannot think of anyone who deserves it more. Third, Jeffrey van Hollstein and Rachel Maas, who put in much effort and time into coding and analysing data for the archival study. Especially with Rachel I spent many hours in the office. Besides these being very productive hours, we came to know each other quite well and could talk for hours about everything, but most of all our shared love for 'high quality English literature' (Rachel will know what I am referring to).

Before turning to thanking my family, I want to take the opportunity to also thank several organizations and specific people within those organizations who made it possible for me to ground my research in everyday practice. First of all, I want to thank the Dutch Immigration and Naturalisation Service (INS) and the Swedish Migrationsverket for their cooperation in my empirical studies. Especially, Joris van der Borch from the INS and Christian Andersson from the Migrationsverket have been a key in the process of receiving cooperation. Second, I want to thank 
all the individual asylum officials, judges, lawyers and other practitioners who gave me a look behind the scenes and who were open to discuss their work with me and point me to the challenges they experience on a daily basis. I look forward to the continuation of our exchange of knowledge and experiences.

Finally, I need to thank my family, which always functions as my safety-net. My mum, dad, and sisters are simply always there when needed. Peter has frequently said that it is clear that I originate from a good and warm family, or in Dutch: 'uit een goed nest'. I cannot agree more. Mum and dad are always able to provide perspective when I am overreacting, and think along and provide guidance when I have difficult decisions to make or cannot see the forest through the trees. Probably as a result of their warmth and support, I have the three best sisters, Lotte, Jiska, and Myrte, I could possibly wish for, all with great partners and amazing children. Together they often helped me to take my mind off my PhD during weekends, for example with board-games or day-trips to the zoo. And thanks to Lotte I have a beautifully designed cover for this book, despite the many restrictions that the logos imposed. In addition, I also have very involved parents-in-law, Rinus and Els, who I can always count on, as well as a brother-in-law (also with a great partner) who, as a physical therapist, was often available to remedy any physical complaints.

There is one additional family member I want to briefly mention. My aunt Josita has helped me, more than she probably knows herself, by providing skype-consults when I was feeling homesick. Through these conversations I found a way to cope with my emotions, and to complete my time in Gothenburg feeling much better.

Lastly and most importantly, I want to thank Wouter. Having a PhD-student for a girlfriend and later wife is doubtless never easy considering the mood-swings that each PhD will probably recognize. Add to that the travel time from Utrecht to Maastricht and the lack of sleep that resulted of that, and you know how unreasonable I must have been at times. Still Wouter was more supportive than I could wish for, even over Skype when I was in far-far away Sweden. So, to conclude my acknowledgments with another cliché: Wouter, you are my rock. My period in Gothenburg taught me a very valuable lesson: no matter how much I love a place, the people around me, or the thing I am doing home is wherever I am with you. 


\section{CURRICULUM VITAE}

Tanja Susan van Veldhuizen was born in on January 6, 1990 in Utrecht, the Netherlands. During her secondary education at the Utrechts Stedelijk Gymnasium she gained administrative experience as a board member and president of the national secondary school students union: Landelijk Aktie Komitee Scholieren (LAKS). In 2008 she started studying psychology at Utrecht University, later majoring in social psychology. She filled her electives with courses related to political philosophy, sociology and legal studies at the University of California Berkeley and besides the regular curriculum she participated in the Faculty of Social Sciences' interdisciplinary honours program: the Von Humboldt College. In 2011 she henceforth obtained her Bachelor's degree with honours. As a spin-off of her Bachelor's thesis, she was awarded the best paper award at the 2011 annual conference of the Dutch Association of Social Psychological Researchers (ASPO) for her paper about cultural differences in terror management. Tanja continued her studies with a research master in Social and Health psychology at Utrecht University, in which she focused her own research project on fairness perceptions and cross-cultural psychology. During this time, she also gained teaching experience by giving Methods and Statistics lectures and tutorials, and by giving tutorials and supervising collaborative assignments in the advanced level course Social Cognition. In addition, she worked as a research-assistant in a large project on differentiated calculus education in Dutch primary schools. In 2013, Tanja obtained her Master's degree. In September 2013, she started her PhD project, aimed at obtaining a joined degree from Maastricht University in the Netherlands and the University of Gothenburg in Sweden within the Erasmus Mundus Joint Doctorate Program in Legal Psychology. In 2016, she was awarded the best presentation award at the annual conference of the International Investigative Interviewing Research Group (illRG) in London for a presentation about interviewing practice in the Dutch asylum procedure. Currently, Tanja is working as a postdoctoral researcher within the Montaigne Centre for Judicial Administration and Conflict Resolution at the Faculty of Law and Governance of Utrecht University. 